\title{
Forward exchange market dynamics : an empirical analysis of expectations, risk and innovations in forward foreign exchange
}

Citation for published version (APA):

Verschoor, W. F. C. (1993). Forward exchange market dynamics : an empirical analysis of expectations, risk and innovations in forward foreign exchange. [Doctoral Thesis, Maastricht University]. Datawyse / Universitaire Pers Maastricht. https://doi.org/10.26481/dis.19930422wv

Document status and date:

Published: 01/01/1993

DOI:

10.26481/dis.19930422wv

Document Version:

Publisher's PDF, also known as Version of record

Please check the document version of this publication:

- A submitted manuscript is the version of the article upon submission and before peer-review. There can be important differences between the submitted version and the official published version of record.

People interested in the research are advised to contact the author for the final version of the publication, or visit the DOI to the publisher's website.

- The final author version and the galley proof are versions of the publication after peer review.

- The final published version features the final layout of the paper including the volume, issue and page numbers.

Link to publication

\footnotetext{
General rights rights.

- You may freely distribute the URL identifying the publication in the public portal. please follow below link for the End User Agreement:

www.umlib.nl/taverne-license

Take down policy

If you believe that this document breaches copyright please contact us at:

repository@maastrichtuniversity.nl

providing details and we will investigate your claim.
}

Copyright and moral rights for the publications made accessible in the public portal are retained by the authors and/or other copyright owners and it is a condition of accessing publications that users recognise and abide by the legal requirements associated with these

- Users may download and print one copy of any publication from the public portal for the purpose of private study or research.

- You may not further distribute the material or use it for any profit-making activity or commercial gain

If the publication is distributed under the terms of Article $25 \mathrm{fa}$ of the Dutch Copyright Act, indicated by the "Taverne" license above, 


\title{
Forward Exchange Market Dynamics
}

\author{
An Empirical Analysis of Expectations, Risk and
} Innovations in Forward Foreign Exchange 



\title{
Forward Exchange Market Dynamics
}

\author{
An Empirical Analysis of Expectations, Risk and \\ Innovations in Forward Foreign Exchange
}

\section{PROEFSCHRIFT}

ter verkrijging van de graad van doctor aan de

Rijksuniversiteit Limburg te Maastricht, op gezag van de Rector Magnificus, Prof. Mr. M.J. Cohen, volgens het besluit van het College van Dekanen, in het openbaar te verdedigen op donderdag, 22 april 1993 om 14.00 uur

door

\section{Willem Franciscus Cornelis Verschoor}

geboren te Dordrecht

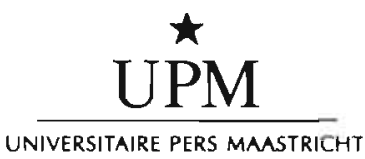




\section{Promotor :}

Prof. dr. C.C.P. Wolff

\section{Beoordelingscommissie :}

Prof. dr. F.Ch. Palm (voorzitter)

Prof. dr. P. de Grauwe, Katholieke Universiteit Leuven (B)

Prof. dr. C.G. Koedijk

CIP-DATA KONINKLIJKE BIBLIOTHEEK, DEN HAAG

Verschoor, Willem Franciscus Cornelis

Forward exchange market dynamics: an empirical analysis of expectations, risk and innovations in forward foreign exchange / Willem F.C. Verschoor. -Maastricht:

Universitaire Pers Maastricht. - III., fig., tab.

Thesis Maastricht. - With ref.

ISBN 90-5278-061-7

NUGI $681 / 683$

Subject headings: exchange rates; expectations; risk premia. 


\section{Acknowledgements}

The research for this dissertation has been supported by grant 450-227-011 from the Economics Research Foundation (Ecozoek), which is part of the Netherlands Organization for Scientific Research (NWO). Financial support from the Staal Stichting 1966 for printing the dissertation is also gratefully acknowledged.

The work described in this dissertation would never have been written in its present form without the contribution and support of a number of people. First, I would like to express my sincere gratitude to Christian Wolff for being the supervisor of the research project and mentor, whose continuous support and guidance stimulated and inspired me whenever necessary. Kees Koedijk also provided me with helpful advice during many enlightening discussions. I would also like to thank the other members of my dissertation committee, Franz Palm (chairman) and Paul de Grauwe for their valuable comments.

Furthermore, I owe a substantial debt to my academic colleagues of the Department of Finance at the University of Limburg for creating a stimulating and enjoyable working environment, and to Fred Nieuwland who especially contributed to that environment. He has provided considerable help, co-authored a number of academic journals and contributed to improvements of this book. Special thanks are due to Art Selender for lecturing the Ph.D. course Finance and to Stefano Cavaglia for encouraging me to write a book on exchange rate expectations.

During the period of writing this book, I received helpful comments from seminar participants at the European Institute for Advanced Studies in Management (EIASM), the Second and Fourth Annual Pacific-Basin Finance Conferences and at the Annual Meetings of the American and European Finance Association.

I am very much indebted to my "paranimfen", Paul Lugard and Herman de Smet, for accepting my obstinacy, especially in hectic moments of playing tennis. In addition, I welcome this opportunity to thank my parents for their mental and financial support and encouragement throughout my student years.

My final words are for Lieke, who has enjoyed all the exciting aspects of my research in International Finance. She has now shared many international 
conferences, jetlags, exotic food and middle-of-the-night phone calls from all over the place. Let this book add to the long list of pleasures and suffering we happily share.

Willem F.C. Verschoor. 
This book is dedicated with love and gratitude to the memory of Francisca C. Verschoor the extraordinary woman who built and inspired our family. 



\section{Table of Contents}

Page

Table of Contents

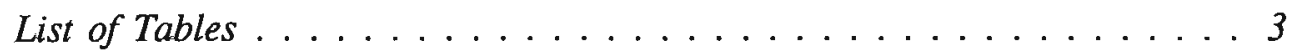

List of Figures $\ldots \ldots \ldots \ldots \ldots \ldots \ldots \ldots \ldots \ldots$

\section{Chapter}

1 Introduction: Aims and Scope $\ldots \ldots \ldots \ldots \ldots \ldots$

2 EMS Exchange Rate Dynamics $\ldots \ldots \ldots \ldots \ldots \ldots$

2.1 Introduction $\ldots \ldots \ldots \ldots \ldots \ldots \ldots \ldots \ldots \ldots \ldots$

2.2 Random Walks or Mean Reversion? . . . . . . . . . . 20

2.3 Modeling EMS Exchange Rates: Methodology . . . . . . 32

2.4 Modeling EMS Exchange rates: Empirical Results . . . . . 36

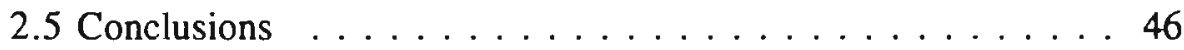

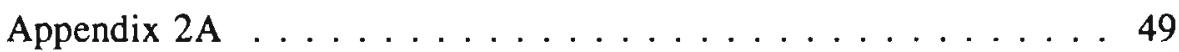

Appendix $2 \mathrm{~B} \ldots \ldots \ldots \ldots \ldots \ldots \ldots \ldots \ldots \ldots \ldots \ldots \ldots \ldots \ldots \ldots$

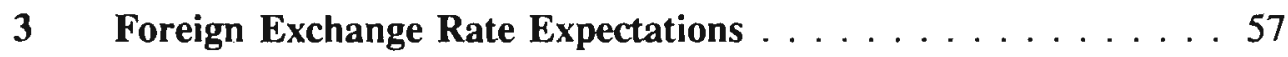

3.1 Introduction $\ldots \ldots \ldots \ldots \ldots \ldots \ldots \ldots \ldots \ldots$

3.2 The Survey Data . . . . . . . . . . . . . . 5 59

3.3 The Rationality of Survey Data . . . . . . . . . . 65

3.4 Models of Expectations Formation . . . . . . . . . 77

3.5 Conclusions $\ldots \ldots \ldots \ldots \ldots \ldots \ldots \ldots \ldots \ldots \ldots$ 
4 The Biasedness of Forward Foreign Exchange Rates:

Irrationality or Risk Premia? . . . . . . . . . . . . 93

4.1 Introduction . . . . . . . . . . . . . . 93

4.2 The Survey Data . . . . . . . . . . . . . 96

4.3 Tests of Forward Discount Bias . . . . . . . . . . 102

4.4 Decomposition of the Bias . . . . . . . . . . . . 112

4.5 Statistical Properties of the Risk Premium . . . . . . . . 119

4.6 Conclusions . . . . . . . . . . . . . . . 128

$5 \quad$ Empirical Modeling of EMS Exchange Risk Premia . . . . . . 131

5.1 Introduction . . . . . . . . . . . . . . . 131

5.2 The Survey Data . . . . . . . . . . . . . . . 134

5.3 Time-Varying Exchange Risk Premia . . . . . . . . . . 136

5.4 Modeling Time-Varying Risk Premia: Methodology . . . . . 142

5.5 Empirical Results . . . . . . . . . . . . . . . . . 147

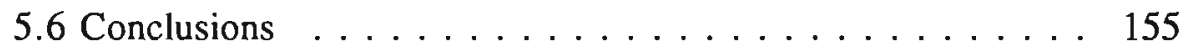

6 Interest Rate Expectations and Exchange Rate Dynamics . . . 161

6.1 Introduction $\ldots \ldots \ldots \ldots \ldots \ldots \ldots \ldots \ldots \ldots$

6.2 The Survey Data . . . . . . . . . . . . . . . 164

6.3 Interest Rates and Exchange Rates: Methodology . . . . . . . 168

6.4 Empirical Results . . . . . . . . . . . . . . . . . . 175

6.5 Conclusions $\ldots \ldots \ldots \ldots \ldots \ldots \ldots 18 \ldots \ldots \ldots$

7 Concluding Comments and Suggestions for Future Research . 183

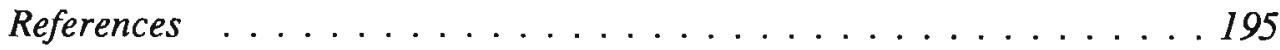

Summary in Dutch . . . . . . . . . . . . . . . . . . 209

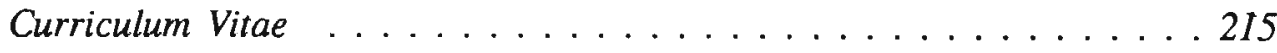




\section{List of Tables}

Table

Page

2.A Realignment Dates and Central Parities of EMS Exchange Rates . . 22

2.1 Summary Statistics of Weekly Log Price Changes . . . . . . . . . 23

2.2 Heteroskedasticity Tests of Weekly Log Price Changes . . . . . 27

2.3A Tests for Unit Roots in the Logarithms of Spot

Exchange Rates . . . . . . . . . . . . . . . . . 30

2.3B Tests for Unit Roots in the Logarithms of Parity

Adjusted Spot Exchange Rates . . . . . . . . . . . . . . . . 31

2.4 Diffusion Models . . . . . . . . . . . . . . . . . . . . . 39

2.5 Diffusion-ARCH Models . . . . . . . . . . . . . . . . . 39

2.6 Diffusion-GARCH Models . . . . . . . . . . . . . . 40

2.7 Jump-Diffusion Models . . . . . . . . . . . . . . . . . . . 40

2.8 Combined Jump-Diffusion-ARCH Models . . . . . . . . . . . . 41

2.9 Combined Jump-Diffusion-GARCH Models . . . . . . . . . . . . 41

2.10A Generalized Likelihood Ratio Tests . . . . . . . . . . . . . 42

2.10B Generalized Likelihood Ratio Tests . . . . . . . . . . . . . 43

2.11 Combined Jump-Diffusion-GARCH Models: t-Estimates . . . . . . 45

2.12 Diagnostics . . . . . . . . . . . . . . . 47

3.1A Summary Statistics of Actual Depreciation . . . . . . . . . 61

3.1B Summary Statistics of Expected Depreciation . . . . . . . . . 62

3.1C Summary Statistics of Survey Forecast Error . . . . . . . . . . . 63

3.2A Tests of Unbiasedness - 3 Months Forecast . . . . . . . . . . 73

3.2B Tests of Unbiasedness - 6 Months Forecast . . . . . . . . . . 74

3.2C Tests of Unbiasedness - 12 Months Forecast . . . . . . . . . 75

3.3A Tests of Orthogonality - 3 Months Forecast . . . . . . . . . 78

3.3B Tests of Orthogonality - 6 Months Forecast . . . . . . . . . . 79

$3.3 \mathrm{C}$ Tests of Orthogonality -12 Months Forecast . . . . . . . . 80

3.4A Tests of Orthogonality - 3 Months Forecast . . . . . . . . . . 81

$3.4 \mathrm{~B}$ Tests of Orthogonality -6 Months Forecast . . . . . . . . . 82

$3.4 \mathrm{C}$ Tests of Orthogonality -12 Months forecast . . . . . . . 83

3.5 Extrapolative Expectations ............... . 88 
3.6 Adaptive Expectations . . . . . . . . . . . . . . . . . . . 89

3.7 Long Run expectations . . . . . . . . . . . . . . 90

4.1A Summary Statistics of Forward Discount . . . . . . . . . . . . . 99

4.1B Summary Statistics of Expected Depreciation . . . . . . . . . . 100

4.1C Summary Statistics of Risk Premium . . . . . . . . . . . . . 101

4.2A Tests of Forward Discount Unbiasedness - 3 Months . . . . . . 108

4.2B Tests of Forward Discount Unbiasedness - 6 Months . . . . . . . 109

4.2C Tests of Forward Discount Unbiasedness - 12 Months . . . . . 110

4.3A Tests of Rational Expectations - 3 Months . . . . . . . . . . 114

4.3B Tests of Rational Expectations - 6 Months . . . . . . . . . 115

4.3C Tests of Rational Expectations - 12 Months . . . . . . . . . . 116

4.4A Tests of Perfect Substitutability - 3 Months . . . . . . . . . . . 120

4.4B Tests of Perfect Substitutability - 6 Months . . . . . . . . . . 121

4.4C Tests of Perfect Substitutability -12 Months . . . . . . . . . 122

4.5 Variance of $E_{t} S_{t+k}-S_{t}$ versus Variance of $P_{t}^{k} \ldots \ldots \ldots 125$

4.6 Correlation Coefficient of $E_{t} S_{t+k}-S_{t}$ with $P_{t}^{k} \ldots \ldots 126$

4.7 Autoregressive Processes of the Risk Premium . . . . . . . . . 127

5.1A Summary Statistics of Expected Depreciation . . . . . . . . . 137

5.1B Summary Statistics of Forward Discount . . . . . . . . . . 138

5.1C Summary Statistics of the Risk Premium . . . . . . . . . . . . 139

5.2 Tests of Perfect Substitutability . . . . . . . . . . . . . . . 141

5.3 Heteroskedasticity Tests of OLS residuals . . . . . . . . . . . 143

5.4 ARCH-in-Mean Models . . . . . . . . . . . . . . . . . . . 149

5.5 GARCH-in-Mean Models . . . . . . . . . . . . . . . 150

5.6 Generalized Likelihood Ratio Tests . . . . . . . . . . . . . . 156

5.7 Diagnostics for ARCH-in-Mean Models . . . . . . . . . . . . . . . . 157

5.8 Diagnostics for GARCH-in-Mean Models . . . . . . . . . . . . 158

6.1 Summary Statistics . . . . . . . . . . . . . . . . . 166

6.1 A Survey Forecast Error . . . . . . . . . . . . . . . . . . . . . . . . . . . 166

6.1 Forward Rate Forecast Error . . . . . . . . . . . . . . 166

6.1C Unanticipated Interest Differential . . . . . . . . . . . 166

$6.1 \mathrm{D}$ Interest Differential . . . . . . . . . . . . . . . . . 167

$6.1 \mathrm{E}$ Exchange Rate Risk Premium . . . . . . . . . . . . 167

6.2 Estimates of: $S_{t+k}-{ }_{t} F_{t+k}=\alpha+\beta_{1}\left(d_{t+k}-E_{t} d_{t+k}\right)+$ 
$\beta_{2}\left(\mathrm{~F}_{\mathrm{t}+\mathrm{k}}-\mathrm{E}_{\mathrm{t}} \mathrm{S}_{\mathrm{t}+\mathrm{k}}\right)+\mathrm{e}_{\mathrm{t}+\mathrm{k}} \ldots \ldots \ldots \ldots \ldots \ldots \ldots \ldots \ldots$

6.3 Estimates of: $S_{t+k}-{ }_{t} F_{t+k}=\alpha+\beta_{1}\left(d_{t+k}-E_{t} d_{t+k}\right)+$

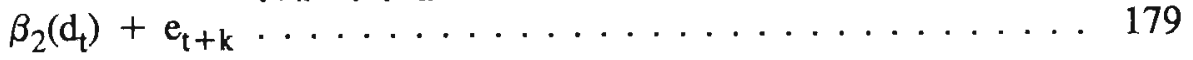

6.4 Estimates of: $\mathrm{S}_{\mathrm{t}+\mathrm{k}}-\mathrm{E}_{\mathrm{t}} \mathrm{S}_{\mathrm{t}+\mathrm{k}}=\alpha+\beta_{1}\left(\mathrm{~d}_{\mathrm{t}+\mathrm{k}}-\mathrm{E}_{\mathrm{t}} \mathrm{d}_{\mathrm{t}+\mathrm{k}}\right)+$

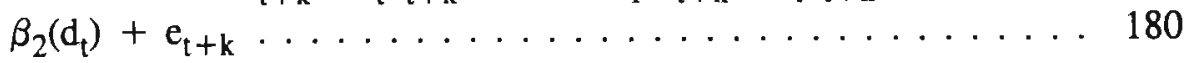




\section{List of Figures}

Figure

Page

2.1 French Franc/Deutschmark Exchange Rate . . . . . . . . . 25

2.2 Weekly Log Price Changes FF/DM Exchange Rate . . . . . . . 25

2.3 Italian Lira/Deutschmark Exchange Rate . . . . . . . . . 26

2.4 Weekly Log Price Changes IL/DM Exchange Rate . . . . . . . . 26

3.1A Actual and Expected Depreciation DM/US - 3 Months . . . . . . 66

3.1B Actual and Expected Depreciation FF/DM - 3 Months . . . . . . 66

3.2A Actual and Expected Depreciation DM/US - 6 Months . . . . . . 67

3.2B Actual and Expected Depreciation FF/DM - 6 Months ....... 67

3.3A Actual and Expected Depreciation DM/US - 12 Months ......66 68

3.3B Actual and Expected Depreciation FF/DM - 12 Months ......668

4.1A Expected Depreciation and Forward Discount DM/US . . . . . 103

4.1B Exchange Rate Risk Premium DM/US - 3 Months . . . . . . . 103

4.2A Expected Depreciation and Forward Discount DM/US . . . . . 104

4.2B Exchange Rate Risk Premium DM/US - 6 Months . . . . . . . 104

4.3A Expected Depreciation and Forward Discount DM/US . . . . . 105

4.3B Exchange Rate Risk Premium DM/US - 12 Months . . . . . . . 105

5.1 A Actual and Estimated ARCH Premia DG/DM . . . . . . . 151

5.1B Actual and Estimated GARCH Premia DG/DM . . . . . . . 151

5.2A Actual and Estimated ARCH Premia BF/DM . . . . . . . . 152

5.2B Actual and Estimated GARCH Premia BF/DM . . . . . . 152

5.3A Estimated ARCH and GARCH Premia DG/DM . . . . . . . 153

5.3B Estimated ARCH and GARCH Premia BF/DM ....... 153 


\section{Chapter one}

\section{Introduction: Aims and Scope}

This study provides an empirical analysis of expectations formation, risk premia and innovations in forward foreign exchange. We examine the efficiency of foreign exchange markets as well as addressing some explanations of market inefficiency and assessments of the influence of new information on the exchange rate. In particular, we concentrate on modeling exchange rate behavior, exchange rate expectations, foreign exchange risk and "news". At the outset it is important to note that, as with other financial markets, any test of foreign exchange market efficiency is a joint test of several composite hypotheses. Forward market efficiency tests are necessarily joint tests of an equilibrium model of expected returns and rational processing of available information by market participants. Hence the concept of efficiency is seen to be inextricably linked with the assumption concerning the mechanisms used by economic agents in the market to form expectations. This empirical analysis has been directed to obtain empirical evidence on the relative importance of "irrationality", "risk" and "news" in explaining unanticipated movements in foreign exchange rates. In particular, we try to shed new light on the relative importance of both irrationality of market participants and the existence of time-varying risk premia in explaining the forward discount bias.

The debate regarding tests of foreign exchange market efficiency is a long standing one. The importance of this topic to government policymakers, firms, investors, and economists and the ready availability of data have spawned a large volume of research in this area - see the surveys on the efficiency of the foreign exchange market by Boothe and Longworth (1986), Hodrick (1987) and Levich (1985). The original concept of an efficient market is due to Fama (1965) who described such a market as consisting of a "large number of rational, profit maximizers actively competing with each other to predict future market values of individual securities and where 
important current information is almost freely available to all market participants". Thus if asset prices are to serve their function as signals for resource allocation they must succesfully process and transmit all relevant information about future market developments to the suppliers and demanders of assets. Hence for a foreign exchange market to be efficient, exchange rates must always fully reflect all relevant and available information and no profit opportunities are left unexploited.

The existence and efficiency of organized markets for future delivery of foreign currencies was a critical link in early arguments for flexible exchange rates. Friedman (1953) argued that the existence of such markets provided international traders a convenient means of hedging risk of currency fluctuations. In contrast, Nurske (1944) argued that flexible exchange rates would be inherently volatile and subject to the whims of speculators. After more than twenty years of experience under floating exchange rates since the breakdown of the Bretton Woods fixed-parity system in the early 1970 's it is clear that exchange rate variability has been more substantial than expected by the advocates of the system. The presence of exchange rate volatility has given rise to substantial differences of interpretations. For instance, Kindleberger (1976) has attributed volatility to the activities of destabilising speculation whereas McKinnon (1976) assumed that it was due to too little speculative capital being available to garuantee the efficiency of the foreign exchange markets. The decision to change from the Bretton Woods fixed-parity system to marked-determined exchange rates dramatically changed the research focus of empirical work on exchange rates. After the breakdown, the empirical research focused on testing foreign exchange market efficiency, inspired by the fact that the economic argument for flexible exchange rates centered largely on the issue of market efficiency.

One approach to testing exchanges rates' informational efficiency, advocated by Fama (1970), argues that efficiency requires that actual prices (or rates of return) follow a "fair game" process relative to expected equilibrium prices (or rates of return). In the context of foreign exchange markets we therefore first require a model of equilibrium exchange rates. Conditional on the equilibrium model we can then derive expectations which are model-consistent or rational. ${ }^{1}$ The main problem confronting this approach concerns the specification of the equilibrium model. While a

\footnotetext{
${ }^{1}$ Rationality in the Muth (1961) sense is defined as an expectation which is "ownmodel-consistent".
} 
number of models have been developed to describe the determination of exchange rates, empirical tests of structural models have had little succes in isolating the important explanatory variables. ${ }^{2}$ Indeed, the results of Meese and Rogoff (1983a, 1983b) indicate that existing models of systematic exchange rate determination could not outperform the simple random walk forecasting rule, even though the models' forecast were based on ex-post realized values of future explanatory variables. One aspect of the economy that is ignored in constructing linear models is the nature of risk and a possible explanation for the poor performance of structural exchange rate models is the risk premium. Meese and Rogoff (1983a, 1983b) suggest that time-varying risk premia could be an important determinant of their findings although they express skepticism about the likelihood of this being the complete explanation. The debate regarding the relative size and variability of the exchange risk premium is a long standing one. Fama (1984) developed a methodology to identify and measure premia in the pricing of forward foreign exchange, which assesses empirically the relative variability of the risk premium and forward rate forecast errors over the period 1973-1982. Fama (1984) concludes on the relative importance of risk premium and forecast errors: "Conditional on the hypothesis that the forward exchange rate is efficient or rational, we find reliable evidence that both components of forward rate - the expected future spot rate and the risk premium - vary through time." His findings indicate that most of the variation in forward rates is attributable to variation in risk premia, the variance of the risk premium is greater than the variance of the expected change in the spot exchange rate, and the premium and expected future spot rate components of forwards rates are negatively correlated. These findings are valid under the hypothesis of rational expectations and the assuptions that the sample statistics are converging to the true moments of the population with correct asymptotic standard errors. Fama's (1984) results provide a useful insight in the relative importance of the risk premium in the foreign exchange market. It is significant because it implies that a time-varying risk premium plays a fundamental role in the determination of spot and forward exchange rates. In contrast, most theoretical rational expectations models of exchange rate determination have focused almost exclusively on the expected rate of

2 See, for example, Frenkel (1976), Branson, Haittunen and Mason (1979), and Edison (1985). 
depreciation. This suggests that future work should be devoted towards understanding the importance and economic sources of risk in foreign exchange markets. As suggested by Fama's (1991) excellent survey on efficient capital markets, the market efficiency literature should be directed towards establishing links between the behavior of expected returns and the real economy. In this study we try to shed new light on the relative importance of both irrationality of market participants and the existence of time-varying risk premia in the pricing of forward foreign exchange.

To establish reduction of exchange rate volatility and increasing economic policy coordination among member countries, the Exchange Rate Mechanism (ERM) of the European Monetary System (EMS) was founded in March 1979. The intra-European exchange rates would be allowed to fluctuate only within official bilateral limits, to be defended by exchange market intervention. The provisions of the European Monetary System provide for participating countries to maintain their exchange rates within bilateral limits of \pm 2.25 percent. $^{3} \mathrm{~A}$ key characteristic of the EMS exchange rate mechanism is the presence of discontiniuities (realignments) in the exchange rate behaviour. No fewer than eleven realignments occured during the first eight years and these always have taken the form of devaluations, in varying degrees, against the Deutschmark.

The outline of this study is as follow. Chapter two considers the statistical time series properties of exchange rate returns within the European Monetary System and attempts to give empirical content to the theory concerning efficient markets and exchange rate volatility - the clustering phenomenon. The knowledge of the resulting exchange rate process is essential for the accurate pricing of currency options and for international asset pricing models. Currency option pricing, for example, usually employs Black and Scholes type models- see Garman and Kohlhagen (1983) - which make the strong assumption of a continuous time stochastic process for the representation of the exchange rate behavior in the form of a geometric Brownian motion. Although this may adequately describe the behavior of freely floating exchange rates, this latter assumption does not seem to describe accurately the behavior of exchange rates within the European Monetary System. The EMS exchange rate returns follow a complicated process that

$3 \pm 6$ percent for Italy (until January 1990), Spain and the United Kingdom (which joined in July 1989 and October 1990, respectively). The United Kingdom and Italy suspended membership as of september 1992 until further notice. 
alternates discontinuous jumps (realignments) to "normal" periods in which the exchange rate might be considered following a continuous sample path process.

In the academic litarature it is agreed upon that empirical distributions of US Dollar exchange rate returns exhibit fatter tails than one expects from a normal distribution. See, for example, Boothe and Glassman (1987) and Hsieh (1989). In this study we aim to provide extensive evidence for EMS currencies. An important question is whether EMS exchange rates follow random walks or whether the ex- change rate coordination agreement introduces a certain degree of mean reversion into the actual statistical distributions. We attempt to answer this question and model the stochastic processes followed by EMS exchange rates, in order to arrive at satisfactory descriptions of the time paths followed by these currencies. The observed leptokurtosis may be explained by several classes of models. See, for example, Akgiray and Booth (1988), Jorion (1988), and Vlaar and Palm (1992). In this chapter we will concentrate on three possible explanations. The observed leptokurtosis may be due to the existence of discontinuities, or jumps, in the data. These jumps, especially with EMS data, can occur because of the official realignments of central rates within the EMS and due to intramarginal interventions to maintain bilateral parities. The occurrence of jumps can also explain the observed positive skewness in our EMS data. A second explanation suggests that exchange rate returns can be described by a normal distribution with time-varying parameters (See Hsieh, 1989). Finally we consider the possibility that EMS exchange rates are generated by a conditionally leptokurtic distribution. Our results indicate that mean reversion is clearly present in EMS exchange rates, although it is somewhat difficult to detect. Our findings indicate that jumps, time-varying parameters and conditional leptokurtosis are pertinent features in the empirical distribution of EMS exchange rate returns. There is considerable interference, however, between jumps in the distribution, on the one hand, and allowing for fat tails, on the other hand. Most successful in capturing the relevant features of EMS exchange rate returns is a combined jump-GARCH model with conditionally t-distributed innovations.

In chapter three, we examine the rationality of agents' expectations which continues to be an issue of central concern in the financial economics literature - see Fama (1991) and Cutler, Poterba and Summers (1990), for instance. These propositions have been tested recently in the foreign 
exchange market by analyzing survey data for some of the major currencies (French Franc, British Pound, German Mark, Japanese Yen, and Swiss Franc) relative to the United States Dollar - see Dominguez (1986), Frankel and Froot (1987a and 1987b), Froot and Frankel (1990), Ito (1990), MacDonald and Torrance (1990), Taylor (1989), and the literature surveys of Takagi (1991) and Froot and Thaler (1990). The principal benefit of using such data is that one obtains a direct measure of agents' beliefs, thus allowing for separate testing of an underlying model of exchange rate determination and a hypothesis about expectations. In order to test the rationality of agents' expectations directly, therefore, survey data of exchange rate expectations are essential.

We address three questions that were considered earlier by Frankel and Froot (1987a) and Dominguez (1986): whether economic agents' exchange rate forecasts are unbiased, whether economic agents use all available information efficiently and which time series process best characterizes investors' expectations formation. This study considers a new survey data set of exchange rate expectations that covers a range of US Dollar and EMS exchange rates over the January 1986 - July 1991 period. Results using the available EMS cross exchange rate forecasts over a different sample period and over relatively long horizons (three, six, and twelve months) provide an interesting complement to previous work that has largely focused on the five most actively traded currencies (vis-à-vis the US Dollar). The estimation procedure employed on regressions with overlapping data allowed both for conditional heteroskedasticity and serially correlated forecast errors. We corroborate the earlier finding in the literature that exchange rate forecasts are not rational and that agents do not use all available information efficiently. Although extrapolative and adaptive expectations formation mechanisms describe non-EMS exchange rate expectations to a certain extent, EMS exchange rates forecasts seem to follow long-run fundamentals more closely, which would suggest that agents believe that EMS exchange rate expectations "undershoot" their long run equilibrium values.

One of the well established empirical regularities in the international financial economics literature is the finding that the forward discount is a biased predictor of the future change in the exchange rate - see the surveys on the efficiency of the foreign exchange market by Hodrick (1987) and Levich (1985). The rejection of forward market efficiency may be attributable to the irrationality of market participants [as suggested by Bilson (1981), Cumby and Obstfeld (1984) and Longworth (1981)], or to the existence of 
time-varying risk premia [as suggested by Fama (1984), Hodrick and Srivastava (1984), Hsieh (1984) and Wolff (1987a)], or to some combination of both of these phenomena.

In chapter four, we use survey data of exchange rate expectations to divide the forward discount into its two components - expected depreciation and the risk premium - in order to shed new light on the large literature that finds bias in the pricing of forward foreign exchange. We adress the pricipal question of whether rejection of forward market efficiency is attributable to the existence of time-varying risk premia or irrational behavior of economic agents. In addition, we examine the time series properties of our estimated risk premia for each bilateral exchange rate to assess whether they are consistent with asset pricing models. In contrast to earlier results for survey data, we find that the bias in the forward discount for major currencies relative to the U.S. Dollar is attributable to both irrationality of exchange rate expectations and the existence of a time-varying risk premium. For EMS currencies the bias is primarily attributable to significant variation in the risk premium component and the variability of the premia exceeds the variability of expected rates of depreciation as in Hodrick and Srivastava (1986). Our exchange risk premia exhibit serial correlation patterns that are broadly consistent with the utility optimizing models of Lucas (1982) and Domowitz and Hakkio (1985).

Motivated by a growing body of empirical evidence against the hypothesis of forward market efficiency, generally attributed to the presence of a timevarying risk premium, there has been considerable interest in empirically tractable theories of a risk premium. Conditional on the hypothesis that the foreign exchange market is efficient or rational, the existence of time-varying premia has been documented in the literature by Fama (1984), Hansen and Hodrick (1980), Hodrick and Srivastava (1984, 1986), Hsieh (1984), Korajczyk (1985), and Wolff (1987a). Alternative methodologies to measure time-varying premia have been explored in the literature. Nevertheless, a number of the models employed have failed to identify statistically significant exchange risk premia and in their review Bollerslev, Chou, Jayaraman and Kroner (1991) note that: "A satisfactory model for the time varying risk premium in the forward foreign exchange market has yet to be formulated". The methodologies used in previous empirical research on premia in the pricing of forward foreign exchange usually involve measurement of timevarying risk premia conditional on market efficiency or rational expectati- 
ons. In addition, in most studies, such as Dornbusch (1982), Hansen and Hodrick (1983), and Frankel (1986), it was explicitly assumed that the conditional variances and covariances of returns were constant over time. In chapter five, we implement an alternative approach to measure premia. We do not have to assume conditional homoskedasticity of exchange returns nor do we have to rely on estimation methods using unobserved variables, see Giovannini and Jorion (1987), and Hodrick and Srivastava (1984, 1986). We extend the analysis of Domowitz and Hakkio (1985) to model time-varying risk premia in the pricing of forward foreign exchange that do not require us to assume rationality on the part of economic agents. In contrast to earlier results, the estimated premium models - ARCH-in-mean and GARCH-inmean - indicate that time-varying risk premia can be explained by the conditional standard deviation of the expected rate of depreciation. In particular, the GARCH-in-mean model appears to be moderately successful in accounting for both time-varying risk premia and conditional heteroskedasticity.

As we have noted previously, the history of floating exchange rates in the 1970 s was characterized by periods of extreme turbulence and volatility. While purchasing power parity (PPP) is at best a long-run phenomenon, the "asset market theory" of exchange rate determination - as developed by Branson (1977), Dornbusch (1976a, 1976b), Frenkel (1976), Mussa (1976), and Frankel and Mussa (1980) - appears necessary to understand short-run fluctuations in exchange rates. According to this theory exchange rates are merely the relative prices of assets determined in organized markets where asset prices can be adjusted on an instanteneous basis to whatever "the market" regards as the currently appropriate price. Thus, exchange rates fluctuate in response to the market's perception of future fundamental determinants that effect the supply and demand for foreign exchange. This approach typically places considerable emphasis on the importance of expectations and is generally taken to imply that empirical research on the determinants of exchange rates should relate innovations in exchange rates to innovations in relevant future fundamentals, which are unobservable and difficult to model empirically.

The idea was first implemented empirically by Frenkel (1981), who notes that the key factor affecting exchange rates has been "news". Following the "news" approach of exchange rate determination, according to which innovations in exchange rates respond only to innovations in relevant future fundamentals, all anticipated movements having already been embodied in 
the current spot rate. Therefore, it is unanticipated rather than anticipated changes in fundamentals that should be closely associated with innovations in exchange rates. Since innovations are inherently unobservable, any empirical study on the "news" approach involves a joint examination of the model and the method that is used to construct innovations. That is, when testing the "news" approach empirically, a specific model of the process of exchange rate determination and an appropriate method of generating expected values of its driving variables must be chosen.

Chapter six empirically implements the "news" version of the DornbuschFrankel overshooting model, as derived in Isard (1983) by using survey data of matched exchange rate and interest rate expectations. This in order to obtain theoretical and empirical evidence on the relative importance of "news" and "risk" in explaining unanticipated movements in exchange rates. In the present context, the survey-based approach allows us to measure market forecasts of the exchange rate directly and generate expected values of the determining variables. Thus, because market participants' perceptions of future exchange rates as well as their perceptions of interest rates are measured simultaneously, we can avoid problems of artificially generating expectations or "news" from econometric modelling nor do we have to assume time invariant exchange rate risk premia. The empirical results indicate that "news" on interest rate differentials enters significantly and with a negative coefficient in equations for the difference between the spot rate and the lagged forward exchange rate for the British Pound, Japanese Yen, Spanish Peseta and the US Dollar. The empirical results suggest that an unexpected rise in the interest rate differential tends to strengthen the domestic exchange rate, which is often referred to as the Dornbusch-Frankel overshooting effect. We also find for each of these currencies significant effects of our ex-ante measure of the risk premium. In addition we investigate the effect of lagged interest differentials and find that lagged interest differentials probably do not reflect time-varying risk premia as widely suggested in the literature but probably capture a peso-problem, learning about a policy change, a market-inefficiency or a combination of these factors.

In chapter seven we present the main empirical results of this study and formulate some general conclusions on the basis of the results presented. A number of suggestions for future research emerge from the discussion in this chapter. 



\section{Chapter two}

\section{EMS Exchange Rate Dynamics}

\subsection{Introduction}

Since the breakdown of the Bretton Woods fixed-parity system in the early 1970s, the nature of exchange rate volatility has changed considerably. Since March 1973, exchange rates have been allowed to adjust more or less continuously in response to market forces. Monetary authorities in most major industrial countries, however, intervene in the foreign exchange market from time to time when they observe developments deemed to be undesirable. The concern about the very high level of exchange rate volatility in the years directly following the abandonment of the Bretton Woods system was the basis for the foundation of the European Monetary System (EMS) in 1979. To establish reduction of exchange rate volatility and increasing economic policy coordination among member countries, the Exchange Rate Mechanism (ERM) of the European Monetary System (EMS) was founded in March 1979.

Since 1979, the European Monetary System (EMS) has provided an interesting example of a formal Exchange Rate Mechanism (ERM) and framework for international policy coordination. Intra-European exchange rates would be allowed to fluctuate only within official bilateral limits, to be defended by exchange market intervention. An incipient move beyond the bilateral limit, therefore, should urge the monetary authorities of the two countries in question to intervene in the market. In order to facilitate the obligatory interventions, special credit facilities have been established to provide central banks participating in the ERM with foreign exchange.

The EMS is literally an exchange rate target zone with narrow bands. The description of exchange rate behavior within a target zone and during a speculative attack has been formalized over the past few years - see Bertola and Svensson (1990), Dumas and Svensson (1991), Flood and Garber 
(1989), Krugman (1991), and Krugman and Rotemberg (1990), for instance. By adopting a continuous process to drive the fundamentals and assuming perfectly credible target zones, Krugman (1991) shows that exchange rates follow a regulated Brownian motion process. ${ }^{1}$ An important feature of fixed exchange rate regimes is that parities are usually imperfectly credible and not permanent. Eleven realignments of central parities occurred during the first eight years of the Exchange Rate Mechanism of the European Monetary System. Dumas and Svensson (1991) and Krugman and Rotemberg (1990) extend the Krugman (1991) model to allow for speculative attacks on the band once official reserves are sufficiently low. Empirical evidence supporting the target zone literature is, at least to our knowledge, still limited. Evidence against the validity of target zone models is provided by Meese and Rose (1990) who found no support for the postulated S-shape of exchange rate behavior.

A huge volume of literature has addressed the distributional properties of speculative prices and the empirical distribution of asset returns continues to be an issue of central concern in the financial economics literature - see Mandelbrot (1963), Fama (1965), Akgiray and Booth (1988), and Boothe and Glassman (1987), for instance. The distribution and the underlying stochastic process giving rise to such a distribution play an important role in financial theory. The assumption of multivariate normal increments of the (log) prices underlies the Capital Asset Pricing Model (CAPM) of Sharpe and Lintner (1965) which states that the equilibrium expected return on an asset is linearly related to its risk. Black and Scholes (1973) assumed a continuous time stochastic process for the representation of price behavior in the form of a geometric Brownian motion where the log of the price relatives are assumed to be independent, identically and normally distributed. Also, the assumption on the distributional properties of the price process are critical in many tests of the efficient market hypothesis.

Most academic studies on the EMS concentrate on macroeconomic relationships. [See, e.g., Giavazzi, Micossi and Miller (1988), Masera and Triffin (1984) and Rogoff (1984a)]. Typically, these studies focus on

1 For tests of target zone credibility see for instance Bertola and Cabellero (1990), Giovannini (1990), and Weber (1991). Frankel and Phillips (1991) have independently applied the Bertola-Svensson (1990) and Rose-Svensson (1991) methodology to evaluate the credibility of EMS exchange rates. 
monetary convergence, capital controls and economic growth. ${ }^{2}$ Interestingly, this branch of literature pays little attention to observed statistical distributions of EMS exchange rates. Exchange rates involving the US Dollar have been subjected to much closer scrutiny. As is well documented, empirical distributions on US Dollar exchange rate returns exhibit leptokurtic behavior and clusters of high and low volatility. The Autoregressive Conditional Heteroskedastic (ARCH) class of models, introduced by Engle (1982) and generalized (GARCH) by Bollerslev (1986), are successful in accounting for most of the heteroskedasticity and clustering phenomenon; this is because ARCH processes possess "fat-tailed" unconditional densities, even though their conditional densities are normal - see the survey on ARCH modeling in finance by Bollerslev, Chou, Jayaraman, and Kroner (1990). Studies by Baillie and Bollerslev (1989), Boothe and Glassman (1987), Hsieh (1989), Jorion (1988), Meese and Rogoff (1983) and Wolff (1987a) provide extensive statistical evidence on US Dollar exchange rates. Overall, the findings overwhelmingly favor the conclusion that the assumption of conditional normality does not capture all the excess kurtosis observed in high frequency exchange rate returns. Several alternative conditional distributions have consequently been employed in the literature, for instance the Student- $t$, normal-Poisson, generalized error, and normal-lognormal distributions [see, e.g., Akgiray and Booth (1988), Baillie and Bollerslev (1989), Jorion (1988), and Hsieh (1989)].

In the current chapter we aim to provide extensive statistical evidence for EMS exchange rates. The EMS exchange rate returns follow a complicated process that alternates discontinuous jumps (realignments) to "normal" periods in which the exchange rate might be considered to follow a continuous sample path process. An important question is whether EMS exchange rates follow random walks or whether the exchange rate coordination agreement introduces a certain degree of mean reversion into the actual statistical distributions. ${ }^{3}$ We attempt to answer this question and model the stochastic processes followed by EMS exchange rates, in order to arrive at

2 An alternative contribution to this literature is the specification of conditional realignment probabilities on the basis of market fundamentals for the EMS currencies, see for instance Collins (1986).

3 Rose and Svensson (1991) provide strong evidence of statistically significant mean reversion of EMS exchange rates within the band. 
satisfactory descriptions of the time paths followed by these currencies. The observed leptokurtosis may be explained by several classes of models. Therefore, alternative time-series processes characterizing EMS exchange rates are considered. We combine normal distributions (with time-varying parameters) and a stochastic jump process to account for the observed leptokurtosis, which may be due to the existence of discontinuities, or jumps, in EMS data. In addition to exploring normal conditional densities, the Student- $t$ distribution is employed. The results will form a body of evidence which can serve as a frame of reference for further research.

This chapter is organized as follows. In section 2 we address the question whether EMS exchange rates exhibit some degree of mean reversion. In that section we also describe our dataset and summary statistics are provided. The methodology and models employed to describe the patterns followed by EMS exchange rates are explained in section 3. Section 4 presents the main empirical results of this chapter and section 5 contains our concluding comments and suggestions for future research.

\subsection{Random Walks or Mean Reversion?}

The Exchange Rate Mechanism of the EMS provides for participating countries to maintain their exchange rates within bilateral limits of \pm 2.25 percent $[ \pm 6$ percent for Italy (until January 1990), Spain and the United Kingdom (which joined in July 1989 and October 1990, respectively)]. ${ }^{4}$ In addition to the provisions for a margin of fluctuations, realignments are permitted and from time to time undertaken. The realignment dates and the bilateral exchange rates are shown in Table 2.A. No fewer than eleven realignments occurred during the first eight years and they always have taken the form of devaluations, in varying degrees, against the Deutschmark. Only the Dutch Guilder maintained a nearly fixed rate against the Deutschmark.

${ }^{4}$ In January 1990 the bands for the Italian Lire were narrowed from $\pm 6 \%$ to the norm of $\pm 2.25 \%$. The transition was accomplished by lowering the upperband limit and leaving the lower limit unchanged. The United Kingdom and Italy suspended membership as of september 1992 until further notice. 
Note that since January 12, 1987 very few realignments were undertaken. ${ }^{5}$ With regard to exchange rates involving the US Dollar, many authors conclude that these rates can be described fairly accurately by random walks. [See Meese and Rogoff (1983a, 1983b) for an early example.] The EMS exchange rate mechanism could very well lead to mean reversion in bilateral EMS exchange rates if the system succeeds in maintaining longer-run target rates or central rates. In this section we will present tests of mean reversion. Our database contains weekly bilateral exchange rates (Thursday closing rates) for currencies of countries that became EMS members in March 1979. For a number of years, prior to the formal adherence to the EMS, the Spanish Peseta was informally kept within a \pm 6 percent band with respect to EMS currencies. This consideration leads us to the inclusion of the Spanish Peseta.

For reasons of comparison, the British Pound is also included. The data were obtained from Datastream. Even though daily rates are available, we choose to employ weekly data in order to avoid issues surrounding the dayof-the-week effect with regard to exchange rate volatility (on which, see Hsieh, 1988). Our sample includes 677 weekly observations, ranging from 15 March 1979 through 27 February 1992. In Table 2.1 we present summary statistics on weekly log price changes. For the period analyzed (March 15th, 1979 through February 27th, 1992) the mean weekly log price changes are all positive, indicating that the EMS currencies depreciated against the Deutschmark. Furthermore, the distribution of exchange rate returns is highly skewed to the right, which may be a result of asymetric movements in the parity adjustments. In order to access the distributional properties of EMS exchange rate returns, the Bera-Jarque (1982) Normality test and the Kiefer-Salmon (1983) Lagrange multiplier normality test are reported in Table 2.1, where the former is a joint test using both skewness and kurtosis and the latter is an LM test for normal skewness (KS-1) and normal kurtosis (KS-2), respectively. ${ }^{6}$ Overall, the evidence presented suggests a consistent rejection of the normality hypotheses. In addition, Table 2.1 reports the

5 For arguments that 1987 marked the beginning of a "new EMS" see Giavazzi and Spaventa (1990). In September (Spanish Peseta) and November 1992 (Spanish Peseta and Portuguese Escudo) realignments of central rates were implemented.

6 The Bera-Jarque test is asymptotically Chi-square(2) distributed, and the KieferSalmon normality tests are asymptotically Chi-square(1) distributed. 
Table 2.A Realignment Dates and Central Parities of EMS Exchange Rates

\begin{tabular}{lllllll}
\hline & BF/DM & DK/DM & DG/DM & FF/DM & IL/DM & IP/DH \\
\hline $03 / 13 / 79$ & 15.72 & 2.822 & 1.084 & 2.309 & 457.46 & 0.264 \\
\hline $09 / 24 / 79$ & 16.03 & 2.964 & 1.105 & 2.356 & 466.64 & 0.269 \\
\hline $11 / 30 / 79$ & 16.03 & 3.111 & 1.105 & 2.356 & 466.64 & 0.269 \\
\hline $03 / 22 / 81$ & 16.03 & 3.111 & 1.105 & 2.356 & 496.28 & 0.269 \\
\hline $10 / 05 / 81$ & 16.91 & 3.283 & 1.105 & 2.562 & 539.96 & 0.284 \\
\hline $02 / 22 / 82$ & 18.48 & 3.384 & 1.105 & 2.562 & 539.96 & 0.284 \\
\hline $06 / 14 / 82$ & 19.27 & 3.529 & 1.105 & 2.834 & 561.17 & 0.296 \\
\hline $03 / 21 / 83$ & 20.03 & 3.631 & 1.127 & 3.067 & 626.17 & 0.324 \\
\hline $07 / 21 / 85$ & 20.03 & 3.631 & 1.127 & 3.067 & 679.35 & 0.324 \\
\hline $04 / 07 / 86$ & 20.42 & 3.704 & 1.127 & 3.256 & 699.79 & 0.333 \\
\hline $08 / 04 / 86$ & 20.42 & 3.704 & 1.127 & 3.256 & 699.79 & 0.362 \\
\hline $01 / 12 / 87$ & 20.63 & 3.814 & 1.127 & 3.353 & 720.98 & 0.373 \\
\hline $01 / 08 / 90$ & 20.63 & 3.814 & 1.127 & 3.353 & 748.22 & 0.373 \\
\hline & & & & & & \\
\hline
\end{tabular}

Source: Ungerer, Hauvonen, Lopez-Claros and Mayer (1990) 
Table 2.1 Summary Statistics of Weekly Log Price Changes: $\ln \left(S_{t} / S_{t-1}\right)$

March 15, 1979 through February 27, 1992: 675 Observations

\begin{tabular}{|c|c|c|c|c|}
\hline & $\mathrm{BF} / \mathrm{DM}$ & BP/DM & $D G / D M$ & DK/DM \\
\hline Mean & 0.0004 & 0.0004 & 0.0001 & 0.0005 \\
\hline St.dev & 0.0076 & 0.0113 & 0.0024 & 0.0042 \\
\hline$T$-test & 1.26 & 0.93 & 0.71 & 3.08 \\
\hline Skewness & 0.49 & 0.49 & 1.09 & 1.49 \\
\hline Kurtosis & 9.80 & 5.23 & 13.97 & 15.02 \\
\hline BJ-test & $1326.09^{\cdots}$ & $166.91^{\cdots}$ & $3515.39 \cdots$ & $4313.48^{\prime \cdots}$ \\
\hline KS-1 & $26.69^{\cdots}$ & $26.91 \cdots$ & $132.45^{\cdots}$ & $249.40^{\cdots}$ \\
\hline ks-2 & $1299.40^{\cdots}$ & $140.01 \cdots$ & $3382.95^{\prime \cdots}$ & $4064.08^{\cdots}$ \\
\hline$D(25) R$ & 11.96 & $34.97^{\circ}$ & $41.74^{\circ}$ & 17.92 \\
\hline$D(50) R$ & 37.06 & 51.84 & $69.59^{\circ *}$ & 43.63 \\
\hline$L B(25) R^{2}$ & $645.44^{\cdots}$ & $81.37 \cdots$ & $99.04 \cdots$ & 14.11 \\
\hline \multirow[t]{2}{*}{$L B(50) R^{2}$} & $871.41^{\cdots}$ & $110.20^{\circ \cdots}$ & $184.11^{\cdots}$ & 21.21 \\
\hline & FF/DH & IL/OH & IP/DH & SP/DM \\
\hline Mean & 0.0006 & 0.0008 & 0.0005 & 0.0008 \\
\hline St.dev & 0.0045 & 0.0057 & 0.0046 & 0.0078 \\
\hline$T$-test & 3.35 & 3.42 & 2.92 & 2.60 \\
\hline Skemness & 6.04 & 1.83 & 4.54 & 2.24 \\
\hline Kurtosis & 67.76 & 33.27 & 53.96 & 21.99 \\
\hline BJ-test & $122070^{\cdots}$ & $26141^{\cdots}$ & $75368^{\cdots}$ & $10706 \cdots$ \\
\hline KS-1 & $4110.59^{\cdots}$ & $376.63^{\cdots}$ & $2323.69^{\cdots}$ & $564.71^{\cdots}$ \\
\hline $\mathrm{ks}-2$ & $117960^{\circ} \cdots$ & $25764 \cdots$ & $73044^{\cdots}$ & $10142 \cdots$ \\
\hline$D(25) R$ & 33.54 & 23.27 & $35.51^{\circ}$ & 21.89 \\
\hline$D(50) R$ & 58.89 & 43.28 & 52.60 & 44.91 \\
\hline$L B(25) R^{2}$ & 6.54 & $63.48^{\circ}$ & 4.36 & 8.00 \\
\hline$L B(50) R^{2}$ & $139.97^{\cdots}$ & $191.20 \cdots$ & 5.32 & 12.89 \\
\hline
\end{tabular}

Legend: $B F=$ Belgian Franc; BP = British Pound: DG = Dutch Guilder; DK = Danish Kroner: DM = Deutschmerk; FF = French Frenc; IL = Italian Lire; IP = Irish Poind: SP = Spanish Peseta. The BJ-test denotes the Bera Jarque test for normality; KS-1 and KS-2 pertain to the Kiefer Salmon Normality test for respectively skewness and kurtosis; $D(p)$ and $L B(p)$ denote the $D i e b o l d$ and $L j u n g-B o x$ test for serial correlation using $p$ lags; * (*) [*\#] denotes rejection at the 10\% (5\%) [1\%] level of the normality hypotheses. 
Diebold (1988) and Ljung-Box (1978) test statistics for kth-order serial correlation in $\ln \left(S_{t} / S_{t-1}\right)$ and $\left[\ln \left(S_{t} / S_{t-1}\right)\right]^{2}$, respectively. ${ }^{7}$ The squared exchange rate returns exhibit substantially more autocorrelation than the raw data, which is indicative of strong conditional heteroskedasticity.

In Graphs 1 and 3 two examples of exchange rate paths and official bilateral intervention limits are presented (the FF/DM and IL/DM exchange rates). Graphs 2 and 4 display corresponding graphs of log differences in these exchange rate levels, corresponding (approximately) to percentage changes in the levels. The shifts of the EMS bands due to realigments can be clearly detected in these figures. Note that the occurrence of a realignment is not always associated with the exchange rate reaching a barrier.

In order to test for the presence of heteroskedasticity in exchange rate returns, two different approaches are employed. First the Lagrange multiplier tests for autoregressive conditional heteroskedasticity - see Breusch and Pagan (1979) - are performed, and secondly a non-parametric test based on finite-state homogeneous Markov chains - see Gregory (1989) - is applied. Further details on the construction of the ARCH test based on finite-state Markov chains are given in Appendix 2A. Using Monte Carlo analysis Gregory (1989) concludes that under other distributions than the Normal the LM test is biased towards the null hypothesis of no ARCH, and that the Markov Chain test is superior to the LM test in terms of better finite sample properties. Both tests only require estimation under the null hypothesis of no heteroskedasticity. The results of the LM and Markov chain tests for the presence of heteroskedasticity are given in Table 2.2. Overall, the evidence presented suggests a fairly consistent rejection of the hypothesis of no heteroskedasticity. However, it is interesting to note that the results for the Danish Kroner, French Franc and Irish Pound lead to conflicting inferences regarding the independence of exchange rate return series and are not unambiguous. ${ }^{8}$

7 Diebold (1988) proposes an adjusted Ljung-Box test statistic to allow for heteroskedasticity. He showed that in the presence of ARCH effects, the Ljung-Box test has a larger empirical size than a nominal test size of $5 \%$, because the asymptotic variance of the autocorrelations under ARCH is larger than under the null of Gaussian white noise.

8 The evidence presented here is consistent with Gregory's (1989) observation that the LM test is biased toward the null hypothesis of no ARCH for non-normal conditional distributions. 
Graph 1: FRENCH FRANC / DEUTSCHMARK EXCHANGE RATE march 15, 1979 - february 27, 1992

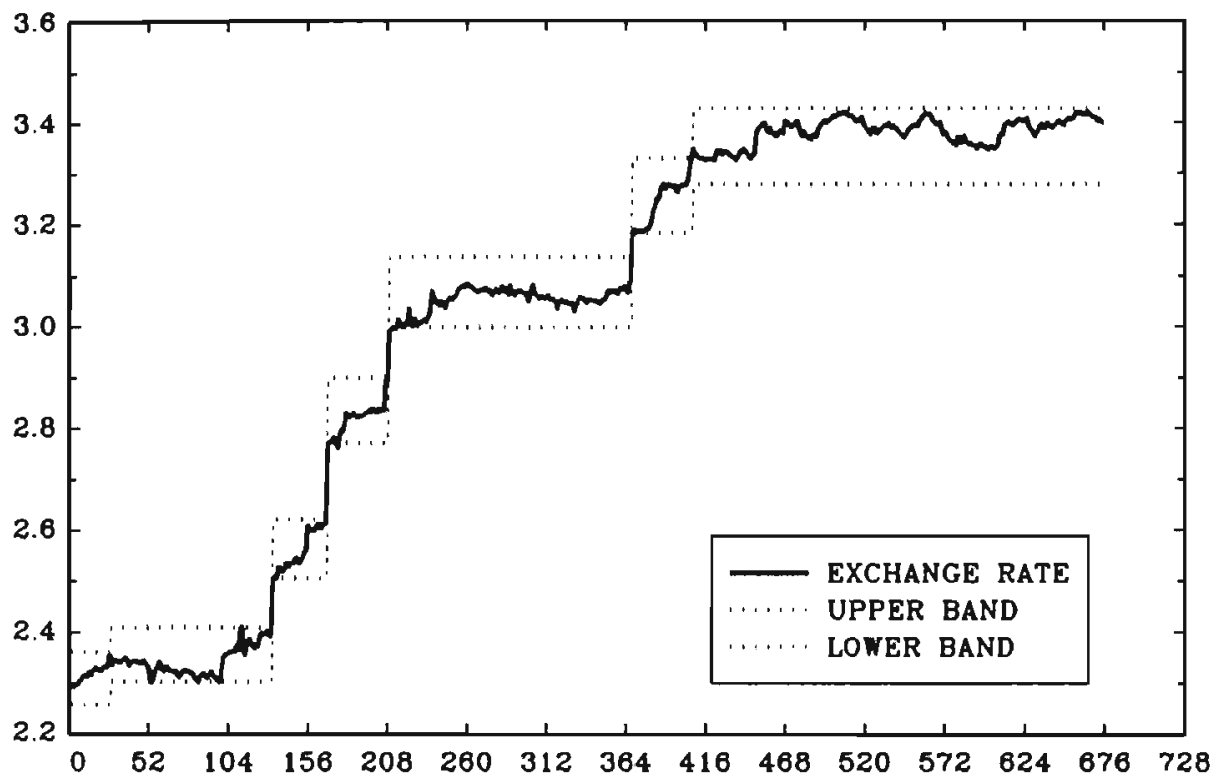

Graph 2: WEEKLY LOG PRICE CHANGES FF/DM EXCHANGE RATE march 15, 1979 - february 27. 1992

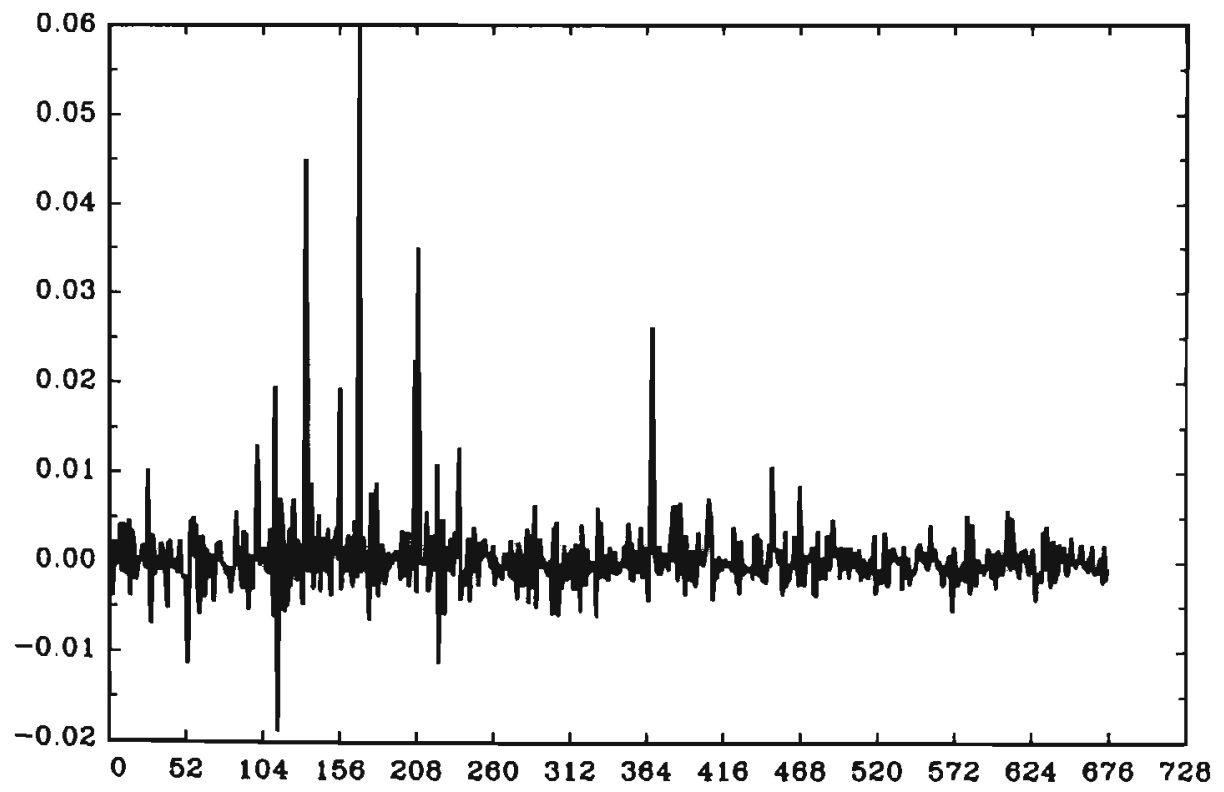


Graph 3: ITALIAN LIRA/DEUTSCHMARK EXCHANGE RATE

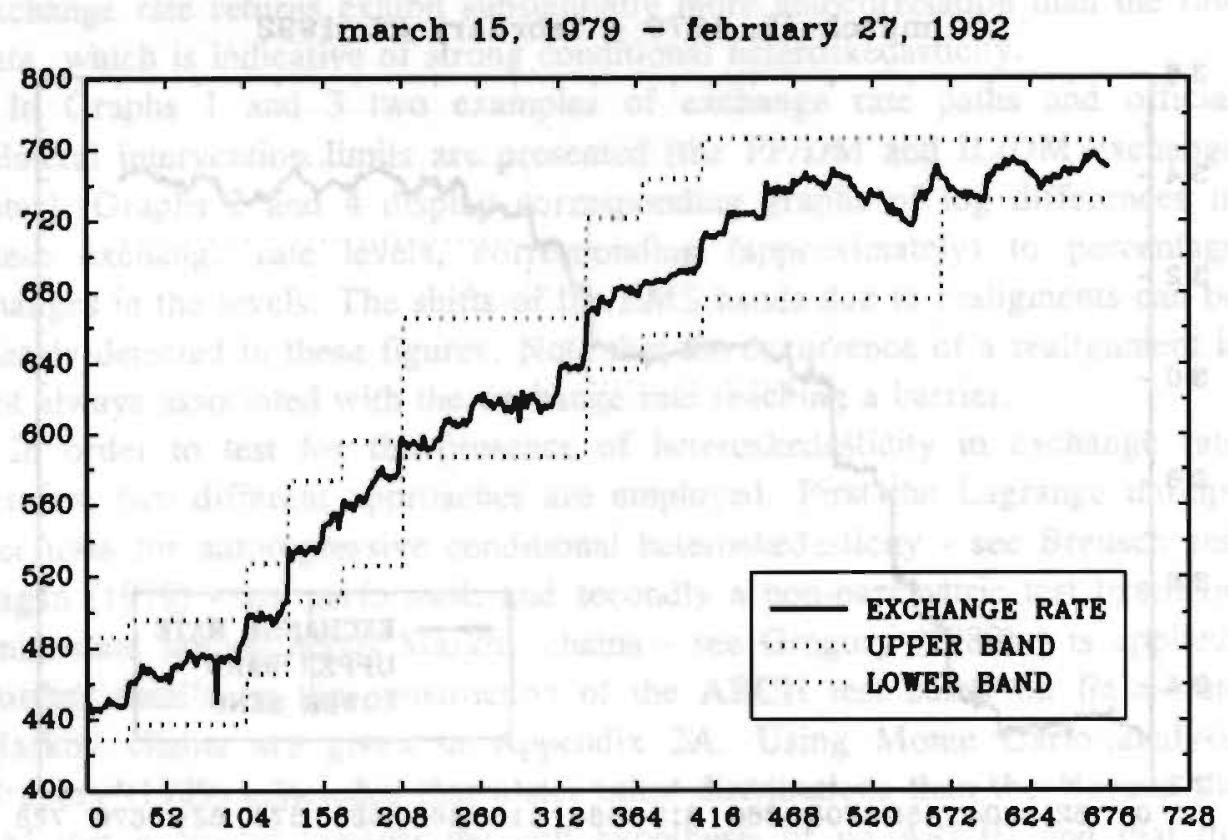

Graph 4: WEEKLY LOG PRICE CHANGES IL/DM EXCHANGE RATE march 15, 1979 - february 27, 1992

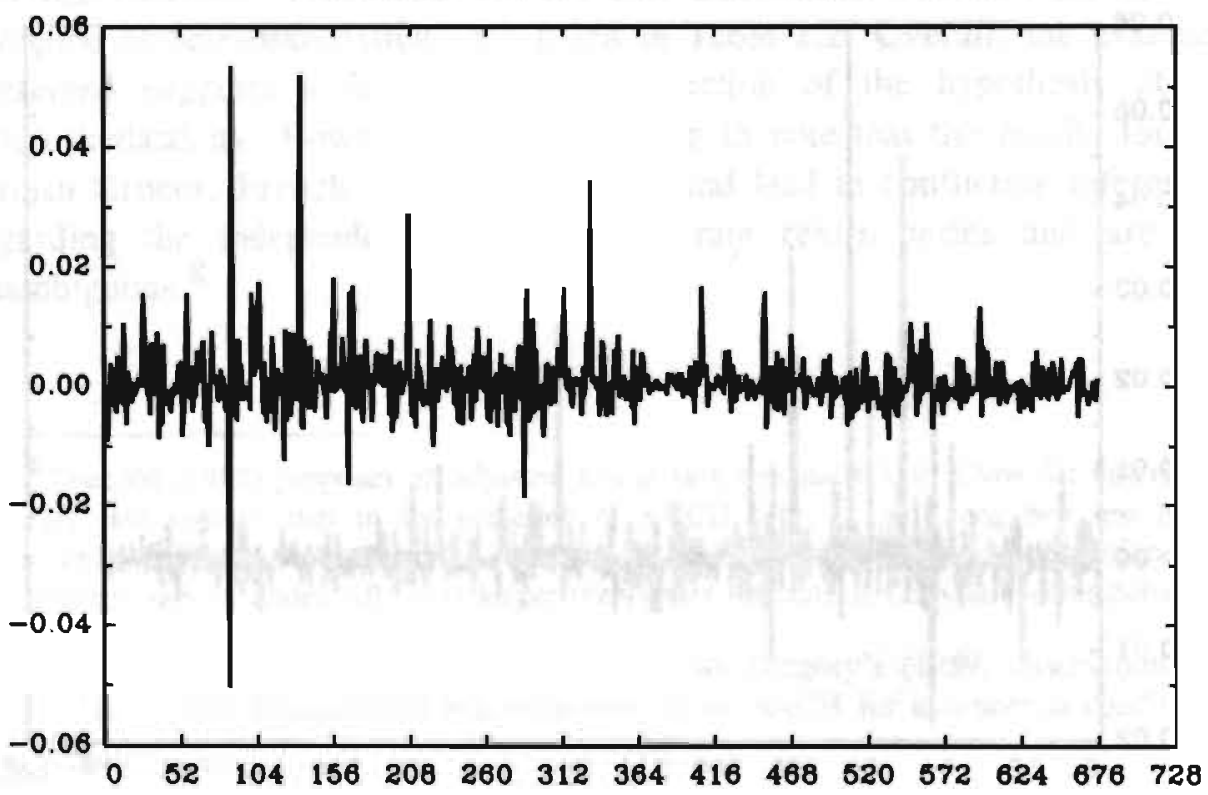


Table 2.2 Heteroskedasticity tests of Weekly Log Price Changes: $\ln \left(\mathrm{S}_{\mathrm{t}} / \mathrm{S}_{\mathrm{t}-1}\right)$

March 15, 1979 through February 27, 1992: 675 Observations

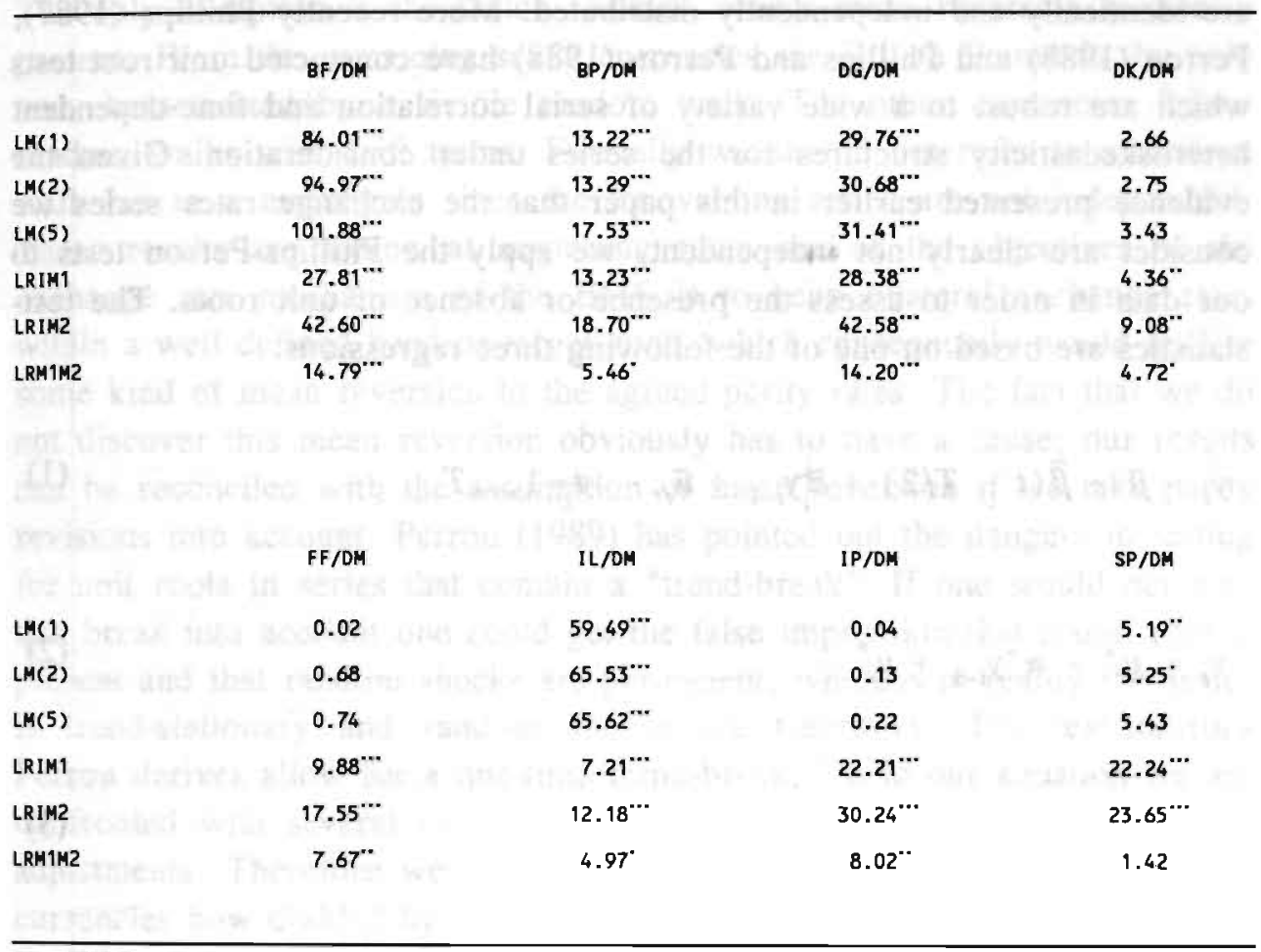

The $\mathrm{LM}(\mathrm{p})$ test is estimated as $\mathrm{TR}^{2}$ from a regression of squared log price changes [ $\left.\ln \left(S_{t} / S_{t-1}\right)\right]$ on a constant and $p$ lags, and is asymptotically Chi-square(p) distributed. LRIM1 is a Likelihood Ratio test of independence against a first order Markov Chain, and is distributed as Chi-square(1); LRIM2 is a Likelihood Ratio test of independence against a second order Markov Chain, and is distributed as Chi-square(3); LRM1M2 is a likelihood Ratio test of a first order against a second order Markov Chain, and is distributed as Chi-square $(2) .{ }^{*}\left({ }^{* *}\right)[* * *]$ denotes significance at the $10 \%(5 \%)[1 \%]$ level. 
By now a respectable number of unit root tests is available in the literature. The original tests for the unit root hypothesis were established by Dickey and Fuller $(1979,1981)$. Although widely used, these tests are restricted by their assumption that the innovations to the assumed data generating process are identically and independently distributed. More recently Phillips (1987), Perron (1988) and Phillips and Perron (1988) have constucted unit root tests which are robust to a wide variety of serial correlation and time-dependent heteroskedasticity structures for the series under consideration. Given the evidence presented earlier in this paper that the exchange rates series we consider are clearly not independent, we apply the Phillips-Perron tests to our data in order to assess the presence or absence of unit roots. The teststatistics are based on one of the following three regressions:

$$
\begin{aligned}
& y_{t}=\tilde{\mu}+\tilde{\beta}(t-T / 2)+\tilde{\alpha} y_{t-1}+\tilde{u}_{t}, \quad t=1, \ldots, T \\
& y_{t}=\mu^{*}+\alpha^{*} y_{t-1}+u_{t}^{*} \\
& y_{t}=\ddot{\alpha} y_{t-1}+a_{t}
\end{aligned}
$$

where $y_{t}$ denotes the logarithm of the spot exchange rate, $\mu$ is a drift term, $\alpha$ and $\beta$ are coefficients and $u_{t}$ is a random error term. Regressions (1)-(3) lead to six different test statistics:

$$
Z\left(\Phi_{1}\right), Z\left(\Phi_{2}\right), Z\left(\Phi_{3}\right), Z\left(t_{\tilde{\alpha}}\right), Z\left(t_{\alpha^{*}}\right), Z\left(t_{\hat{\alpha}}\right)
$$

The simple test statistics based on the $t$-values of the autoregressive parameters in the respective regressions test for the presence of a unit root only. The joint statistics test for both presence of a unit root as well as for absence of constant terms and time trends (where appropriate). Further details on the construction of these statistics and the testing strategies used are given in Appendix 2B. For comparison purposes we have also performed the Aug- 
mented Dickey-Fuller (ADF) test. ${ }^{9}$ The results of these tests are contained in Table 2.3a. The overall conclusion that can be drawn is that we cannot reject the unit root hypothesis for seven out of the eight currencies analyzed. The only exception is the Dutch Guilder, where mean reversion is clearly present. From the remaining seven currencies the British Pound is the only one characterized by a simple random walk. The other currencies follow random walks with drift terms. Formally we should not refer to a random walk but to a martingale since the innovations series are not independent. These results are somewhat surprising since one of the objectives of the exchange rate mechanism of the EMS is to keep bilateral exchange rates within a well defined band or target zone, which consequently would lead to some kind of mean reversion to the agreed parity rates. The fact that we do not discover this mean reversion obviously has to have a cause; our results can be reconciled with the assumption of mean reversion if we take parity revisions into account. Perron (1989) has pointed out the dangers in testing for unit roots in series that contain a "trend-break". If one would not take this break into account one could get the false impression that a unit root is present and that random shocks are permanent, whereas in reality the series is trend-stationary and random shocks are transitory. The test-statistics Perron derives allow for a one-time trend-break, but in our situation we are confronted with several of these breaks or interventions, leading to parity adjustments. Therefore we have performed the same unit root tests on the currencies now divided by the appropriate parities. The results are described in Table $2.3 \mathrm{~b}$ and clearly indicate mean reversion. ${ }^{10}$ Summarizing we can conclude that the time series behavior of EMS exchange rates is characterized by mean reversion between two realignments, but that the occurrence of realignments leads to the non-rejection of unit roots for the overall series.

${ }^{9}$ The Augmented Dickey-Fuller test also accounts for serial dependence in the series.

10 The British Pound and the Spanish Peseta are excluded, as no realignments involving these currencies occurred since their adherence to the ERM. 
Table 2.3A Tests for Unit Roots in the Logarithms of Spot Exchange Rates: $\ln \left(S_{\mathrm{t}}\right)$ March 15, 1979 through February 27, 1992: 675 Observations

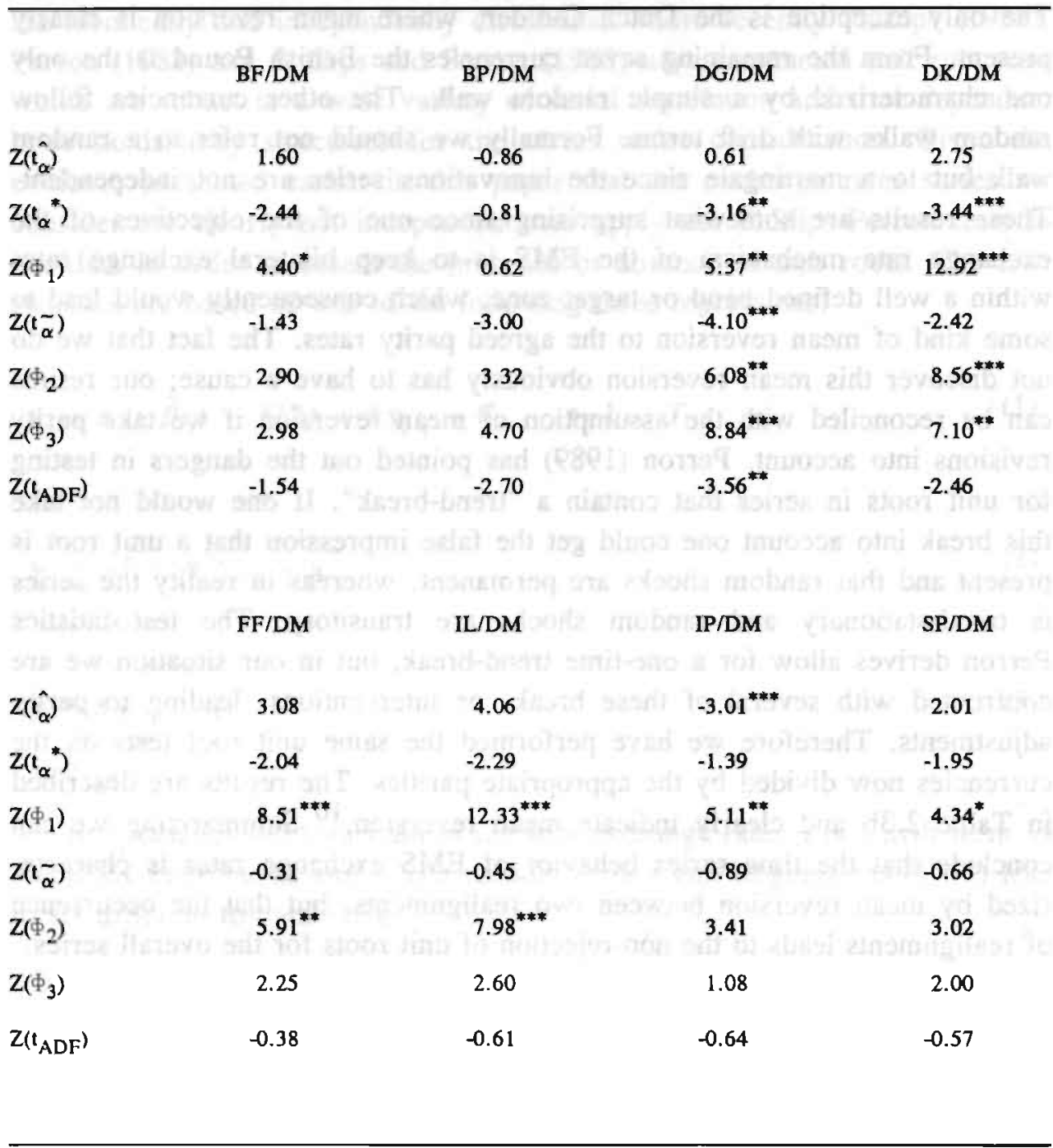

The seven different statistics all test for a unit root in the univariate time-series representation for each of the eight spot rates, $S_{t}$, against a stationary or trend-stationary alternative. The exact forms of the tests are given in Appendix A. ${ }^{*}\left({ }^{* *}\right)\left[{ }^{* *}\right]$ denotes significance at the $10 \%(5 \%)[1 \%]$ level. 
Table 2.3B Tests for Unit Roots in the Logarithms of Parity Adjusted Spot Exchange Rates: $\ln \left(S_{t} / P_{t}\right)$

March 15, 1979 through February 27, 1992: 675 Observations

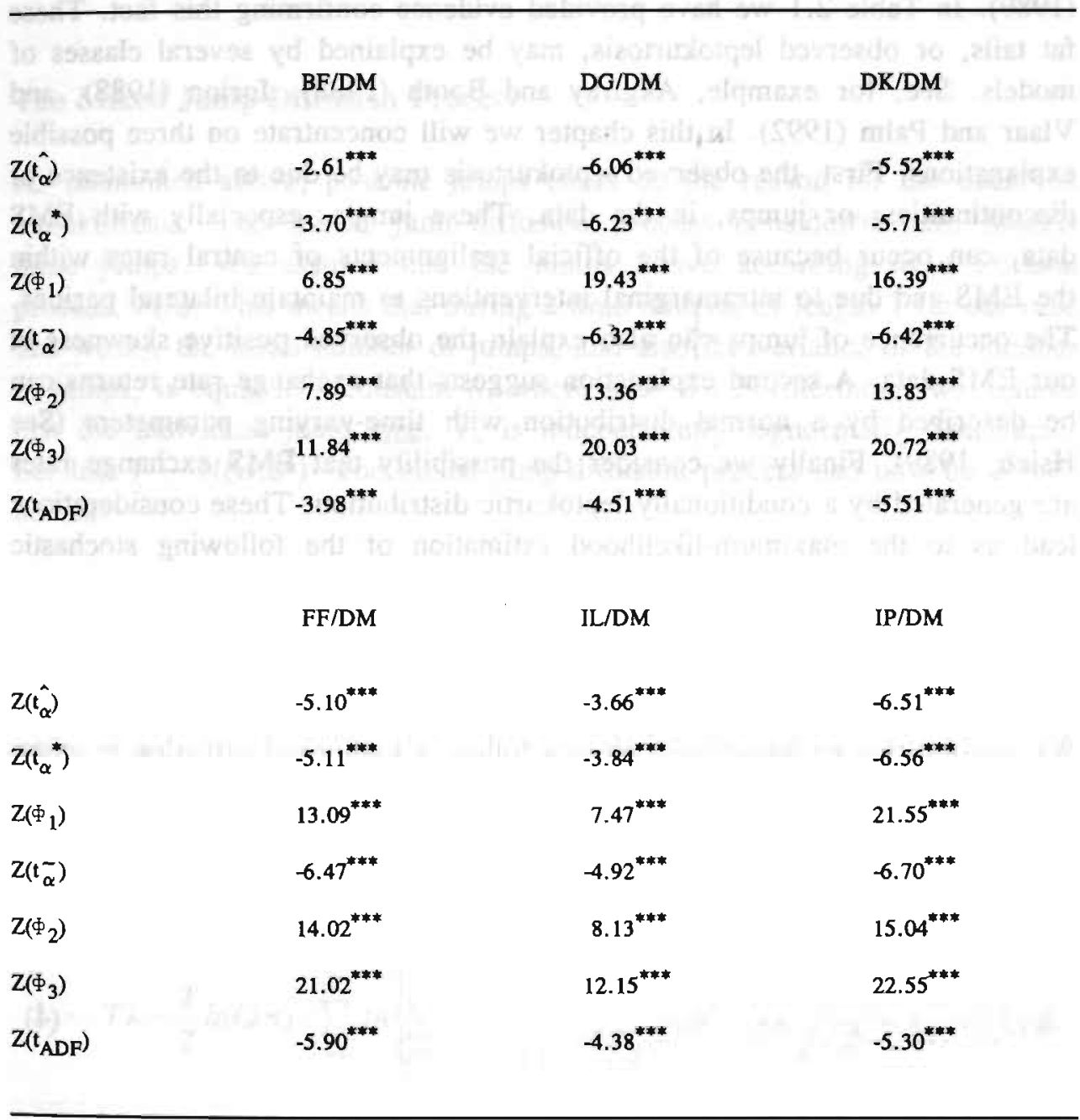

The seven different statistics all test for a unit root in the univariate time-series representation for each of the six parity adjusted spot rates, $\ln \left(S_{1} / P_{1}\right)$, against a stationary or trendstationary alternative. The exact forms of the tests are given in Appendix A. * $\left(^{* *}\right)[* * *]$ denotes significance at the $10 \%(5 \%)$ [1\%] level. 


\subsection{Modeling EMS Exchange Rates: Methodology}

In the academic literature it is agreed upon that empirical distributions of exchange rate returns exhibit fatter tails than one expects from a normal distribution. See, for example, Boothe and Glassman (1987) and Hsieh (1989). In Table 2.1 we have provided evidence confirming this fact. These fat tails, or observed leptokurtosis, may be explained by several classes of models. See, for example, Akgiray and Booth (1988), Jorion (1988), and Vlaar and Palm (1992). In this chapter we will concentrate on three possible explanations. First, the observed leptokurtosis may be due to the existence of discontinuities, or jumps, in the data. These jumps, especially with EMS data, can occur because of the official realignments of central rates within the EMS and due to intramarginal interventions to maintain bilateral parities. The occurrence of jumps can also explain the observed positive skewness in our EMS data. A second explanation suggests that exchange rate returns can be described by a normal distribution with time-varying parameters (See Hsieh, 1989). Finally we consider the possibility that EMS exchange rates are generated by a conditionally leptokurtic distribution. These considerations lead us to the maximum-likelihood estimation of the following stochastic processes:

\section{The Lognormal Diffusion Process}

We assume that exchange rate returns follow a lognormal diffusion process: $\mathrm{dS} / \mathrm{S}_{\mathrm{t}}=\alpha \mathrm{dt}+\sigma \mathrm{dz}$, where $\alpha$ is the instantaneous expected return and $\mathrm{z}$ is a Wiener process. This assumption implies that $\ln \left(S_{\mathfrak{t}} / S_{t-1}\right)$ is normally distributed with mean $\mu, \mu=\alpha-\sigma^{2} / 2$, and variance $\sigma^{2}$. In discrete-time the model is:

$$
\ln \left(S_{t} / S_{t-1}\right)=\mu+\sigma z
$$

where $\mathrm{z}$ is a standard normal deviate. This process will serve as a benchmark. Given the evidence presented earlier, however, this process is unlikely to be the true data generating process. Given $\mathbf{N}$ independent observations the associated log-likelihood function can be written as: 


$$
L_{d}=-\frac{T}{2} \ln (2 \pi)+\sum_{t=1}^{T} \ln \left\{\left(\frac{1}{\sigma}\right) \exp \left(\frac{-\left(\ln \left(S_{t} / S_{t-1}\right)-\mu\right)^{2}}{2 \sigma^{2}}\right)\right\}
$$

\section{The Mixed Jump-Diffusion Process}

As mentioned above, possible jumps could be the reason for the observed leptokurtosis. The mixed jump-diffusion process considered here models these jumps. We assume that the jumps arrive according to a Poisson process, $P(\lambda)$. This means that during a time interval of length 1 (in our case one week), the mean number of jumps, and also the variance of the number of jumps, is equal to a constant $\lambda$, where $\lambda>0$. Furthermore, we assume that the individual jump size, $\mathrm{Y}$, is independently lognormally distributed, i.e. $\ln (\mathrm{Y}) \sim \mathrm{N}\left(\theta, \delta^{2}\right)$. The mixed jump-diffusion process can now be described as:

$$
\ln \left(S_{t} / S_{t-1}\right)=\mu+\sigma z+\sum_{i=1}^{n_{t}} \ln \left(Y_{i}\right)
$$

where $n_{t}$ represents the actual number of jumps during the time interval [see Jorion (1988)]. The log-likelihood function for this process can be expressed as:

$$
L_{j}=-T \lambda-\frac{T}{2} \ln (2 \pi)+\sum_{i=1}^{r} \ln \left\{\sum_{j=0}^{\infty} \frac{\lambda^{j}}{j !} \frac{1}{\sqrt{\left(\sigma^{2}+\delta^{2} j\right)}} \exp \left(-\frac{\left(\ln \left(S_{t} / S_{t-1}\right)-\mu-\theta j\right)^{2}}{2\left(\sigma^{2}+\delta^{2} j\right)}\right)\right\}
$$

The infinite sum in the above likelihood function poses a problem in the numerical optimization of this function. The infinite sum has to be truncated 
at a suitable truncation number, $\mathrm{U}$, so that sufficient accuracy for all parameter values is guaranteed. An upper bound for the truncation error was derived by Ball and Torous (1985). This upper bound can be used to select a suitable $U$. For our purposes $U=20$ gives sufficient accuracy.

The second possible explanation for the observed leptokurtosis was that exchange rate returns can be normally distributed with time-varying parameters. We will focus on the time variation in second moments and, specifically, we estimate a first-order diffusion-ARCH and a GARCH $(1,1)$ process, which were introduced by Engle (1982) respectively Bollerslev (1986). We know that GARCH processes with conditionally normal innovations generate unconditional distributions with fat tails.

\section{The Diffusion-(G)ARCH Process}

Here we make a distributional assumption: $\ln \left(S_{t} / S_{t-1}\right) \sim N\left(\mu, h_{t}\right)$. Conditional on all available information at time $t-1$, the process can be described as:

$$
\left.\ln \left(S_{t} / S_{t-1}\right)\right|_{t-1}=\mu+\varepsilon_{t}
$$

where,

$$
\varepsilon_{t}=\sqrt{h_{t}} z, \quad h_{t}=E_{t-1}\left(\varepsilon_{t}^{2}\right)=\alpha_{0}+\alpha_{1} \varepsilon_{t-1}^{2}+\beta_{1} h_{t-1}
$$

In the $\operatorname{ARCH}(1)$ formulation $\beta_{1}$ is zero. The associated log-likelihood function reads:

$$
L_{a}=-\frac{T}{2} \ln (2 \pi)+\sum_{t=1}^{T} \ln \left\{\frac{1}{\sqrt{h_{t}}} \exp \left(\frac{-\left(\ln \left(S_{t} / S_{t-1}\right)-\mu\right)^{2}}{2 h_{t}}\right)\right\}
$$

Both the diffusion-(G)ARCH process and the jump-diffusion process can outperform the standard lognormal diffusion process. It is, however, possible 
that neither model alone can fully account for the observed leptokurtosis. Therefore, we also investigate a model that combines both a jump process and a (G)ARCH process: the combined jump-diffusion-(G)ARCH model.

\section{The Jump-Diffusion-(G)ARCH Process}

$$
\left.\ln \left(S_{t} / S_{t-1}\right)\right|_{t-1}=\mu+\varepsilon_{t}+\sum_{i=1}^{n_{t}} \ln \left(Y_{i}\right)
$$

where the conditional variance function remains as given in equation (9). The associated log-likelihood function can be formulated as:

$$
L_{j a}=-T \lambda-\frac{T}{2} \ln (2 \pi)+\sum_{t=1}^{T} \ln \left\{\sum_{j=0}^{\infty} \frac{\lambda^{j}}{j !} \frac{1}{\sqrt{\left(h_{t}+\delta^{2} j\right)}} \exp \left(-\frac{\left(\ln \left(S_{t} / S_{t-1}\right)-\mu-\theta j\right)^{2}}{2\left(h_{t}+\delta^{2} j\right)}\right)\right\}
$$

Again, the infinite sum will be truncated at $U=20$ in the actual estimation procedure.

It would be inappropriate to limit our attention to jump-ARCH processes for the following reasons. Consider the situation where a realignment has been effected just recently, which is translated into a large innovation term. In the ARCH model this would cause a sudden large increase in the conditional variance and a subsequent large drop in variance, whereas in the GARCH model the conditional variance would change more gradually. In the former case the large increase in volatility could be confused with an additional jump, causing the jump intensity to move upwards. This is less likely to happen in the latter case. This was pointed out by Vlaar and Palm (1992). Furthermore we know from empirical evidence, e.g. Baillie and Bollerslev (1989), that volatility shocks are much more persistent than is implied by an ARCH(1) model. This suggests that the parameter on the lagged conditional variance in the $\operatorname{GARCH}(1,1)$ model will be highly 
significant.

The third explanation we offer for the observed leptokurtosis considers a conditionally fat-tailed distribution for the innovation series. Although GARCH models with conditionally normal innovations and the jump part in our models both generate unconditional fat tails, and are thus in accordance with stylized facts, these two explanations may be subsumed by conditionally fat-tailed innovation distributions. In order to assess this possibility we propose a Student-t distribution for the innovations. The model remains as is described in equations (9) and (11). The associated log likelihood function however changes into:

$$
\begin{aligned}
& L_{j a}=T\left(-\lambda-\frac{1}{2} \ln (\pi(v-2))+\ln \Gamma\left(\frac{v+1}{2}\right)-\ln \Gamma\left(\frac{v}{2}\right)\right)+ \\
& \sum_{t=1}^{T} \ln \left\{\sum_{j=0}^{\infty} \frac{\lambda^{j}}{j !} \frac{1}{\sqrt{\left(h_{t}+\delta^{2} j\right)}}\left(1+\frac{\left(\ln \left(S_{t} / S_{t-1}\right)-\mu-\theta j\right)^{2}}{(v-2)\left(h_{t}+\delta^{2} j\right)}\right)^{\frac{-(v+1)}{2}}\right\}
\end{aligned}
$$

\subsection{Modeling EMS Exchange Rates: Empirical Results}

In this section we present empirical results from the estimation procedures outlined in the previous section. First, we present the estimation results for individual models and then the various models are compared and formal hypotheses are tested. Maximum likelihood estimates of the parameters and their heteroskedasticity consistent asymptotic standard errors were obtained by numerical methods using the Berndt, Hall, Hall and Hausman (1974) (BHHH) algorithm. ${ }^{11}$ In Tables 2.4-2.9, the estimation results are reported for the six stochastic processes described in the previous section. The results for the diffusion model are described in Table 2.4. This is our base case or

${ }^{11}$ All calculations were performed with the software package GAUSS. 
benchmark model. All estimated values of the mean $\mu$ are positive (and five of these statistically significant) indicating that all currencies depreciated visà-vis the DM. The standard deviation of the BP/DM exchange rate is statistically significant greater than those for other EMS exchange rates. The results for the diffusion-ARCH model are summarized in Table 2.5. All but two of the estimated models result in statistically significant $\alpha_{1}$ coefficients, thus supporting the ARCH-specification. The diffusion-GARCH estimation results are reported in Table 2.6. The estimated $\alpha_{1}$ and $\beta_{1}$ coefficients are statistically significant in five out of eight cases. However, for the Belgian Franc, Dutch Guilder, French Franc and Irish Pound, the estimates of $\alpha_{1}$ and $\beta_{1}$ are greater than one, indicating infinite persistence in the volatility shocks, or IGARCH behavior [see Engle and Bollerslev (1986)]. As conjectured by Diebold (1986), and Lamoureux and Lastrapes (1990), this may be the result of not accounting for discrete shifts in monetary regimes which affect the level of the unconditional variances, and, therefore can lead to misspecification of the GARCH model. ${ }^{12}$ In Table 2.7 the estimation results for the mixed jump-diffusion process are presented. We find that four of the estimated jump intensity coefficients, $\lambda$, are statistically significant, and $\lambda$ ranges from $5.8 \%$ (the FF/DM exchange rate) to $95.5 \%$ (the BP/DM exchange rate). Interpreting the estimated $\lambda$ coefficient for the FF/DM exchange rate, an estimated jump intensity of $5.8 \%$ implies an estimated expected number of jumps equal to 39 over the analyzed period. However, only six realignments involving the FF/DM exchange rate occured during the life of the ERM. Some of the additional jumps could result from intramarginal or exchange market interventions to maintain bilateral parities. The estimated average jump size, $\theta$, is always positive (with a maximum of 0.8 percent for the French Franc) and sometimes significantly so, which is in accordance with the positive skewness. On average, when restricting our attention to the official realignments, we can say that the estimated jump intensity is excessively high, and the estimated jump size is rather low.

Looking at Table 2.8, where the results of the combined jump-diffusionARCH process are described, two interesting observations emerge. First of all we can see that compared to the results of Table 2.5 , the diffusion-ARCH

12 Lastrapes (1989) finds that persistence of exchange rate volatility decreases when regime shifts are accounted for, diminishing the likelihood of integrated-in-variance processes. 
process, the ARCH parameter drops significantly and uniformly. The hypothesis that the process is integrated in variance can be rejected altogether, where it cannot be rejected in four cases in the diffusion ARCH case. Furthermore all ARCH parameters are highly significant. Secondly, we oberve that compared to the results of Table 2.7, the jump-diffusion model, the estimated jump intensity drops in 6 out of 8 cases, and on average reaches a higher level of significance. It appears that the combination of a Jump and an ARCH process is more appropriate than modeling the processes individually. Not surprisingly, the same statement can be made regarding combined jump-diffusion-GARCH process. Comparing the results of the diffusion-GARCH model to the results of the jump-diffusion-GARCH model in Table 2.9, we notice that the GARCH parameters are highly significant and that IGARCH behavior, which was a problem in the former case, is no longer present, with the exception of the Dutch Guilder. The estimated jump intensities are consistently smaller, and the average jump sizes are consistently larger in the combined jump-diffusion-GARCH case than in the simple jump-diffusion case. Given our previous remark about the magnitudes of intensities and sizes it seems that a combined jump-diffusion-GARCH process constitutes a considerable improvement over the simple jumpdiffusion process. As was mentioned before, it would be inappropriate to limit our attention to jump-diffusion-ARCH processes; jump intensities may have a positive bias. This is confirmed empirically when we compare the estimated jump intensities of the jump-diffusion-ARCH process to the intensities of the jump-diffusion-GARCH process. In the latter case the intensities are substantially smaller.

Given the results in Tables 2.4-2.9, it is interesting to compare the relative fit of various models. We employ generalized likelihood ratio tests to compare nested models. Tables $2.10 \mathrm{a}$ and $2.10 \mathrm{~b}$ present the generalized likelihood ratio tests to compare the relative fit of the models employed. From Table $2.10 \mathrm{a}$, all p-values associated with the chi-square statistics are very close to zero, except the values for the IL/DM and SP/DM exchange rates in the fifth column. In Table $2.10 \mathrm{~b}$, all but three of the p-values associated with the chi-square statistics are close to zero. Thus, the generalized likelihood ratio tests reject the simpler model in favor of the more complicated model in most of the cases. It is clear that the combined jumpdiffusion-GARCH model performs best. However, in the case of the DK/$\mathrm{DM}, \mathrm{FF} / \mathrm{DM}$ and SP/DM exchange rate, the generalized likelihood ratio tests cannot reject the simpler (combined jump-diffusion-ARCH) model in 
Table 2.4 Diffusion Models

March 15, 1979 through February 27, 1992: 675 Observations

\begin{tabular}{|c|c|c|c|c|c|c|c|}
\hline & & $\hat{\mu}\left(.10^{2}\right)$ & & $\hat{\sigma}\left(.10^{2}\right)$ & & L.L. & \\
\hline $10 x+4=$ & & & & 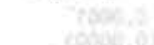 & & 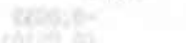 & xany \\
\hline BF/DH & & $\begin{array}{c}0.0370 \\
(0.0294)\end{array}$ & 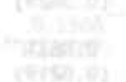 & $\begin{array}{c}0.7628^{\cdots} \\
(0.0435)\end{array}$ & & 2333.52 & 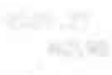 \\
\hline BP/DM & & $\begin{array}{c}0.0405 \\
(0.0435)\end{array}$ & 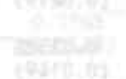 & $\begin{array}{c}1.1313^{\cdots} \\
(0.0448)\end{array}$ & & 2067.44 & $x^{2}+x^{2}=$ \\
\hline DG/DH & & $\begin{array}{c}0.0065 \\
(0.0092)\end{array}$ & 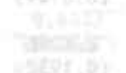 & $\begin{array}{c}0.2391 \cdots \\
(0.0166)\end{array}$ & & 3116.66 & $+2 x$ \\
\hline DK/DM & & $\begin{array}{l}0.0494 \cdots \\
(0.0160)\end{array}$ & 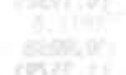 & $\begin{array}{c}0.4162 \cdots \\
(0.0300)\end{array}$ & $1,8=10$ & 2742.45 & novist \\
\hline FF/DH & & $\begin{array}{c}0.0579 \% \\
(0.0173)\end{array}$ & $\tan =0$ & $\begin{array}{c}0.4493^{\cdots} \\
(0.0707)\end{array}$ & & 2690.75 & +2 \\
\hline IL/DH & & $\begin{array}{c}0.0757^{* . *} \\
(0.0221)\end{array}$ & $x^{2}+1=$ & $\begin{array}{c}0.5740^{\circ .} \\
(0.0627)\end{array}$ & & 2525.45 & \\
\hline IP/DH & & $\begin{array}{c}0.0521 \cdots \\
(0.0178)\end{array}$ & $6 x^{2}=18$ & $\begin{array}{c}0.4635^{\cdots} \\
(0.0649)\end{array}$ & & 2669.81 & \\
\hline SP/DM & & $\begin{array}{c}0.0784 \cdots \\
(0.0301)\end{array}$ & $x^{2}+y^{2}=$ & $\begin{array}{c}0.7810^{\cdots} \\
(0.0689)\end{array}$ & & 2317.54 & \\
\hline
\end{tabular}

The heteroskedasticity consistent standard errors of the coefficients ore given in porentheses; (\#) [*t*1] denotes significance at the $10 \%(5 \%)$ [1\%] level. L.L. denotes the log-likelihood values.

Table 2.5 Diffusion-ARCH Models

March 15, 1979 through February 27, 1992: 675 Observations

\begin{tabular}{|c|c|c|c|c|c|c|c|}
\hline & $\hat{\mu}\left(.10^{2}\right)$ & & $\hat{\alpha}_{0}\left(\cdot 10^{2}\right)$ & $\hat{\alpha}_{1}$ & & L.L. & \\
\hline $\mathrm{BF} / \mathrm{DM}$ & $\begin{array}{c}0.0138 \\
(0.0206)\end{array}$ & 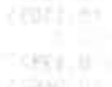 & $\begin{array}{l}0.0020^{\cdots} \\
(0.0004)\end{array}$ & $\begin{array}{l}0.9787^{\cdots} \\
(0.2543)\end{array}$ & & 2448.50 & \\
\hline $\mathrm{BP} / \mathrm{DM}$ & $\begin{array}{c}0.0351 \\
(0.0415)\end{array}$ & & $\begin{array}{c}0.0102 \cdots \\
(0.0011)\end{array}$ & $\begin{array}{l}0.2171^{\cdots} \\
(0.0758)\end{array}$ & & 2080.61 & \\
\hline$D G / D H$ & $\begin{array}{c}0.0062 \\
(0.0063)\end{array}$ & & $\begin{array}{l}0.0003^{\cdots} \\
(0.0001)\end{array}$ & $\begin{array}{l}0.5075 \cdots \\
(0.1597)\end{array}$ & & 3193.13 & \\
\hline DK/DM & $\begin{array}{c}0.0279^{\circ} \\
(0.0148)\end{array}$ & & $\begin{array}{c}0.0012^{\cdots} \\
(0.0002)\end{array}$ & $\begin{array}{l}0.3768^{\circ} \\
(0.2149)\end{array}$ & & 2771.37 & \\
\hline FF/DH & $\begin{array}{c}0.0596 \\
(0.0461)\end{array}$ & & $\begin{array}{l}0.0013 * \\
(0.0007)\end{array}$ & $\begin{array}{c}1.2753 \\
(2.1416)\end{array}$ & & 2697.51 & \\
\hline IL/DM & $\begin{array}{c}0.0377 \\
(0.0281)\end{array}$ & & $\begin{array}{l}0.0018 \cdots \\
(0.0005)\end{array}$ & $\begin{array}{c}0.7261 \\
(0.6830)\end{array}$ & & 2588.10 & \\
\hline IP/DM & $\begin{array}{l}0.0461^{\circ} \\
(0.0243)\end{array}$ & $2+28$ & $\begin{array}{c}0.0010^{\cdots} \\
(0.0002)\end{array}$ & $\begin{array}{c}0.9231^{\circ} \\
(0.4892)\end{array}$ & & 2749.35 & \\
\hline SP/OM & $\begin{array}{l}0.0582 * \\
(0.0262)\end{array}$ & & $\begin{array}{l}0.0035 \cdots \\
(0.0004)\end{array}$ & $\begin{array}{l}0.4678^{\cdots} \\
(0.1479)\end{array}$ & & 2382.36 & \\
\hline
\end{tabular}


Table 2.6 Diffusion-GARCH Models

March 15, 1979 through February 27, 1992: 675 Observations

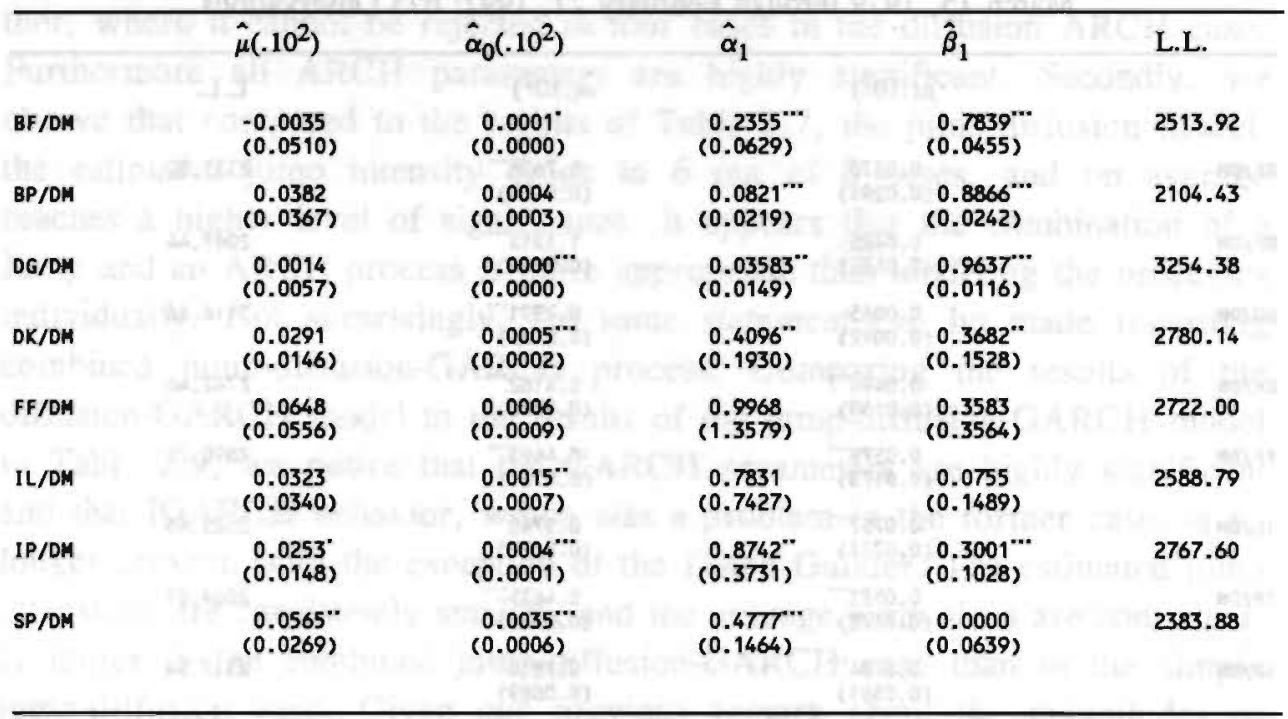

For notes see table 2.4 .

Table 2.7 Jump-Diffusion Models

March 15, 1979 through February 27, 1992: 675 Observations

\begin{tabular}{|c|c|c|c|c|c|c|}
\hline & $\hat{\mu}\left(.10^{2}\right)$ & $\hat{\alpha}_{0}\left(.10^{2}\right)$ & $\hat{\lambda}$ & $\hat{\theta}\left(.10^{2}\right)$ & $\hat{\delta}\left(.10^{2}\right)$ & L.L. \\
\hline $\mathrm{BF} / \mathrm{OM}$ & $\begin{array}{c}0.0009 \\
(0.0214)\end{array}$ & $\begin{array}{c}0.3605 \cdots \\
(0.0892)\end{array}$ & $\begin{array}{c}0.3573 \\
(0.2402)\end{array}$ & $\begin{array}{c}0.1011 \\
(0.1105)\end{array}$ & $\begin{array}{c}1.0997 \\
(0.3498)\end{array}$ & 2451.72 \\
\hline$B P / D M$ & $\begin{array}{l}-0.1253^{\cdots} \\
(0.0479)\end{array}$ & $\begin{array}{l}0.3955^{\cdots} \\
(0.1288)\end{array}$ & $\begin{array}{l}0.9548 . \\
(0.3741)\end{array}$ & $\begin{array}{c}0.1737^{*} \\
(0.0694)\end{array}$ & $\begin{array}{c}1.0672 \cdots \\
(0.1795)\end{array}$ & 2126.01 \\
\hline DG/DM & $\begin{array}{l}-0.0054 \\
(0.0072)\end{array}$ & $\begin{array}{l}0.1280^{\cdots} \\
(0.0253)\end{array}$ & $\begin{array}{c}0.2669 \\
(0.1874)\end{array}$ & $\begin{array}{c}0.0477 \\
(0.0458)\end{array}$ & $\begin{array}{c}0.3755^{\cdots} \\
(0.1227)\end{array}$ & 3233.80 \\
\hline $\mathrm{DK} / \mathrm{DH}$ & $\begin{array}{c}0.0153 \\
(0.0142)\end{array}$ & $\begin{array}{c}0.2436 \cdots \\
(0.0492)\end{array}$ & $\begin{array}{c}0.2799 \\
(0.2348)\end{array}$ & $\begin{array}{r}0.1219 \\
(0.1147)\end{array}$ & $\begin{array}{l}0.5978^{\cdots} \\
(0.2134)\end{array}$ & 2833.11 \\
\hline $\mathrm{FF} / \mathrm{DM}$ & $\begin{array}{c}0.0120 \\
(0.0107)\end{array}$ & $\begin{array}{c}0.2189 \cdots \\
(0.0154)\end{array}$ & $\begin{array}{c}0.0575 \\
(0.0313)\end{array}$ & $\begin{array}{c}0.7987^{\circ} \\
(0.4692)\end{array}$ & $\begin{array}{c}1.3224 \\
(0.6234)\end{array}$ & 3023.89 \\
\hline IL/OM & $\begin{array}{c}0.0223 \\
(0.0202)\end{array}$ & $\begin{array}{l}0.3324 \cdots \\
(0.0309)\end{array}$ & $\begin{array}{c}0.0844 \\
(0.0626)\end{array}$ & $\begin{array}{c}0.6328^{\circ} \\
(0.3558)\end{array}$ & $\begin{array}{r}1.4268^{\circ} \\
(0.7960)\end{array}$ & 2724.00 \\
\hline IP/OM & $\begin{array}{l}-0.0022 \\
(0.0133)\end{array}$ & $\begin{array}{c}0.2054 \cdots \\
(0.0281)\end{array}$ & $\begin{array}{c}0.3835 \% \\
(0.1630)\end{array}$ & $\begin{array}{c}0.1417 \\
(0.0812)\end{array}$ & $\begin{array}{c}0.5428 \cdots \\
(0.1321)\end{array}$ & 2847.62 \\
\hline SP/DM & $\begin{array}{l}-0.0204 \\
(0.0261)\end{array}$ & $\begin{array}{l}0.4760^{\cdots} \\
(0.0529)\end{array}$ & $\begin{array}{c}0.2281^{\circ} \\
(0.1234)\end{array}$ & $\begin{array}{c}0.4330^{\circ} \\
(0.2571)\end{array}$ & $\begin{array}{c}1.1344 \cdots \\
(0.2648)\end{array}$ & 2617.88 \\
\hline
\end{tabular}

For notes see table 2.4 . 
Table 2.8 Combined Jump-Diffusion-ARCH Models

March 15, 1979 through February 27, 1992: 675 Observations

\begin{tabular}{|c|c|c|c|c|c|c|c|}
\hline warate & $\hat{\mu}\left(.10^{2}\right)$ & $\hat{\alpha}_{0}\left(.10^{2}\right)$ & $\hat{\alpha}_{1}$ & $\hat{\lambda}$ & $\hat{\theta}\left(.10^{2}\right)$ & $\hat{\delta}\left(.10^{2}\right)$ & L.L. \\
\hline$B F / D M$ & $\begin{array}{l}-0.0202 \\
(0.0180)\end{array}$ & $\begin{array}{c}0.0004^{\circ} \\
(0.0002)\end{array}$ & $\begin{array}{l}0.5568^{\cdots \cdots} \\
(0.1087)\end{array}$ & $\begin{array}{c}0.4472^{\circ} \\
(0.2407)\end{array}$ & $\begin{array}{c}0.0801 \\
(0.0696)\end{array}$ & $\begin{array}{c}0.7077^{*} \\
(0.1772)\end{array}$ & 2509.35 \\
\hline BP/DH & $\begin{array}{l}-0.0825^{\circ} \\
(0.0357)\end{array}$ & $\begin{array}{c}0.0010^{*} \\
(0.0004)\end{array}$ & $\begin{array}{c}0.1965 \cdots \\
(0.0560)\end{array}$ & $\begin{array}{c}0.8127^{\circ} \\
(0.1902)\end{array}$ & $\begin{array}{c}0.1272^{\circ} \\
(0.0674)\end{array}$ & $\begin{array}{c}1.0617^{*} \cdot \\
(0.1172)\end{array}$ & 2139.94 \\
\hline $\mathrm{DG} / \mathrm{DH}$ & $\begin{array}{l}-0.0062 \\
(0.0056)\end{array}$ & $\begin{array}{c}0.0001^{\cdots} \\
(0.0000)\end{array}$ & $\begin{array}{c}0.4033^{\cdots} \\
(0.0867)\end{array}$ & $\begin{array}{c}0.2568^{\circ} \\
(0.0840)\end{array}$ & $\begin{array}{c}0.0427 \\
(0.0373)\end{array}$ & $\begin{array}{c}0.3166^{\cdots} \\
(0.0570)\end{array}$ & 3281.69 \\
\hline DK/DH & $\begin{array}{c}0.0170 \\
(0.0140)\end{array}$ & $\begin{array}{c}0.0007^{\cdots} \\
(0.0002)\end{array}$ & $\begin{array}{c}0.1197^{\cdots} \\
(0.0517)\end{array}$ & $\begin{array}{c}0.1417 \\
(0.1441)\end{array}$ & $\begin{array}{c}0.2024 \\
(0.2046)\end{array}$ & $\begin{array}{c}0.7294 \times \\
(0.3037)\end{array}$ & 2837.34 \\
\hline FF/DH & $\begin{array}{c}0.0105 \\
(0.0085)\end{array}$ & $\begin{array}{c}0.0004 \cdots \\
(0.0000)\end{array}$ & $\begin{array}{c}0.2189 \cdots \\
(0.0679)\end{array}$ & $\begin{array}{c}0.0387^{\prime} \\
(0.0148)\end{array}$ & $\begin{array}{c}0.9533 \\
(0.4152)\end{array}$ & $\begin{array}{c}1.5758 \cdots \\
(0.4669)\end{array}$ & 3035.91 \\
\hline IL/DH & $\begin{array}{c}0.0123 \\
(0.0238)\end{array}$ & $\begin{array}{c}0.0008 \cdots \\
(0.0003)\end{array}$ & $\begin{array}{c}0.1762 \\
(0.0658)\end{array}$ & $\begin{array}{c}0.1051 \\
(0.1219)\end{array}$ & $\begin{array}{c}0.3730 \\
(0.2509)\end{array}$ & $\begin{array}{c}1.1408 \\
(0.8570)\end{array}$ & 2734.13 \\
\hline IP/OH & $\begin{array}{l}-0.0130 \\
(0.0138)\end{array}$ & $\begin{array}{c}0.0003^{\prime \cdots} \\
(0.0001)\end{array}$ & $\begin{array}{l}0.2552 \cdots \\
(0.0832)\end{array}$ & $\begin{array}{c}0.2722 \\
(0.1595)\end{array}$ & $\begin{array}{c}0.2001^{\circ} \\
(0.1196)\end{array}$ & $\begin{array}{c}0.5417 \\
(0.1708)\end{array}$ & 2860.29 \\
\hline SP/DM & $\begin{array}{l}-0.0250 \\
(0.0258)\end{array}$ & $\begin{array}{l}0.0021 \cdots \\
(0.0003)\end{array}$ & $\begin{array}{c}0.1367^{\cdots \cdot} \\
(0.0521)\end{array}$ & $\begin{array}{c}0.1691^{\cdots} \\
(0.0643)\end{array}$ & $\begin{array}{c}0.5957^{*} \\
(0.2318)\end{array}$ & $\begin{array}{c}1.1442 \cdots \\
(0.2111)\end{array}$ & 2425.75 \\
\hline
\end{tabular}

For notes see table 2.4.

Table 2.9 Combined Jump-Diffusion-GARCH Models

March 15, 1979 through February 27, 1992: 675 Observations

\begin{tabular}{|c|c|c|c|c|c|c|c|c|}
\hline & $\hat{\mu}\left(.10^{2}\right)$ & $\hat{\alpha}_{0}\left(.10^{2}\right)$ & $\hat{\alpha}_{1}$ & $\hat{\beta}_{1}$ & $\hat{\lambda}$ & $\hat{\theta}\left(.10^{2}\right)$ & $\hat{\delta}\left(.10^{2}\right)$ & L.L. \\
\hline BF /DH & $\begin{array}{l}-0.0220 \\
(0.0002)\end{array}$ & $\begin{array}{c}0.0000 \\
(0.0001)\end{array}$ & $\begin{array}{c}0.3214^{\cdots} \\
(0.0988)\end{array}$ & $\begin{array}{c}0.5671^{\cdots} \\
(0.1133)\end{array}$ & $\begin{array}{c}0.2137^{\circ} \\
(0.1165)\end{array}$ & $\begin{array}{c}0.1687 \\
(0.1250)\end{array}$ & $\begin{array}{c}0.78177^{\cdots} \\
(0.2281)\end{array}$ & 2534.9 \\
\hline BP/DH & $\begin{array}{l}-0.0700^{\prime} \\
(0.0301)\end{array}$ & $\begin{array}{c}0.0000 \\
(0.0030)\end{array}$ & $\begin{array}{c}0.1064 \cdots \\
(0.0272)\end{array}$ & $\begin{array}{c}0.7761^{\cdots} \\
(0.0485)\end{array}$ & $\begin{array}{c}0.4174 \\
(0.0999)\end{array}$ & $\begin{array}{c}0.2589^{\circ} \\
(0.1120)\end{array}$ & $\begin{array}{c}1.2146 \cdots \\
(0.1375)\end{array}$ & 2162.3 \\
\hline$D G / D A$ & $\begin{array}{l}-0.0018 \\
(0.0052)\end{array}$ & $\begin{array}{c}0.0000 " \\
(0.0000)\end{array}$ & $\begin{array}{c}0.0110^{\circ} \\
(0.0042)\end{array}$ & $\begin{array}{c}0.9753 \\
(0.0067)\end{array}$ & $\begin{array}{c}0.0582 \cdots \\
(0.0193)\end{array}$ & $\begin{array}{c}0.1643 \\
(0.1232)\end{array}$ & $\begin{array}{c}0.6242 \cdots \\
(0.1083)\end{array}$ & 3305.6 \\
\hline DK/DH & $\begin{array}{c}0.0134 \\
(0.0179)\end{array}$ & $\begin{array}{c}0.0004 \\
(0.0003)\end{array}$ & $\begin{array}{c}0.1141 " * \\
(0.0518)\end{array}$ & $\begin{array}{c}0.2710 \\
(0.2424)\end{array}$ & $\begin{array}{c}0.1856 \\
(0.2032)\end{array}$ & $\begin{array}{c}0.1851 \\
(0.1730)\end{array}$ & $\begin{array}{c}0.6550^{\circ} \\
(0.2961)\end{array}$ & 2838.1 \\
\hline FF/DM & $\begin{array}{c}0.0093 \\
(0.0084)\end{array}$ & $\begin{array}{c}0.0002 \cdots \\
(0.0000)\end{array}$ & $\begin{array}{c}0.1492^{\circ} \\
(0.0793)\end{array}$ & $\begin{array}{c}0.4897^{\circ} \\
(0.1451)\end{array}$ & $\begin{array}{c}0.0335 \cdots \\
(0.0126)\end{array}$ & $\begin{array}{c}1.1079 \% \\
(0.4368)\end{array}$ & $\begin{array}{c}1.5702 \cdots \\
(0.4630)\end{array}$ & 3036.3 \\
\hline IL/OH & $\begin{array}{c}0.0097 \\
(0.0181)\end{array}$ & $\begin{array}{c}0.0003^{\circ} \\
(0.0001)\end{array}$ & $\begin{array}{c}0.1601 \cdots \\
(0.0585)\end{array}$ & $\begin{array}{c}0.5139^{\circ} \\
(0.1070)\end{array}$ & $\begin{array}{c}0.0999 \\
(0.0804)\end{array}$ & $\begin{array}{c}0.3658^{\circ} \\
(0.2002)\end{array}$ & $\begin{array}{c}1.1589^{\circ} \\
(0.6897)\end{array}$ & 2739.4 \\
\hline IP/DN & $\begin{array}{c}0.0015 \\
(0.0216)\end{array}$ & $\begin{array}{c}0.0002^{\circ} \\
(0.0001)\end{array}$ & $\begin{array}{c}0.2596 \cdots \\
(0.0761)\end{array}$ & $\begin{array}{c}0.2944^{\circ} \\
(0.1606)\end{array}$ & $\begin{array}{c}0.1507 \\
(0.2253)\end{array}$ & $\begin{array}{c}0.3949 \\
(0.4863)\end{array}$ & $\begin{array}{c}0.6478 \\
(0.5377)\end{array}$ & 2868.2 \\
\hline SP/DH & $\begin{array}{l}-0.0256 \\
(0.0263)\end{array}$ & $\begin{array}{c}0.0015 \\
(0.0010)\end{array}$ & $\begin{array}{c}0.1275 \\
(0.0621)\end{array}$ & $\begin{array}{c}0.2169 \\
(0.3921)\end{array}$ & $\begin{array}{c}0.1624^{\circ} \\
(0.0652)\end{array}$ & $\begin{array}{c}0.6084 \% \\
(0.2476)\end{array}$ & $\begin{array}{c}1.1510^{\cdots} \\
(0.2183)\end{array}$ & 2426.6 \\
\hline
\end{tabular}

For notes see table 2.4 . 
Table 2.10A Generalized Likelihood Ratio Tests

March 15, 1979 through February 27, 1992: 675 Observations

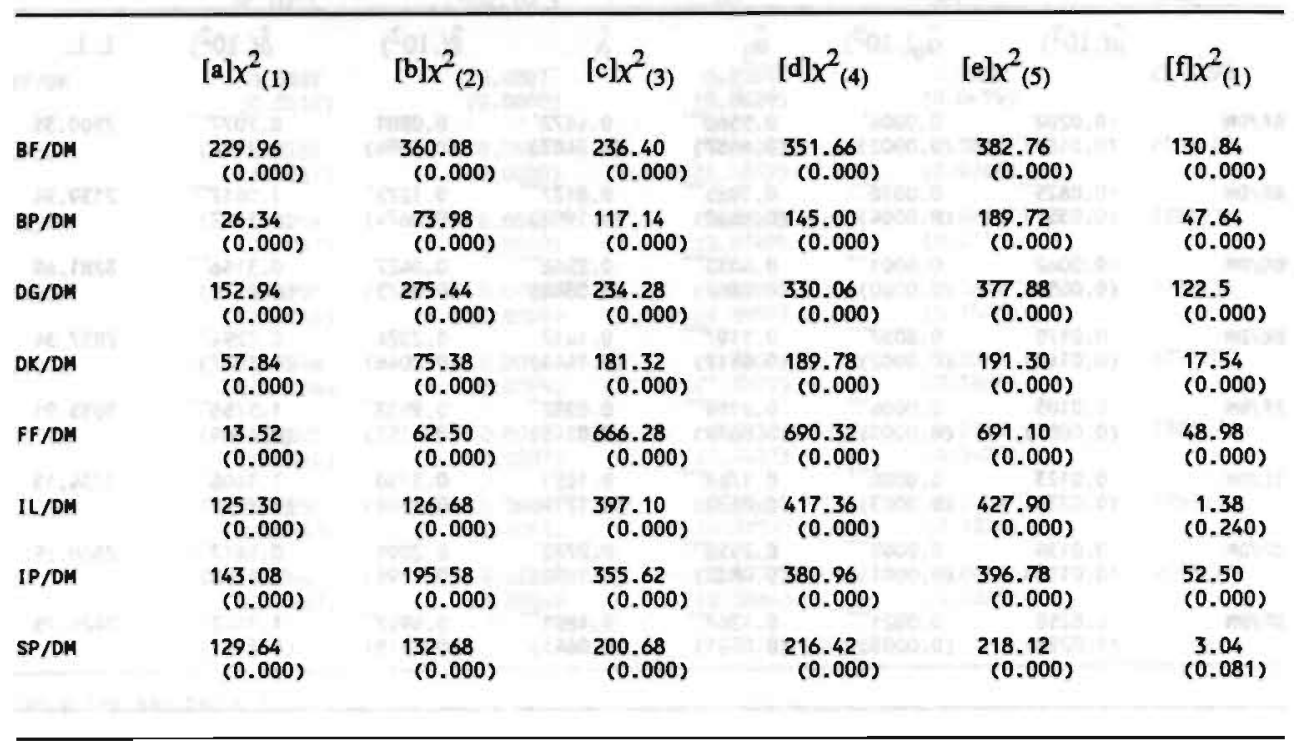

[a] Diffusion Model against Diffusion-ARCH Model; [b] Diffusion Model against Diffusion-GARCH Model; [c] Diffusion Model against Jump-Diffusion Model; [d] Diffusion Model against Jump-Diffusion-ARCH Model; [e] Diffusion Model against Jump-Diffusion-GARCH Model; [f] Diffusion-ARCH Model against Diffusion-GARCH Model; P-Values are given in parentheses. 


\section{Table 2.10B Generalized Likelihood Ratio Tests}

March 15, 1979 through February 27, 1992: 675 Observations

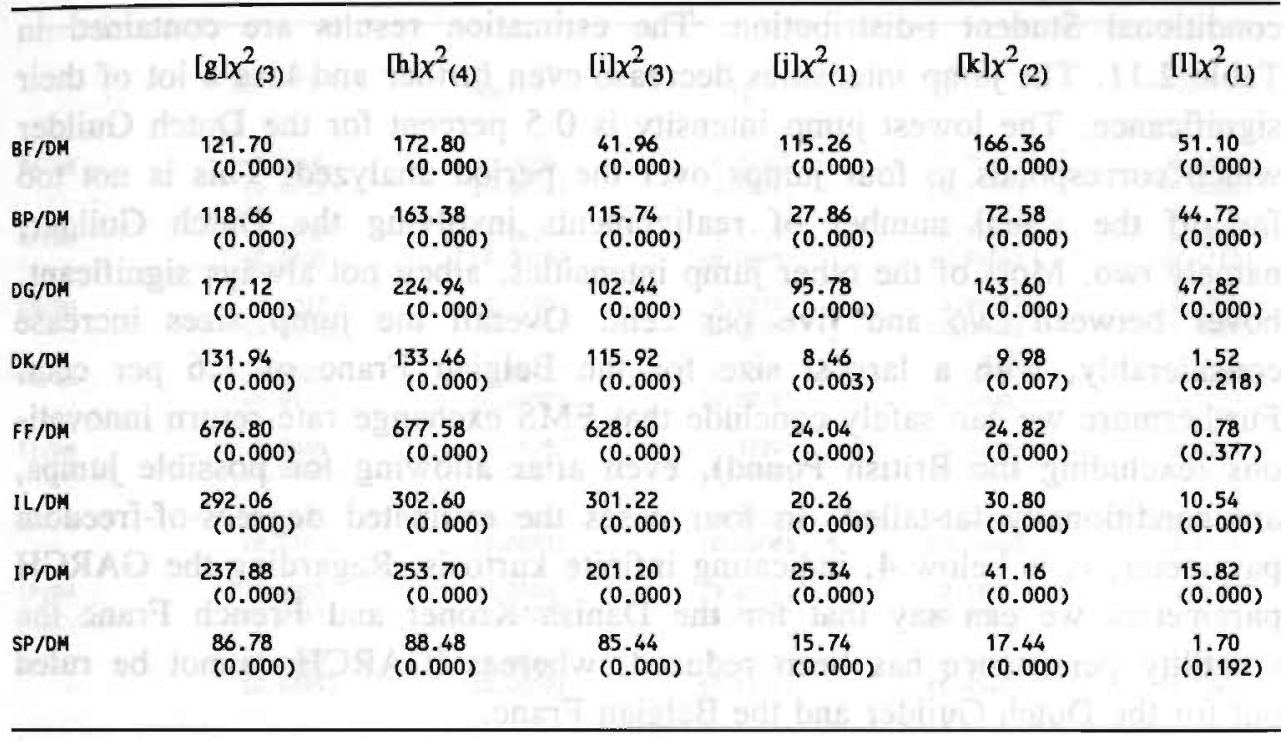

[g] Diffusion-ARCH Model against Jump-Diffusion-ARCH Model; [h] Diffusion-ARCH Model against Jump-Diffusion-GARCH Model; [i] Diffusion-GARCH Model against Jump-Diffusion-GARCH Model; [j] Jump-Diffusion Model against Jump-Diffusion-ARCH Model; [k] Jump-Diffusion Model against Jump-Diffusion-GARCH Model; [1] JumpDiffusion-ARCH Model against Jump-Diffusion-GARCH Model. 
favor of the more complicated (combined jump-diffusion-GARCH) model.

Our third explanation for the stylized facts in EMS exchange rates considers conditionally fat-tailed innovation terms. We re-estimated the jumpdiffusion-GARCH process, which was deemed most appropriate, using a conditional Student t-distribution. The estimation results are contained in Table 2.11. The jump intensities decrease even further and lose a lot of their significance. The lowest jump intensity is 0.5 percent for the Dutch Guilder which corresponds to four jumps over the period analyzed. This is not too far off the actual number of realignments involving the Dutch Guilder, namely two. Most of the other jump intensities, albeit not always significant, hover between two and five per cent. Overall the jump sizes increase considerably, with a largest size for the Belgian Franc of 1.6 per cent. Furthermore we can safely conclude that EMS exchange rate return innovations (excluding the British Pound), even after allowing for possible jumps, are conditionally fat-tailed. In four cases the estimated degrees-of-freedom parameter, $\nu$, is below 4 , indicating infinite kurtosis. Regarding the GARCH parameters we can say that for the Danish Kroner and French Franc the volatility persistence has been reduced, whereas IGARCH cannot be ruled out for the Dutch Guilder and the Belgian Franc.

Overall, the conclusion must be that each of the three explanations we have offered has its own merit but that the use of a conditionally fat-tailed distribution, largely affects the relevance of jump processes.

In order to determine the adequacy of the statistical specification, the models are subjected to diagnostic checks on the standardized residuals, $z_{t}=$ $\hat{\epsilon}_{\mathrm{t}} / \sqrt{\mathrm{h}} \mathrm{t}$, where $\hat{\epsilon}_{\mathrm{t}}$ is the residual from equation (11) and $\hat{\mathrm{h}}_{\mathrm{t}}$ is the estimated conditional variance from equation (9). From Jensen's inequality it follows that the standardized residuals, $z_{t}$, should demonstrate less absolute skewness and should be thinner tailed than their unconditional raw data counterparts. Any strong violation of this rule should be regarded as evidence of model misspecification - see Hsieh (1989). The diagnostics for the combined jumpdiffusion-GARCH models are presented in Table 2.12. Overall, we find that in most cases the standardized residuals demonstrate less absolute skewness and kurtosis as compared to those reported by Table 2.1, thus supporting our model specifications. However, in the case of the BP/DM exchange rate, skewness and kurtosis are substantially larger than their unconditional raw data counterparts, indicating model misspecification. Note that a conditional Student-t distribution leads to smaller skewness and kurtosis values of the standardized residuals than is the case for a normal distribution. 
Table 2.11 Combined Jump-Diffusion-GARCH Models: t-Estimates

March 15, 1979 through February 27, 1992: 675 Observations

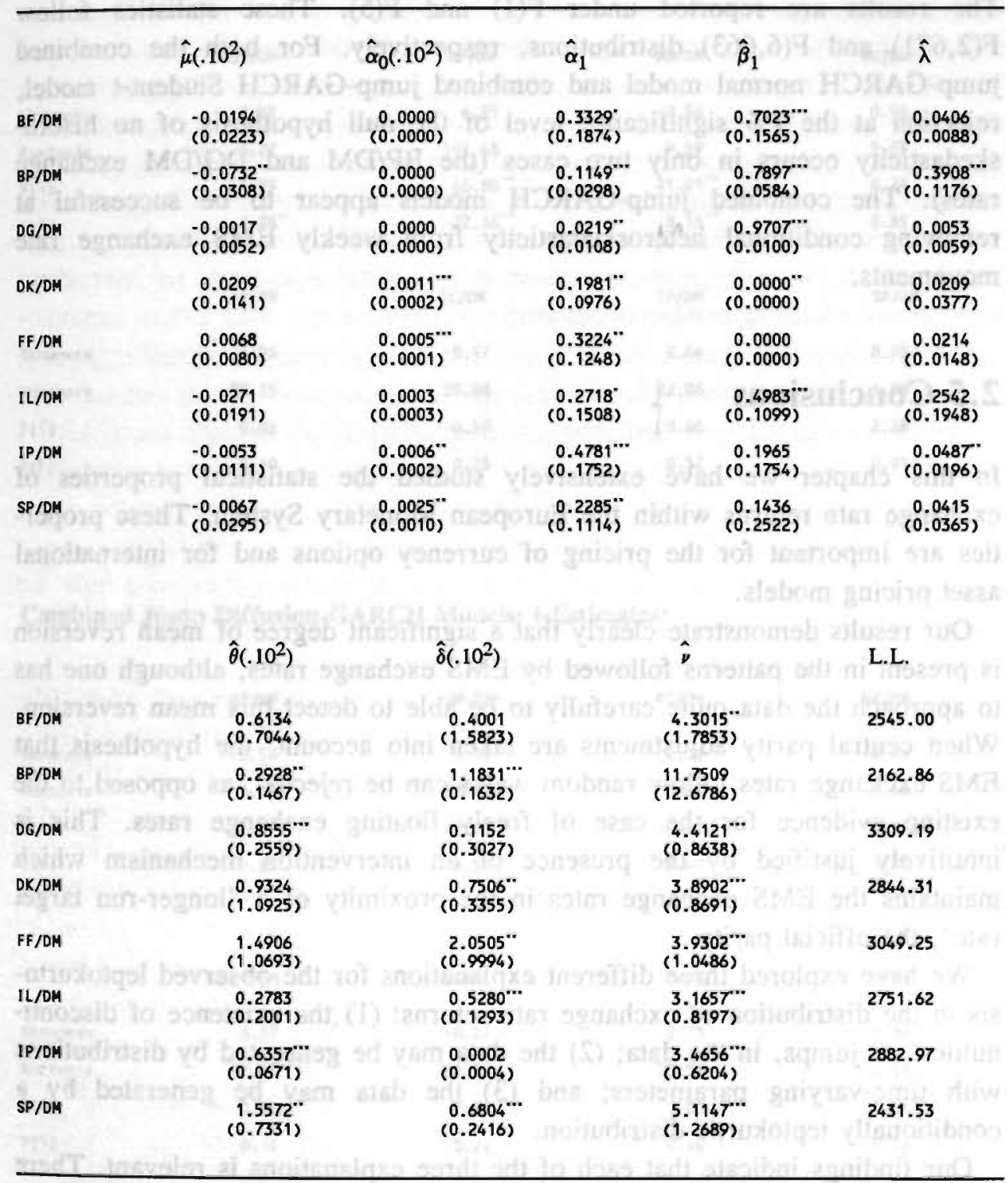

For notes see table 2.4 . 
In order to test for remaining heteroskedasticity, a residual-based test of the models may be carried out by regressing $\left(\hat{\epsilon}_{t}{ }^{2}-\hat{h}_{t}\right) / \hat{h}_{t}$ on $1 / \hat{h}_{t}$ and on one to five lags of the dependent variable and testing whether the estimated coefficients are significantly different from zero by a conventional F-test. The results are reported under $F(1)$ and $F(5)$. These statistics follow $F(2,671)$ and $F(6,663)$ distributions, respectively. For both the combined jump-GARCH normal model and combined jump-GARCH Student-t model, rejection at the $1 \%$ significance level of the null hypothesis of no heteroskedasticity occurs in only two cases (the BP/DM and DG/DM exchange rates). The combined jump-GARCH models appear to be successful at removing conditional heteroskedasticity from weekly EMS exchange rate movements.

\subsection{Conclusions}

In this chapter we have extensively studied the statistical properties of exchange rate returns within the European Monetary System. These properties are important for the pricing of currency options and for international asset pricing models.

Our results demonstrate clearly that a significant degree of mean reversion is present in the patterns followed by EMS exchange rates, although one has to approach the data quite carefully to be able to detect this mean reversion. When central parity adjustments are taken into account, the hypothesis that EMS exchange rates follow random walks can be rejected, as opposed to the existing evidence for the case of freely floating exchange rates. This is intuitively justified by the presence of an intervention mechanism which maintains the EMS exchange rates in the proximity of a "longer-run target rate", the official parity.

We have explored three different explanations for the observed leptokurtosis in the distribution of exchange rate returns: (1) the existence of discontinuities, or jumps, in the data; (2) the data may be generated by distributions with time-varying parameters; and (3) the data may be generated by a conditionally leptokurtic distribution.

Our findings indicate that each of the three explanations is relevant. There is considerable interference, however, between jumps in the distributions, on the one hand, and allowing for fat tails, on the other hand. Allowance for fat 
Table 2.12 Diagnostics: March 15, 1979 through February 27, 1992: 675 Observations

\section{Combined Jump-Diffusion-Garch Models:}

\begin{tabular}{|c|c|c|c|c|}
\hline & $\mathrm{BF} / \mathrm{DM}$ & BP/DM & $D G / D M$ & DK/DH \\
\hline Skewness & 0.65 & 6.25 & 0.56 & 0.96 \\
\hline Kurtosis & 6.27 & 101.48 & 9.59 & 9.03 \\
\hline$F(1)$ & 1.29 & $66.88^{\cdots *}$ & $21.91^{\cdots}$ & 0.74 \\
\hline$F(5)$ & $2.76^{\circ}$ & $22.16^{\cdots}$ & $8.18^{\circ}$ & 0.35 \\
\hline & FF/OM & IL/DM & IP/DM & SP/DM \\
\hline Skeuness & 6.98 & -0.17 & 2.64 & 0.95 \\
\hline Kurtosis & 88.15 & 29.88 & 22.96 & 6.88 \\
\hline$F(1)$ & 0.02 & 0.59 & 0.66 & $2.38^{\circ}$ \\
\hline$F(5)$ & 0.10 & 0.23 & 0.32 & 0.91 \\
\hline
\end{tabular}

Combined Jump Diffusion-GARCH Models: t-Estimates:

\begin{tabular}{|c|c|c|c|c|}
\hline 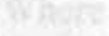 & $B F / D M$ & BP/DM & DG/DM & DK/DM \\
\hline Skewness & 0.53 & 5.58 & 0.49 & 0.99 \\
\hline Kurtosis & 5.07 & 87.72 & 8.56 & 9.56 \\
\hline$F(1)$ & 1.27 & $49.35 \cdots$ & $19.66^{\cdots}$ & 0.39 \\
\hline$F(5)$ & $1.85^{\circ}$ & $18.56^{\cdots}$ & $7.42^{\cdots}$ & 0.45 \\
\hline & FF/DM & IL/DM & IP/DM & SP/DM \\
\hline Skeiness & 6.37 & -0.22 & 2.73 & 0.89 \\
\hline Kurtosis & 77.47 & 29.51 & 23.56 & 6.53 \\
\hline$F(1)$ & 0.32 & 0.60 & 0.00 & 1.46 \\
\hline$F(5)$ & 0.14 & 0.24 & 0.10 & 0.58 \\
\hline
\end{tabular}

$\left.{ }^{*}{ }^{* *}\right)[* * *]$ denotes significance at the $10 \%(5 \%)[1 \%]$ level. 
tails tends to increase the average jump size, but to reduce the frequency of jumps to more realistic proportions. Most successful in capturing the relevant features of EMS exchange rate returns is a combined jump-GARCH model with conditionally $\mathrm{t}$-distributed innovations.

The statistical evidence presented in this chapter is sufficiently strong to suggest further research in various directions. Models similar to ours could be estimated in a framework in which the jump intensity depends on an exchange rate's position within the formal exchange rate band. Alternatively, the impact of jumps and stochastic volatility in EMS exchange rates on the pricing of forward foreign exchange could be studied formally. In particular, a derivation of the risk premium under the jump-diffusion-GARCH dynamics for the EMS exchange rates presented in this chapter is itself an interesting topic which deserves further research. 


\section{Appendix 2A}

This appendix outlines the construction of the ARCH test based on finitestate Markov Chains. A detailed description of the construction of this test can be found in Gregory (1989) and Nieuwland (1991). Basically this test is equivalent to a test for independence in a two way contingency table. The first step in the construction of the test is to obtain the squared residuals from the estimation of equation 2 in the main text. The next step is to apply a discretization rule, by which the squared residuals are divided into different categories or states. The rule applied here is to mark the residuals as being high or low, with the sample median as the boundary. This results in a two-state definition: the squared residual are either low (state 1) or high (state 2). Next it is assumed that that $\left\{\epsilon_{\mathrm{t}}{ }^{2}\right\}$, which values are now either 1 or 2, possesses the Markov property that says that the probability distribution of $\epsilon_{\mathrm{t}}{ }^{2}$ conditional on its entire past equals the probability distribution conditional on its first previous value only:

$$
P\left(e_{t}^{2}=j \mid e_{t-1}^{2}=i, e_{t-2}^{2}, e_{t-3}^{2}, \ldots . .\right)=P\left(e_{t}^{2}=j \mid e_{t-1}^{2}=i\right)=\lambda_{i j t}
$$

Where $i, j=1,2$; and $t=2, \ldots, T$. $\lambda_{i j t}$ is the probability of being in state $j$ at time $t$, coming from state $i$ at time $t-1$. The transition probabilities are assumed to be time independent ( the subscript $t$ can now be deleted), allowing us to define $\left\{\epsilon_{\mathrm{t}}{ }^{2}\right\}$ as a homogeneous first order Markov chain. A second order homogeneous Markov chain will also be used to test for second order ARCH effects. In this case the transition probabilities are defined as:

$$
\lambda_{i j k}=P\left(e_{t}^{2}=k \mid e_{t-1}^{2}=j, e_{t-2}^{2}=i\right) \quad i, j=1,2 \quad t=2, \ldots, T \quad 2 \mathrm{~A} .2
$$

$\lambda_{\mathrm{ijk}}$ is the probability of being in state $\mathrm{k}$ at time $\mathrm{t}$, coming from state $\mathrm{j}$ at time $t-1$ and from sate $i$ at time $t-2$. The $M L$ estimates of the transition probabilities for the first order Markov chain are determined as $\lambda_{i j}=n_{i j}$ $/\left(n_{i 1}+n_{i 2}\right)$, where $n_{i j}$ is the number of times that a transition from $i$ to $j$ is observed. For the second order Markov chain they are determined as $\lambda_{\mathrm{ijk}}=$ 
$n_{i j k} /\left(n_{i j 1}+n_{i j 2}\right)$, where $n_{i j k}$ is the number of transitions from $i$ to $j$ to $k$. For the first order Markov chain the log-likelihood value at the ML estimates becomes:

$$
\overline{L L M 1}=\sum_{i=1}^{2} \sum_{j=1}^{2} n_{i j} \ln \left(n_{i j} / N_{i}\right)
$$

where $\mathrm{N}_{\mathrm{i}}$ is the number of times that state $\mathrm{i}$ is observed. For the second order Markov chain the log-likelihood value at the ML estimates becomes:

$$
\overline{L L M 2}=\sum_{i=1}^{2} \sum_{j=1}^{2} \sum_{k=1}^{2} n_{i j k} \ln \left(n_{i j k} / N_{i j}\right)
$$

where $\mathrm{N}_{\mathrm{ij}}$ is the number of times that a transition from $\mathrm{i}$ to $\mathrm{j}$ occurs. These likelihoods are necessary to develop tests for the null hypothesis of homoskedasticity. If this hypothesis were true then there would be no serial dependence in the squared residuals and the transition probabilities would be without any structure. This means that the probability of observing a current state $\mathrm{k}$, is independent of previous realizations ( $\mathrm{i}$ and $\mathrm{j}$ ). This translates into:

$$
H_{0}: \lambda_{i j}=\lambda_{j}
$$

when testing independence against a first order Markov chain, and into:

$$
H_{0}: \lambda_{i j k}=\lambda_{k}
$$

when testing independence against a second order Markov chain. The ML estimates under both null hypotheses are: $\lambda_{j}=N_{j} / N ; N$ is the total number of observations used in the estimation procedure. The log-likelihood value under the null at the ML estimates is: 


$$
\overline{L L I}=\sum_{i=1}^{2} N_{i} \ln \left(N_{i} / N\right)
$$

Two likelihood ratio tests can now be constructed: The first one is a test of independence against a first order homogeneous Markov chain:

$$
L R(I / M I)=-2(\overline{L L I}-\overline{L L M I}) \stackrel{a}{\sim} \chi^{2}(1) \quad \text { 2A.8 }
$$

The second one is a test of independence against a second order homogeneous Markov chain:

$$
L R(I / M 2)=-2(\overline{L L I}-\overline{L L M 2}) \stackrel{a}{\sim} \chi^{2}(3)
$$

These are the tests that are used in the main text. 


\section{Appendix 2B}

In this appendix we define the seven test statistics used in the text to test for unit roots. This presentation follows the same ordering as is given by the testing strategy in Perron (1988). Define $y_{t}$ as the series to be analyzed (where $\mathrm{y}_{0}$ is given), preferably in logarithms. Then start by running the following, most elaborate regression:

$$
y_{t}=\tilde{\mu}+\tilde{\beta}(t-T / 2)+\tilde{\alpha} y_{t-1}+\tilde{u}_{t}, \quad t=1, \ldots, T
$$

This regression allows for a deterministic trend and a drift term. Now we can use three test statistics to determine the presence or absence of a unit root:

$$
\begin{aligned}
& Z\left(t_{\tilde{\alpha}}\right)=\left(S_{u} / S_{T l}\right) t_{\tilde{\alpha}}-\left(T^{3} / \sqrt{48} \sqrt{D_{x}} S_{T l}\right)\left(S_{T l}^{2}-S_{u}^{2}\right) \\
& Z\left(\Phi_{3}\right)=\left(S_{u}^{2} / S_{T l}^{2}\right) \Phi_{3}-\left(\frac{1}{2 S_{T l}^{2}}\right)\left(S_{T l}^{2}-S_{u}^{2}\right)\left(T(\tilde{\alpha}-1)-\left(\frac{T^{6}}{48 D_{x}}\right)\left(S_{T l}^{2}-S_{u}^{2}\right)\right) \\
& Z\left(\Phi_{2}\right)=\left(S_{u}^{2} / S_{T l}^{2}\right) \Phi_{2}-\left(\frac{1}{3 S_{T l}^{2}}\right)\left(S_{T l}^{2}-S_{u}^{2}\right)\left(T(\tilde{\alpha}-1)-\left(\frac{T^{6}}{48 D_{x}}\right)\left(S_{T l}^{2}-S_{u}^{2}\right)\right)
\end{aligned}
$$

These statistics respectively test for the presence of a unit root alone, the presence of a unit root cum absence of a trend, and the presence of a unit root cum absence of a trend and a drift term:

$$
H_{0}^{1}: \tilde{\alpha}=1, H_{0}^{2}: \tilde{\alpha}=1, \widetilde{\beta}=0, H_{0}^{3}: \tilde{\alpha}=1, \tilde{\beta}=0, \tilde{\mu}=0
$$


The various components of these statistics are defined as:

$$
\begin{array}{ll}
\Phi_{1}=\left(2 S^{* 2}\right)^{-1}\left(T S_{0}^{2}-T S^{* 2}\right) & 2 \mathrm{~B} .6 \\
\Phi_{2}=\left(2 \tilde{S}^{2}\right)^{-1}\left(T S_{0}^{2}-T \tilde{S}^{2}\right) & 2 \mathrm{~B} .7 \\
\Phi_{3}=\left(2 \tilde{S}^{2}\right)^{-1}\left(T\left\{S_{0}^{2}-\left(\bar{Y}-\bar{Y}_{-1}\right)^{2}\right\}-T \tilde{S}^{2}\right. & 2 \mathrm{~B} .8
\end{array}
$$

where:

$$
\begin{aligned}
& S_{0}^{2}=\frac{1}{T} \sum_{t=1}^{T}\left(y_{t}-y_{t-1}\right)^{2} \quad, \quad S^{* 2}=\frac{1}{T} \sum_{t=1}^{T} u_{t}^{* 2}, \quad \tilde{S}^{2}=\frac{1}{T} \sum_{t=1}^{T} \tilde{u}_{t}^{2} \\
& D_{x}=\operatorname{det}(X \cdot X) \quad, \quad \bar{Y}=\frac{1}{T} \sum_{t=1}^{T} y_{t}, \quad \bar{Y}_{-1}=\frac{1}{T} \sum_{t=1}^{T} y_{t-1}
\end{aligned}
$$

The statistics in $2 \mathrm{~B} .6,2 \mathrm{~B} .7$, and $2 \mathrm{~B} .8$ can be interpreted as regression Ftests. $X$ is the $T \times 3$ matrix of explanatory variables in the OLS regression defined by 2 B.1. Finally we need to establish a consistent estimator of the nuisance parameter:

$$
\sigma_{u}^{2} / \sigma^{2}=S_{u}^{2} / S_{T l}^{2}
$$


Consistent estimators for $S_{u}{ }^{2}$ are given by the estimated residual variances corresponding to the chosen regression. Consistent estimators for $S_{T l}^{2}$, which takes the temporal dependence of the residuals into account are constructed in the following manner:

$$
S_{T l}^{2}=\frac{1}{T} \sum_{t=1}^{T} u_{t}^{2}+\frac{2}{T} \sum_{\tau=1}^{l} \omega(\tau, l) \sum_{i=\tau+1}^{T} u_{t} u_{t-\tau}
$$

Here again the $u_{t}$ 's correspond to the residuals of the esimated regression. The $\omega(\tau, l)$ 's denote a weighting scheme to guarantee a nonnegative estimate (e.g. a Newey-West or Parzen Window). All our estimates were initially positive, so all the weights were set to one. Also $l$, the truncation lag parameter, was set at 10 .

If, based on the results of the first two test statistics, rejection of the unit root hypothesis is possible then we are done. However if rejection is not possible this may be attributable to the poor power properties of these statistics relative to test statistics based on the following regression, see Perron (1988):

$$
y_{t}=\mu^{*}+\alpha^{*} y_{t-1}+u_{t}^{*}
$$

Test statistics based on this regression are not invariant with respect to $\mu$, so it must be verified, via $Z\left(\Phi_{2}\right)$, that the drift term $\mu$ is essentially equal to zero. Regression 2B.6 cannot be used as a starting point in a testing strategy as it cannot distinguish between a unit root and a linear stationary trend. Only when the absence of a trend is verified, using 2B.1, statistics based on 2B.6 can be safely used to test for a unit root:

$$
Z\left(t_{\alpha^{*}}\right)=\left(S_{u} / S_{T l}\right)_{\alpha^{*}}-\left(\frac{1}{2 S_{T l}}\right)\left(S_{T l}^{2}-S_{u}^{2}\right)\left(\frac{1}{T^{2}} \sum_{t=1}^{T}\left(y_{t-1}-\bar{Y}_{-1}\right)^{2}\right)^{-1 / 2}
$$




$$
\begin{aligned}
Z\left(\Phi_{l}\right)= & \left(S_{u}^{2} / S_{T l}^{2}\right) \Phi_{1}-\left(\frac{1}{2 S_{T l}^{2}}\right)\left(S_{T l}^{2}-S_{u}^{2}\right) * \\
& \left(T\left(\alpha^{*}-1\right)-\left(\frac{1}{4}\right)\left(S_{T l}^{2}-S_{u}^{2}\right)\left(\frac{1}{T^{2}} \sum_{t=1}^{T}\left(y_{t-1}-\bar{Y}_{-1}\right)^{2}\right)^{-1}\right)
\end{aligned}
$$

The accompaning null hypotheses are:

$$
H_{0}^{4}: \alpha^{*}=1, \quad H_{0}^{5}: \alpha^{*}=1, \mu^{*}=0
$$

If rejection of the unit root hypothesis is still not possible, and the absence of a drift term is verified via $Z\left(\Phi_{I}\right)$, then we can turn to the simplest regression:

$$
y_{t}=\hat{a} y_{t-1}+a_{t}
$$

and compute:

$$
\begin{aligned}
& Z\left(t_{\vec{d}}\right)=\left(S_{u} / S_{T l}\right) t_{a}-\left(\frac{1}{2}\right)\left(S_{T l}^{2}-S_{u}^{2}\right)\left(S_{T l}\left(\frac{1}{T^{2}} \sum_{t=1}^{T} y_{t-1}^{2}\right)^{1 / 2}\right)^{-1} \\
& H_{0}^{6}: \hat{\alpha}=1
\end{aligned}
$$

Furthermore we have employed an Augmented Dickey Fuller (ADF) test to test for a unit root. The estimated regression reads: 


$$
\Delta y_{t}=\mu_{0}+\mu_{1} t+\left(\alpha_{1}+\alpha_{2}-1\right) y_{t-1}-\alpha_{2} \Delta y_{t-1}+u_{t} \quad \text { 2B.18 }
$$

$$
H_{0}^{7}: \alpha_{2}+\alpha_{1}-1=0
$$

The test statistic to be used is the t-value of $\alpha_{1}+\alpha_{2}-1$, with critical values tabulated by Fuller (1976). The first six test statistics presented above only require estimation of a first order autoregression by least squares and a correction factor based on the structure of the residuals from this regression. This procedure is valid under a wide range of data generating processes, e.g. the tests are robust against ARCH effects. 


\section{Chapter three}

\section{Foreign Exchange Rate Expectations}

\subsection{Introduction}

For three decades, theories of the expectations formation process have been at the forefront of economic research in the financial economics literature. Out of the theories of expectations formation so far advanced, Muth's (1961) "rational expectations hypothesis" (REH) has attracted the greatest attention. Rationality of agents' expectations in the Muth (1961) sense states that subjective expectations held by economic agents will be the same as the conditional mathematical expectations based on the "true" probability model of the economy, or more general, that agents' subjective probability distribution coincide with the "objective" probability distribution of events.

As the debate regarding the rationality of agents' expectations and the informational efficiency of financial markets continues to be an issue of central concern in the financial economics literature - see Fama (1991) and Cutler, Poterba and Summers (1990), for instance - many economists have become more interested in directly measuring the expectations of market participants. The importance of direct measures of expectations for the analysis of the effect of expectations on economic behavior, as well as for the study of the expectations formation process, has long been recognized in the literature. For early contributions see Klein (1954), Modigliani and Sauerlender (1955), and Katona (1958). In the absence of direct observations on expectations, empirical analysis of the expectations formation process can be carried out only indirectly, and conditional on the behavioral model which embodies the expectational variables. Therefore, conclusions concerning the expectations formation process will not be invariant to the choice of the underlying behavioral model.

The rationality of agents' expectations have been tested recently in the foreign exchange market by analyzing survey data for some of the major cur- 
rencies (French Franc, British Pound, German Mark, Japanese Yen, and Swiss Franc) relative to the United States Dollar - see Dominguez (1986), Frankel and Froot (1987a and 1987b), Froot and Frankel (1990), Ito (1990), MacDonald and Torrance (1990), Taylor (1989), and the literature surveys of Takagi (1991) and Froot and Thaler (1990). The principal benefit of using such data is that one obtains a direct measure of agents' beliefs, thus allowing for separate testing of an underlying model of exchange rate determination and a hypothesis about expectations. Survey data on exchange rate expectations allow single-hypothesis, model-free test of rational expectations in foreign exchange markets. In order to test the rationality of exchange rate expectations, therefore, survey expectations data are essential. On the other hand, critics of survey data often question the extent to which such data is representative of "the market's" expectations. Furthermore, the rather narrow survey datasets that are collected often limit the scope of investigative analysis.

This chapter extends the seminal work of Frankel and Froot (1987a) to a new data set that covers a wider range of currencies over a different sample period. The dataset allows us to focus on differences between EMS and US Dollar exchange rate expectations. Previous work, as enumerated above, has focused mainly on the early 1980 s period associated with the sustained US dollar appreciation. Our data set begins in January 1986 and ends in December 1990 covering a period of US Dollar depreciation (and Deutschmark appreciation) relative to the currencies we review; the different sample period and different overall pattern of currency movements thus permit an additional test of the robustness of previously reported results. In addition to exploring differences between EMS and US Dollar exchange rates, we address three questions that were considered earlier by Frankel and Froot (1987a) and Dominguez (1986): whether economic agents' exchange rate forecasts are unbiased, whether economic agents use all available information efficiently and which time series process best characterizes investors' expectations formation. Results using the available cross exchange rate forecasts over relatively long horizons (three, six, and twelve months) covering nearly all EMS currencies provide an interesting complement to previous work that has largely focused on the five most actively traded currencies (vis-à-vis the US Dollar). The breadth of our sample of currencies across forecast horizons is exploited by providing statistical tests on an individual currency basis rather than adopting the pooling technique of Frankel and Froot (1987a). As our dataset is based only on 3, 6, and 12- 
months expectations, we do not consider the widely discussed topic of how longer-term expectations might differ from shorter-term expectations.

This chapter is presented in five sections. In section 2, the construction of the exchange rate survey is outlined and summary statistics describing the data are provided. In section 3 , the rationality of the survey forecasts is examined as well as the efficiency with which economic agents use publicly available information. Alternative models characterizing the formation of exchange rate expectations are considered in section 4 . In section 5 , the results of this investigation are sum-marized.

\subsection{The Survey Data}

Since 1985, Business International Corporation has been conducting a monthly survey of exchange rate expectations covering ten currencies relative to the Dollar and eight currencies relative to the Deutschmark which are published in its Cross Rates Bulletin. For publication purposes, survey participants are asked a few days prior to month's end to fax three, six and twelve month ahead expectations of a number of currencies with projections being made from the beginning of the following month. Thus, for instance, the three, six and twelve month ahead expected Deutschmark/Dollar exchange rate recorded on December 27th, 1990 reflect a slightly longer forecast horizon as they represent the expected spot rate on April 1st, 1991, June 1st, 1991 and January 2nd, 1992 respectively. I The dates when the surveys are conducted have been recorded as well as the spot, three, six, and twelve month ahead forward rates recorded on that particular day.

The thirty-odd participants of the survey are treasurers of multinationals and private banks residing in four of the world's continents. The professional exchange rate forecasters in the foreign currency trading divisions have upto-the-minute information on the values of the currencies covered. Although not all participants will provide their views regarding a particular currency, the response rate is at worst 60 percent.

1 Although the notation used in sections 3 and 4 will be presented as if the survey was constructed on December 31 (in the example at hand), care has been exercised throughout the empirical analysis to ensure that conditional expectations are computed on the proper information set. 
We adopt the convention of treating expectations as if they were homogeneous. In reality, any survey data will immediately reveal that expectations have a distribution. If distributions of future spot exchange rates are asymmetric, then the different statistics that measure the "expectations" of respondents will differ. The question which naturally arises is which statistic is a reliable representation of the interpretation of (most of) the respondents. We follow the existing literature in talking as if there exists a single expectation that is homogeneously held by investors, which we measure by the geometric mean of the survey responses. The Cross Rates Bulletin reports the geometric mean forecast of the responses received thus minimizing the effect of extreme forecasts. Unfortunately disaggregated survey respondent data are not available, although the standard deviation of the respondents' expectation is reported. ${ }^{2}$

Tables 3.1a and 3.1b provide summary statistics for the actual and expected annualized exchange rate depreciation across forecast horizon and across currencies. ${ }^{3}$ The summary statistics for the annualized survey forecast error across horizon and across currencies are reported in Table 3.1c. Four currency "groups" are presented - non-EMS currencies relative to the US Dollar, EMS currencies relative to the US Dollar, non-EMS currencies relative to the Deutschmark, EMS currencies relative to the Deutschmark.

In the tables, as in the rest of the chapter, $S_{t}$ is defined as the natural logarithm of the spot exchange rate at time $t, E_{t} S_{t+k}$ is defined as the natural logarithm of the expected spot exchange rate at time $t+k$ formed at time $t$ and ${ }_{t} F_{t+k}$ is defined as the natural logarithm of the forward rate at time $t$ for delivery at time $t+k$. For the period analyzed (January 1st, 1986 through December 1st, 1990), the mean expected depreciation declines in absolute value as the forecast horizon increases. Thus, survey respondants implicitly believe that there exists a mean reverting component in exchange rate changes as is implied by the Dornbusch (1976) asset model of exchange rate determination. This empirical regularity differs from summary statistics reported by Frankel and Froot (1987a, 1987b), MacDonald and Torrance (1990), and Dominguez (1986) which broadly suggest that the expected short

2 To allow for the possibility of measurement error in the survey data as a reflection of the "true" expectations, we make the assumption that this measurement error is random.

3 Defining $\mathrm{k}$ to be the forecast horizon in months, annualized returns are obtained by multiplying the log differences by $1200 / \mathrm{k}$. 
Table 3.1A Summary Statistics of Actual Depreciation: $S_{t+k}-S_{t}$ (percent per annum) January 1, 1986 through December 1, 1990

\begin{tabular}{|c|c|c|c|c|c|c|}
\hline & \multicolumn{2}{|c|}{3 Months } & \multicolumn{2}{|c|}{6 Months } & \multicolumn{2}{|c|}{12 Months } \\
\hline & Mean & $\begin{array}{l}\text { Standard } \\
\text { Deviation }\end{array}$ & Hean & $\begin{array}{l}\text { Standard } \\
\text { Deviation }\end{array}$ & Mean & $\begin{array}{l}\text { Standard } \\
\text { Deviation }\end{array}$ \\
\hline $\begin{array}{l}\text { JY/US } \\
\text { SF/US } \\
\text { BP/US } \\
\text { CD/US }\end{array}$ & $\begin{array}{r}-11.48 \\
-14.04 \\
-8.06 \\
-5.29\end{array}$ & $\begin{array}{r}30.26 \\
28.11 \\
26.58 \\
7.45\end{array}$ & $\begin{array}{r}-7.72 \\
-11.16 \\
-6.51 \\
-4.81\end{array}$ & $\begin{array}{r}19.86 \\
19.86 \\
16.67 \\
4.28\end{array}$ & $\begin{array}{l}-5.05 \\
-7.71 \\
-5.07 \\
-6.74\end{array}$ & $\begin{array}{r}13.57 \\
14.79 \\
11.22 \\
2.76\end{array}$ \\
\hline $\begin{array}{l}\text { FF/US } \\
\text { DF/US } \\
\text { IL/US } \\
\text { BF/US } \\
\text { DH/US } \\
\text { IP/US }\end{array}$ & $\begin{array}{l}-11.33 \\
-14.12 \\
-11.28 \\
-13.04 \\
-14.04 \\
-11.53\end{array}$ & $\begin{array}{l}22.84 \\
25.69 \\
22.91 \\
24.78 \\
25.40 \\
25.45\end{array}$ & $\begin{array}{r}-9.08 \\
-11.26 \\
-8.92 \\
-10.64 \\
-11.20 \\
-8.49\end{array}$ & $\begin{array}{l}15.50 \\
17.48 \\
15.55 \\
17.16 \\
17.28 \\
16.14\end{array}$ & $\begin{array}{l}-7.04 \\
-8.77 \\
-6.56 \\
-8.32 \\
-8.72 \\
-6.48\end{array}$ & $\begin{array}{l}11.25 \\
12.65 \\
10.76 \\
12.64 \\
12.41 \\
10.95\end{array}$ \\
\hline $\begin{array}{l}\text { JY/DH } \\
\text { SF/DH } \\
\text { BP/DH } \\
\mathrm{CD} / \mathrm{DH}\end{array}$ & $\begin{array}{l}2.53 \\
0.14 \\
5.48 \\
8.17\end{array}$ & $\begin{array}{r}22.38 \\
9.97 \\
21.44 \\
26.80\end{array}$ & $\begin{array}{l}3.47 \\
0.13 \\
4.44 \\
6.12\end{array}$ & $\begin{array}{r}16.61 \\
5.77 \\
15.20 \\
18.70\end{array}$ & $\begin{array}{l}3.67 \\
1.04 \\
3.52 \\
3.87\end{array}$ & $\begin{array}{r}12.33 \\
3.22 \\
9.54 \\
13.61\end{array}$ \\
\hline $\begin{array}{l}\mathrm{FF} / \mathrm{DH} \\
\mathrm{DF} / \mathrm{DH} \\
\mathrm{IL} / \mathrm{DH} \\
\mathrm{BF} / \mathrm{DH}\end{array}$ & $\begin{array}{l}2.76 \\
0.13 \\
2.75 \\
0.47\end{array}$ & $\begin{array}{l}5.66 \\
1.19 \\
5.45 \\
2.90\end{array}$ & $\begin{array}{l}2.16 \\
0.06 \\
2.29 \\
0.32\end{array}$ & $\begin{array}{l}4.06 \\
0.74 \\
3.64 \\
1.95\end{array}$ & $\begin{array}{l}1.70 \\
0.00 \\
2.16 \\
0.26\end{array}$ & $\begin{array}{l}2.74 \\
0.42 \\
2.67 \\
1.13\end{array}$ \\
\hline
\end{tabular}

Legend: $\quad \mathrm{BF}=$ Belgian Franc; $\mathrm{BP}=$ British Pound $\mathrm{CD}=$ Canadian Dollar; $\mathrm{DF}=$ Dutch Guilder; DM = German Mark; FF = French Franc; IL = Italian Lira; IP = Irish Pound; JY = Japanese Yen; US = US Dollar. 
Table 3.1B Summary Statistics of Expected Depreciation: $E_{\tau} S_{t+k}-S_{t}$ (percent per annum)

January 1, 1986 through December 1, 1990

\begin{tabular}{|c|c|c|c|c|c|c|}
\hline & \multicolumn{2}{|c|}{3 Months } & \multicolumn{2}{|c|}{6 Months } & \multicolumn{2}{|c|}{12 Months } \\
\hline & Mean & $\begin{array}{l}\text { Standard } \\
\text { Deviation }\end{array}$ & Mean & $\begin{array}{l}\text { Standerd } \\
\text { Deviation }\end{array}$ & Mean & $\begin{array}{l}\text { Standard } \\
\text { Deviation }\end{array}$ \\
\hline $\begin{array}{l}J Y / U S \\
\text { SF/US } \\
\text { BP/US } \\
\text { CD/US }\end{array}$ & $\begin{array}{r}-3.64 \\
-3.16 \\
1.61 \\
2.31\end{array}$ & $\begin{array}{l}7.79 \\
8.79 \\
8.16 \\
4.17\end{array}$ & $\begin{array}{r}-2.46 \\
-1.56 \\
2.31 \\
2.10\end{array}$ & $\begin{array}{l}6.90 \\
6.03 \\
4.68 \\
2.27\end{array}$ & $\begin{array}{r}-0.48 \\
-0.30 \\
2.34 \\
1.46\end{array}$ & $\begin{array}{l}3.56 \\
3.77 \\
2.52 \\
1.17\end{array}$ \\
\hline $\begin{array}{l}\text { FF/US } \\
\text { DF/US } \\
\text { IL/US } \\
\text { BF/US } \\
\text { DH/US } \\
\text { IP/US }\end{array}$ & $\begin{array}{r}-0.91 \\
-2.52 \\
0.54 \\
-1.84 \\
-3.32 \\
-3.06\end{array}$ & $\begin{array}{r}7.86 \\
8.96 \\
11.58 \\
9.98 \\
8.26 \\
13.64\end{array}$ & $\begin{array}{r}0.37 \\
-1.66 \\
1.74 \\
-0.70 \\
-1.56 \\
-0.38\end{array}$ & $\begin{array}{l}4.85 \\
5.25 \\
5.92 \\
6.49 \\
5.35 \\
8.24\end{array}$ & $\begin{array}{r}1.28 \\
-0.36 \\
2.14 \\
0.27 \\
-0.41 \\
1.16\end{array}$ & $\begin{array}{l}3.24 \\
3.26 \\
3.67 \\
3.88 \\
3.33 \\
4.70\end{array}$ \\
\hline $\begin{array}{l}J Y / D K \\
\text { SF/DM } \\
\text { BP/DM } \\
C D / D M\end{array}$ & $\begin{array}{r}-1.01 \\
-0.85 \\
5.08 \\
4.32\end{array}$ & $\begin{array}{r}5.11 \\
4.42 \\
7.12 \\
10.52\end{array}$ & $\begin{array}{r}-1.42 \\
-0.65 \\
3.65 \\
2.40\end{array}$ & $\begin{array}{l}5.90 \\
2.59 \\
2.72 \\
6.37\end{array}$ & $\begin{array}{r}-0.27 \\
-0.40 \\
2.63 \\
1.09\end{array}$ & $\begin{array}{l}1.95 \\
1.16 \\
2.07 \\
3.70\end{array}$ \\
\hline $\begin{array}{l}\text { FF/DM } \\
\text { DF/DM } \\
\text { IL/DM } \\
B F / D M\end{array}$ & $\begin{array}{l}2.48 \\
1.29 \\
4.00 \\
1.32\end{array}$ & $\begin{array}{l}2.30 \\
3.43 \\
8.55 \\
4.47\end{array}$ & $\begin{array}{l}2.40 \\
0.22 \\
4.04 \\
1.41\end{array}$ & $\begin{array}{l}2.06 \\
1.15 \\
2.65 \\
2.30\end{array}$ & $\begin{array}{l}1.79 \\
0.10 \\
2.89 \\
1.00\end{array}$ & $\begin{array}{l}1.26 \\
0.78 \\
1.69 \\
1.45\end{array}$ \\
\hline
\end{tabular}

Legend: $\quad \mathrm{BF}=$ Belgian Franc; $\mathrm{BP}=$ British Pound $\mathrm{CD}=$ Canadian Dollar; $\mathrm{DF}=$ Dutch Guilder; DM $=$ German Mark; FF $=$ French Franc; IL = Italian Lira; IP = Irish Pound; JY = Japanese Yen; US = US Dollar. 
Table 3.1C Summary Statistics of Survey Forecast Error: $S_{t+k}-E_{t} S_{t+k}$ (percent per annum)

January 1, 1986 through December 1, 1990

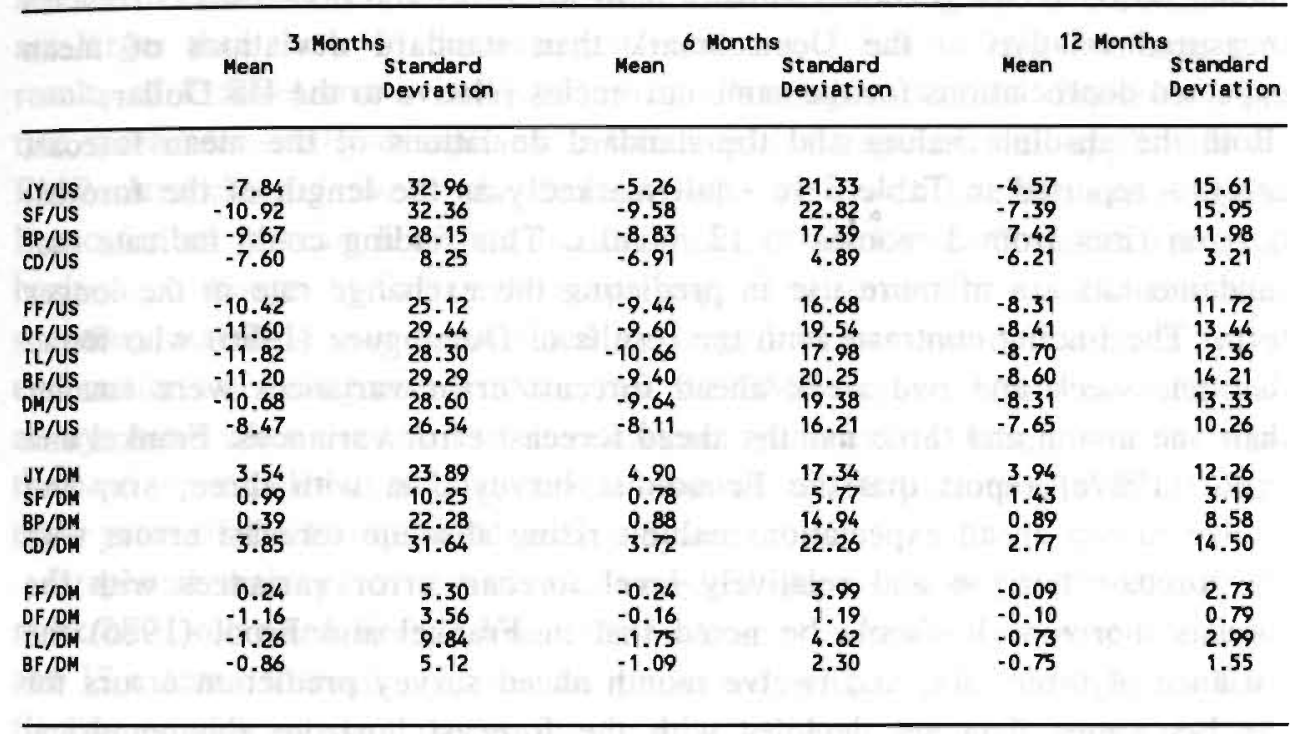

Legend: $\quad \mathrm{BF}=$ Belgian Franc; $\mathrm{BP}=$ British Pound; $\mathrm{CD}=$ Canadian Dollar; $\mathrm{DF}=$ Dutch Guilder; DM = German Mark; FF = French Franc; IL = Italian Lira; IP = Irish Pound; JY = Japanese Yen; US = US Dollar. 
term depreciation were smaller than the expected "long term" depreciations over the $1984-1986$ period. $^{4}$

It is interesting to note that - with the exception of the Canadian Dollar the standard deviations of the expected depreciation across the 3, 6, and 12 month horizons are generally smaller both for EMS and non-EMS currencies measured relative to the Deutschmark than standard deviations of mean expected depreciations for the same currencies relative to the US Dollar.

Both the absolute values and the standard deviations of the mean forecast errors - reported in Table $3.1 \mathrm{c}$ - fall markedly as the length of the forecast horizon rises from 3 months to 12 months. This finding could indicate that fundamentals are of more use in predicting the exchange rate in the longer term. The finding contrasts with the results of Dominguez (1986) who found that one week and two week ahead forecast error variances were smaller than one month and three months ahead forecast error variances. Frankel and Froot (1987a) report that the Economist survey data with three, six, and twelve month ahead expectations exhibit rising absolute forecast errors with the forecast horizon and relatively level forecast error variances with the forecast horizon. It should be noted that in Frankel and Froot (1986) the variance of three, six, and twelve month ahead survey prediction errors for the Economist data set declines with the forecast horizon; this empirical observation is reversed in Frankel and Froot (1987a) when four data points are added to the sample. In Frankel and Froot (1986), the mean forecast errors at the six month horizon exceed those at the three month horizon and are higher than mean forecast errors at the twelve month horizon.

It is also interesting to note that both the absolute value and the standard deviation of the mean forecast errors are significantly smaller for EMS currencies relative to the Deutschmark than for non-EMS currencies relative to the Deutsch-mark and relative to the US Dollar. This corroborates the findings of other research - Artis and Taylor (1988), Giavazzi and Giovannini (1989) and Nieuwland, Verschoor and Wolff (1991) - namely that the European Monetary System has acted to reduce the volatility of exchange rate changes and thus has exerted a stabilizing role on exchange rate expecta-

4 In Table 3.1b, one may note that the standard deviation of the mean expected depreciation declines with the forecast horizon. The data analyzed by Frankel and Froot (1987a) exhibit somewhat different properties; the standard deviations of the mean expected depreciation rises for the 6 month forecast horizon and then declines for the 12 month forecast horizon, relative to the 3 month forecasts. 
tions. As is shown in section 3, this need not imply that exchange rate forecasts are unbiased predictors of future exchange rates.

Comparing Tables $3.1 \mathrm{a}$ and $3.1 \mathrm{~b}$, one notes that in general both the absolute value and the standard deviation of the mean realized depreciation are larger than those of the expected mean depreciation. This confirms the results of Frankel and Froot (1987a) and Dominguez (1986). However, we find three noteworthy exceptions to this empirical regularity all applicable to EMS currencies relative to the Deutschmark: the Dutch Guilder and Belgian Franc for all forecast horizons and the Italian Lira for the 3 month forecast horizon. Although at first sight surprising, it is important to note that the summary statistics may be affected by large extreme values resulting from expectations of realignments. Note that the EMS exchange rate expectations always have taken the form of devaluations against the Deutschmark, as was the case for the eleven official realignments of central parities during the first eight years of the European Monetary System.

Graphical displays of actual and expected depreciation for the Deutschmark/US Dollar and French Franc/Deutschmark exchange rate over the 3, 6, and 12 months forecast horizons are presented in figures 1a through $3 \mathrm{~b}$. The figures indicate substantial variation of actual depreciation, whereas expected depreciation demonstrates less volatility. Note that the variation of both the actual and expected depreciation across the 3, 6, and 12 month horizons are significantly smaller for the FF/DM exchange rate than for the DM/US Dollar exchange rate. The three, six, and twelve month ahead forecasts for the FF/DM exchange rate generally predicted Deutschmark appreciation (and French Franc depreciation) throughout the sample period.

\subsection{The Rationality of the Survey Data}

Hodrick's (1987) and Levich's (1985) reviews of the literature on the efficiency of foreign exchange market suggest that there is overwhelming evidence in favor of the view that forward rates are biased predictors of future spot rates. Rejection of the unbiasedness hypothesis may be attributable to the irrationality of market participants [as suggested by Cumby and Obstfeld (1984) and Longworth (1981)], or to the existence of a risk premium [as suggested by Fama (1984), Hodrick and Srivastava (1984) and Wolff (1987a)], or to some combination of both of these phenomena. The availabi- 
Fig. Ta Actual and Expected Depreciation DM/US 3 -Months Forecast

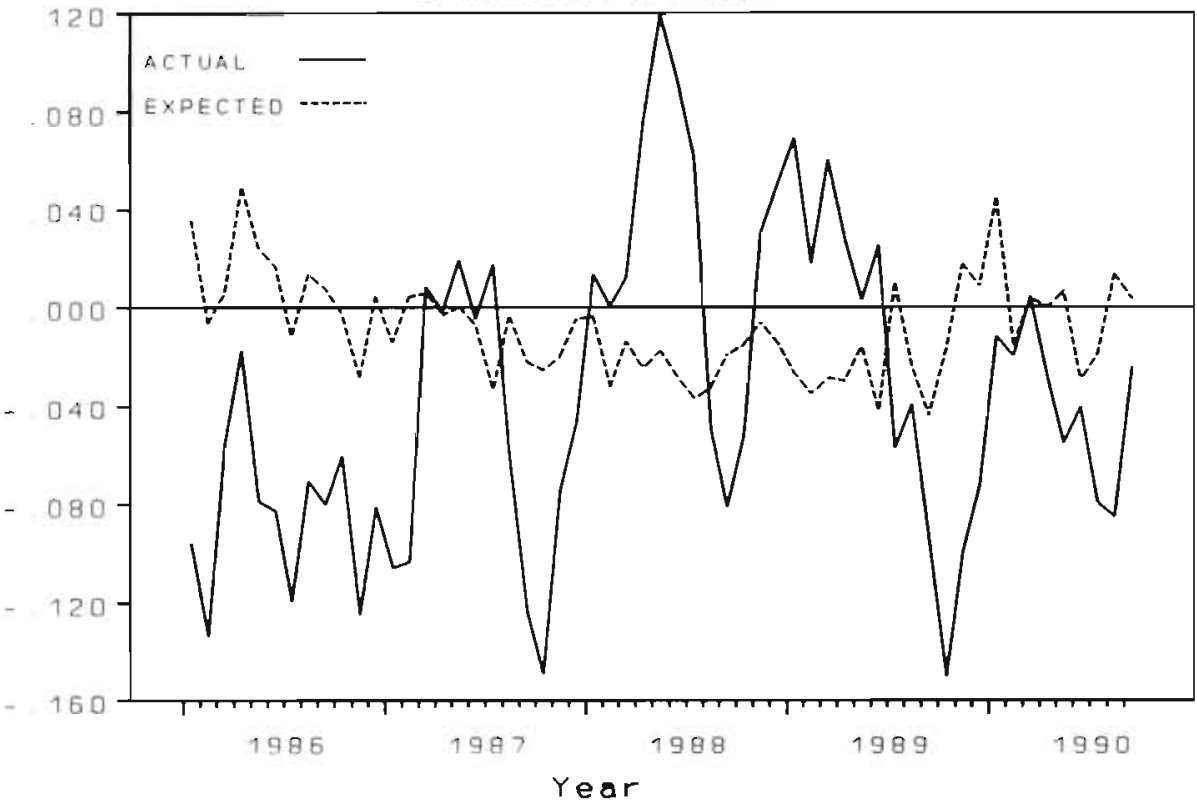

Fig 1b. Actual and Expected Depreciation FF/DM 3-Months forecast

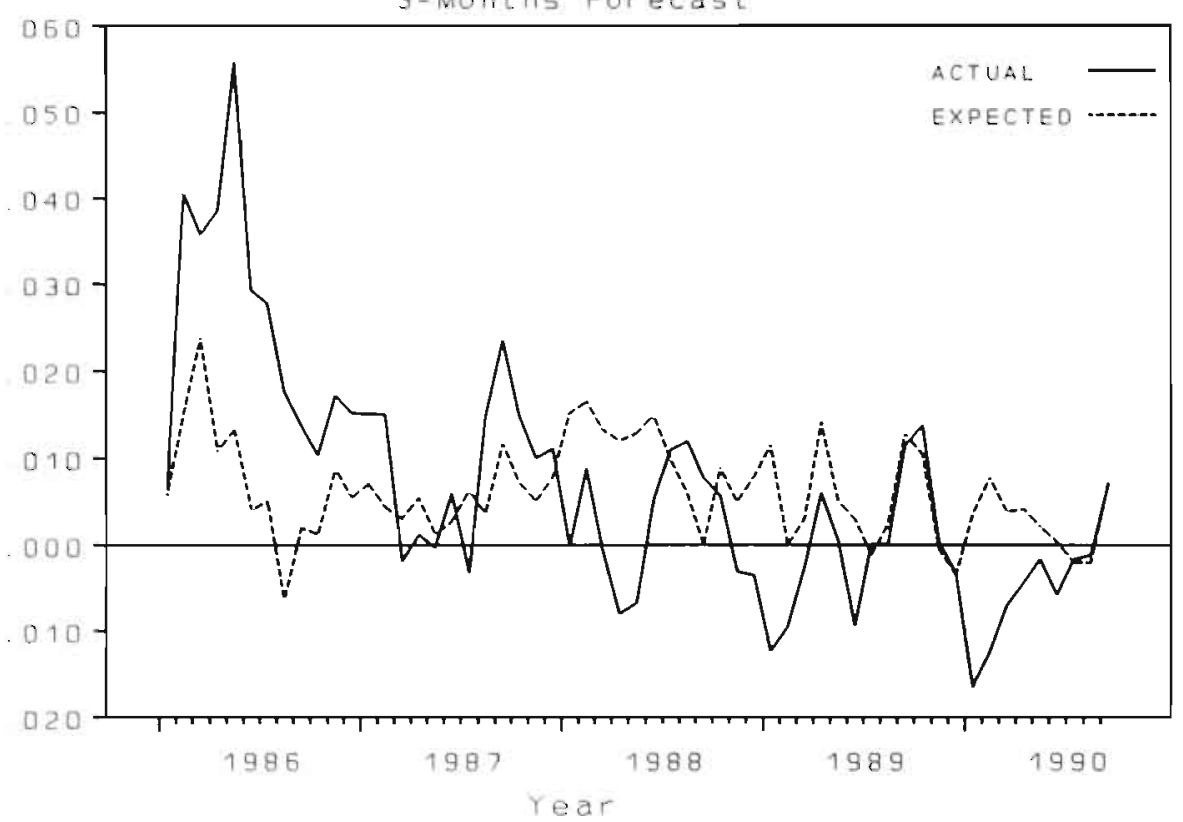




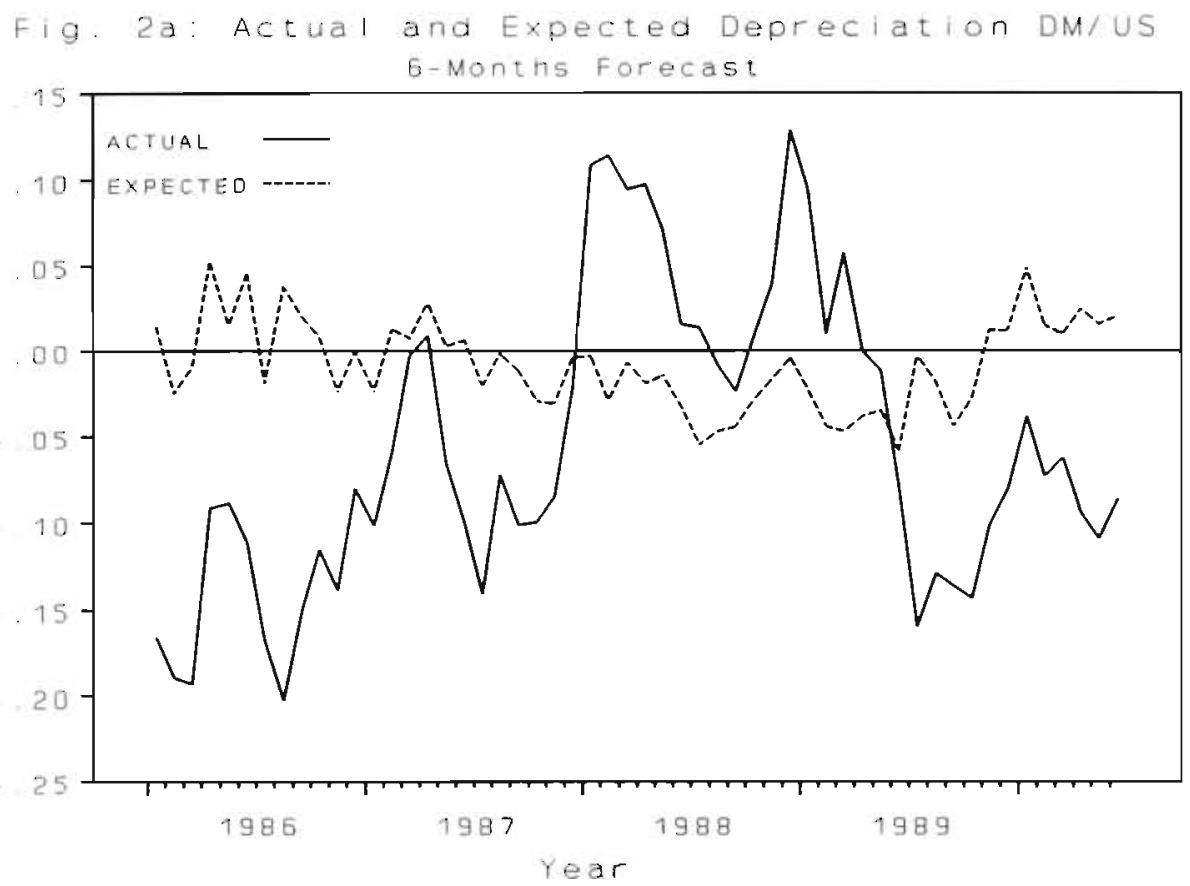

Fig. 20. Actual and Expected Depreciation FF/DM

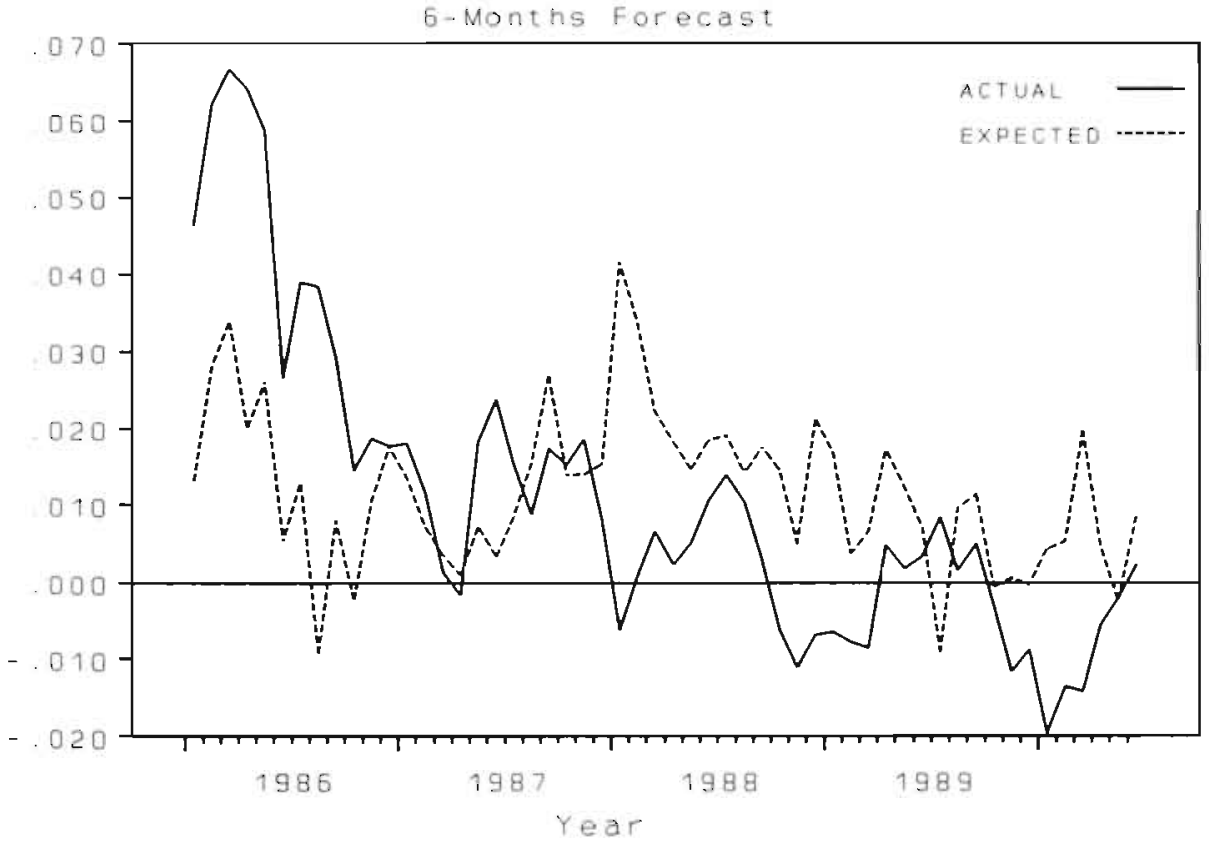


Fig. Ja. Actual and Expected Depreciation DM/US 12-Months. Forecast

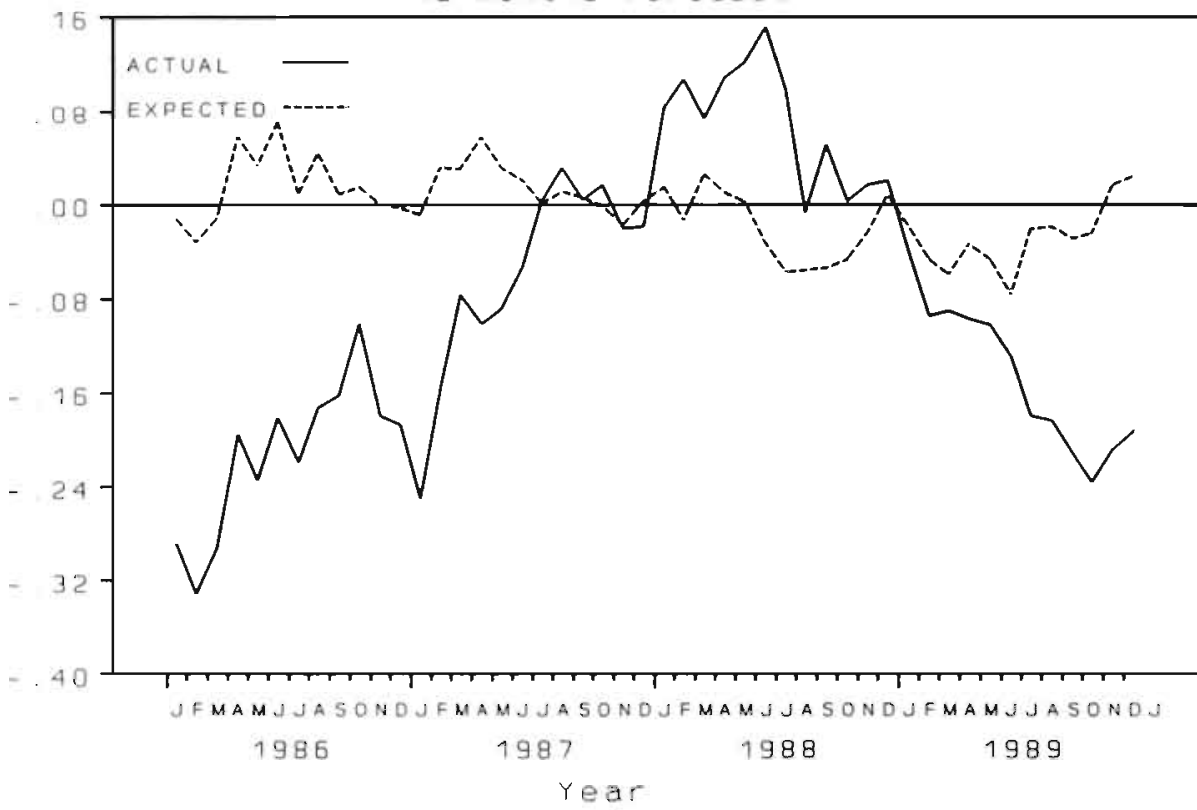

Fig 3b Actual and Expected Depreciation FF/ DM 12 -Months Forecast.

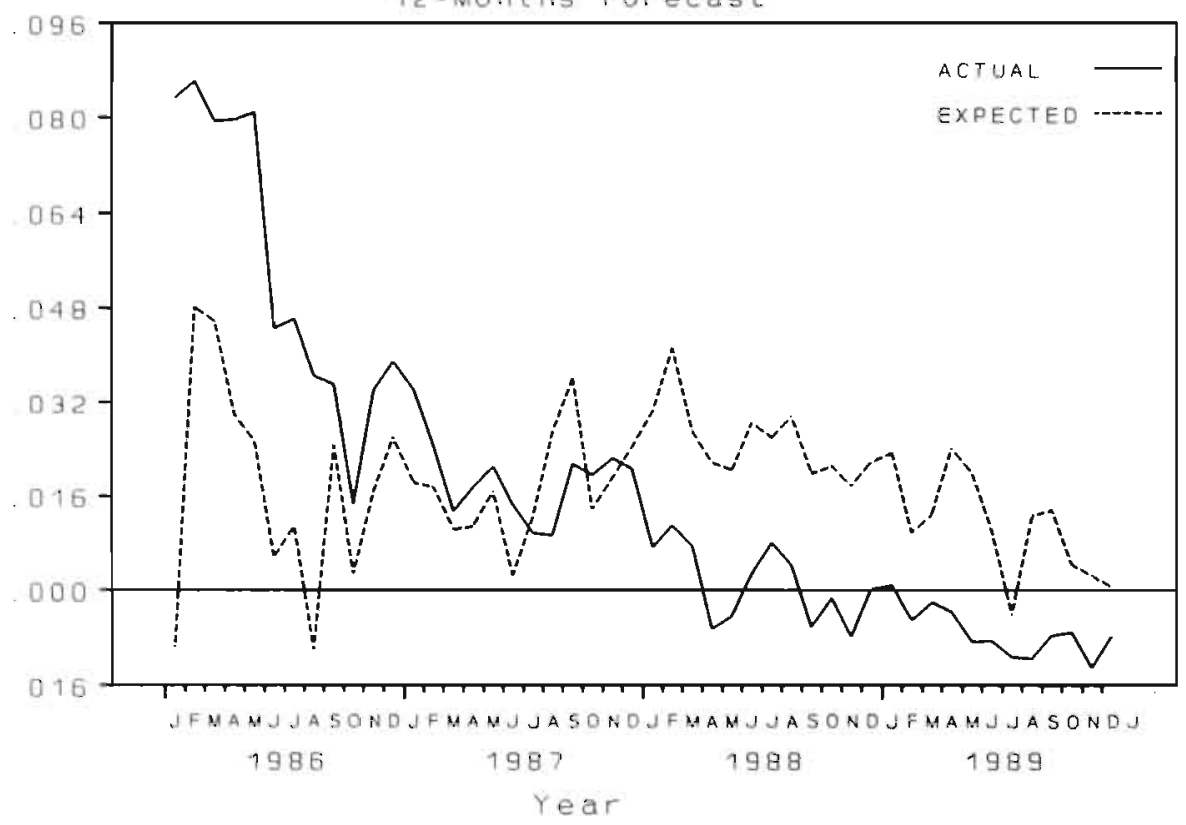


lity of survey data enables us to identify the relative importance of the explanations. In this chapter we focus our attention on the rationality issue and in a companion study (chapter four) we examine the economic importance of the risk premium explanation.

To test the rationality of the survey data, two fairly standard tests [see Pesaran (1987)] are considered - the unbiasedness test and the orthogonality test. The unbiasedness test examines whether the expected exchange rate is an unbiased predictor of the future spot rate, whereas the orthogonality test aims to assess whether agents use information that is available to them efficiently to forecast future exchange rates.

In both cases the tests are performed on bilateral rates relative to the US Dollar and bilateral rates relative to the Deutschmark. In a sense, if the null hypothesis of rationality held, then the Deutschmark based tests would be redundant as they represent linear combinations of bilateral US Dollar based tests; however, rejection of the null hypothesis for US Dollar rates does not imply rejection of the null for Deutschmark rates. The advent of the European Monetary System implying a market-wide concern for fluctuations of member currencies relative to the DM warrants the examination of such tests. In addition, not all survey respondents provide expectations for the same exchange rate, and Jensen's inequality will generally lead to DM/\$ forecasts that differ from the reciproque of $\$ / D M$ forecasts.

Define the exchange rate forecast error, $e_{t+k}$, as $S_{t+k}-E_{t} S_{t+k}$. The null hypothesis of rational expectations (unbiasedness) implies that $\alpha=0$ and $\beta$ $=1$ in regressions of the following form: ${ }^{5}$

$$
S_{t+k}-S_{t}=\alpha+\beta\left(E_{t} S_{t+k}-S_{t}\right)+\varepsilon_{t+k}
$$

where $e_{t+k}$ is a random error term. Equation (1) was fitted for each currency and for each forecast horizon ( $k=3,6$ and 12 months). Realized spot

${ }^{5}$ The equation is fitted in first difference form following Meese and Singleton (1982). 
exchange rates were obtained from Datastream. ${ }^{6}$ Hansen and Hodrick (1980) demonstrate that when the forecast horizon is longer than the observational frequency, the forecast error $e_{t+k}$ will be serially correlated. While OLS point estimates of $\beta$ remain consistent in spite of the serially correlated residuals, the OLS standard errors for the regression coefficient are biased. Hansen (1982) provides an estimator for the covariance matrix that is consistent in the presence of heteroskedasticity and serial correlation.

The method of moments estimate of the sample covariance matrix of the OLS estimate, $\hat{\beta}$ is given by

$$
\hat{V}(\hat{\beta})=T\left(X^{\prime} X\right)^{-1} \hat{\Omega}\left(X^{\prime} X\right)^{-1}
$$

where $\mathrm{X}=\left(\mathrm{x}_{1}, \ldots, \mathrm{x}_{\mathrm{T}}\right)^{\prime}$ is the matrix of observations on the explanatory variables $x_{t}$. The matrix $\hat{\Omega}$ refers to the following matrix

$$
\hat{\Omega}=\sum_{L=-k}^{k} \frac{1}{T} \sum_{t=1}^{T} \hat{u}_{t} x_{t} x_{t-L}^{\prime} \hat{u}_{t-L}
$$

where $k$ is the order of the moving average autocorrelation, and $\hat{u}_{t}$ is the OLS residual for observation $t$. However, there is one rather serious complication with the estimate of $\hat{\Omega}$. If $\mathrm{k}$ is non-zero, there is no guarantee that the estimate of $\hat{\Omega}$ becomes positive definite in small samples. To ensure positive-definiteness of the estimator of $\hat{\Omega}$, both frequency domain and time domain techniques have been proposed in the literature. Newey and West (1987) provide a consistent estimate of $\hat{\Omega}$ that discounts the $\mathrm{L}$-th order autocovariance by $1-[|\mathrm{L}| /(\mathrm{k}+1)]$, and is positive definite in small samples.

${ }^{6}$ As is suggested in section 2, the surveys are collected at month end; survey forecast dates and matching exchange rate expectations and survey data are reported in the Business International publication. Using the notation in section $3, E_{t} S_{t+k}$ represents the $\mathrm{k}$ period ahead forecast starting from the first day of the following month. The realized spot rate, $S_{1+k}$, is the average of the bid and ask quotes reported by Datastream on days corresponding to the survey forecast dates. When $k$-period-ahead forecasts fall on a weekend or holiday, the next business day is chosen. 
The Newey-West estimator is given by

$$
\hat{V}(\hat{\beta})=T\left(X^{\prime} X\right)^{-1} \hat{W}\left(X^{\prime} X\right)^{-1}
$$

where $\hat{\mathrm{W}}$ is formed by

$$
\hat{W}=\sum_{L=-k}^{k}\left[\frac{1}{T}\right]\left[\frac{K+1-|L|}{K+1}\right] \sum_{t=1}^{T} \hat{u}_{t} x_{t} x_{t-L}^{\prime} \hat{u}_{t-L}
$$

Serial correlation of the forecast errors is dealt with by making $\mathrm{k}$ non-zero. This corrects the covariance matrix for serial correlation in the form of a moving average process of order $\mathrm{k}$. The $\mathrm{k}$-month-ahead forecast equations in this section are estimated with the Newey-West estimator, assuming a moving average process of order $k$ for the monthly $k$-month ahead forecast errors. Note that the $\mathrm{k}$-month ahead forecast is in reality a $\mathrm{k}$-month plus a few days ahead forecast.

Tables $3.2 \mathrm{a}, 3.2 \mathrm{~b}$, and $3.2 \mathrm{c}$ report the results of fitting equation (1) via the Generalized Method of Moments (GMM) procedure. Overall, the evidence presented suggests a fairly consistent rejection of the null hypothesis that the expected depreciation is an unbiased predictor of the realized depreciation. Rejection of the null is attributable to both $\alpha$ being significantly different from zero and $\beta$ being significantly different from one. In fact, it is generally the case that the $\beta$-coefficient is significantly negative for exchange rates relative to the US Dollar. Thus survey respondents predicted the wrong direction of exchange rate depreciation. Similar results were obtained by Dominguez (1986) for exchange rate forecasts of the four major currencies relative to the US Dollar over the three month forecast horizon, and by MacDonald and Torrance (1988) for the Deutschmark over the one week and one month forecast horizons. Their results cover the 1983-1984 and 19831986 period, whereas our results cover the post-1986 period.

It is interesting to note though that the significance of the level bias in our tests, which can be verified via a standard t-test on the estimated $\alpha$-coef- 
ficient, declines as the length of the forecast horizon increases. At the 3 month forecast horizon the estimated coefficient was significantly different from zero at the $5 \%$ level in eleven of the eighteen bilateral exchange rates, whereas at the 12 month horizon rejection was obtained in only two of eighteen cases. Further, the estimated $\beta$-coefficient is insignificantly different from zero in thirty four of fifty four cases, suggesting that generally the exchange rate forecasts do not improve the contemporaneous spot exchange rate in predicting future spot exchange rate changes.

It is interesting to note that the forecasted exchange rate appreciations for both EMS and non-EMS currencies relative to the Deutschmark are generally of the same sign as those for the actual appreciations. Another important feature is that the null hypothesis was rejected for all but one EMS exchange rate (the FF/DM exchange rate). Thus, although the European Monetary System reduced the volatility of exchange rate changes and exerted a stabilizing role on exchange rate expectations, the EMS exchange rate forecasts seem to be affected by extreme values resulting from expectations of periodic realignments and are biased predictors of future exchange rates. These results should be interpreted with some caution. The forecast bias that is obtained in our small sample tests need not imply that expectations are formed irrationally. If conditional forecasts are formed rationally, allowing for a small probability of a large exchange rate movement, then forecasts will appear biased when judged from ex-post forecast errors - this is the familiar "peso problem" [see Krasker (1980)]. Economic agents may actually have rationally incorporated the true probability of exchange rate depreciation in their predictions, but because the forecast sample ended before the spot exchange rate actually depreciates, the test statistics are able to reject unbiasedness. It should also be noted that our test assumes that expectations are homogeneous. Ito (1990) presents evidence which suggests that exchange rate expectations are heterogeneous and that economic agents exhibit "wishful expectations" behavior; namely, exporters have a depreciation bias while importers have an appreciation bias.

Thus, rejection of the unbiasedness hypothesis need not imply that all economic agents are irrational; indeed, the disaggregated expectations data used by Ito shows that bankers' expectations are unbiased at all forecast horizons. An alternative explanation would be that the time series process which describes the expected exchange depreciation is not ergodic as is implied in the application of the GMM procedure. 
Table 3.2A Tests of Unbiasedness: $S_{t+3}-S_{t}=\alpha+\beta\left(E_{t} S_{t+3}-S_{t}\right)+e_{t+3}$

January 1, 1986 through December 1, 1990: 57 Observations

\begin{tabular}{|c|c|c|c|}
\hline & $\hat{\alpha}$ & $\hat{\beta}$ & $x^{2}$ \\
\hline JY/US & $\begin{array}{l}-0.0369 " \\
(0.0154)\end{array}$ & $\begin{array}{l}-0.9054^{\circ} \\
(0.5563)\end{array}$ & $\begin{array}{l}14.70^{\circ} \\
(0.000)\end{array}$ \\
\hline SF/US & $\begin{array}{l}-0.0442^{*} \\
(0.0103)\end{array}$ & $\begin{array}{l}-9.15977^{\circ} \\
(0.4389)\end{array}$ & $\begin{array}{l}89.67^{\circ} \\
(0.000)\end{array}$ \\
\hline BP/US & $\begin{array}{l}-0.0197 \\
(0.0144)\end{array}$ & $\begin{array}{l}-0.1467 \\
(0.5770)\end{array}$ & $\begin{array}{l}11.23 * \\
(0.004)\end{array}$ \\
\hline CD/US & $\begin{array}{l}-0.0142^{*} \\
(0.0034)\end{array}$ & $\begin{array}{c}0.1371^{*} \\
(0.3408)\end{array}$ & $\begin{array}{l}30.10^{\circ} \\
(0.000)\end{array}$ \\
\hline FF/US & $\begin{array}{l}-0.0292^{\circ} \\
(0.0111)\end{array}$ & $\begin{array}{l}-0.3852^{*} \\
(0.3830)\end{array}$ & $\begin{array}{l}46.62^{\circ} \\
(0.000)\end{array}$ \\
\hline DF/US & $\begin{array}{l}-0.0402 " . \\
(0.0108)\end{array}$ & $\begin{array}{l}-0.7921 " * \\
(0.3886)\end{array}$ & $\begin{array}{l}79.50 \% \\
(0.000)\end{array}$ \\
\hline IL/US & $\begin{array}{l}-0.0275 \% \\
(0.0112)\end{array}$ & $\begin{array}{l}-0.5297^{\circ} \\
(0.2100)\end{array}$ & $\begin{array}{l}96.26 \\
(0.000)\end{array}$ \\
\hline$B F / U S$ & $\begin{array}{l}-0.0359^{*} \\
(0.0108)\end{array}$ & $\begin{array}{l}-0.7223^{*} \\
(0.2820)\end{array}$ & $\begin{array}{c}183.97^{\circ} \\
(0.000)\end{array}$ \\
\hline$D M / U S$ & $\begin{array}{l}-0.0416 \% \\
(0.0098)\end{array}$ & $\begin{array}{l}-0.7592^{*} \\
(0.4225)\end{array}$ & $\begin{array}{l}76.04^{\circ} \\
(0.000)\end{array}$ \\
\hline $1 P / U S$ & $\begin{array}{l}-0.0262 \\
(0.0122)\end{array}$ & $\begin{array}{c}0.3477^{\circ} \\
(0.2974)\end{array}$ & $\begin{array}{l}15.19^{\circ} \\
(0.000)\end{array}$ \\
\hline JY/DM & $\begin{array}{c}0.0043 \\
(0.0122)\end{array}$ & $\begin{array}{l}-0.8196^{\circ} \\
(0.8599)\end{array}$ & $\begin{array}{c}4.59 \\
(0.101)\end{array}$ \\
\hline SF/DM & $\begin{array}{c}0.0011 \\
(0.0052)\end{array}$ & $\begin{array}{c}0.3534 \\
(0.3662)\end{array}$ & $\begin{array}{l}4.11 \\
(0.128)\end{array}$ \\
\hline BP/DM & $\begin{array}{c}0.0094 \\
(0.0150)\end{array}$ & $\begin{array}{c}0.3968 \\
(0.6073)\end{array}$ & $\begin{array}{c}0.99 \\
(0.610)\end{array}$ \\
\hline $\mathrm{CD} / \mathrm{OM}$ & $\begin{array}{c}0.0289^{*} \\
(0.0104)\end{array}$ & $\begin{array}{c}0.7794 \\
(0.3703)\end{array}$ & $\begin{array}{l}47.87^{\circ} \\
(0.000)\end{array}$ \\
\hline $\mathrm{FF} / \mathrm{DM}$ & $\begin{array}{c}0.0014 \\
(0.0032)\end{array}$ & $\begin{array}{c}0.8714 \\
(0.4891)\end{array}$ & $\begin{array}{l}0.20 \\
(0.904)\end{array}$ \\
\hline$D F / D M$ & $\begin{array}{c}0.0003 \\
(0.0006)\end{array}$ & $\begin{array}{c}0.0211^{\circ} \\
(0.0326)\end{array}$ & $\begin{array}{c}2.113 .58 * \\
(0.000)\end{array}$ \\
\hline IL/DH & $\begin{array}{c}0.0065^{\circ} \\
(0.0030)\end{array}$ & $\begin{array}{c}0.0411 \% \\
(0.0589)\end{array}$ & $\begin{array}{c}270.86 * \\
(0.000)\end{array}$ \\
\hline $\mathrm{BF} / \mathrm{OM}$ & $\begin{array}{c}0.0010 \\
(0.0015)\end{array}$ & $\begin{array}{c}0.0542 . * \\
(0.1259)\end{array}$ & $\begin{array}{l}56.47^{*} \\
(0.000)\end{array}$ \\
\hline
\end{tabular}

The Standard errors of the coefficients are given in parentheses; ${ }^{*}\left({ }^{* *}\right)$ denotes rejection at the $5 \%(1 \%)$ level for the hypotheses that $\alpha=0$ or $\beta=1$. The Chi-square Statistic pertains to the joint hypothesis that $\alpha=0$ and $\beta=1$ ( $\mathrm{p}$-Values are given in parentheses). 
Table 3.2B Tests of Unbiasedness: $S_{t+6}-S_{t}=\alpha+\beta\left(E_{t} S_{t+6}-S_{t}\right)+e_{t+6}$ January 1, 1986 through December 1, 1990: 54 Observations

\begin{tabular}{|c|c|c|c|}
\hline & $\hat{\alpha}$ & $\hat{\beta}$ & $x^{2}$ \\
\hline JY/US & -0.0403 & $\begin{array}{l}-0.1406 \\
(0.5323)\end{array}$ & $\begin{array}{l}7.97^{\circ} \\
(0.020)\end{array}$ \\
\hline SF/US & $\begin{array}{l}-0.0655 * \\
(0.0213)\end{array}$ & $\begin{array}{l}-1.2370^{\circ} \\
(0.34 \pi 5)\end{array}$ & $\begin{array}{l}91.38^{\circ} \\
(0.000)\end{array}$ \\
\hline BP/US & $\begin{array}{l}-0.0319 \\
(0.0242)\end{array}$ & $\begin{array}{l}-0.0626 \\
(0.7832)\end{array}$ & $\begin{array}{l}5.64 \\
(0.059)\end{array}$ \\
\hline CD/US & $\begin{array}{l}-0.02355^{\circ} \\
(0.0040)\end{array}$ & $\begin{array}{l}-0.0517^{\prime} \\
(0.1797)\end{array}$ & $\begin{array}{l}57.04 \% \\
(0.000)\end{array}$ \\
\hline FF/US & $\begin{array}{l}-0.0448^{\circ} \\
(0.0212)\end{array}$ & $\begin{array}{l}-0.3134^{*} \\
(0.3808)\end{array}$ & $\begin{array}{l}24.37^{\circ} \\
(0.000)\end{array}$ \\
\hline IL/US & $\begin{array}{l}-0.0636 " \\
(0.0205)\end{array}$ & $\begin{array}{l}-0.8865^{\circ} \\
(0.3773)\end{array}$ & $\begin{array}{l}43.64 \\
(0.000)\end{array}$ \\
\hline$B F / U S$ & $\begin{array}{l}-0.0388^{\circ} \\
(0.0191)\end{array}$ & $\begin{array}{l}-0.6616 \\
(0.3027)\end{array}$ & $\begin{array}{l}39.17^{\circ} \\
(0.000)\end{array}$ \\
\hline DM/US & $\begin{array}{l}-0.0562 "= \\
(0.0199)\end{array}$ & $\begin{array}{l}-0.8750^{\circ} \\
(0.2597)\end{array}$ & $\begin{array}{l}99.86 " \\
(0.000)\end{array}$ \\
\hline & $\begin{array}{l}-0.0627^{\circ} \\
(0.0192)\end{array}$ & $\begin{array}{l}-0.8555^{\circ} \\
(0.3999)\end{array}$ & $\begin{array}{l}52.76^{\circ \prime} \\
(0.000)\end{array}$ \\
\hline IP/US & $\begin{array}{l}-0.0415 \\
(0.0217)\end{array}$ & $\begin{array}{c}0.4835^{\circ} \\
(0.2576)\end{array}$ & $\begin{array}{c}8.93^{\circ} \\
(0.012)\end{array}$ \\
\hline JY/DH & $\begin{array}{c}0.0184 \\
(0.0249)\end{array}$ & $\begin{array}{c}0.1418^{*} \\
(0.3618)\end{array}$ & $\begin{array}{l}6.43^{\circ} \\
(0.040)\end{array}$ \\
\hline SF/DH & $\begin{array}{c}0.0023 \\
(0.0075)\end{array}$ & $\begin{array}{c}0.4987 \\
(0.2724)\end{array}$ & $\begin{array}{l}5.12 \\
(0.077)\end{array}$ \\
\hline$B P / O A$ & $\begin{array}{c}0.0036 \\
(0.0281)\end{array}$ & $\begin{array}{c}1.0445 \\
(0.8013)\end{array}$ & $\begin{array}{l}0.05 \\
(0.975)\end{array}$ \\
\hline $\mathrm{CD} / \mathrm{DH}$ & $\begin{array}{c}0.0462^{*} \\
(0.0181)\end{array}$ & $\begin{array}{l}-1.2974 \\
(0.5049)\end{array}$ & $\begin{array}{l}27.50^{\circ} \\
(0.000)\end{array}$ \\
\hline FF/DM & $\begin{array}{c}0.0041 \\
(0.0060)\end{array}$ & $\begin{array}{c}0.5568 \\
(0.5004)\end{array}$ & $\begin{array}{c}0.85 \\
(0.655)\end{array}$ \\
\hline $1 \mathrm{~L} / \mathrm{DM}$ & $\begin{array}{c}0.0001 \\
(0.0008)\end{array}$ & $\begin{array}{c}0.1747^{\circ} \\
(0.0662)\end{array}$ & $\begin{array}{l}170.38 * \\
(0.000)\end{array}$ \\
\hline$B F / D M$ & $\begin{array}{c}0.0130^{\circ} \\
(0.0057)\end{array}$ & $\begin{array}{l}-0.0768^{*} \\
(0.1872)\end{array}$ & $\begin{array}{l}33.19^{*} \\
(0.000)\end{array}$ \\
\hline $\mathrm{BF} / \mathrm{DM}$ & $\begin{array}{l}-0.0009 \\
(0.0027)\end{array}$ & $\begin{array}{r}0.3569^{\circ} \\
(0.1044)\end{array}$ & $\begin{array}{l}74.95 \% \\
(0.000)\end{array}$ \\
\hline
\end{tabular}

The Standard errors of the coefficients are given in parentheses; ${ }^{*}\left({ }^{* *}\right)$ denotes rejection at the $5 \%(1 \%)$ level for the hypotheses that $\alpha=0$ or $\beta=1$. The Chi-square Statistic pertains to the joint hypothesis that $\alpha=0$ and $\beta=1$ (p-Values are given in parentheses). 
Table 3.2C Tests of Unbiasedness: $S_{t+12}-S_{t}=\alpha+\beta\left(E_{t} S_{t+12}-S_{t}\right)+e_{t+12}$ January 1, 1986 through December 1, 1990: 48 Observations

\begin{tabular}{|c|c|c|c|}
\hline & $\hat{\alpha}$ & $\hat{\beta}$ & $x^{2}$ \\
\hline JY/US & $\begin{array}{l}-0.0587 \\
(0.0365)\end{array}$ & $\begin{array}{l}-1.7180^{\circ} \\
(0.4960)\end{array}$ & $\begin{array}{c}144.09 \cdot \\
(0.000)\end{array}$ \\
\hline SF/US & $\begin{array}{l}-0.0795 \\
(0.0542)\end{array}$ & $\begin{array}{l}-0.7526 \\
(0.5409)\end{array}$ & $\begin{array}{l}16.30^{\circ} \\
(0.000)\end{array}$ \\
\hline BP/US & $\begin{array}{l}-0.0297 \\
(0.0433)\end{array}$ & $\begin{array}{l}-0.8959^{\circ} \\
(0.5171)\end{array}$ & $\begin{array}{l}26.17^{\circ} \\
(0.000)\end{array}$ \\
\hline CD/US & $\begin{array}{l}-0.0405^{\circ} \\
(0.0099)\end{array}$ & $\begin{array}{l}-0.4719^{\circ} \\
(0.2540)\end{array}$ & $\begin{array}{l}71.53^{\circ} \\
(0.000)\end{array}$ \\
\hline FF/US & $\begin{array}{l}-0.0701 \\
(0.0445)\end{array}$ & $\begin{array}{l}-0.0176 \\
(0.5887)\end{array}$ & $\begin{array}{l}6.07 \\
(0.050)\end{array}$ \\
\hline DF/US & $\begin{array}{l}-0.0895 \\
(0.0495)\end{array}$ & $\begin{array}{l}-0.4756 \% \\
(0.4032)\end{array}$ & $\begin{array}{l}14.78^{\circ} \\
(0.000)\end{array}$ \\
\hline IL/US & $\begin{array}{l}-0.0470 \\
(0.0409)\end{array}$ & $\begin{array}{l}-0.8684 \cdots \\
(0.4734)\end{array}$ & $\begin{array}{l}25.12^{\circ} \\
(0.000)\end{array}$ \\
\hline BF/US & $\begin{array}{l}-0.0808 \\
(0.0460)\end{array}$ & $\begin{array}{l}-0.9005^{\circ} \\
(0.4899)\end{array}$ & $\begin{array}{l}18.35^{\circ} \\
(0.000)\end{array}$ \\
\hline DH/US & $\begin{array}{l}-0.0895 \\
(0.0472)\end{array}$ & $\begin{array}{l}-0.5586 " \\
(0.4613)\end{array}$ & $\begin{array}{l}16.71^{\circ} \\
(0.000)\end{array}$ \\
\hline IP/US & $\begin{array}{l}-0.0745^{\circ} \\
(0.0358)\end{array}$ & $\begin{array}{c}0.8288 \\
(0.2704)\end{array}$ & $\begin{array}{c}4.45 \\
(0.099)\end{array}$ \\
\hline $\mathrm{JY} / O \mathrm{M}$ & $\begin{array}{c}0.0386 \\
(0.0513)\end{array}$ & $\begin{array}{c}0.7351 \\
(0.8525)\end{array}$ & $\begin{array}{c}0.56 \\
(0.752)\end{array}$ \\
\hline$S F / O M$ & $\begin{array}{c}0.0126 \\
(0.0093)\end{array}$ & $\begin{array}{c}0.5598 \\
(0.3362)\end{array}$ & $\begin{array}{l}2.94 \\
(0.229)\end{array}$ \\
\hline $\mathrm{BP} / \mathrm{OM}$ & $\begin{array}{l}-0.0316 \\
(0.0304)\end{array}$ & $\begin{array}{l}2.5370^{\circ} \\
(0.4774)\end{array}$ & $\begin{array}{l}10.89^{\circ} \\
(0.004)\end{array}$ \\
\hline $\mathrm{CD} / \mathrm{DH}$ & $\begin{array}{c}0.0432 \\
(0.0524)\end{array}$ & $\begin{array}{l}-0.4106 \\
(0.4293)\end{array}$ & $\begin{array}{l}11.39^{-0} \\
(0.003)\end{array}$ \\
\hline $\mathrm{FF} / \mathrm{OM}$ & $\begin{array}{c}0.0077 \\
(0.0111)\end{array}$ & $\begin{array}{c}0.5216 \\
(0.3399)\end{array}$ & $\begin{array}{l}2.02 \\
(0.364)\end{array}$ \\
\hline$D F / D M$ & $\begin{array}{l}-0.0001 \\
(0.0012)\end{array}$ & $\begin{array}{c}0.1423^{\circ} \\
(0.0625)\end{array}$ & $\begin{array}{c}193.97^{\circ} \\
(0.000)\end{array}$ \\
\hline $\mathrm{IL} / \mathrm{DM}$ & $\begin{array}{c}0.0163 \\
(0.0101)\end{array}$ & $\begin{array}{c}0.1824^{\circ} \\
(0.2249)\end{array}$ & $\begin{array}{l}15.37^{\circ} \\
(0.000)\end{array}$ \\
\hline BF/DH & $\begin{array}{l}-0.0002 \\
(0.0052)\end{array}$ & $\begin{array}{c}0.2359^{\circ} \\
(0.1528)\end{array}$ & $\begin{array}{l}65.14 \% \\
(0.000)\end{array}$ \\
\hline
\end{tabular}

The Standard errors of the coefficients are given in parentheses; ${ }^{*}\left(^{* *}\right)$ denotes rejection at the $5 \%(1 \%)$ level for the hypotheses that $\alpha=0$ or $\beta=1$. The Chi-square Statistic pertains to the joint hypothesis that $\alpha=0$ and $\beta=1$ ( $p$-Values are given in parentheses). 
The second type of test of the rational expectations hypothesis is concerned with the efficient use of information available at the time expectations are formed. If economic agents use all available information efficiently, the expectational errors must be orthogonal to any variable in the set of information known to agents at the time they formed their expectations. The null hypothesis of rational expectations (orthogonality) implies that $\alpha=0$ and $\beta$ $=0$ in regressions of the following form:

$$
S_{t+k}-E_{t} S_{t+k}=\alpha+\beta\left(X_{t}\right)+\varepsilon_{t+k}
$$

where the left-hand-side variable is the exchange rate forecast error, $X_{t}$ is a set of information known at time $t$, and $e_{t+k}$ is a random error term. In order to test whether economic agents use all available information efficiently, equation (6) was fitted for each currency and for each forecast horizon. The information set $X_{t}$ included the lagged forecast error and the forward premium, which are both known at the time expectations are formed.

Tables $3.3 \mathrm{a}, 3.3 \mathrm{~b}$, and $3.3 \mathrm{c}$ report regressions of the exchange rate forecast error on past forecast errors for each currency and for each forecast horizon. The estimated Chi-square statistics provide weak evidence for the hypothesis that the lagged expectation error is correlated with the current forecast error for nearly all currencies and forecast horizons. In only seventeen of fifty four cases was the joint hypothesis that both the constant and slope coefficient equal zero rejected at the five per cent significance level. These results corroborate the results of Dominguez (1986) over shorter forecast horizons for the four most actively traded currencies.

Tables $3.4 \mathrm{a}, 3.4 \mathrm{~b}$, and $3.4 \mathrm{c}$ report regressions of the forecast error on the 3,6 , and 12 month ahead forward premium. The results provide a fairly consistent rejection of the null hypothesis for all currencies relative to the US Dollar. This indicates that the forward premium contains additional information for the exchange rate forecasts of the major currencies relative to the US Dollar. It is generally the case that the estimated $\beta$-coefficients are significantly negative and less than one. ${ }^{7}$ Thus, investors could do better, i.e.,

7 Bilson (1981) proposed the altemative hypothesis of $\beta<0$ "excessive speculation", because investors could improve their forecasts by consistently betting against the forward discount. 
reduce their forecast errors, by adjusting one's exchange rate forecasts for change in the direction of betting against the forward discount. Similar results were obtained by Dominguez (1986) for data over the 3 month forecast horizon. In contrast, the results for the exchange rates relative to the Deutschmark provide a less consistent rejection of the null hypothesis.

Taken together, the results of both the unbiasedness test and the orthogonality tests provide a strong rejection of the rational expectations hypothesis for exchange rates relative to the US Dollar. This is not an isolated finding, but is in line with the general conclusion that so far has emerged from the analysis of survey results on exchange rate expectations for some of the major currencies relative to the US Dollar. The results for the currencies relative to the Deutschmark suggest that EMS exchange rate forecasts are biased predictors of future exchange rates, however, it may be difficult to find publicly available information that would help improve the forecast accuracy of economic agents. Thus, although the rational expectations hypothesis has considerable appeal as a theoretical model, it does not appear to provide an adequate explanation of exchange rate expectation in the sampled period. The direct observations on exchange rate expectations do not support the rational expectations hypothesis. It is therefore important to consider other models of expectation formation. In the next section we examine three alternative models: extrapolative, adaptive, and long run expectations.

\subsection{Models of Expectations Formation}

Although recent empirical evidence suggests that exchange rates exhibit mean reverting behavior - see Huizinga (1987) and Cavaglia (1990) - it would seem that the random walk hypothesis is a relatively accurate characterization of the time series of exchange rates. Indeed, Meese and Rogoff (1983a and 1983b) and Wolff (1987b) show that standard models of exchange rate determination fail to outperform the predictive power of the random walk hypothesis even when allowing for time varying model parameters. Conditional on the hypothesis that the foreign exchange market is efficient or rational, Fama (1984) finds that most of the variation in the forward discount is attributable to variation in the risk premium, and thus one might conclude that the random walk may also be a proper characterization of investor's 
Table 3.3A Tests of Orthogonality: $\mathrm{S}_{\mathrm{t}+3}-\mathrm{E}_{\mathrm{t}} \mathrm{S}_{\mathrm{t}+3}=\alpha+\beta\left(\mathrm{S}_{\mathrm{t}}-\mathrm{E}_{\mathrm{t}-3} \mathrm{~S}_{\mathrm{t}}\right)+\mathrm{e}_{\mathrm{t}+3}$ January 1, 1986 through December 1, 1990: 57 Observations

\begin{tabular}{|c|c|c|c|}
\hline & $\hat{\alpha}$ & $\hat{\beta}$ & $x^{2}$ \\
\hline JYIUS & $\begin{array}{l}-0.0081 \\
(0.0164)\end{array}$ & $\begin{array}{c}0.1016 \\
(0.1456)\end{array}$ & $\begin{array}{c}0.89 \\
(0.642)\end{array}$ \\
\hline SF/US & $\begin{array}{l}-0.0155 \\
(0.0171)\end{array}$ & $\begin{array}{c}0.2166 \\
(0.1329)\end{array}$ & $\begin{array}{l}4.00 \\
(0.135)\end{array}$ \\
\hline BP/US & $\begin{array}{l}-0.0192 \\
(0.0159)\end{array}$ & $\begin{array}{c}0.1353 \\
(0.1382)\end{array}$ & $\begin{array}{c}3.96 \\
(0.138)\end{array}$ \\
\hline CD/US & $\begin{array}{l}-0.0187 . \\
(0.0050)\end{array}$ & $\begin{array}{c}0.0306 \\
(0.1132)\end{array}$ & $\begin{array}{l}21.61^{\circ} \\
(0.000)\end{array}$ \\
\hline FF/US & $\begin{array}{l}-0.0145 \\
(0.0138)\end{array}$ & $\begin{array}{c}0.3245 \\
(0.1501)\end{array}$ & $\begin{array}{l}12.29^{\circ} \\
(0.002)\end{array}$ \\
\hline OF/US & $\begin{array}{l}-0.0180 \\
(0.0163)\end{array}$ & $\begin{array}{c}0.1641 \\
(0.1343)\end{array}$ & $\begin{array}{c}4.18 \\
(0.123)\end{array}$ \\
\hline IL/US & $\begin{array}{l}-0.0124 \\
(0.0143)\end{array}$ & $\begin{array}{c}0.3720 \\
(0.1706)\end{array}$ & $\begin{array}{l}10.46 \\
(0.005)\end{array}$ \\
\hline $\mathrm{BF} / \mathrm{US}$ & $\begin{array}{l}-0.0152 \\
(0.0161)\end{array}$ & $\begin{array}{c}0.2195 \\
(0.1352)\end{array}$ & $\begin{array}{c}5.51 \\
(0.064)\end{array}$ \\
\hline DM/US & $\begin{array}{l}-0.0172 \\
(0.0160)\end{array}$ & $\begin{array}{c}0.1694 \\
(0.1390)\end{array}$ & $\begin{array}{c}3.83 \\
(0.148)\end{array}$ \\
\hline IP/US & $\begin{array}{l}-0.0119 \\
(0.0140)\end{array}$ & $\begin{array}{c}0.26866^{\circ} \\
(0.1288)\end{array}$ & $\begin{array}{c}9.20 \\
(0.010)\end{array}$ \\
\hline JY/DM & $\begin{array}{c}0.0105 \\
(0.0130)\end{array}$ & $\begin{array}{c}0.2451 \\
(0.1890)\end{array}$ & $\begin{array}{c}2.13 \\
(0.345)\end{array}$ \\
\hline SF/OM & $\begin{array}{c}0.0016 \\
(0.0053)\end{array}$ & $\begin{array}{l}-0.0074 \\
(0.1478)\end{array}$ & $\begin{array}{c}0.11 \\
(0.947)\end{array}$ \\
\hline$B P / D M$ & $\begin{array}{l}-0.0017 \\
(0.0124)\end{array}$ & $\begin{array}{c}0.1977 \\
(0.1287)\end{array}$ & $\begin{array}{c}2.86 \\
(0.240)\end{array}$ \\
\hline$C D / D M$ & $\begin{array}{c}0.0008 \\
(0.0157)\end{array}$ & $\begin{array}{c}0.2823 \\
(0.1511)\end{array}$ & $\begin{array}{c}3.56 \\
(0.169)\end{array}$ \\
\hline FF/DM & $\begin{array}{l}-0.0008 \\
(0.0024)\end{array}$ & $\begin{array}{c}0.2970^{\circ} \\
(0.1286)\end{array}$ & $\begin{array}{c}7.67^{\circ} \\
(0.022)\end{array}$ \\
\hline$D F / D M$ & $\begin{array}{l}-0.0032^{\circ} \\
(0.0013)\end{array}$ & $\begin{array}{l}-0.2687^{*} \\
(0.0772)\end{array}$ & $\begin{array}{l}13.32 \% \\
(0.001)\end{array}$ \\
\hline $1 \mathrm{~L} / \mathrm{DM}$ & $\begin{array}{c}0.0007 \\
(0.0045)\end{array}$ & $\begin{array}{c}0.1900 \\
(0.1226)\end{array}$ & $\begin{array}{l}4.45 \\
(0.108)\end{array}$ \\
\hline $\mathrm{BF} / \mathrm{DH}$ & $\begin{array}{l}-0.0019 \\
(0.0022)\end{array}$ & $\begin{array}{l}0.0452 \\
(0.1261)\end{array}$ & $\begin{array}{c}0.78 \\
(0.678)\end{array}$ \\
\hline
\end{tabular}

The Standard errors of the coefficients are given in parentheses; * $\left(^{* *}\right)$ denotes rejection at the $5 \%(1 \%)$ level for the hypotheses that $\alpha=0$ and $\beta=0$. The Chi-square Statistic pertains to the joint hypothesis that $\alpha=0$ and $\beta=0$ ( $\mathrm{p}$-Values are given in parentheses). 
Table 3.3C Tests of Orthogonality: $S_{t+12}-E_{t} S_{t+12}=\alpha+\beta\left(S_{t}-E_{t-12} S_{t}\right)+e_{t+12}$ January 1, 1986 through December 1, 1990: 48 Observations

\begin{tabular}{|c|c|c|c|}
\hline & $\hat{\alpha}$ & $\hat{\beta}$ & $x^{2}$ \\
\hline JY/US & $\begin{array}{c}0.0533 \\
(0.0461)\end{array}$ & $\begin{array}{c}0.4054 \\
(0.2642)\end{array}$ & $\begin{array}{l}3.24 \\
(0.198)\end{array}$ \\
\hline SF/US & $\begin{array}{l}-0.0264 \\
(0.0598)\end{array}$ & $\begin{array}{l}-0.0887 \\
(0.2551)\end{array}$ & $\begin{array}{c}0.26 \\
(0.880)\end{array}$ \\
\hline BP/US & $\begin{array}{l}-0.0753 \\
(0.0450)\end{array}$ & $\begin{array}{l}-0.3542^{\circ} \\
(0.1688)\end{array}$ & $\begin{array}{l}6.69^{\circ} \\
(0.035)\end{array}$ \\
\hline CD/US & $\begin{array}{l}-0.0654^{*} \\
(0.0255)\end{array}$ & $\begin{array}{l}-0.0450 \\
(0.2079)\end{array}$ & $\begin{array}{l}20.15^{\circ} \\
(0.000)\end{array}$ \\
\hline FF/US & $\begin{array}{l}-0.0558 \\
(0.0472)\end{array}$ & $\begin{array}{l}-0.1304 \\
(0.2523)\end{array}$ & $\begin{array}{c}1.40 \\
(0.496)\end{array}$ \\
\hline DF/US & $\begin{array}{l}-0.0469 \\
(0.0462)\end{array}$ & $\begin{array}{l}-0.2132 \\
(0.2409)\end{array}$ & $\begin{array}{c}1.39 \\
(0.499)\end{array}$ \\
\hline IL/US & $\begin{array}{l}-0.0467 \\
(0.0456)\end{array}$ & $\begin{array}{l}-0.0349 \\
(0.1964)\end{array}$ & $\begin{array}{c}1.14 \\
(0.567)\end{array}$ \\
\hline BF/US & $\begin{array}{l}-0.0480 \\
(0.0517)\end{array}$ & $\begin{array}{l}-0.2045 \\
(0.2461)\end{array}$ & $\begin{array}{c}1.10 \\
(0.58)\end{array}$ \\
\hline DM/US & $\begin{array}{l}-0.0428 \\
(0.0446)\end{array}$ & $\begin{array}{l}-0.1857 \\
(0.2270)\end{array}$ & $\begin{array}{c}1.21 \\
(0.546)\end{array}$ \\
\hline IP/US & $\begin{array}{l}-0.0712 \\
(0.0472)\end{array}$ & $\begin{array}{l}-0.2319 \\
(0.2940)\end{array}$ & $\begin{array}{l}2.29 \\
(0.319)\end{array}$ \\
\hline JY/DM & $\begin{array}{c}0.0274 \\
(0.0703)\end{array}$ & $\begin{array}{l}-0.6872 \\
(0.4357)\end{array}$ & $\begin{array}{c}5.20 \\
(0.074)\end{array}$ \\
\hline SF / DH & $\begin{array}{c}0.0251 \\
(0.0113)\end{array}$ & $\begin{array}{l}-0.4259^{\prime} \\
(0.1900)\end{array}$ & $\begin{array}{c}7.67^{\circ} \\
(0.022)\end{array}$ \\
\hline $\mathrm{BP} / \mathrm{OH}$ & $\begin{array}{l}-0.0195 " \\
(0.0210)\end{array}$ & $\begin{array}{l}-0.3670^{\circ} \\
(0.1474)\end{array}$ & $\begin{array}{l}105.41 \% \\
(0.000)\end{array}$ \\
\hline $\mathrm{CD} / \mathrm{OM}$ & $\begin{array}{l}-0.0260 \\
(0.0464)\end{array}$ & $\begin{array}{l}-0.2772 \\
(0.2170)\end{array}$ & $\begin{array}{c}2.09 \\
(0.353)\end{array}$ \\
\hline $\mathrm{FF} / \mathrm{OH}$ & $\begin{array}{l}-0.0149^{\circ} \\
(0.0027)\end{array}$ & $\begin{array}{c}0.3034^{*} \\
(0.0571)\end{array}$ & $\begin{array}{l}57.14^{\circ} \\
(0.000)\end{array}$ \\
\hline$D F / O M$ & $\begin{array}{l}-0.0011 \\
(0.0008)\end{array}$ & $\begin{array}{l}-0.0452 \\
(0.1483)\end{array}$ & $\begin{array}{l}3.65 \\
(0.162)\end{array}$ \\
\hline$I L / D M$ & $\begin{array}{l}-0.0124 \\
(0.0131)\end{array}$ & $\begin{array}{l}-0.2275^{\star} \\
(0.1524)\end{array}$ & $\begin{array}{l}2.23^{\circ} \\
(0.328)\end{array}$ \\
\hline $\mathrm{BF} / \mathrm{DH}$ & $\begin{array}{l}-0.0073 \\
(0.0048)\end{array}$ & $\begin{array}{c}0.1605 \\
(0.1623)\end{array}$ & $\begin{array}{c}2.27 \\
(0.321)\end{array}$ \\
\hline
\end{tabular}

The Standard errors of the coefficients are given in parentheses; * $\left(^{* *}\right)$ denotes rejection at the $5 \%(1 \%)$ level for the hypotheses that $\alpha=0$ and $\beta=0$. The Chi-square Statistic pertains to the joint hypothesis that $\alpha=0$ and $\beta=0$ (p-Values are given in parentheses). 
Table 3.4A Tests of Orthogonality: $S_{t+3}-E_{t} S_{t+3}=\alpha+\beta\left(F_{t+3}-S_{t}\right)+e_{t+3}$ January 1, 1986 through December 1, 1990: 57 Observations

\begin{tabular}{|c|c|c|c|}
\hline & $\hat{\alpha}$ & $\hat{\beta}$ & $x^{2}$ \\
\hline JY/US & $\begin{array}{l}-0.1000^{*} \\
(0.0308)\end{array}$ & $\begin{array}{r}-12.1662^{*} \\
(3.3247)\end{array}$ & $\begin{array}{l}13.41^{*} \\
(0.001)\end{array}$ \\
\hline SF/US & $\begin{array}{l}-0.0721^{*} \\
(0.0137)\end{array}$ & $\begin{array}{l}-6.7123^{*} \\
(2.8588)\end{array}$ & $\begin{array}{l}28.40^{* 1} \\
(0.000)\end{array}$ \\
\hline $\mathrm{BP} / \mathrm{US}$ & $\begin{array}{c}0.0064 \\
(0.0249)\end{array}$ & $\begin{array}{l}-3.1161 \\
(2.0217)\end{array}$ & $\begin{array}{l}5.75 \\
(0.056)\end{array}$ \\
\hline CD/US & $\begin{array}{c}0.0259^{\prime \prime} \\
(0.0064)\end{array}$ & $\begin{array}{c}1.1592 \\
(0.7640)\end{array}$ & $\begin{array}{l}24.97^{\circ} \\
(0.000)\end{array}$ \\
\hline $\mathrm{FF} / \mathrm{US}$ & $\begin{array}{l}-0.0060 \\
(0.0147)\end{array}$ & $\begin{array}{l}-6.5709^{\circ *} \\
(1.8021)\end{array}$ & $\begin{array}{l}32.05 \% \\
(0.000)\end{array}$ \\
\hline DF/US & $\begin{array}{l}-0.0671^{*} \\
(0.0147)\end{array}$ & $\begin{array}{l}-9.2252^{*} \\
(2.6906)\end{array}$ & $\begin{array}{l}22.65 " \\
(0.000)\end{array}$ \\
\hline IL/US & $\begin{array}{c}0.0655^{\circ} \\
(0.0212)\end{array}$ & $\begin{array}{l}-9.32966^{\circ} \\
(1.2599)\end{array}$ & $\begin{array}{r}149.16 \% \\
(0.000)\end{array}$ \\
\hline $\mathrm{BF} / \mathrm{US}$ & $\begin{array}{l}-0.0210 \\
(0.1380)\end{array}$ & $\begin{array}{l}-6.1255 \\
(3.5111)\end{array}$ & $\begin{array}{c}6.59^{\circ} \\
(0.037)\end{array}$ \\
\hline DM/US & $\begin{array}{l}-0.0710^{\circ} \\
(0.0174)\end{array}$ & $\begin{array}{l}-7.4329^{*} \\
(2.6525)\end{array}$ & $\begin{array}{l}16.64 \% \\
(0.000)\end{array}$ \\
\hline IP/US & $\begin{array}{l}-0.0213 \\
(0.0149)\end{array}$ & $\begin{array}{l}-0.0625 \\
(0.6744)\end{array}$ & $\begin{array}{c}2.29 \\
(0.319)\end{array}$ \\
\hline JY/DH & $\begin{array}{c}0.0013 \\
(0.0108)\end{array}$ & $\begin{array}{l}-8.3810^{\circ} \\
(2.5654)\end{array}$ & $\begin{array}{l}10.79^{*} \\
(0.004)\end{array}$ \\
\hline SF/DM & $\begin{array}{r}0.0014 \\
(0.0050)\end{array}$ & $\begin{array}{l}-2.8638 \\
(2.5477)\end{array}$ & $\begin{array}{c}2.26 \\
(0.324)\end{array}$ \\
\hline BP/DM & $\begin{array}{l}-0.0088 \\
(0.0287)\end{array}$ & $\begin{array}{c}0.8281 \\
(1.7461)\end{array}$ & $\begin{array}{c}0.32 \\
(0.853)\end{array}$ \\
\hline $\mathrm{CD} / \mathrm{DH}$ & $\begin{array}{c}0.0332 \\
(0.0382)\end{array}$ & $\begin{array}{l}-2.3138 \\
(4.2222)\end{array}$ & $\begin{array}{c}1.13 \\
(0.569)\end{array}$ \\
\hline $\mathrm{FF} / \mathrm{DH}$ & $\begin{array}{l}-0.0098^{\circ} \\
(0.0040)\end{array}$ & $\begin{array}{c}1.1625^{\circ} \\
(0.4984)\end{array}$ & $\begin{array}{l}6.32^{\circ} \\
(0.042)\end{array}$ \\
\hline$D F / D M$ & $\begin{array}{c}0.0005 \\
(0.0029)\end{array}$ & $\begin{array}{l}-1.6543 \\
(1.4219)\end{array}$ & $\begin{array}{c}5.92 \\
(0.052)\end{array}$ \\
\hline IL/DM & $\begin{array}{c}0.0328^{\circ} \\
(0.0142)\end{array}$ & $\begin{array}{l}-2.2122 " \\
(0.7337)\end{array}$ & $\begin{array}{l}17.48^{\circ \prime} \\
(0.000)\end{array}$ \\
\hline $\mathrm{BF} / \mathrm{DH}$ & $\begin{array}{l}-0.0021 \\
(0.0031)\end{array}$ & $\begin{array}{l}-0.0079 \\
(0.2369)\end{array}$ & $\begin{array}{c}1.22 \\
(0.542)\end{array}$ \\
\hline
\end{tabular}

The Standard errors of the coefficients are given in parentheses; ${ }^{*}\left({ }^{*}\right)$ denotes rejection at the $5 \%(1 \%)$ level for the hypotheses that $\alpha=0$ or $\beta=0$. The Chi-square Statistic pertains to the joint hypothesis that $\alpha=0$ and $\beta=0$ ( $\mathrm{p}$-Values are given in parentheses). 
Table 3.4B Tests of Orthogonality: $S_{t+6}-E_{t} S_{t+6}=\alpha+\beta\left({ }_{t} F_{t+6}-S_{t}\right)+e_{t+6}$ January 1, 1986 through December 1, 1990: 54 Observations

\begin{tabular}{|c|c|c|c|}
\hline & $\hat{\alpha}$ & $\hat{\beta}$ & $x^{2}$ \\
\hline JY/US & $\begin{array}{l}-0.1581 \\
(0.0473)\end{array}$ & $\begin{array}{l}-9.7537 \% \\
(2.5536)\end{array}$ & $\begin{array}{l}14.63^{*} \\
(0.000)\end{array}$ \\
\hline SF/US & $\begin{array}{l}-0.1011 \% \\
(0.0255)\end{array}$ & $\begin{array}{l}-4.1794 . \\
(1.7911)\end{array}$ & $\begin{array}{l}16.96^{\circ} \\
(0.000)\end{array}$ \\
\hline BP/US & $\begin{array}{c}0.0279 \\
(0.0430)\end{array}$ & $\begin{array}{l}-4.0545^{\circ} \\
(1.9094)\end{array}$ & $\begin{array}{l}10.28^{*} \\
(0.006)\end{array}$ \\
\hline CD/US & $\begin{array}{l}-0.0395 \% \\
(0.0107)\end{array}$ & $\begin{array}{c}0.4612 \\
(0.6967)\end{array}$ & $\begin{array}{l}34.12^{* *} \\
(0.000)\end{array}$ \\
\hline FF/US & $\begin{array}{l}-0.0180 \\
(0.0249)\end{array}$ & $\begin{array}{l}-5.0207 . \\
(1.4699)\end{array}$ & $\begin{array}{l}30.02 " 1 \\
(0.000)\end{array}$ \\
\hline DF/US & $\begin{array}{l}-0.1210^{\circ} \\
(0.0269)\end{array}$ & $\begin{array}{l}-7.8593^{\circ} \\
(2.8380)\end{array}$ & $\begin{array}{l}20.40^{* 1} \\
(0.000)\end{array}$ \\
\hline IL/US & $\begin{array}{c}0.0955 \\
(0.0307)\end{array}$ & $\begin{array}{l}-7.4155^{\circ} \\
(1.003)\end{array}$ & $\begin{array}{l}89.30^{\circ} \\
(0.000)\end{array}$ \\
\hline BF/US & $\begin{array}{l}-0.0699^{*} \\
(0.0174)\end{array}$ & $\begin{array}{l}-8.1168 . \\
(1.4254)\end{array}$ & $\begin{array}{l}38.75 * \\
(0.000)\end{array}$ \\
\hline DM/US & $\begin{array}{l}-0.1339^{\circ} \\
(0.0238)\end{array}$ & $\begin{array}{l}-7.1149^{\circ} \\
(2.3486)\end{array}$ & $\begin{array}{l}32.10^{* *} \\
(0.000)\end{array}$ \\
\hline IP/US & $\begin{array}{l}-0.0375 \\
(0.0268)\end{array}$ & $\begin{array}{l}-0.4151 \\
(0.9606)\end{array}$ & $\begin{array}{l}6.05 \\
(0.049)\end{array}$ \\
\hline$J Y / D M$ & $\begin{array}{c}0.0058 \\
(0.0159)\end{array}$ & $\begin{array}{l}-9.92233^{\circ} \\
(2.2635)\end{array}$ & $\begin{array}{l}21.06^{\prime \prime} \\
(0.000)\end{array}$ \\
\hline$S F / D M$ & $\begin{array}{c}0.0033 \\
(0.0053)\end{array}$ & $\begin{array}{l}-1.3154 * \\
(0.1927)\end{array}$ & $\begin{array}{l}67.92 * \\
(0.000)\end{array}$ \\
\hline BP/DM & $\begin{array}{l}-0.0513 \\
(0.0942)\end{array}$ & $\begin{array}{c}1.9817 \\
(3.2813)\end{array}$ & $\begin{array}{c}0.60 \\
(0.817)\end{array}$ \\
\hline$C D / D M$ & $\begin{array}{c}0.1259^{\circ} \\
(0.0488)\end{array}$ & $\begin{array}{l}-5.1209 \\
(3.3532)\end{array}$ & $\begin{array}{l}10.81 \% \\
(0.005)\end{array}$ \\
\hline FF/DM & $\begin{array}{l}-0.0153^{\circ} \\
(0.0073)\end{array}$ & $\begin{array}{c}0.8080 \\
(0.5261)\end{array}$ & $\begin{array}{l}4.46 \\
(0.107)\end{array}$ \\
\hline DF/DH & $\begin{array}{c}0.0004 \\
(0.0010)\end{array}$ & $\begin{array}{l}-0.3628 \\
(0.3093)\end{array}$ & $\begin{array}{c}1.61 \\
(0.447)\end{array}$ \\
\hline $1 \mathrm{~L} / \mathrm{DM}$ & $\begin{array}{c}0.0142 \\
(0.0114)\end{array}$ & $\begin{array}{l}-0.7235 . \\
(0.2430)\end{array}$ & $\begin{array}{l}16.54^{\circ} \\
(0.000)\end{array}$ \\
\hline$B F / D M$ & $\begin{array}{l}-0.0048 \\
(0.0048)\end{array}$ & $\begin{array}{l}-0.0466 \\
(0.3609)\end{array}$ & $\begin{array}{l}6.04^{\circ} \\
(0.049)\end{array}$ \\
\hline
\end{tabular}

The Standard errors of the coefficients are given in parentheses; ${ }^{*}\left({ }^{*}\right)$ denotes rejection at the $5 \%(1 \%)$ level for the hypotheses that $\alpha=0$ or $\beta=0$. The Chi-square Statistic pertains to the joint hypothesis that $\alpha=0$ and $\beta=0$ (p-Values are given in parentheses). 
Table 3.4C Tests of Orthogonality: $S_{t+12}-E_{t} S_{t+12}=\alpha+\beta\left(F_{t+12}-S_{t}\right)+e_{t+12}$ January 1, 1986 through December 1, 1990: 48 Observations

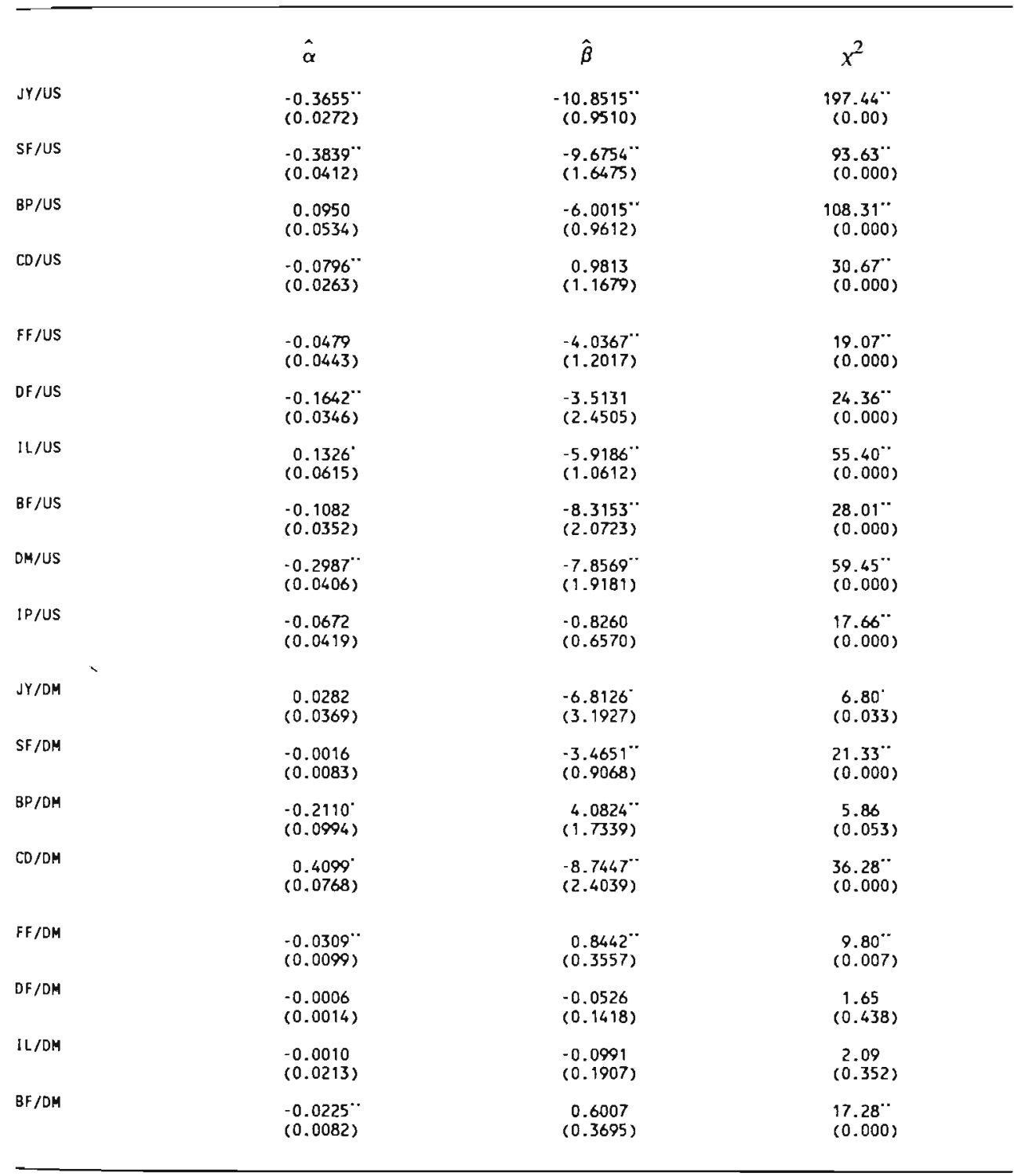

The Standard errors of the coefficients are given in parentheses; * $\left(^{* *}\right)$ denotes rejection at the $5 \%(1 \%)$ level for the hypotheses that $\alpha=0$ or $\beta=0$. The Chi-square Statistic pertains to the joint hypothesis that $\alpha=0$ and $\beta=0$ (p-Values are given in parentheses). 
expectations formation, namely that $\mathrm{E}_{\mathrm{t}} \mathrm{S}_{\mathrm{t}+\mathrm{k}}-\mathrm{S}_{\mathrm{t}}=0 .{ }^{8}$ Allen and Taylor (1990) present survey based evidence that foreign exchange dealers utilise some combination of charts and fundamentals in predicting currency movements with greater weight being given to fundamentals as the forecast horizon lengthens. The availability of survey data permits us to test directly how economic agents form their expectations of future appreciation of a currency. In this section, three alternative models of expectations formation are considered - the extrapolative, the adaptive, and the "fundamentals" against the null hypothesis that expectations are static. The central point of our analysis is to investigate the robustness of a rejection of static expectations, not to decide which of the three alternative expectations formation models is correct or even closest to the actual spot process. As in section 3, we chose not to pool across currencies; because not all respondents provide expectations for the same exchange rate, results for linear models of bilateral exchange rates relative to the Deutschmark may not be inferred from the models of exchange rates relative to the US Dollar. The extrapolative expectations model is first considered; namely, economic agents extrapolate the most recent trend into the future, formally:

$$
\Delta E S_{t+k}=\beta\left(\Delta S_{t}\right)
$$

Where $\Delta \mathrm{S}_{\mathrm{t}}$ is the most recent change in the exchange rate. If $\beta$ is greater than zero, then exchange rate expectations are said to exhibit bandwagon effects, and if $\beta$ equals zero then expectations are said to be static. In the former case a current appreciation by itself generates expectations of further future appreciation, whereas in the latter the expected depreciation is equal to zero. The existence of bandwagon exchange rate expectations has been a concern of critics of floating exchange rates in that it would render the system unstable. For example, Nurske (1944) states:

[Speculative] anticipations are apt to bring about their own realization. Anticipatory purchases of foreign exchange tend to produce or at any rate to hasten the anticipated fall in the exchange rate value of the national currency, and the actual

${ }^{8}$ For a more detailed discussion on this issue, see chapter four. 
fall may set up or strenghten expectations of a further fall... Exchange rates under such circumstances are bound to become highly unstable, and the influence of psychological factors may at times be overwhelming. [1944, p. 118]

Nurske's view was challenged by Friedman (1953), who argued that speculation would be stabilizing. By defining "speculation" as the buying and selling of foreign exchange in response to non-zero expected exchange rate changes, we can interpret a finding of $\beta>0$ (bandwagon expectations) as implying that speculation is destabilizing and a finding of $\beta<0$ (distributed lag expectations) as implying that speculation is stabilizing.

The the following equation was fitted for each currency and for each forecast horizon $(k=3,6$, and 12$):^{9}$

$$
E_{t} S_{t+k}-S_{t}=\alpha+\beta\left(S_{t}-S_{t-1}\right)+\varepsilon_{t}
$$

The results of fitting equation (8) for each currency and for all forecast horizons are reported in Table 3.5. We find that the sign of the $\beta$-coefficient is negative in all regressions. Thus, past exchange rate depreciations are expected to be reversed in the future, as implied by stabilizing expectations models. Interpreting the regression coefficient for the Japanese Yen/US Dollar exchange rate at the three month horizon, a current depreciation of 10 per cent in the Yen implies an expected appreciation over the next three months of 3 per cent. This result is largely consistent with Frankel and Froot (1987a, 1987b, and 1990), although the absolute size of our coefficient is higher then theirs. ${ }^{10}$ The results for the EMS exchange rates relative to the Deutschmark indicate that, with the exceptions of the 6 months expectations

9 In this section, where the expected depreciation is on the left-hand side of the regressions, forecast horizons longer than the observational frequency do not themselves imply that the error term is serially correlated, since expectations are formed using only contemporaneous and past information. Therefore, equations 8 and 10 were estimated using the standard OLS procedure.

10 The comparison in the text refers to results obtained for survey expectations of the same horizon. It should be noted that for short horizon expectations (one week and one month) Frankel and Froot (1987b and 1990) and MacDonald and Torrance (1988) obtain parameter estimates suggesting destabilizing expectations models. 
for the French Franc and 12 month expectations for the Belgian Franc, the slope coefficients are insignificant.

Adaptive expectations models were subsequently considered; namely, the expected future spot rate is formed as a weighted average of the current spot rate and the lagged expected spot rate, or

$$
E S_{t+k}=(1-b) S_{t}+b E_{t-k} S_{t}
$$

Alternatively, one can view the expected depreciation as a function of past forecast errors, and then the following equation may be fitted:

$$
E S_{t+k}-S_{t}=\alpha+\beta\left(S_{t}-E_{t-k} S_{t}\right)+\varepsilon_{t}
$$

Equation (10) corresponds to equation (9) if we set $\alpha=0$ and $\beta=-b$. The results of fitting the above equation for each currency for all forecast horizons are reported in Table 3.6. Significantly negative slope coefficients are obtained for nearly all currencies relative to the US Dollar and for some non-EMS currencies relative to the Deutschmark. Once again, models for EMS currencies relative to the Deutschmark did not yield significant slope coefficients. Interpreting the regression coefficient for the Japanese Yen/US Dollar exchange rate at the three month horizon, an unexpected depreciation of 10 per cent in the Yen implies an expected appreciation over the next three months of about 1 per cent. The results of Tables 3.5 and 3.6 suggest that long-term expectations (3, 6, and 12 months ahead) feature a strongly positive weight on the lagged spot rate (distributed lag expectations) or on the lagged expected spot rate (adaptive expectations) rather than complete weight on the contemporaneous spot rate, and in this sense are stabilizing. These results are similar to those obtained by Frankel and Froot (1987a, 1987b). ${ }^{11}$

Finally, we considered expectations models which incorporate agents' views regarding long-run fundamentals. In the Dornbusch (1976a) overshoot-

11 Frankel and Froot (1987b) and MacDonald and Torrance (1988) obtain for short term expectations (one week and one month ahead) a regression coefficient that is opposite in sign to that of long term expectations (3,6, and 12 months ahead). 
ing model, a monetary shock induces the exchange rate to jump and subsequently mean-revert to its long run PPP value. Mussa (1984) has extended this model to allow for a time-varying long-run equilibrium value of the exchange rate that is consistent with desired steady-state asset holdings. Thus a distinction is drawn between the response of nominal and real exchange rates to "equilibrium" and "disequilibrium" disturbances. He shows that expected exchange rate changes are a function of changes in the long-run equilibrium value of the exchange rate and of the parameters which define differing speeds of adjustment in the goods market and asset markets. Frankel and Froot (1987a) fitted models of expected exchange rate changes using different proxies for the long value of the exchange rate. An alternative approach is to assume that the twelve month ahead expectation serves as a relatively good proxy for the long run value of the exchange rate. Thus, we fitted the following model for the 3 month ahead expected exchange rate: 12

$$
E S_{t+3}-S_{t}=\alpha+\beta\left(E S_{t+12}-E_{t-1} S_{t+11}\right)+\varepsilon_{t}
$$

Equation (11) estimates the extent to which revisions in long run fundamentals are reflected in short term expectations. The results of fitting (11) to our survey data are reported in Table 3.7. The coefficient estimates are all significant at the one per cent level. We note that for EMS exchange rates relative to the Deutschmark, we now obtain positive coefficients. This suggests that EMS exchange rate expectations "undershoot" their long run values. If long run EMS exchange rates (proxied by 12 month ahead exchange rate forecasts) decline, then exchange rates are expected to depreciate over the "short term" (the next three months) by a smaller amount. On the other hand, non-EMS currencies relative to the US Dollar and relative to the Deutschmark generally behave differently, as reflected in the negative slope coefficients; a positive innovation in long run fundamentals is associated with a negative change in short run ( 3 month) expectations, suggesting subsequent

12 Because ordinary least squares estimates would be inconsistent in the context of equation (11), we implemented the instrumental variables estimation technique outlined in Hansen (1982). Instruments used were a constant term and lagged exchange rate returns. 
Table 3.5 Extrapolative Expectations: $E_{\mathrm{q}} S_{t+k}-S_{t}=\alpha+\beta\left(S_{t}-S_{t-1}\right)+e_{t}$

January 1, 1986 through November 1, 1990: 59 Observations

\begin{tabular}{|c|c|c|c|c|c|c|}
\hline & \multicolumn{2}{|c|}{3 Months } & \multicolumn{2}{|c|}{6 Months } & \multicolumn{2}{|c|}{12 Months } \\
\hline & $\hat{\alpha}$ & $\hat{\beta}$ & $\hat{\alpha}$ & $\hat{\beta}$ & $\hat{\alpha}$ & $\hat{\beta}$ \\
\hline JY/US & $\begin{array}{l}-0.0114 \% \\
(0.0021)\end{array}$ & $\begin{array}{l}-0.3019^{\circ} \\
(0.0573)\end{array}$ & $\begin{array}{l}-0.0153^{\circ} \\
(0.0039)\end{array}$ & $\begin{array}{l}-0.4649^{\circ} \\
(0.1053)\end{array}$ & $\begin{array}{l}-0.0067 \\
(0.0039)\end{array}$ & $\begin{array}{l}-0.4982 \\
(0.1038)\end{array}$ \\
\hline SF/US & $\begin{array}{l}-0.0118^{*} \\
(0.0020)\end{array}$ & $\begin{array}{l}-0.3951 "= \\
(0.0544)\end{array}$ & $\begin{array}{c}0.0095 \% \\
(0.0034)\end{array}$ & $\begin{array}{l}-0.5693 * \\
(0.0922)\end{array}$ & $\begin{array}{c}0.0030 \\
(0.0049)\end{array}$ & $\begin{array}{l}-0.64311^{\circ} \\
(0.1305)\end{array}$ \\
\hline BP/US & $\begin{array}{c}0.0013 \\
(0.0020)\end{array}$ & $\begin{array}{l}-0.3549 . \\
(0.0579)\end{array}$ & $\begin{array}{c}0.0101 \cdots \\
(0.0023)\end{array}$ & $\begin{array}{l}-0.4373 \\
(0.0674)\end{array}$ & $\begin{array}{l}-0.0272 \\
(0.0028)\end{array}$ & $\begin{array}{l}-0.5049^{n} \\
(0.0804)\end{array}$ \\
\hline CD/US & $\begin{array}{c}0.0049^{\circ} \\
(0.0016)\end{array}$ & $\begin{array}{l}-0.2312 \\
(0.1931)\end{array}$ & $\begin{array}{c}0.0091^{\circ} \\
(0.0017)\end{array}$ & $\begin{array}{l}-0.2757 \\
(0.1385)\end{array}$ & $\begin{array}{c}0.0151 \% \\
(0.0017)\end{array}$ & $\begin{array}{l}-0.2507 \\
(0.1431)\end{array}$ \\
\hline FF/US & $\begin{array}{l}-0.0059^{\circ} \\
(0.0020)\end{array}$ & $\begin{array}{l}-0.4036 \% \\
(0.0699)\end{array}$ & $\begin{array}{l}-0.0013 \\
(0.0026)\end{array}$ & $\begin{array}{l}-0.5208^{*} \\
(0.0885)\end{array}$ & $\begin{array}{c}0.0166 \\
(0.0044)\end{array}$ & $\begin{array}{l}-0.6199^{\circ} \\
(0.1503)\end{array}$ \\
\hline DF/US & $\begin{array}{l}-0.0109^{*} \\
(0.0022)\end{array}$ & $\begin{array}{l}-0.6391^{\circ} \\
(0.0707)\end{array}$ & $\begin{array}{l}-0.0115 \% \\
(-0.0029)\end{array}$ & $\begin{array}{l}-0.5353^{*} \\
(0.0902)\end{array}$ & $\begin{array}{c}0.0016 \\
(0.0046)\end{array}$ & $\begin{array}{l}-0.6097^{\prime} \\
(0.1446)\end{array}$ \\
\hline IL/US & $\begin{array}{l}-0.0029 \\
(0.0034)\end{array}$ & $\begin{array}{l}-0.4756^{\circ} \\
(0.1234)\end{array}$ & $\begin{array}{c}0.0040 \\
(0.0031)\end{array}$ & $\begin{array}{l}-0.6570^{\circ} \\
(0.1109)\end{array}$ & $\begin{array}{c}0.0216 \% \\
(0.0043)\end{array}$ & $\begin{array}{l}-0.6744^{\circ} \\
(0.1531)\end{array}$ \\
\hline BF/US & $\begin{array}{l}-0.0097^{*} \\
(0.0026)\end{array}$ & $\begin{array}{l}-0.4505^{\circ} \\
(0.0827)\end{array}$ & $\begin{array}{l}-0.0092 * \\
(0.0035)\end{array}$ & $\begin{array}{l}-0.6401 \% \\
(0.1115)\end{array}$ & $\begin{array}{c}0.0057 \\
(0.0050)\end{array}$ & $\begin{array}{l}-0.7447^{\circ} \\
(0.1591)\end{array}$ \\
\hline DH/US & $\begin{array}{l}-0.01251 " \\
(0.0021)\end{array}$ & $\begin{array}{l}-0.3873 " . \\
(0.0626)\end{array}$ & $\begin{array}{l}-0.0106^{\circ} \\
(0.0030)\end{array}$ & $\begin{array}{l}-0.4971 " . \\
(0.0896)\end{array}$ & $\begin{array}{c}0.0017 \\
(0.0048)\end{array}$ & $\begin{array}{l}-0.5653^{\circ} \\
(0.1428)\end{array}$ \\
\hline IPIUS & $\begin{array}{c}0.0124= \\
(0.0040)\end{array}$ & $\begin{array}{l}-0.5371 " . \\
(0.1183)\end{array}$ & $\begin{array}{l}-0.0068 \\
(0.0045)\end{array}$ & $\begin{array}{l}-0.6548 \% \\
(0.1346)\end{array}$ & $\begin{array}{c}0.0165 \\
(0.0055)\end{array}$ & $\begin{array}{l}-0.6300 \% \\
(0.1652)\end{array}$ \\
\hline $\mathrm{JY} / \mathrm{DH}$ & $\begin{array}{l}-0.0016 \\
(0.0013)\end{array}$ & $\begin{array}{l}-0.2762^{*} \\
(0.0510)\end{array}$ & $\begin{array}{l}-0.0074 " \\
(0.0034)\end{array}$ & $\begin{array}{l}-0.4730^{\circ} \\
(0.1307)\end{array}$ & $\begin{array}{l}-0.0104 \% \\
(0.0030)\end{array}$ & $\begin{array}{l}-0.3797^{\circ} \\
(0.1155)\end{array}$ \\
\hline SF/DH & $\begin{array}{l}-0.0008 \\
(0.0011)\end{array}$ & $\begin{array}{l}-0.2432^{*} \\
(0.0704)\end{array}$ & $\begin{array}{l}-0.0007 \\
(0.0012)\end{array}$ & $\begin{array}{l}-0.3543^{\circ} \\
(0.0804)\end{array}$ & $\begin{array}{l}-0.0017 \\
(0.0014)\end{array}$ & $\begin{array}{l}-0.3051 . \\
(0.0958)\end{array}$ \\
\hline BP/OH & $\begin{array}{c}0.0137^{\circ} \\
(0.0021)\end{array}$ & $\begin{array}{l}-0.3330^{\circ} \\
(0.0916)\end{array}$ & $\begin{array}{c}0.017^{*} \\
(0.0017)\end{array}$ & $\begin{array}{l}-0.1944^{\circ} \\
(0.0744)\end{array}$ & $\begin{array}{c}0.0217^{*} \\
(0.0028)\end{array}$ & $\begin{array}{l}-0.1138 \\
(0.2109)\end{array}$ \\
\hline $\mathrm{CD} / \mathrm{DH}$ & $\begin{array}{c}0.0142 \% \\
(0.0028)\end{array}$ & $\begin{array}{l}-0.3748^{\circ} \\
(0.0833)\end{array}$ & $\begin{array}{r}0.0144 \% \\
(0.0037)\end{array}$ & $\begin{array}{l}-0.4351 \% \\
(0.1090)\end{array}$ & $\begin{array}{c}0.0085^{\circ} \\
(0.0043)\end{array}$ & $\begin{array}{l}-0.6558 " \\
(0.1282)\end{array}$ \\
\hline FF/OH & $\begin{array}{c}0.0062 * \\
(0.0008)\end{array}$ & $\begin{array}{l}-0.1101 \\
(0.1160)\end{array}$ & $\begin{array}{c}0.0109 " * \\
(0.0015)\end{array}$ & $\begin{array}{l}-0.4678^{\circ} \\
(0.2164)\end{array}$ & $\begin{array}{c}0.0164 \% \\
(0.0017)\end{array}$ & $\begin{array}{l}-0.2058 \\
(0.2478)\end{array}$ \\
\hline$D F / D H$ & $\begin{array}{c}0.0032 \% \\
(0.0011)\end{array}$ & $\begin{array}{l}-0.4376 \\
(0.4593)\end{array}$ & $\begin{array}{c}0.0007 \\
(0.0008)\end{array}$ & $\begin{array}{l}-0.3276 \\
(0.3133)\end{array}$ & $\begin{array}{c}0.0000 \\
(0.0011)\end{array}$ & $\begin{array}{l}-0.2609 \\
(0.4567)\end{array}$ \\
\hline IL/OM & $\begin{array}{c}0.0110^{\circ} \\
(0.0028)\end{array}$ & $\begin{array}{l}-0.7260 \\
(0.3862)\end{array}$ & $\begin{array}{c}0.0186 \\
(0.0020)\end{array}$ & $\begin{array}{l}-0.3619 \\
(0.2751)\end{array}$ & $\begin{array}{c}0.0239^{\circ} \\
(0.0027)\end{array}$ & $\begin{array}{l}-0.6602 \\
(0.3730)\end{array}$ \\
\hline $\mathrm{BF} / \mathrm{OM}$ & $\begin{array}{c}0.0035 \% \\
(0.0015)\end{array}$ & $\begin{array}{l}-0.3667 \\
(0.3146)\end{array}$ & $\begin{array}{c}0.0068 * \\
(0.0015)\end{array}$ & $\begin{array}{l}-0.0356 \\
(0.3231)\end{array}$ & $\begin{array}{c}0.0087^{\circ} \\
(0.0019)\end{array}$ & $\begin{array}{l}-0.7205^{\circ} \\
(0.3993)\end{array}$ \\
\hline
\end{tabular}

Standard errors are given in parentheses

* = significant at the $5 \%$ level

** = significant at the $1 \%$ level 
Table 3.6 Adaptive Expectations: $E_{t} S_{t+k}-S_{t}=\alpha+\beta\left(S_{t}-E_{t-k} S_{t}\right)+e_{t}$

January 1, 1986 through December 1, 1990: 57, 54, and 48 Observations

\begin{tabular}{|c|c|c|c|c|c|c|}
\hline & \multicolumn{2}{|c|}{3 Months } & \multicolumn{2}{|c|}{6 Months } & \multicolumn{2}{|c|}{12 Months } \\
\hline & $\hat{\alpha}$ & $\hat{\beta}$ & $\hat{\alpha}$ & $\hat{\beta}$ & $\hat{\alpha}$ & $\hat{\beta}$ \\
\hline JY/US & $\begin{array}{l}-0.0122 * \\
(0.0022)\end{array}$ & $\begin{array}{l}-0.1002 " \\
(0.0268)\end{array}$ & $\begin{array}{l}-0.0199^{\circ} \\
(0.0044)\end{array}$ & $\begin{array}{l}-0.1289^{\circ} \\
(0.0391)\end{array}$ & $\begin{array}{l}-0.0269 \\
(0.0053)\end{array}$ & $\begin{array}{l}-0.1224^{\circ} \\
(0.0319)\end{array}$ \\
\hline SF/US & $\begin{array}{l}-0.0130 \% \\
(0.0025)\end{array}$ & $\begin{array}{l}-0.1103 * \\
(0.0294)\end{array}$ & $\begin{array}{l}-0.0161^{*} \\
(0.0035)\end{array}$ & $\begin{array}{l}-0.1423 * \\
(0.0295)\end{array}$ & $\begin{array}{l}-0.0208^{\circ} \\
(0.0047)\end{array}$ & $\begin{array}{l}-0.1359^{\circ} \\
(0.0261)\end{array}$ \\
\hline BP/US & $\begin{array}{c}0.0017 \\
(0.0028)\end{array}$ & $\begin{array}{l}-0.0531 \\
(0.0380)\end{array}$ & $\begin{array}{c}0.0089^{\circ} \\
(0.0032)\end{array}$ & $\begin{array}{c}0.0237 \\
(0.0379)\end{array}$ & $\begin{array}{c}0.0147^{\circ} \\
(0.0045)\end{array}$ & $\begin{array}{l}-0.0508 \\
(0.0329)\end{array}$ \\
\hline CD/US & $\begin{array}{c}0.0069^{\circ} \\
(0.0021)\end{array}$ & $\begin{array}{c}0.0662 \\
(0.0734)\end{array}$ & $\begin{array}{c}0.0127^{\circ} \\
(0.0030)\end{array}$ & $\begin{array}{c}0.0626 \\
(0.0678)\end{array}$ & $\begin{array}{c}0.0215 \% \\
(0.0038)\end{array}$ & $\begin{array}{c}0.1004^{\circ} \\
(0.0492)\end{array}$ \\
\hline FF/US & $\begin{array}{l}-0.0079 " . \\
(0.0022)\end{array}$ & $\begin{array}{l}-0.1186^{\prime \prime} \\
(0.0325)\end{array}$ & $\begin{array}{l}-0.0073 . \\
(0.0030)\end{array}$ & $\begin{array}{l}-0.1439^{\circ} \\
(0.0319)\end{array}$ & $\begin{array}{l}-0.0067 \\
(0.0044)\end{array}$ & $\begin{array}{l}-0.1994^{\circ} \\
(0.0315)\end{array}$ \\
\hline DF/US & $\begin{array}{l}-0.0118^{\circ} \\
(0.0027)\end{array}$ & $\begin{array}{l}-0.0959^{\circ} \\
(0.0342)\end{array}$ & $\begin{array}{c}-0.0159^{\circ} \\
(0.0036)\end{array}$ & $\begin{array}{l}-0.1217^{\circ} \\
(0.0324)\end{array}$ & $\begin{array}{l}-0.0175 \\
(0.0053)\end{array}$ & $\begin{array}{l}-0.1339^{\circ} \\
(0.0329)\end{array}$ \\
\hline IL/US & $\begin{array}{l}-0.0069^{\circ} \\
(0.0031)\end{array}$ & $\begin{array}{l}-0.1171^{\prime} \\
(0.0399)\end{array}$ & $\begin{array}{l}-0.0034 \\
(0.0031)\end{array}$ & $\begin{array}{l}-0.1195^{\circ} \\
(0.0299)\end{array}$ & $\begin{array}{l}-0.0002 \\
(0.0047)\end{array}$ & $\begin{array}{l}-0.1295^{\circ} \\
(0.0307)\end{array}$ \\
\hline $\mathrm{BF} / \mathrm{US}$ & $\begin{array}{l}-0.0124^{\circ} \\
(0.0024)\end{array}$ & $\begin{array}{l}-0.1466 " \\
(0.0302)\end{array}$ & $\begin{array}{l}-0.0161 " . \\
(0.0035)\end{array}$ & $\begin{array}{l}-0.1378 \% \\
(0.0317)\end{array}$ & $\begin{array}{l}-0.0169 \\
(0.0054)\end{array}$ & $\begin{array}{l}-0.1354 \\
(0.0325)\end{array}$ \\
\hline DM/US & $\begin{array}{l}-0.0133^{*} \\
(0.0025)\end{array}$ & $\begin{array}{l}-0.1090 \\
(0.0322)\end{array}$ & $\begin{array}{l}-0.0162^{\circ} \\
(0.0033)\end{array}$ & $\begin{array}{l}-0.1390^{\circ} \\
(0.0309)\end{array}$ & $\begin{array}{l}-0.0217^{\prime} \\
(0.0045)\end{array}$ & $\begin{array}{l}-0.1514^{\circ} \\
(0.0279)\end{array}$ \\
\hline IP/US & $\begin{array}{l}-0.0113 \\
(0.0037)\end{array}$ & $\begin{array}{l}-0.1804 \\
(0.0519)\end{array}$ & $\begin{array}{l}-0.0063 \\
(0.0051)\end{array}$ & $\begin{array}{l}-0.0904 \\
(0.0585)\end{array}$ & $\begin{array}{c}0.0125 \\
(0.0076)\end{array}$ & $\begin{array}{l}-0.1164 \\
(0.0724)\end{array}$ \\
\hline JY/DH & $\begin{array}{l}-0.0012 \\
(0.0016)\end{array}$ & $\begin{array}{l}-0.0964 \% \\
(0.0257)\end{array}$ & $\begin{array}{l}-0.0051 \\
(0.0035)\end{array}$ & $\begin{array}{l}-0.2307 \\
(0.0398)\end{array}$ & $\begin{array}{l}-0.0099 \\
(0.0028)\end{array}$ & $\begin{array}{l}-0.1360^{\circ} \\
(0.0397)\end{array}$ \\
\hline SF/OH & $\begin{array}{l}-0.0001 \\
(0.0009)\end{array}$ & $\begin{array}{l}-0.1730 \\
(0.0373)\end{array}$ & $\begin{array}{l}-0.0010 \\
(0.0015)\end{array}$ & $\begin{array}{l}-0.0321 \\
(0.0623)\end{array}$ & $\begin{array}{l}-0.0031 \\
(0.0017)\end{array}$ & $\begin{array}{l}-0.0622 \\
(0.0549)\end{array}$ \\
\hline $\mathrm{BP} / \mathrm{DM}$ & $\begin{array}{c}0.0130^{\circ} \\
(0.0025)\end{array}$ & $\begin{array}{l}-0.0333 \\
(0.0460)\end{array}$ & $\begin{array}{r}0.0175 \\
(0.0021)\end{array}$ & $\begin{array}{l}-0.0420 \\
(0.0271)\end{array}$ & $\begin{array}{c}0.0265^{\circ} \\
(0.0025)\end{array}$ & $\begin{array}{l}-0.1653^{\circ} \\
(0.0278)\end{array}$ \\
\hline $\mathrm{CD} / \mathrm{DH}$ & $\begin{array}{c}0.0144^{\circ} \\
(0.0031)\end{array}$ & $\begin{array}{l}-0.1287^{\circ} \\
(0.0389)\end{array}$ & $\begin{array}{c}0.0182^{*} \\
(0.0039)\end{array}$ & $\begin{array}{l}-0.1378 \\
(0.0336)\end{array}$ & $\begin{array}{c}0.0178 . \\
(0.0056)\end{array}$ & $\begin{array}{l}-0.1086 \\
(0.0361)\end{array}$ \\
\hline FF/DM & $\begin{array}{r}0.0057^{\circ} \\
(0.0007)\end{array}$ & $\begin{array}{l}-0.0201 \\
(0.0535)\end{array}$ & $\begin{array}{c}0.0109^{\circ} \\
(0.0015)\end{array}$ & $\begin{array}{l}-0.0272 \\
(0.0727)\end{array}$ & $\begin{array}{c}0.0174 \% \\
(0.0017)\end{array}$ & $\begin{array}{c}0.0846 \\
(0.0581)\end{array}$ \\
\hline$D F / D M$ & $\begin{array}{c}0.0029^{\prime \prime} \\
(0.0012)\end{array}$ & $\begin{array}{c}0.1013 \\
(0.1309)\end{array}$ & $\begin{array}{c}0.0011 \\
(0.0008)\end{array}$ & $\begin{array}{l}-0.0432 \\
(0.1237)\end{array}$ & $\begin{array}{c}0.0013 \\
(0.0013)\end{array}$ & $\begin{array}{l}-0.1384 \\
(0.1795)\end{array}$ \\
\hline IL/DH & $\begin{array}{c}0.007 n^{*} \\
(0.0025)\end{array}$ & $\begin{array}{l}-0.0464 \\
(0.1282)\end{array}$ & $\begin{array}{c}0.0177^{\circ} \\
(0.0017)\end{array}$ & $\begin{array}{l}-0.0132 \\
(0.0654)\end{array}$ & $\begin{array}{c}0.0233^{\circ} \\
(0.0022)\end{array}$ & $\begin{array}{c}0.0219 \\
(0.0684)\end{array}$ \\
\hline$B F / D M$ & $\begin{array}{c}0.00311^{\circ} \\
(0.0015)\end{array}$ & $\begin{array}{l}-0.1960 \\
(0.1546)\end{array}$ & $\begin{array}{c}0.0048 * \\
(0.0014)\end{array}$ & $\begin{array}{l}-0.0544 \\
(0.1304)\end{array}$ & $\begin{array}{c}0.0078 * \\
(0.0018)\end{array}$ & $\begin{array}{c}0.0684 \\
(0.1965)\end{array}$ \\
\hline
\end{tabular}

Standard errors are given in parentheses

* = significant at the $5 \%$ level

** = significant at the $1 \%$ level 
Table 3.7 Long Run Expectations: $\mathrm{E}_{\mathrm{q}} \mathrm{S}_{\mathrm{t}+3}-\mathrm{S}_{\mathrm{t}}=\alpha+\beta\left(\mathrm{E}_{\mathrm{t}} \mathrm{S}_{\mathrm{t}+12}-\mathrm{E}_{\mathrm{t}-1} \mathrm{~S}_{\mathrm{t}+11}\right)+\mathrm{e}_{\mathrm{t}}$ January 1, 1986 through November 1, 1990: 59 Observations

\begin{tabular}{|c|c|c|}
\hline & $\hat{\alpha}$ & $\hat{\beta}$ \\
\hline JY/US & $\begin{array}{l}-0.0123 \\
(0.0000)\end{array}$ & $\begin{array}{c}0.0296 \\
(0.0028)\end{array}$ \\
\hline SF/US & $\begin{array}{l}-0.0125^{\prime \prime} \\
(0.000)\end{array}$ & $\begin{array}{l}-0.2009^{\circ} \\
(0.0021)\end{array}$ \\
\hline$B P / U S$ & $\begin{array}{c}0.0022 \% \\
(0.0000)\end{array}$ & $\begin{array}{c}0.0841 \% \\
(0.0036)\end{array}$ \\
\hline CD/US & $\begin{array}{c}0.0072 " * \\
(0.0000)\end{array}$ & $\begin{array}{c}0.7645^{\circ} \\
(0.0034)\end{array}$ \\
\hline FF/US & $\begin{array}{l}-0.0083 \\
(0.0000)\end{array}$ & $\begin{array}{l}-0.3310^{\circ} \\
(0.0041)\end{array}$ \\
\hline DF/US & $\begin{array}{l}-0.0104 \\
(0.0001)\end{array}$ & $\begin{array}{l}-0.0695^{*} \\
(0.0026)\end{array}$ \\
\hline IL/US & $\begin{array}{l}-0.0045^{\circ} \\
(0.0001)\end{array}$ & $\begin{array}{l}-0.1698 . \\
(0.0038)\end{array}$ \\
\hline BF/US & $\begin{array}{l}-0.0142^{\circ} \\
(0.0000)\end{array}$ & $\begin{array}{l}-0.2412^{*} \\
(0.0021)\end{array}$ \\
\hline DM/US & $\begin{array}{l}-0.0129 \\
(0.0001)\end{array}$ & $\begin{array}{l}-0.1423 \\
(0.0033)\end{array}$ \\
\hline IP/US & $\begin{array}{l}-0.0150^{\circ} \\
(0.0001)\end{array}$ & $\begin{array}{l}-0.3812 " \\
(0.0071)\end{array}$ \\
\hline JY/DM & $\begin{array}{l}-0.0008 . " \\
(0.0000)\end{array}$ & $\begin{array}{l}-0.2025 . \\
(0.0014)\end{array}$ \\
\hline SF /DH & $\begin{array}{l}-0.0018 . \\
(0.0000)\end{array}$ & $\begin{array}{l}-0.3545^{\circ} \\
(0.0012)\end{array}$ \\
\hline BP/DH & $\begin{array}{r}0.0106 \\
(0.0000)\end{array}$ & $\begin{array}{l}-0.0946 . \\
(0.0021)\end{array}$ \\
\hline $\mathrm{CO} / \mathrm{DH}$ & $\begin{array}{c}0.0156 \\
(0.0001)\end{array}$ & $\begin{array}{l}-0.4229^{\circ} \\
(0.0107)\end{array}$ \\
\hline FF/DM & $\begin{array}{r}0.0054^{\circ} \\
(0.0000)\end{array}$ & $\begin{array}{c}0.1046 \cdot 0 \\
(0.0007)\end{array}$ \\
\hline$D F / D M$ & $\begin{array}{c}0.0030^{\circ} \\
(0.0000)\end{array}$ & $\begin{array}{c}0.3866 \% \\
(0.0022)\end{array}$ \\
\hline IL/DM & $\begin{array}{c}0.0075^{*} \\
(0.0000)\end{array}$ & $\begin{array}{c}0.9949^{\circ} \\
(0.0262)\end{array}$ \\
\hline $\mathrm{BF} / \mathrm{OM}$ & $\begin{array}{c}0.0017^{-} \\
(0.0000)\end{array}$ & $\begin{array}{r}0.0079^{*} \\
(0.0010)\end{array}$ \\
\hline
\end{tabular}

Standard errors are given in parentheses

* = significant at the $5 \%$ level

** = significant at the $1 \%$ level 
"overshooting". 13

\subsection{Conclusions}

This chapter has extended the analyzes of Frankel and Froot (1987a), Dominguez (1986), and MacDonald and Torrance (1990) to consider a new data set of exchange rate expectations over the 1985-1990 period which allows us to focus on differences between EMS and US Dollar exchange rate expectations. The evidence presented suggests that Deutschmark and US Dollar exchange rate forecasts are biased predictors of future exchange rates. Indeed, the exchange rate forecasts do not improve the contemporaneous spot exchange rate in predicting future spot exchange rate changes. We corroborate the finding that exchange rate forecasts are not rational and that agents do not use all available information in an efficient manner; this finding applies to the post 1986 period, thus questioning the assertion of Frankel and Froot (1987a) that "the nature of the rejection of rational expectations strongly depends on the sample period".

We reject the hypothesis that non-EMS exchange rate expectations are static. Extrapolative and adaptive expectations formation mechanisms describe non-EMS exchange rate expectations to a certain extent and suggest stabilizing expectations models. On the other hand, extrapolative and adaptive expectations formation models for EMS currencies did not yield significant slope coefficients, thus supporting the hypothesis of static expectations. EMS exchange rate forecasts seem to follow their long run fundamentals more closely and would suggest that agents believe that EMS currencies "undershoot" their long-run equilibrium values.

In the current chapter, we have focused our attention on characterizing the formation of exchange rate expectations at various forecast horizons $(3,6$, and 12 months) for a set of US Dollar and Deutschmark exchange rates. Our analysis is extended in chapter four which examines the efficiency of the foreign exchange market and where we use forward rates to impute exchange

13 We investigate whether changes in exchange rate expectations (not actual levels) overshoot their long run values in the short term. Our concept of overshooting is linked to work by Mussa (1984), who shows that expected exchange rate changes are a function of changes in the long-run equilibrium value of the exchange rate. 
rate risk premia to assess whether the rejection of the forward rate as an unbiased predictor of the spot exchange rate is predominantly attributable to irrationality on the part of economic agents (as evidenced in this chapter) or significant variation in risk premia. 


\section{Chapter four}

\section{The Biasedness of Foreign Exchange Rates: Irrationality or Risk Premia?}

\subsection{Introduction}

The period since the abandonment of the Bretton Woods fixed exchange rate arrangement in the early 1970's has generated a growing body of empirical literature on the informational efficiency of financial markets - see Fama (1991) and Hodrick (1987), for instance. Following the methodology of Fama (1970) on the efficiency of stock markets, many economist have applied empirical tests whether foreign exchange rates always "fully reflect" all available information. One approach to testing exchange rates' informational efficiency, advocated by Fama (1970), argues that efficiency requires that actual prices (or rates of return) follow a "fair game" process relative to the expected equilibrium prices (or rates of return). Under such circumstances no investor or speculator can earn excess profits by exploiting publically available information, where excess profit is defined relative to an expected equilibrium rate of return. This does not imply that equilibrium expected returns on assets are all the same, though, since assets may differ in their degree of riskiness. With respect to testing foreign exchange market efficiency, we therefore first require a model of equilibrium exchange rates and then derive expectations which are model-consistent or rational, conditional on the equilibrium model specified. Tests of market efficiency in the foreign exchange market are necessarily joint tests of an equilibrium model of expected returns and rational processing of available information by investors. Conclusions concerning the efficiency of foreign exchange markets, therefore, will not be invariant to the choice of the equilibrium exchange rates.

One of the well established empirical regularities in the international 
financial economics literature is the finding that the forward discount is a biased predictor of the future change in the exchange rate - see the surveys on the efficiency of the foreign exchange market by Hodrick (1987) and Levich (1985). The rejection of forward market efficiency may be attributable to the irrationality of market participants [as suggested by Bilson (1981), Cumby and Obstfeld (1984) and Longworth (1981)], or to the existence of time-varying risk premia [as suggested by Fama (1984), Hodrick and Srivastava (1984), Hsieh (1984) and Wolff (1987a)], or to some combination of both of these phenomena. The policy implications that follow from favoring either one of these possible explanations are noteworthy. Thus, as suggested by Frankel (1986), Branson et al (1978) and Rogoff (1984), if domestic and foreign assets are imperfect substitutes and there exists a significant time-varying risk premium, then sterilized intervention may be an effective policy tool. Similarly, the existence of irrationality on the part of economic agents suggests that policies of "leaning against the wind" could have a stabilizing impact on exchange rate movements.

The debate regarding the relative size and variability of the exchange risk premium is a long standing one. Fama (1984) developed a methodology to identify and measure premia in the pricing of forward foreign exchange, which assesses empirically the relative variability of the risk premium and forward rate forecast errors over the period 1973-1982. Fama (1984) concludes on the relative importance of risk premium and forecast errors: "Conditional on the hypothesis that the forward exchange rate is efficient or rational, we find reliable evidence that both components of forward rate - the expected future spot rate and the risk premium - vary through time." His findings indicate that most of the variation in forward rates is attributable to variation in risk premia, the variance of the risk premium is greater than the variance of the expected change in the spot exchange rate, and the premium and expected future spot rate components of forwards rates are negatively correlated. In his review of this issue, Frankel (1988) notes that no satisfactory mean variance optimizing model has as yet succeeded in explaining the postulated temporal behavior of the risk premium that follows from the forward discount. Frankel and Froot (1987) and others have recently examined exchange rate survey data. ${ }^{l}$ Overall the findings overwhelmingly favor

1 The seminal work of Frankel and Froot has stimulated wide interest in further analysis of exchange rate expectations via survey data - see for instance Dominguez. (1986), Ito (1990), MacDonald (1990), MacDonald and Torrance (1989), Tagaki (1991) 
the conclusion that economic agents exhibit irrational behavior. Frankel and Froot (1987b) and Froot and Frankel (1989) extend the analysis of their seminal paper to determine whether irrationality of exchange rate expectations or the existence of time-varying risk premia is the economically important reason for rejection of forward market efficiency. For the period 19811985 , they find that variation in the forward dollar discount of the four most actively traded currencies (Deutschmark, Swiss Franc, Japanese Yen, British Pound) primarily reflects changes in expected depreciation rather than risk premia and, thus, that forward dollar discount bias is primarily attributable to irrationality on the part of economic agents. However, the risk premia implied by the survey data are significantly different from zero and vary on average between approximately 2 and 10 per cent on an annual basis. The results of Frankel and Froot (1987b) and Froot and Frankel (1989) are obtained from an examination of three survey data sets ${ }^{2}$ covering the period 1981-1985. In order to increase the sample size, empirical tests are conducted by pooling across currencies. ${ }^{3}$ Although the statistical merits of this technique are well recognized it remains unclear whether their results can be interpreted unambigously. Variation in the risk premium is captured by a regression coefficient - assumed equal for all currencies - that measures the covariation of the forward discount with the risk premium. ${ }^{4}$ In an unpublished follow-up paper, Frankel and Chinn (1991) extend the analysis of Frankel and Froot (1989) by considering a new data set - the Currency Forecasters Digest - which covers 17 currencies over a different time period (1988-1991). Single currency as well as pooled regression results are presented. Evidence favoring the existence of time-varying risk premia is

and Taylor (1989).

2 The three survey data sets have been conducted by American Express Banking Corporation (AMEX), Money Market Services (MMS), and the Japan Center for International Finance (JCIF).

3 The exchange rate survey data covers bilateral rates relative to the US Dollar for the Deutschmark, French Franc, Swiss Franc, the Japanese Yen, and the Pound Sterling.

${ }^{4}$ See equation (9) and the ensuing discussion for further details. A pooled regression coefficient that was equal to one could result from one sample of currencies that was negatively correlated with the forward discount and another sample that was positively correlated with the forward discount; thus a regression coefficient of one might lead one to conclude mistakenly that the risk premium was invariant over time. 
found for a number of currencies.

This chapter, presented in five sections, extends the analysis of Frankel and Froot (1987b) and Froot and Frankel (1989) and corroborates some of the results of Frankel and Chinn (1991) by considering a new data set of market participants expectations that covers bilateral exchange rates relative to the U.S. Dollar and relative to the Deutschmark spanning a longer time period (1986-1990) of than previously published study. The empirical regularities which we present highlight the importance of examining cross exchange rate forecasts and thus provides an interesting complement to previous work that has largely focused on the four most actively traded currencies vis-à-vis the U.S. Dollar. In section 2, summary statistics describing the exchange rate survey data are provided. In section 3 and 4 we address the principal question of whether rejection of forward market efficiency is attributable to the existence of time-varying risk premia or irrational behavior of economic agents. In addition, in section 5 we examine the time series properties of our estimated risk premia for each bilateral exchange rate to assess whether they are consistent with asset pricing models. Finally, in section 6 the results of this investigation are summarized.

\subsection{The Survey Data}

This chapter examines the same survey data set of exchange rate expectations used in the previous chapter. Our monthly dataset contains ten currencies relative to the US Dollar and eight currencies relative to the Deutschmark, covering the period from January 1986 through December $1990.5^{5}$

The use of survey data allows the direct measurement of a risk premium: Conditional on market efficiency and rational expectations, the forward exchange rate is equal to the expected future spot rate plus a risk premium. Thus, the forward discount can be decomposed into its two components - the expected depreciation and the risk premium: ${ }^{6}$

${ }^{5}$ See chapter three for a more detailed description of the construction of the exchange rate survey.

6 The few days discrepancy between the maturity date of the forward contracts and the maturity data of the expected spot rate is no larger than that of other authors who have examined the efficiency of foreign exchange markets. 


$$
\left(F_{t+k}-S_{t}\right)=\left(E_{t} S_{t+k}-S_{t}\right)+P_{t}^{k}
$$

Here, as in the remainder of the chapter, $S_{t}$ is defined as the natural logarithm of the spot exchange rate at time $t, E_{t} S_{t+k}$ is defined as the logarithm of the expected future spot exchange rate at time $t+k$ formed at time $t$, ${ }_{\mathrm{t}} \mathrm{F}_{\mathrm{t}+\mathrm{k}}$ is defined as the natural logarithm of the forward rate at time $\mathrm{t}$ for delivery at time $t+k$ and $P_{t}^{k}$ is the associated risk premium.

The left-hand side of equation (1) is the forward discount, and the righthand side is the expected rate of depreciation of the home currency relative to the foreign currency (US Dollar or Deutschmark - the exchange rates are expressed as units of home currency per unit of foreign currency) plus the risk premium. If investors need to be rewarded for exposure to the additional risk of holding an open position in the foreign currency, they will demand a risk premium in addition to the forward rate. Because the surveys are direct estimates we do not need to assume any particular model of expected depreciation or of the risk premium. To give equation (1) economic content, a model of international asset pricing that describes the determination of $P_{t}^{k}$ is required. Equilibrium models of international asset pricing that provide us with such descriptions are presented, for instance, in Adler and Dumas (1983), Fama and Farber (1979), Hodrick (1981), Hodrick and Srivastava (1984), Roll and Solnik (1977), and Stulz (1981). Examples of such models and other approaches for assessing the risk premium interpretation (the existence of time-varying risk premia) are discussed in section 4 .

Tables $4.1 \mathrm{a}$ and $4.1 \mathrm{~b}$ provide summary statistics for the forward discount and expected annualized exchange rate depreciation across forecast horizons and across currencies. ${ }^{7}$ The summary statistics for the annualized risk premium across horizons and across currencies are reported in table 4.1c. Four currency "groups" are presented - non-EMS currencies relative to the US Dollar, EMS currencies relative to the US Dollar, non-EMS currencies relative to the Deutschmark, EMS currencies relative to the Deutschmark. Since Frankel and Chinn (1991) do not report summary statistics for their data, only qualitative comparisons can be made relative to those previous

7 Defining $k$ to be the forecast horizon in months, annualized returns are obtained by multiplying the log differences by $1200 / \mathrm{k}$. 
studies that have examined the four most actively traded currencies.

For the period analyzed (January 1st, 1986 through December 1st, 1990), the standard deviations of the expected depreciation across the 3, 6, and 12 month horizons are generally larger than those of the forward discount. This confirms the results of Frankel and Froot (1987a, 1987b). It is interesting to note that in most cases the absolute values of the mean forward discount are larger than those of the expected mean depreciation. In addition, for all EMS exchange rates relative to the Deutschmark - except the Dutch guilder at the three month horizon - the absolute values of the mean forward discount are larger than those of the expected mean depreciation. This empirical regularity differs from summary statistics reported by Frankel and Froot (1987a, 1987b) and MacDonald and Torrance (1990). More striking is the fact that for EMS currencies relative to the Deutschmark the mean forward discount is larger in magnitude than the mean realized depreciation reported in chapter three (Table 3.1a). ${ }^{8}$ Comparing Tables $4.1 \mathrm{a}$ and $4.1 \mathrm{~b}$, one notes that in general the expected rates of depreciation and the forward discount are of the same sign. Thus the currencies that were expected to depreciate were at a forward discount. This confirms the results of Frankel and Froot (1987a, 1987b). Table 4.1c suggests the presence of time-varying risk premia, thus regarding domestic and foreign assets as imperfect substitutes. The numbers broadly differ from summary statistics reported by Frankel and Froot (1987a, 1987b), which demonstrate surprisingly large exchange risk premia for the four currencies they examine relative to the US Dollar.

Fama (1984) demonstrates that rejection of the unbiasedness hypothesis in most instances implies that risk premia are more variable than expected rates of depreciation and that the two covary negatively. Comparing Tables $4.1 \mathrm{~b}$ and $4.1 \mathrm{c}$, one notes that in general the standard deviation of the expected depreciation is of the same order of magnitude as the standard deviation of the risk premium, but is nevertheless larger. This corroborates, in contrast to the discussion of Fama (1984) and Hodrick and Srivastava (1986), the findings of Froot and Frankel (1989). As in Froot and Frankel (1989), we find that the point estimates of the variability of the risk premium are smaller than those of the expected depreciation, although the relative difference is markedly smaller for our data compared with Froot and Frankel. Formal

8 Note that for EMS currencies relative to the Deutschmark the absolute values of the mean realized depreciation are smaller than those of the expected mean depreciation. See chapter three, Tables 3.1a and 3.1b. 
Table 4.1A Summary Statistics of Forward Discount: ${ }_{t} F_{t+k}-S_{t}$ (percent per annum)

January 1, 1986 through December 1, 1990

\begin{tabular}{|c|c|c|c|c|c|c|}
\hline & Mean ${ }^{3}$ & $\begin{array}{l}\text { Standard } \\
\text { Deviation }\end{array}$ & Mean $^{6}$ & $\begin{array}{l}\text { Standard } \\
\text { Deviation }\end{array}$ & Mean ${ }^{12}$ & $\begin{array}{l}\text { Standard } \\
\text { Deviation }\end{array}$ \\
\hline $\begin{array}{l}\text { JY/US } \\
\text { SF/US } \\
\text { BP/US } \\
\text { CD/US }\end{array}$ & $\begin{array}{r}-2.65 \\
-2.67 \\
3.93 \\
2.37\end{array}$ & $\begin{array}{l}1.37 \\
1.85 \\
2.61 \\
1.40\end{array}$ & $\begin{array}{r}-2.70 \\
-2.54 \\
3.56 \\
2.16\end{array}$ & $\begin{array}{l}1.34 \\
2.69 \\
1.84 \\
1.05\end{array}$ & $\begin{array}{r}-2.95 \\
-3.20 \\
2.81 \\
1.79\end{array}$ & $\begin{array}{l}1.20 \\
1.26 \\
1.36 \\
0.66\end{array}$ \\
\hline $\begin{array}{l}\text { FF/US } \\
\text { DF/US } \\
\text { IL/US } \\
\text { BF/US } \\
\text { DM/US } \\
\text { IP/US }\end{array}$ & $\begin{array}{r}1.22 \\
-1.65 \\
4.07 \\
0.47 \\
-2.38 \\
0.91\end{array}$ & $\begin{array}{l}1.55 \\
1.48 \\
1.83 \\
1.83 \\
1.61 \\
6.65\end{array}$ & $\begin{array}{r}1.16 \\
-1.86 \\
4.01 \\
0.05 \\
-2.41 \\
1.47\end{array}$ & $\begin{array}{l}1.46 \\
1.37 \\
1.59 \\
1.67 \\
1.45 \\
3.99\end{array}$ & $\begin{array}{r}0.87 \\
-2.28 \\
3.71 \\
-0.25 \\
-2.74 \\
1.36\end{array}$ & $\begin{array}{l}1.28 \\
1.55 \\
1.39 \\
1.22 \\
1.10 \\
2.74\end{array}$ \\
\hline $\begin{array}{l}\text { JY/DH } \\
\text { SF/DM } \\
\text { BP/DM } \\
\text { CD/DM }\end{array}$ & $\begin{array}{r}-0.36 \\
-0.15 \\
5.64 \\
4.08\end{array}$ & $\begin{array}{l}1.46 \\
0.75 \\
1.24 \\
1.28\end{array}$ & $\begin{array}{r}-0.38 \\
-0.09 \\
5.62 \\
4.19\end{array}$ & $\begin{array}{l}1.25 \\
1.97 \\
0.82 \\
0.93\end{array}$ & $\begin{array}{r}-0.16 \\
-0.46 \\
5.39 \\
4.37\end{array}$ & $\begin{array}{l}1.15 \\
0.43 \\
0.71 \\
0.77\end{array}$ \\
\hline $\begin{array}{l}F F / D H \\
D F / D M \\
I L / D M \\
B F / D M\end{array}$ & $\begin{array}{l}3.59 \\
0.82 \\
6.52 \\
2.88\end{array}$ & $\begin{array}{l}1.78 \\
0.65 \\
2.23 \\
1.78\end{array}$ & $\begin{array}{l}3.48 \\
0.67 \\
6.34 \\
2.53\end{array}$ & $\begin{array}{l}1.74 \\
0.53 \\
1.95 \\
1.08\end{array}$ & $\begin{array}{l}3.56 \\
0.69 \\
6.31 \\
2.50\end{array}$ & $\begin{array}{l}1.44 \\
0.45 \\
1.50 \\
0.98\end{array}$ \\
\hline
\end{tabular}

Legend: $\quad \mathrm{BF}=$ Belgian Franc; $\mathrm{BP}=$ British Pound $\mathrm{CD}=$ Canadian Dollar; $\mathrm{DF}=$ Dutch Guilder; DM = German Mark; FF = French Franc; IL = Italian Lira; IP = Irish Pound; JY = Japanese Yen; US = US Dollar. 
100

Table 4.1B Summary Statistics of Expected Depreciation: $E_{t} S_{t+k}-S_{t}$ (percent per annum)

January 1, 1986 through December 1, 1990

\begin{tabular}{|c|c|c|c|c|c|c|}
\hline & Mean 3 & $\begin{array}{l}\text { Standerd } \\
\text { Deviation }\end{array}$ & $\begin{array}{r}6 \\
\text { Mesn }\end{array}$ & $\begin{array}{l}\text { Standard } \\
\text { Deviation }\end{array}$ & ${ }_{\text {Mean }}^{12}$ & $\begin{array}{l}\text { Standard } \\
\text { Deviation }\end{array}$ \\
\hline $\begin{array}{l}\text { JY/US } \\
\text { SF /US } \\
\text { BP/US } \\
\mathrm{CD} / U S\end{array}$ & $\begin{array}{r}-3.64 \\
-3.16 \\
1.61 \\
2.31\end{array}$ & $\begin{array}{l}7.79 \\
8.79 \\
8.16 \\
4.17\end{array}$ & $\begin{array}{r}-2.46 \\
-1.56 \\
2.32 \\
2.10\end{array}$ & $\begin{array}{l}6.90 \\
6.03 \\
4.68 \\
2.27\end{array}$ & $\begin{array}{r}-0.48 \\
-0.32 \\
2.34 \\
1.46\end{array}$ & $\begin{array}{l}3.56 \\
3.77 \\
2.52 \\
1.16\end{array}$ \\
\hline $\begin{array}{l}\text { FF/US } \\
\text { OF/US } \\
\text { IL/US } \\
\text { BF/US } \\
\text { OM/US } \\
\text { IP/US }\end{array}$ & $\begin{array}{r}-0.91 \\
-2.52 \\
0.51 \\
-1.83 \\
-3.32 \\
-3.06\end{array}$ & $\begin{array}{r}7.86 \\
8.96 \\
11.58 \\
9.90 \\
8.26 \\
13.64\end{array}$ & $\begin{array}{r}0.37 \\
-1.66 \\
1.74 \\
-0.67 \\
-1.56 \\
-0.38\end{array}$ & $\begin{array}{l}4.85 \\
5.25 \\
5.92 \\
6.43 \\
5.35 \\
8.24\end{array}$ & $\begin{array}{r}1.27 \\
-0.36 \\
2.14 \\
0.28 \\
-0.41 \\
1.17\end{array}$ & $\begin{array}{l}3.24 \\
3.26 \\
3.67 \\
3.84 \\
3.33 \\
4.70\end{array}$ \\
\hline $\begin{array}{l}J Y / D H \\
\text { SF/DM } \\
\text { BP/DH } \\
\text { CD/DM }\end{array}$ & $\begin{array}{r}-1.01 \\
-0.85 \\
4.33 \\
4.32\end{array}$ & $\begin{array}{r}5.11 \\
4.42 \\
4.45 \\
10.52\end{array}$ & $\begin{array}{r}-1.42 \\
-0.65 \\
3.56 \\
2.40\end{array}$ & $\begin{array}{l}5.90 \\
2.59 \\
2.73 \\
6.37\end{array}$ & $\begin{array}{r}-0.27 \\
-0.40 \\
2.63 \\
1.09\end{array}$ & $\begin{array}{l}1.95 \\
1.16 \\
2.07 \\
3.70\end{array}$ \\
\hline $\begin{array}{l}F F / D M \\
O F / D H \\
I L / D M \\
B F / D M\end{array}$ & $\begin{array}{l}2.48 \\
1.29 \\
4.00 \\
1.29\end{array}$ & $\begin{array}{l}2.30 \\
3.43 \\
8.55 \\
4.44\end{array}$ & $\begin{array}{l}2.40 \\
0.22 \\
4.04 \\
1.39\end{array}$ & $\begin{array}{l}2.06 \\
1.15 \\
2.65 \\
2.28\end{array}$ & $\begin{array}{l}1.78 \\
0.10 \\
2.89 \\
1.00\end{array}$ & $\begin{array}{l}1.26 \\
0.78 \\
1.69 \\
1.45\end{array}$ \\
\hline
\end{tabular}

Legend: $\quad \mathrm{BF}=$ Belgian Franc; $\mathrm{BP}=$ British Pound $\mathrm{CD}=$ Canadian Dollar; $\mathrm{DF}=$ Dutch Guilder; DM = German Mark; FF = French Franc; IL = Italian Lira; IP = Irish Pound; JY = Japanese Yen; US = US Dollar. 
Table 4.1C Summary Statistics of Risk Premium: ${ }_{t} F_{t+k}-E_{q} S_{t+k}$ (percent per annum)

January 1, 1986 through December 1, 1990

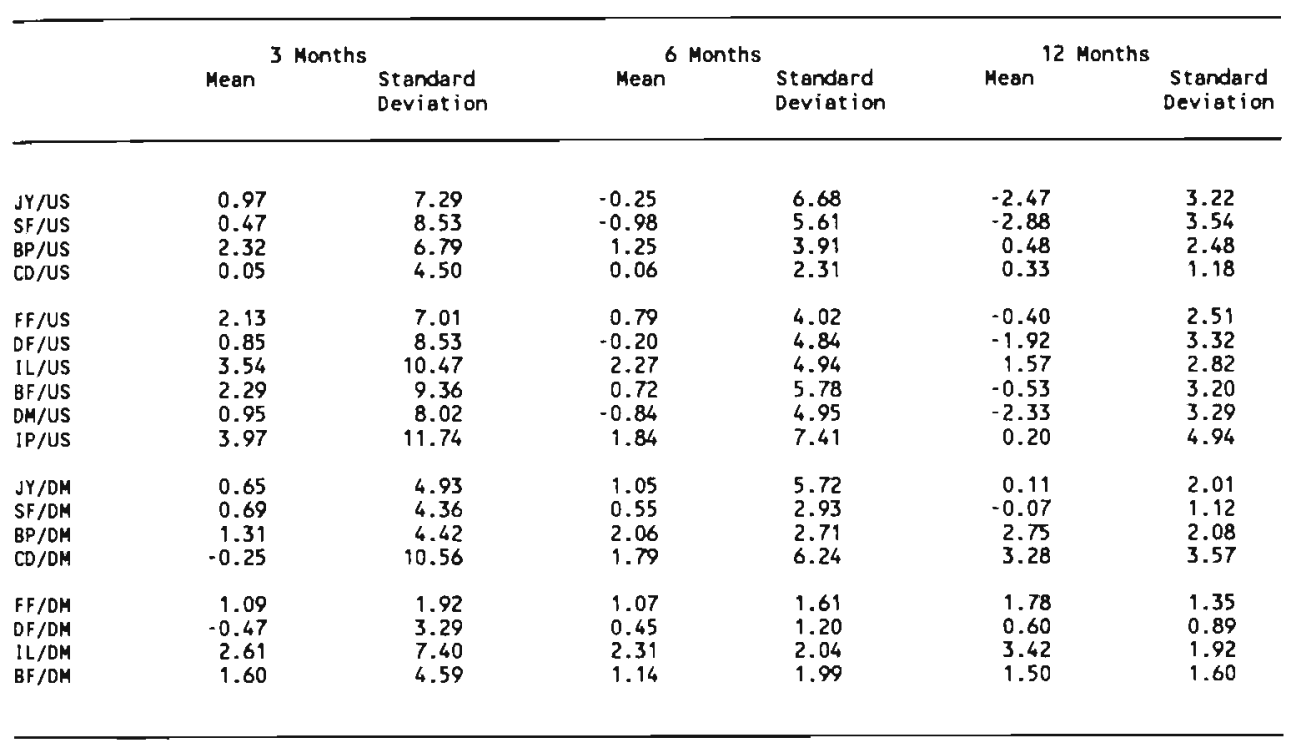

Legend: $\quad \mathrm{BF}=$ Belgian Franc; $\mathrm{BP}=$ British Pound; $\mathrm{CD}=$ Canadian Dollar; $\mathrm{DF}=$ Dutch Guilder; DM = German Mark; FF = French Franc; IL = Italian Lira; IP = Irish Pound; JY = Japanese Yen; US = US Dollar. 
tests whether expected depreciation is less variable than the exchange risk premium are presented in section 4.

Graphical displays of expected depreciation, forward discount, and exchange risk premia for the Deutschmark/US Dollar exchange rate over the 3,6 , and 12 month forecast horizons are presented in figures 1 a through $3 b$. These figures indicate relative constancy of the forward discount relative to the expected exchange rate depreciation. Note that the variability of the expected rate of depreciation is broadly similar to the variability of the exchange risk premia and (given the constancy of the forward discount) the expected depreciation and the risk premia also appear to move in opposite directions, i.e., are negatively correlated.

\subsection{Tests of Forward Discount Bias}

The literature on forward foreign exchange market efficiency has generally used some form of regression-based analysis of spot and forward exchange rates. As is clear from the preceding discussion, the efficient market hypothesis can be seen as a joint hypothesis of an equilibrium model of expected returns and the contention that agents are endowed with rational expectations. ${ }^{9}$ If agents are risk neutral, then, since a profit can be expected to be made when the forward exchange rate differs from the expected future spot rate (by taking open forward positions), one might expect the forward rate for maturity k-periods ahead to be forced into equality with the market's expectations of the spot rate at time $t+k$ formed at time $t$ :

$$
F_{t+k}=E_{t} S_{t+k}
$$

If agents are risk averse, however, then the forward rate will not be driven to full equality with the expected future spot rate because of the risk involved in taken open forward positions. Thus, a risk premium, $\mathrm{P}_{\mathrm{t}}^{\mathrm{k}}$, might be expected to drive a wedge between the forward rate and the expected future

9 Another method of testing spot market efficiency is to test for the profitability of filter rules - see Poole (1967), Cornell and Dietrich (1978), Dooley and Shafer (1976, 1983), and Sweeney (1986), for instance. 
Fig. 1a: Expected Depreciation and Forward Discount
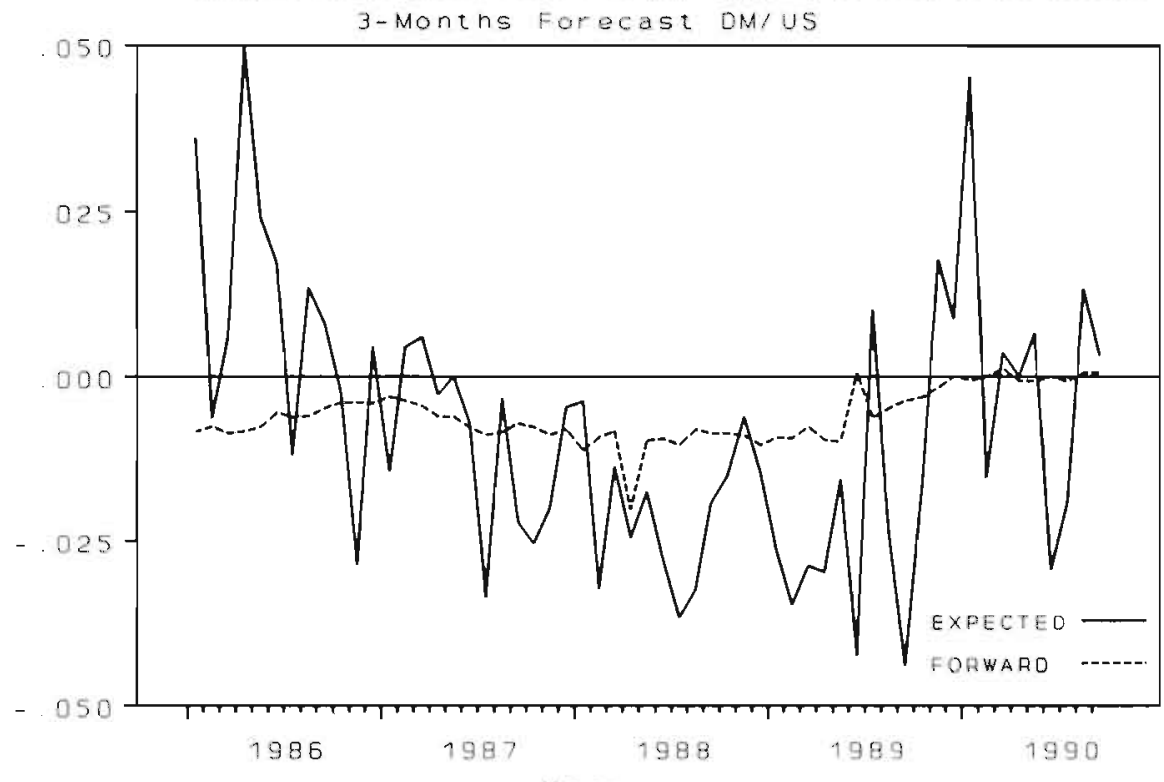

Fig. 1b. Exchange Rate Risk Premium DM/US 3-Months Forecast

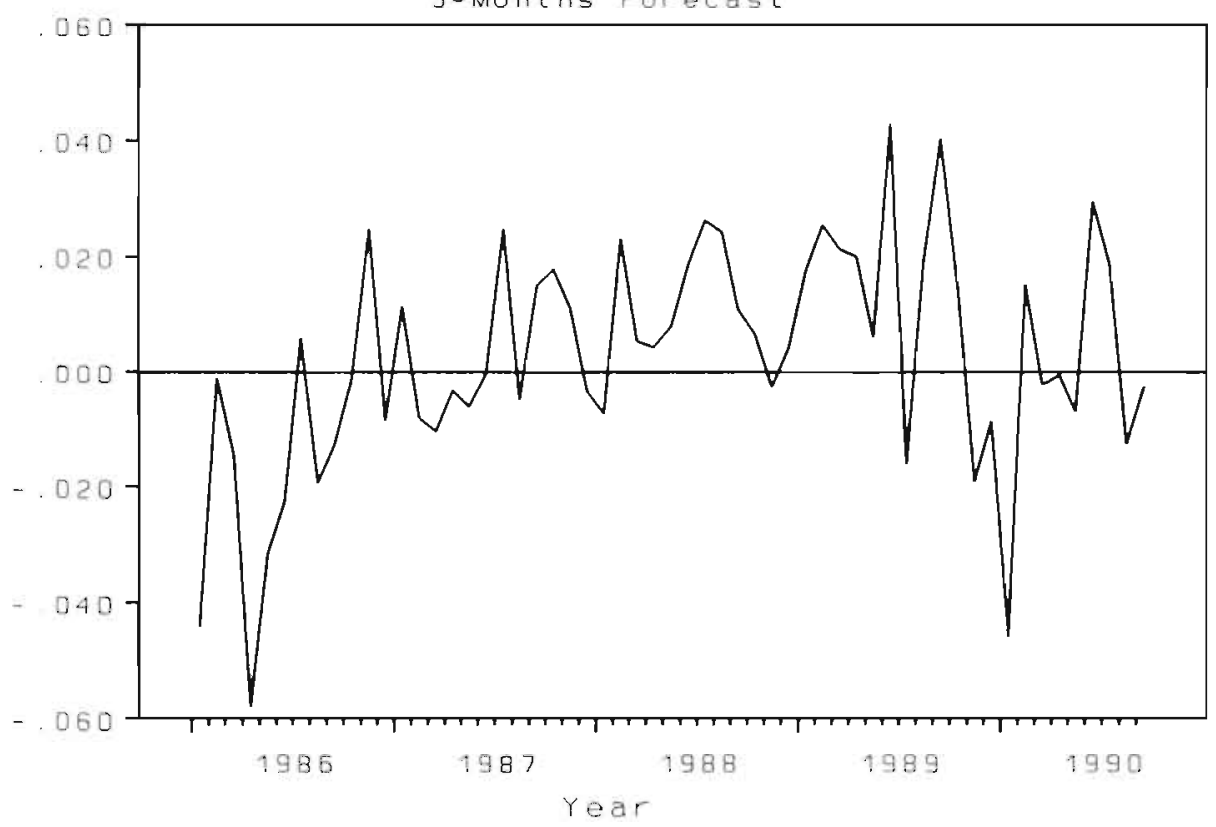


Fig. 2a. Expected Depreciation and Forward Discount 6-Months Forecast DM/US

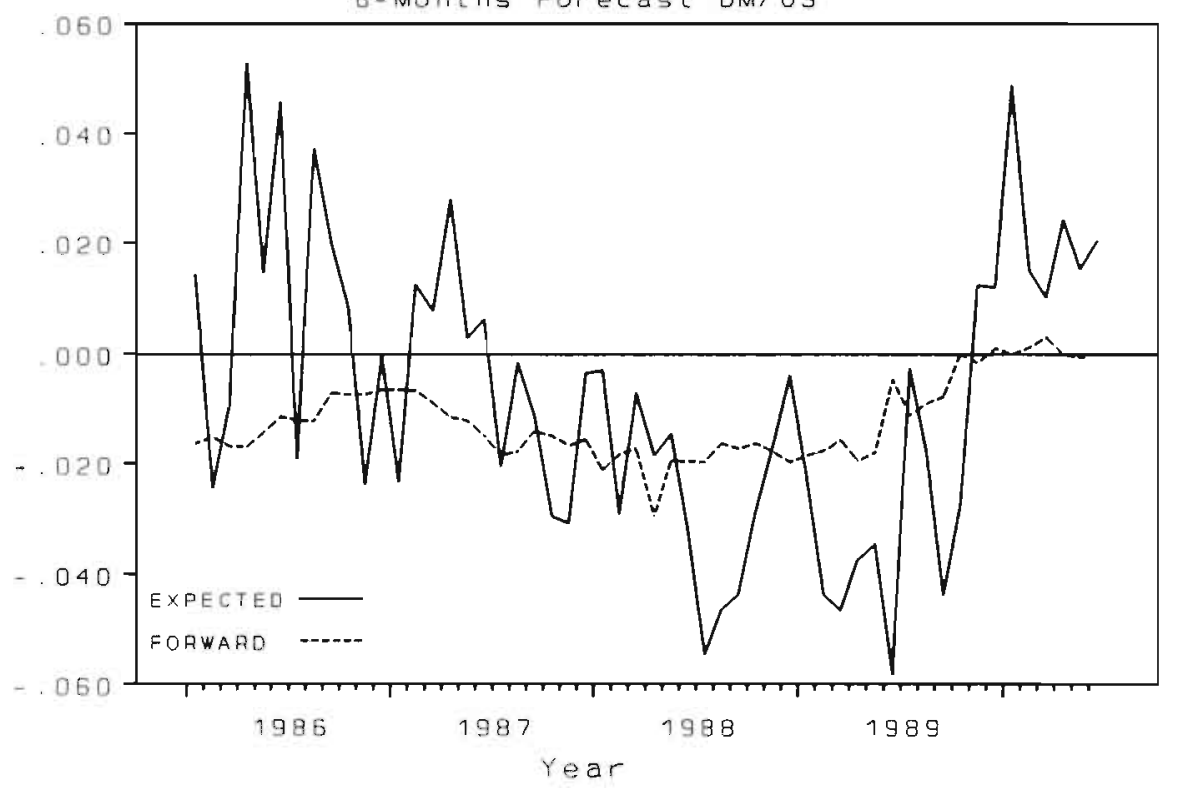

Fig. 2b. Exchange Rate Risk Premium DM/US 6-Months Forecast

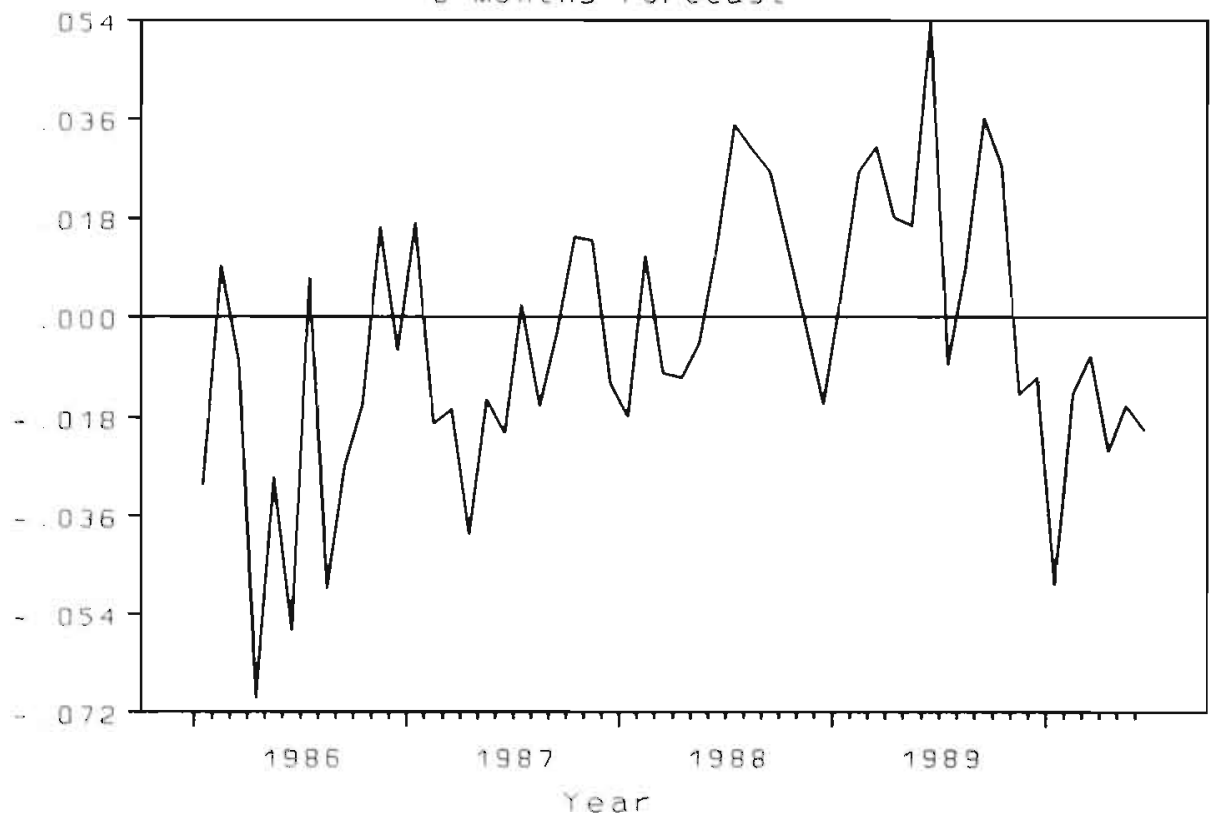


Fig 3a: Expected Depreciat ion and Forward Discount 12 -Months Forecast DM/US
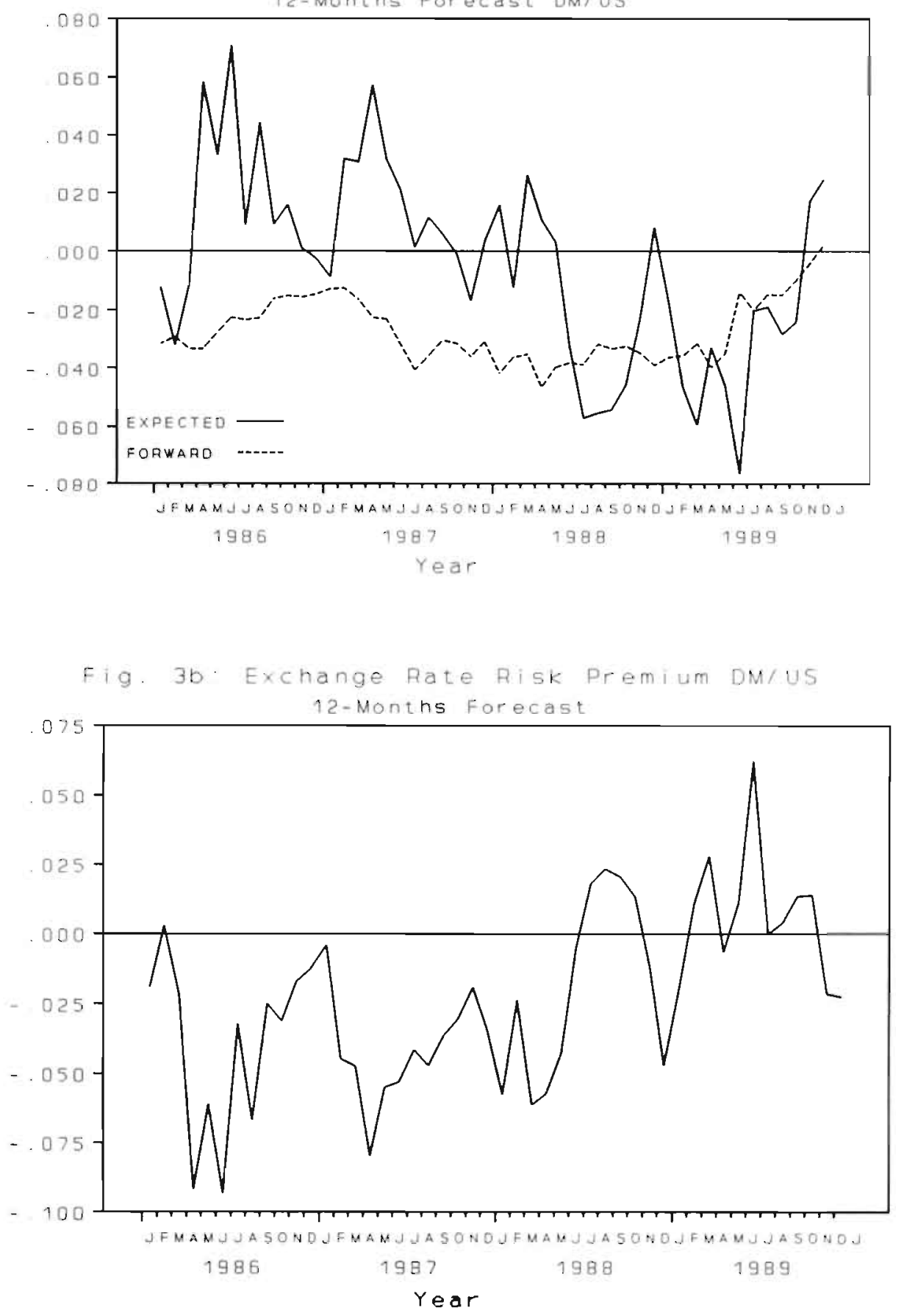
spot rate - see equation (1). A substantial number of studies investigated empirically the relationship between the spot exchange rate and the lagged forward rate ${ }^{10}$ and found that the forward market efficiency hypothesis could not be rejected in level form. ${ }^{11}$

In more recent studies, forward market efficiency has generally been tested by regressing the observed change in the spot exchange rate on the forward discount. Thus the null hypothesis of unbiasedness implies that $\alpha=0$ and $\beta$ $=1$ in regressions of the following form:

$$
S_{t+k}-S_{t}=\alpha+\beta\left(F_{t+k}-S_{t}\right)+\varepsilon_{t+k}
$$

where $e_{t+k}$ is a random error term. Equation (3) was fitted for each currency and for each forecast horizon ( $\mathrm{k}=3,6$ and 12 months). Realized spot exchange rates were obtained from Datastream. ${ }^{12}$ Hansen and Hodrick (1980) demonstrate that when the forecast horizon is longer than the observational frequency, the forecast error $e_{t+k}$ will be serially correlated. While OLS point estimates of $\beta$ remain consistent in spite of the serially correlated residuals, the OLS standard errors for the regression coefficient are biased. This can be corrected via the Newey-West (1987) estimation procedure. Therefore, the k-month-ahead forecast equations in this section are estimated with the Newey-West estimator, assuming a moving average process of order $\mathrm{k}$ for the monthly $\mathrm{k}$-month ahead forecast errors. ${ }^{13}$ Note that the k-month ahead forecast is in reality a $k$-month plus a few days ahead forecast.

The results of previous research overwhelmingly suggest rejection of the null hypothesis across the full spectrum of forward rates - see the surveys on

10 See Cornell (1977), Frenkel (1976, 1978, 1980), Levich (1979), and Stockman (1978), for instance.

11 It has been conjectured in a number of studies, including Meese (1985) and Hodrick (1987), that the apparent failure to reject the forward efficiency hypothesis in level form is due to the non-stationarity of $S_{t}$ and $F_{t+k}$.

12 The spot exchange rates at time $t+k, S_{t+k}$, used to compute the change in the spot rate are obtained from Datastream on days corresponding to the survey forecast dates. If the forecast date falls on a holiday or weekend, the next business day is chosen.

13 See chapter three for a more detailed description on this issue. 
the efficiency of the foreign exchange market by Hodrick (1987) and Levich (1985). Oftentimes the estimate of the $\beta$-coefficient is reliably less than one. In fact, $\beta$ is frequently estimated to be less than zero, evidenced by an average coefficient of -0.88 across some 75 published estimates [Froot and Thaler (1990)]. This result seems particulary robust given the variety of estimation techniques used by researchers and the mix of overlapping and non-overlapping data sets using a variety of currencies and time periods for the recent floating experience. The interpretation of this rejection is not clear however. Perhaps the most popular explanation is that there is a non-zero, time-varying risk premium that drives a wedge between the forward rate and the expected future spot rate - see Fama (1984) and Hodrick and Srivastava (1986). If the presence of time-varying risk premia is the reason for the failure, then this has important theoretical and policy implications. The existence of such risk premia implies that bonds denominated in different currencies will be regarded as imperfect substitutes by international portfolio holders and, therefore, the portfolio balance model of exchange rate determination $^{14}$ will be the correct one from a theoretical perspective and sterilized foreign exchange market intervention may be an effective policy tool. This chapter examines exchange rate survey data in order to shed some new light on the relative importance of risk premia in the pricing of forward foreign exchange.

Tables $4.2 \mathrm{a}, 4.2 \mathrm{~b}$, and $4.2 \mathrm{c}$ report the results of fitting equation (3) for each currency and for each forecast horizon via the Generalized Method of Moments (GMM) procedure. Overall, as others have found, the evidence presented suggests a fairly consistent rejection of the null hypothesis that the forward discount is an unbiased predictor of the future change in the exchange rate. Failure to reject the null occurs in only eight out of fifty-four cases. It is interesting to note that the estimated $\beta$-coefficients are generally nonnegative for EMS currencies relative to the Deutschmark (except for the $\mathrm{DF} / \mathrm{DM}$ exchange rate at the three and six months forecast horizon). Thus, it appears that on average the forward premium of the DM against the EMS currencies predicts the sign of the future change of the DM relative to these currencies correctly.

As was stated in section 1, rejection of forward market efficiency has been attributed to either the failure of rational expectations or the existence of

${ }^{14}$ For a discussion of the portfolio balance model see Frankel (1983). 
Table 4.2A Tests of Forward Discount Unbiasedness: $S_{t+3}-S_{t}=\alpha+\beta\left(F_{t}+3-S_{t}\right)$ $+\mathrm{e}_{\mathrm{t}+3}$.

January 1, 1986 through December 1, 1990: 57 Observations

\begin{tabular}{|c|c|c|c|}
\hline & $\hat{\alpha}$ & $\hat{\beta}$ & $x^{2}$ \\
\hline JY/US & $\begin{array}{l}-0.0926 \\
(0.0300)\end{array}$ & $\begin{array}{l}-9.6632 * \\
(3.2322)\end{array}$ & $\begin{array}{l}10.94 \% \\
(0.004)\end{array}$ \\
\hline SF/US & $\begin{array}{l}-0.0271^{\circ} \\
(0.0138)\end{array}$ & $\begin{array}{l}-5.5380^{*} \\
(2.5754)\end{array}$ & $\begin{array}{l}28.69^{*} \\
(0.000)\end{array}$ \\
\hline BP/US & $\begin{array}{l}-0.0092 \\
(0.0236)\end{array}$ & $\begin{array}{l}-1.1201 \\
(2.0152)\end{array}$ & $\begin{array}{l}5.93 \\
(0.051)\end{array}$ \\
\hline CD/US & $\begin{array}{l}-0.0186 \\
(0.0067)\end{array}$ & $\begin{array}{c}0.9094 \\
(0.8295)\end{array}$ & $\begin{array}{l}36.566^{\circ} \\
(0.000)\end{array}$ \\
\hline FF/US & $\begin{array}{l}-0.0179 \\
(0.0142)\end{array}$ & $\begin{array}{l}-3.4259^{\circ} \\
(2.0524)\end{array}$ & $\begin{array}{l}16.85^{\circ} \\
(0.000)\end{array}$ \\
\hline DF/US & $\begin{array}{l}-0.0642 . \\
(0.0142)\end{array}$ & $\begin{array}{l}-7.0037^{\prime \prime} \\
(2.4492)\end{array}$ & $\begin{array}{l}21.07^{\circ} \\
(0.000)\end{array}$ \\
\hline IL/US & $\begin{array}{l}-0.0245 \\
(0.0209)\end{array}$ & $\begin{array}{l}-5.1734 * \\
(1.4373)\end{array}$ & $\begin{array}{l}53.36 " \\
(0.000)\end{array}$ \\
\hline BF/US & $\begin{array}{c}-0.0290^{\circ} \\
(0.0126)\end{array}$ & $\begin{array}{l}-4.2005^{\circ} \\
(2.7313)\end{array}$ & $\begin{array}{l}13.60^{* 0} \\
(0.001)\end{array}$ \\
\hline DH/US & $\begin{array}{l}-0.01719^{\circ} \\
(0.0166)\end{array}$ & $\begin{array}{l}-6.1755^{\circ} \\
(2.4050)\end{array}$ & $\begin{array}{l}18.88^{* 1} \\
(0.000)\end{array}$ \\
\hline IP/US & $\begin{array}{l}-0.0313^{*} \\
(0.0134)\end{array}$ & $\begin{array}{c}1.1067 \\
(0.6502)\end{array}$ & $\begin{array}{c}5.93 \\
(0.052)\end{array}$ \\
\hline JY/DH & $\begin{array}{l}-0.0004 \\
(0.0103)\end{array}$ & $\begin{array}{l}-7.4455^{\circ} \\
(2.3277)\end{array}$ & $\begin{array}{l}13.35^{* 1} \\
(0.001)\end{array}$ \\
\hline SF/DM & $\begin{array}{l}-0.0004 \\
(0.0530)\end{array}$ & $\begin{array}{l}-1.9285 \\
(2.6358)\end{array}$ & $\begin{array}{c}1.48 \\
(0.478)\end{array}$ \\
\hline$B P / D M$ & $\begin{array}{l}-0.0064 \\
(0.0267)\end{array}$ & $\begin{array}{c}1.4256 \\
(1.6310)\end{array}$ & $\begin{array}{c}0.07 \\
(0.966)\end{array}$ \\
\hline$C D / D M$ & $\begin{array}{c}0.0420 \\
(0.0331)\end{array}$ & $\begin{array}{l}-2.1132 \\
(3.5139)\end{array}$ & $\begin{array}{c}2.10 \\
(0.350)\end{array}$ \\
\hline $\mathrm{FF} / \mathrm{DH}$ & $\begin{array}{l}-0.0106 " \\
(0.0040)\end{array}$ & $\begin{array}{c}1.9200^{\circ} \\
(0.4735)\end{array}$ & $\begin{array}{l}7.09^{\circ} \\
(0.029)\end{array}$ \\
\hline$D F / D H$ & $\begin{array}{c}0.0004 \\
(0.0010)\end{array}$ & $\begin{array}{l}-0.0184, " \\
(0.4082)\end{array}$ & $\begin{array}{l}21.31 \% \\
(0.000)\end{array}$ \\
\hline $\mathrm{IL} / \mathrm{DM}$ & $\begin{array}{c}0.0048 \\
(0.0077)\end{array}$ & $\begin{array}{c}0.1270^{\circ} \\
(0.3564)\end{array}$ & $\begin{array}{l}34.07^{\circ} \\
(0.000)\end{array}$ \\
\hline$B F / D M$ & $\begin{array}{l}-0.0008 \\
(0.0019)\end{array}$ & $\begin{array}{c}0.2625{ }^{\circ} \\
(0.1225)\end{array}$ & $\begin{array}{l}72.49^{\circ} \\
(0.000)\end{array}$ \\
\hline
\end{tabular}

The Standard errors of the coefficients are given in parentheses; * (**) denotes rejection at the $5 \%(1 \%)$ level for the hypotheses that $\alpha=0$ and $\beta=1$. The Chi-square Statistic pertains to the joint hypothesis that $\alpha=0$ and $\beta=1$ ( $\mathrm{p}$-Values are given in parentheses). 
Table 4.2B Tests of Forward Discount Unbiasedness: $S_{t+6}-S_{t}=\alpha+\beta\left({ }_{t} F_{t+6}-S_{t}\right)$ $+e_{t+6}$.

January 1, 1986 through December 1, 1990: 54 Observations

\begin{tabular}{|c|c|c|c|}
\hline & $\hat{\alpha}$ & $\hat{\beta}$ & $\chi^{2}$ \\
\hline JY/US & $\begin{array}{l}-0.9523^{*} \\
(0.0439)\end{array}$ & $\begin{array}{l}-8.4154^{\circ} \\
(2.4182)\end{array}$ & $\begin{array}{l}15.18^{\circ} \\
(0.001)\end{array}$ \\
\hline SF/US & $\begin{array}{l}-0.0984 * \\
(0.0216)\end{array}$ & $\begin{array}{l}-3.3457^{\circ} \\
(1.5641)\end{array}$ & $\begin{array}{l}22.34{ }^{\circ} \\
(0.000)\end{array}$ \\
\hline BP/US & $\begin{array}{l}-0.0133 \\
(0.0421)\end{array}$ & $\begin{array}{l}-2.5787 \\
(2.0110)\end{array}$ & $\begin{array}{c}9.47^{\circ} \\
(0.009)\end{array}$ \\
\hline CD/US & $\begin{array}{l}-0.0333^{\prime \prime} \\
(0.0104)\end{array}$ & $\begin{array}{c}0.8564 \\
(0.6443)\end{array}$ & $\begin{array}{l}72.71 * \\
(0.000)\end{array}$ \\
\hline FF/US & $\begin{array}{l}-0.0291 \\
(0.0246)\end{array}$ & $\begin{array}{l}-2.7976^{\circ} \\
(1.5245)\end{array}$ & $\begin{array}{l}23.17^{\circ} \\
(0.000)\end{array}$ \\
\hline DF/US & $\begin{array}{l}-0.1142 " * \\
(0.0257)\end{array}$ & $\begin{array}{l}-6.2353^{* *} \\
(2.6186)\end{array}$ & $\begin{array}{l}20.03^{*} \\
(0.000)\end{array}$ \\
\hline IL/US & $\begin{array}{l}-0.0518 \\
(0.0306)\end{array}$ & $\begin{array}{l}-4.8088{ }^{*} \\
(0.9392)\end{array}$ & $\begin{array}{c}102.75^{*} \\
(0.000)\end{array}$ \\
\hline BF/US & $\begin{array}{l}-0.0529^{\circ} \\
(0.0154)\end{array}$ & $\begin{array}{l}-6.0996 \% \\
(1.1987)\end{array}$ & $\begin{array}{l}66.47^{\circ} \\
(0.000)\end{array}$ \\
\hline DM/US & $\begin{array}{l}-0.1240^{\circ} \\
(0.0256)\end{array}$ & $\begin{array}{l}-5.6402^{*} \\
(2.3230)\end{array}$ & $\begin{array}{l}24.50^{\circ} \\
(0.000)\end{array}$ \\
\hline IP/US & $\begin{array}{l}-0.0461)^{\circ} \\
(0.0263)\end{array}$ & $\begin{array}{c}0.4938 \\
(1.1037)\end{array}$ & $\begin{array}{c}7.84 \\
(0.025)\end{array}$ \\
\hline JY/DM & $\begin{array}{c}0.0009 \\
(0.0160)\end{array}$ & $\begin{array}{l}-8.7270^{\circ} \\
(2.2226)\end{array}$ & $\begin{array}{l}19.64 \% \\
(0.000)\end{array}$ \\
\hline SF/DM & $\begin{array}{c}0.0001 \\
(0.0061)\end{array}$ & $\begin{array}{l}-1.0565^{*} \\
(0.1671)\end{array}$ & $\begin{array}{c}201.87^{\circ} \\
(0.000)\end{array}$ \\
\hline BP/DM & $\begin{array}{l}-0.0494 \\
(0.0918)\end{array}$ & $\begin{array}{c}2.5470 \\
(3.2263)\end{array}$ & $\begin{array}{c}0.32 \\
(0.851)\end{array}$ \\
\hline CD/DH & $\begin{array}{c}0.1070^{\circ} \\
(0.0496)\end{array}$ & $\begin{array}{l}-3.6461 \\
(3.0417)\end{array}$ & $\begin{array}{l}6.20^{\circ} \\
(0.045)\end{array}$ \\
\hline $\mathrm{FF} / \mathrm{DM}$ & $\begin{array}{l}-0.0167^{\prime} \\
(0.0064)\end{array}$ & $\begin{array}{c}1.5807 \\
(0.4569)\end{array}$ & $\begin{array}{l}10.25^{\circ} \\
(0.006)\end{array}$ \\
\hline DF/DM & $\begin{array}{c}0.0005 \\
(0.0009)\end{array}$ & $\begin{array}{l}-0.0588^{*} \\
(0.2499)\end{array}$ & $\begin{array}{l}23.62^{\circ} \\
(0.000)\end{array}$ \\
\hline IL/DM & $\begin{array}{c}0.0065 \\
(0.0092)\end{array}$ & $\begin{array}{c}0.1553^{*} \\
(0.1674)\end{array}$ & $\begin{array}{l}89.87^{\prime \prime} \\
(0.000)\end{array}$ \\
\hline$B F / D M$ & $\begin{array}{c}-0.0110^{\circ} \\
(0.0047)\end{array}$ & $\begin{array}{c}0.9962 \\
(0.2473)\end{array}$ & $\begin{array}{l}61.47^{\circ} \\
(0.000)\end{array}$ \\
\hline
\end{tabular}

The Standard errors of the coefficients are given in parentheses; ${ }^{*}\left({ }^{*}\right)$ denotes rejection at the $5 \%(1 \%)$ level for the hypotheses that $\alpha=0$ and $\beta=1$. The Chi-square Statistic pertains to the joint hypothesis that $\alpha=0$ and $\beta=1$ ( $p$-Values are given in parentheses). 
Table 4.2C Tests of Forward Discount Unbiasedness: $\mathrm{S}_{\mathrm{t}+12}-\mathrm{S}_{\mathrm{t}}=\alpha+\beta \mathrm{C}_{\mathrm{t}} \mathrm{F}_{\mathrm{t}+12}-$ $\left.\mathrm{S}_{\mathrm{t}}\right)+\mathrm{e}_{\mathrm{t}+12}$. January 1, 1986 through December 1, 1990: 48 Observations

\begin{tabular}{|c|c|c|c|}
\hline & $\hat{\alpha}$ & $\hat{\beta}$ & $x^{2}$ \\
\hline JY/US & $\begin{array}{l}-0.3317^{*} \\
(0.0259)\end{array}$ & $\begin{array}{l}-9.5225^{\circ} \\
(0.8542)\end{array}$ & $\begin{array}{c}184.95^{\circ} \\
(0.000)\end{array}$ \\
\hline SF/US & $\begin{array}{l}-0.3546 \\
(0.0306)\end{array}$ & $\begin{array}{l}-8.6610^{\circ} \\
(1.5032)\end{array}$ & $\begin{array}{c}156.93^{*} \\
(0.000)\end{array}$ \\
\hline$B P / U S$ & $\begin{array}{c}0.1030^{\circ} \\
(0.0490)\end{array}$ & $\begin{array}{l}-5.4541^{\circ} \\
(0.9638)\end{array}$ & $\begin{array}{r}101.49^{\circ} \\
(0.000)\end{array}$ \\
\hline CD/US & $\begin{array}{l}-0.0735 * \\
(0.0205)\end{array}$ & $\begin{array}{c}1.4574 \\
(0.9223)\end{array}$ & $\begin{array}{l}55.24^{\circ} \\
(0.000)\end{array}$ \\
\hline FF/US & $\begin{array}{l}-0.0509 \\
(0.0456)\end{array}$ & $\begin{array}{l}-2.2339^{\circ} \\
(1.3997)\end{array}$ & $\begin{array}{c}9.86 \\
(0.007)\end{array}$ \\
\hline DF/US & $\begin{array}{l}-0.1585^{\circ} \\
(0.0335)\end{array}$ & $\begin{array}{l}-3.1052^{\circ} \\
(2.0506)\end{array}$ & $\begin{array}{l}22.32^{*} \\
(0.000)\end{array}$ \\
\hline IL/US & $\begin{array}{c}0.0829 \\
(0.0666)\end{array}$ & $\begin{array}{l}-4.0021^{\circ} \\
(1.1645)\end{array}$ & $\begin{array}{l}47.83^{\prime \prime} \\
(0.000)\end{array}$ \\
\hline$B F / U S$ & $\begin{array}{l}-0.1004^{*} \\
(0.0355)\end{array}$ & $\begin{array}{l}-6.2909 " \\
(1.9992)\end{array}$ & $\begin{array}{l}31.67 \\
(0.000)\end{array}$ \\
\hline DM/US & $\begin{array}{l}-0.2859^{\circ} \\
(0.0336)\end{array}$ & $\begin{array}{l}-7.2391 * \\
(1.8547)\end{array}$ & $\begin{array}{l}90.20^{\circ} \\
(0.000)\end{array}$ \\
\hline IP/US & $\begin{array}{l}-0.0584 \\
(0.0482)\end{array}$ & $\begin{array}{l}-0.4750 \\
(0.9150)\end{array}$ & $\begin{array}{l}16.87^{\circ} \\
(0.000)\end{array}$ \\
\hline JY/DM & $\begin{array}{c}0.0262 \\
(0.0385)\end{array}$ & $\begin{array}{l}-6.4139^{\circ} \\
(3.2860)\end{array}$ & $\begin{array}{l}7.12^{\circ} \\
(0.028)\end{array}$ \\
\hline SF/DM & $\begin{array}{l}-0.0022 \\
(0.0082)\end{array}$ & $\begin{array}{l}-2.7244 \\
(1.1745)\end{array}$ & $\begin{array}{l}12.39^{\circ} \\
(0.002)\end{array}$ \\
\hline$B P / D M$ & $\begin{array}{l}-0.2092^{\circ} \\
(0.0988)\end{array}$ & $\begin{array}{r}4.5390^{\circ} \\
(1.7469)\end{array}$ & $\begin{array}{l}4.48 \\
(0.106)\end{array}$ \\
\hline CD/DH & $\begin{array}{c}0.3638^{\circ} \\
(0.0849)\end{array}$ & $\begin{array}{l}-7.4400^{\circ} \\
(2.3649)\end{array}$ & $\begin{array}{l}18.76 \\
(0.000)\end{array}$ \\
\hline FF/DM & $\begin{array}{l}-0.0288 \\
(0.0097)\end{array}$ & $\begin{array}{c}1.2864 \\
(0.3914)\end{array}$ & $\begin{array}{l}21.32^{*} \\
(0.000)\end{array}$ \\
\hline DF/DM & $\begin{array}{l}-0.0003 \\
(0.0012)\end{array}$ & $\begin{array}{c}0.0423^{\circ} \\
(0.1718)\end{array}$ & $\begin{array}{l}39.47^{\circ} \\
(0.000)\end{array}$ \\
\hline IL/OM & $\begin{array}{c}0.0079 \\
(0.0182)\end{array}$ & $\begin{array}{c}0.2167^{\circ} \\
(0.1918)\end{array}$ & $\begin{array}{l}39.94^{\circ} \\
(0.000)\end{array}$ \\
\hline$B F / D M$ & $\begin{array}{l}-0.0191 * \\
(0.0070)\end{array}$ & $\begin{array}{c}0.8663 \\
(0.2205)\end{array}$ & $\begin{array}{c}962.21^{\circ} \\
(0.000)\end{array}$ \\
\hline
\end{tabular}

The Standard errors of the coefficients are given in parentheses; ${ }^{*}(*)$ denotes rejection at the $5 \%(1 \%)$ level for the hypotheses that $\alpha=0$ and $\beta=1$. The Chi-square Statistic pertains to the joint hypothesis that $\alpha=0$ and $\beta=1$ ( $\mathrm{p}$-Values are given in parentheses). 
time-varying risk premia. Froot and Frankel (1989), Frankel and Froot (1987b), and Taylor (1987) demonstrate how survey expectations data can be exploited to ascertain the economic importance of these competing explanations. From equation (3) it follows that:

$$
\beta=\frac{\operatorname{cov}\left({ }_{t} F_{t+k}-S_{t}, S_{t+k}-S_{t}\right)}{\operatorname{var}\left(F_{t+k}-S_{t}\right)}
$$

Hence, combining the rational expectations assumption with the decomposition of the forward discount in equation (1) implies that:

$$
\beta=\frac{\operatorname{cov}\left(F_{t} F_{t+k}-S_{t}, E_{t} S_{t+k}-S_{t}+\varepsilon_{t+k}\right)}{\operatorname{var}\left(F_{t+k}-S_{t}\right)}
$$

or, equivalently,

$$
\beta=\frac{\operatorname{cov}\left(F_{t+k}-S_{t}, \varepsilon_{t+k}\right)+\operatorname{cov}\left(F_{t} F_{t+k}-S_{t}, E_{t} S_{t+k}-S_{t}\right)}{\operatorname{var}\left(F_{t+k}-S_{t}\right)}
$$

Hence,

$$
\beta=\beta_{1}+\beta_{2},
$$

where,

$$
\beta_{1}=\frac{\operatorname{cov}\left(F_{t+k}-S_{t}, \varepsilon_{t+k}\right)}{\operatorname{var}\left(F_{t+k}-S_{t}\right)}
$$

and 


$$
\beta_{2}=\frac{\operatorname{cov}\left({ }_{t} F_{t+k}-S_{t}, E_{t} S_{t+k}-S_{t}\right)}{\operatorname{var}\left(F_{t+k}-S_{t}\right)},
$$

or, equivalently,

$$
\beta_{2}=1-\frac{\operatorname{cov}\left({ }_{t} F_{t+k}-S_{t}, P_{t}^{k}\right)}{\operatorname{var}\left({ }_{t} F_{t+k}-S_{t}\right)} .
$$

Under the hypothesis of rational expectations, $\beta_{1}$ will equal zero since the forecast error, $e_{t+k}$, will be orthogonal to any variable in the set of information known to agents at the time they formed their expectations.

Under the hypothesis that the correlation of the risk premium with the forward discount is zero (no time-varying risk premium), $\beta_{2}$ will equal one. Formal tests whether rejection of forward market efficiency is attributable to irrationality of exchange rate expectations or to the existence of time-varying risk premia are presented in the next section.

\subsection{Decomposition of the Bias: Irrationality or Exchange Risk Premia?}

Survey expectations data can be exploited to decompose the forward discount bias into portions attributable to irrational behavior of economic agents [equation (8)] or to the existence of time-varying risk premia [equation (10)] - see Frankel and Froot (1987b), Froot and Frankel (1989), MacDonald and Torrance (1989), and Taylor (1987), for instance.

To test the rationality of survey exchange rate expectations, a fairly standard test [see Pesaran (1987)] is considered - the orthogonality test. The orthogonality test aims to assess whether economic agents use information that is available to them efficiently to forecast future exchange rates. The null hypothesis of rational expectations (orthogonality) implies that $\alpha_{1}=0$ and $\beta_{1}=0$ in regressions of the following form: 


$$
S_{t+k}-E_{t} S_{t+k}=\alpha_{1}+\beta_{l}\left(F_{t+k}-S_{t}\right)+\varepsilon_{t+k},
$$

where the left-hand-side variable is the exchange rate forecast error and $e_{t+k}$ is a random error term. By inspection, the $\beta_{1}$-coefficient is precisely equal to $\beta_{1}$ in equation (8), reflecting a deviation from forward discount unbiasedness due to irrationality of economic agents. In order to test whether economic agents use all available information efficiently, equation (11) was fitted via the GMM procedure for each currency and for each forecast horizon.

Tables $4.3 \mathrm{a}, 4.3 \mathrm{~b}$, and $4.3 \mathrm{c}$ report regressions of the forecast error on the 3,6 , and 12 month ahead forward discount. The results provide a fairly consistent rejection of the null hypothesis for all forecast horizons for currencies relative to the US Dollar. Rejection of the hypothesis $\beta_{1}=0$ was obtained in twenty-one of the thirty cases relative to the US Dollar. This indicates that the forward discount contains additional information for the exchange rate forecasts of the major currencies relative to the US Dollar. Similar results were obtained by Dominguez (1986) for data over the 3 month forecast horizon. In contrast, the results for the exchange rates relative to the Deutschmark provide a less consistent rejection of the null hypothesis. Rejection of the hypothesis $\beta_{1}=0$ was obtained in only ten of the twenty-four exchange rates relative to the Deutschmark.

These results should be interpreted with some caution. If conditional forecast are formed rationally, allowing for a small probability of a large exchange rate movement, then forecasts will appear to be biased when judged from ex-post forecast errors. ${ }^{15}$ However, it is unlikely that this was the case over the ten year period considered by Dominiguez (1986) and the current authors together. An alternative explanation would be that the time series process which describes the expected exchange depreciation is not ergodic as is implied in the application of the GMM procedure.

Conditional on the hypothesis that the foreign exchange market is efficient or rational, the existence of time-varying premia has been documented in the literature by Fama (1984), Frankel (1982), Hansen and Hodrick (1980), Hodrick and Srivastava (1984), Hsieh (1984), Korajczyk (1985), and Wolff (1987a). Alternative methodologies to measure time-varying premia have

15 This is the familiar "peso-problem" - see Krasker (1980). 
Table 4.3A Tests of Rational Expectations: $S_{t+3}-E_{t} S_{t+3}=\alpha_{1}+\beta_{1}\left(F_{t+3}-S_{t}\right)+$ $e_{i+3}$. January 1, 1986 through December 1, 1990: 57 Observations

\begin{tabular}{|c|c|c|c|}
\hline & $\hat{\alpha}_{1}$ & $\hat{\beta}_{1}$ & $x^{2}$ \\
\hline JY/US & $\begin{array}{l}-0.1000^{\circ} \\
(0.0308)\end{array}$ & $\begin{array}{r}-12.1062 " * \\
(3.3247)\end{array}$ & $\begin{array}{l}13.41^{\circ} \\
(0.001)\end{array}$ \\
\hline SF/US & $\begin{array}{l}-0.0721^{*} \\
(0.0137)\end{array}$ & $\begin{array}{l}-6.7123^{*} \\
(2.8588)\end{array}$ & $\begin{array}{l}28.40^{\circ} \\
(0.000)\end{array}$ \\
\hline BP/US & $\begin{array}{c}0.0064 \\
(0.0249)\end{array}$ & $\begin{array}{l}-3.1161 \\
(2.0217)\end{array}$ & $\begin{array}{l}5.75 \\
(0.056)\end{array}$ \\
\hline CD/US & $\begin{array}{l}-0.0259^{\circ} \\
(0.0064)\end{array}$ & $\begin{array}{c}1.1592 \\
(0.7640)\end{array}$ & $\begin{array}{l}24.97^{\circ *} \\
(0.000)\end{array}$ \\
\hline FF/US & $\begin{array}{l}-0.0060 \\
(0.0147)\end{array}$ & $\begin{array}{l}-6.5709^{\prime \prime} \\
(1.8021)\end{array}$ & $\begin{array}{l}32.05 \% \\
(0.000)\end{array}$ \\
\hline DF/US & $\begin{array}{l}-0.0671^{*} \\
(0.0147)\end{array}$ & $\begin{array}{l}-9.2252^{*} \\
(2.6906)\end{array}$ & $\begin{array}{l}22.65^{\circ} \\
(0.000)\end{array}$ \\
\hline IL/US & $\begin{array}{c}0.0655 \% \\
(0.0212)\end{array}$ & $\begin{array}{l}-9.3296^{\circ} \\
(1.2599)\end{array}$ & $\begin{array}{c}149.16^{\circ} \\
(0.000)\end{array}$ \\
\hline BF/US & $\begin{array}{l}-0.0210 \\
(0.1380)\end{array}$ & $\begin{array}{l}-6.2524 \\
(3.5411)\end{array}$ & $\begin{array}{l}6.59^{\circ} \\
(0.037)\end{array}$ \\
\hline $\mathrm{DM} / \mathrm{US}$ & $\begin{array}{l}-0.0710^{\circ} \\
(0.0174)\end{array}$ & $\begin{array}{l}-7.4329^{\circ} \\
(2.6525)\end{array}$ & $\begin{array}{l}16.64^{\circ} \\
(0.000)\end{array}$ \\
\hline IP/US & $\begin{array}{l}-0.0213 \\
(0.0149)\end{array}$ & $\begin{array}{l}-0.0625 \\
(0.6744)\end{array}$ & $\begin{array}{l}2.29 \\
(0.319)\end{array}$ \\
\hline JY/DM & $\begin{array}{c}0.0013 \\
(0.0108)\end{array}$ & $\begin{array}{l}-8.3810^{\circ} \\
(2.5654)\end{array}$ & $\begin{array}{l}10.79^{\circ} \\
(0.004)\end{array}$ \\
\hline $\mathrm{SF} / \mathrm{OH}$ & $\begin{array}{c}0.0014 \\
(0.0050)\end{array}$ & $\begin{array}{l}-2.8638 \\
(2.5477)\end{array}$ & $\begin{array}{l}2.26 \\
(0.324)\end{array}$ \\
\hline $\mathrm{BP} / \mathrm{DM}$ & $\begin{array}{l}-0.0088 \\
(0.0287)\end{array}$ & $\begin{array}{c}0.8281 \\
(1.7461)\end{array}$ & $\begin{array}{c}0.32 \\
(0.853)\end{array}$ \\
\hline $\mathrm{CD} / \mathrm{OM}$ & $\begin{array}{c}0.0332 \\
(0.0382)\end{array}$ & $\begin{array}{l}-2.3138 \\
(4.2222)\end{array}$ & $\begin{array}{c}1.13 \\
(0.569)\end{array}$ \\
\hline $\mathrm{FF} / \mathrm{DM}$ & $\begin{array}{l}-0.0098^{\circ} \\
(0.0040)\end{array}$ & $\begin{array}{c}1.1625^{\circ} \\
(0.4984)\end{array}$ & $\begin{array}{c}6.32^{\circ} \\
(0.042)\end{array}$ \\
\hline$D F / D M$ & $\begin{array}{c}0.0005 \\
(0.0029)\end{array}$ & $\begin{array}{l}-1.6543 \\
(1.4219)\end{array}$ & $\begin{array}{l}5.92 \\
(0.052)\end{array}$ \\
\hline $11 / D M$ & $\begin{array}{c}0.0328^{\circ} \\
(0.0142)\end{array}$ & $\begin{array}{l}-2.2123^{\circ} \\
(0.7337)\end{array}$ & $\begin{array}{l}17.48^{*} \\
(0.000)\end{array}$ \\
\hline$B F / D M$ & $\begin{array}{l}-0.0021 \\
(0.0031)\end{array}$ & $\begin{array}{l}-0.0079 \\
(0.2369)\end{array}$ & $\begin{array}{c}1.22 \\
(0.542)\end{array}$ \\
\hline
\end{tabular}

The Standard errors of the coefficients are given in parentheses; $\left.{ }^{* * *}\right)$ denotes rejection at the $5 \%$ (1\%) level for the hypotheses that $\alpha_{1}=0$ and $\beta_{1}=0$. The Chi-square Statistic pertains to the joint hypothesis that $\alpha_{1}=0$ and $\beta_{1}=0$ ( $p$-Values are given in parentheses). 
Table 4.3B Tests of Rational Expectations: $S_{t+6}-E_{t} S_{t+6}=\alpha_{1}+\beta_{1}\left(F_{t+6}-S_{t}\right)+$ $e_{t+6}$.

January 1, 1986 through December 1, 1990: 54 Observations

\begin{tabular}{|c|c|c|c|}
\hline & $\hat{\alpha}_{1}$ & $\hat{\beta}_{1}$ & $\chi^{2}$ \\
\hline JY/US & $\begin{array}{l}-0.1581 \\
(0.0473)\end{array}$ & $\begin{array}{l}-9.7537^{\circ} \\
(2.5536)\end{array}$ & $\begin{array}{l}14.63^{\circ} \\
(0.000)\end{array}$ \\
\hline SF/US & $\begin{array}{l}-0.1011^{*} \\
(0.0255)\end{array}$ & $\begin{array}{l}-4.1794^{\circ} \\
(1.7911)\end{array}$ & $\begin{array}{l}16.96^{\circ} \\
(0.000)\end{array}$ \\
\hline BP/US & $\begin{array}{c}0.0279 \\
(0.0430)\end{array}$ & $\begin{array}{l}-4.0545^{\circ} \\
(1.9094)\end{array}$ & $\begin{array}{l}10.28^{*} \\
(0.006)\end{array}$ \\
\hline CD/US & $\begin{array}{l}-0.0395 " \\
(0.0107)\end{array}$ & $\begin{array}{c}0.4612 \\
(0.6967)\end{array}$ & $\begin{array}{l}34.12^{\prime \prime} \\
(0.000)\end{array}$ \\
\hline FF/US & $\begin{array}{l}-0.0180 \\
(0.0249)\end{array}$ & $\begin{array}{l}-5.0207^{\circ} \\
(1.4699)\end{array}$ & $\begin{array}{l}30.02 \% \\
(0.000)\end{array}$ \\
\hline DF/US & $\begin{array}{l}-0.1210^{\circ} \\
(0.0269)\end{array}$ & $\begin{array}{l}-7.8593^{\circ} \\
(2.8380)\end{array}$ & $\begin{array}{l}20.40^{\circ} \\
(0.000)\end{array}$ \\
\hline IL/US & $\begin{array}{c}0.0953^{*} \\
(0.0307)\end{array}$ & $\begin{array}{l}-7.4155^{\circ} \\
(1.003)\end{array}$ & $\begin{array}{l}89.30^{\circ} \\
(0.000)\end{array}$ \\
\hline BF/US & $\begin{array}{l}-0.0491^{\circ} \\
(0.0174)\end{array}$ & $\begin{array}{l}-8.1168 \\
(1.4254)\end{array}$ & $\begin{array}{l}38.75^{\circ} \\
(0.000)\end{array}$ \\
\hline DH/US & $\begin{array}{l}-0.1339^{\circ} \\
(0.0238)\end{array}$ & $\begin{array}{l}-7.1149^{\circ} \\
(2.3486)\end{array}$ & $\begin{array}{l}32.19^{\circ} \\
(0.000)\end{array}$ \\
\hline IP/US & $\begin{array}{l}-0.0375 \\
(0.0268)\end{array}$ & $\begin{array}{l}-0.4151 \\
(0.9606)\end{array}$ & $\begin{array}{l}6.05^{\circ} \\
(0.049)\end{array}$ \\
\hline JY/DM & $\begin{array}{c}0.0058 \\
(0.0159)\end{array}$ & $\begin{array}{l}-9.9223^{\circ} \\
(2.2635)\end{array}$ & $\begin{array}{l}21.06 . \\
(0.000)\end{array}$ \\
\hline SF/OH & $\begin{array}{c}0.0033 \\
(0.0053)\end{array}$ & $\begin{array}{l}-1.3154^{\circ} \\
(0.1927)\end{array}$ & $\begin{array}{l}67.92^{\circ} \\
(0.000)\end{array}$ \\
\hline BP/DH & $\begin{array}{l}-0.0513 \\
(0.0942)\end{array}$ & $\begin{array}{c}1.9817 \\
(3.2813)\end{array}$ & $\begin{array}{l}0.40 \\
(0.817)\end{array}$ \\
\hline$C D / D M$ & $\begin{array}{c}0.1259^{\circ} \\
(0.0488)\end{array}$ & $\begin{array}{l}-5.1209 \\
(3.3532)\end{array}$ & $\begin{array}{l}90.81 * \\
(0.005)\end{array}$ \\
\hline FF/DH & $\begin{array}{l}-0.0153^{\circ} \\
(0.0073)\end{array}$ & $\begin{array}{c}0.8080 \\
(0.5261)\end{array}$ & $\begin{array}{c}4.46 \\
(0.107)\end{array}$ \\
\hline DF/DM & $\begin{array}{c}0.0004 \\
(0.0010)\end{array}$ & $\begin{array}{l}-0.3628 \\
(0.3093)\end{array}$ & $\begin{array}{c}1.61 \\
(0.447)\end{array}$ \\
\hline IL/DH & $\begin{array}{c}0.0142 \\
(0.0114)\end{array}$ & $\begin{array}{l}-0.7235^{\circ} \\
(0.2430)\end{array}$ & $\begin{array}{l}16.54^{\circ} \\
(0.000)\end{array}$ \\
\hline$B F / D H$ & $\begin{array}{l}-0.0048 \\
(0.0048)\end{array}$ & $\begin{array}{l}-0.0466 \\
(0.3609)\end{array}$ & $\begin{array}{c}6.04^{\circ} \\
(0.049)\end{array}$ \\
\hline
\end{tabular}

The Standard errors of the coefficients are given in parentheses; ${ }^{*}\left({ }^{*}\right)$ denotes rejection at the $5 \%$ (1\%) level for the hypotheses that $\alpha_{1}=0$ and $\beta_{1}=0$. The Chi-square Statistic pertains to the joint hypothesis that $\alpha_{1}=0$ and $\beta_{1}=0$ ( $\mathrm{p}$-Values are given in parentheses). 
Table 4.3C Tests of Rational Expectations: $S_{t+12}-E_{\tau} S_{t+12}=\alpha_{1}+\beta_{1}\left(F_{t+12}-S_{t}\right)$ $+e_{t+12}$.

January 1, 1986 through December 1, 1990: 48 Observations

\begin{tabular}{|c|c|c|c|}
\hline & $\hat{\alpha}_{1}$ & $\hat{\beta}_{1}$ & $x^{2}$ \\
\hline JY/US & $\begin{array}{l}-0.3655^{*} \\
(0.0272)\end{array}$ & $\begin{array}{r}-10.8515^{\circ} \\
(0.9510)\end{array}$ & $\begin{array}{c}197.44 " \\
(0.000)\end{array}$ \\
\hline SF/US & $\begin{array}{l}-0.3839 * \\
(0.0412)\end{array}$ & $\begin{array}{l}-9.6734^{\circ} \\
(1.64 \pi 5)\end{array}$ & $\begin{array}{l}91.99 " 1 \\
(0.000)\end{array}$ \\
\hline BP /US & $\begin{array}{c}0.0950 \\
(0.0536)\end{array}$ & $\begin{array}{l}-6.0015^{\circ} \\
(0.9612)\end{array}$ & $\begin{array}{r}108.31 " * \\
(0.000)\end{array}$ \\
\hline CD/US & $\begin{array}{l}-0.0796 \\
(0.0263)\end{array}$ & $\begin{array}{c}0.9813 \\
(1.1679)\end{array}$ & $\begin{array}{l}30.67^{\circ} \\
(0.000)\end{array}$ \\
\hline FF/US & $\begin{array}{l}-0.0479 \\
(0.0443)\end{array}$ & $\begin{array}{l}-4.0361^{*} \\
(1.2017)\end{array}$ & $\begin{array}{l}19.07^{\circ} \\
(0.000)\end{array}$ \\
\hline DF/US & $\begin{array}{l}-0.1642^{*} \\
(0.0346)\end{array}$ & $\begin{array}{l}-3.5131 \\
(2.4505)\end{array}$ & $\begin{array}{l}24.36 \% \\
(0.000)\end{array}$ \\
\hline IL/US & $\begin{array}{c}0.1326^{\circ} \\
(0.0615)\end{array}$ & $\begin{array}{l}-5.9186 \\
(1.0612)\end{array}$ & $\begin{array}{l}55.40^{\circ} \\
(0.000)\end{array}$ \\
\hline$B F / U S$ & $\begin{array}{l}-0.1082 \\
(0.0323)\end{array}$ & $\begin{array}{l}-8.3153 * \\
(2.0723)\end{array}$ & $\begin{array}{l}28.01 \% \\
(0.000)\end{array}$ \\
\hline DM/US & $\begin{array}{l}-0.2987^{\circ} \\
(0.0406)\end{array}$ & $\begin{array}{l}-7.8569^{\circ} \\
(1.9181)\end{array}$ & $\begin{array}{l}59.45^{\circ} \\
(0.000)\end{array}$ \\
\hline IP/US & $\begin{array}{l}-0.0852 \\
(0.0419)\end{array}$ & $\begin{array}{l}-0.8260 \\
(0.6570)\end{array}$ & $\begin{array}{l}17.66 \% \\
(0.000)\end{array}$ \\
\hline JY/DM & $\begin{array}{c}0.0282 \\
(0.0369)\end{array}$ & $\begin{array}{l}-6.8126^{\circ} \\
(3.1927)\end{array}$ & $\begin{array}{l}6.80^{\circ} \\
(0.033)\end{array}$ \\
\hline SF/DM & $\begin{array}{l}-0.0016 \\
(0.0083)\end{array}$ & $\begin{array}{l}-3.4652^{*} \\
(0.9068)\end{array}$ & $\begin{array}{l}21.33^{\circ} \\
(0.000)\end{array}$ \\
\hline$B P / D M$ & $\begin{array}{l}-0.2110^{\circ} \\
(0.0994)\end{array}$ & $\begin{array}{c}4.0824 \cdot * \\
(1.7339)\end{array}$ & $\begin{array}{c}5.86 \\
(0.053)\end{array}$ \\
\hline $\mathrm{CD} / \mathrm{OM}$ & $\begin{array}{c}0.4099^{\circ} \\
(0.0768)\end{array}$ & $\begin{array}{l}-8.7447 \\
(2.4039)\end{array}$ & $\begin{array}{l}36.28 " \\
(0.000)\end{array}$ \\
\hline $\mathrm{FF} / \mathrm{DH}$ & $\begin{array}{l}-0.0309 . \\
(0.0099)\end{array}$ & $\begin{array}{c}0.8442^{\circ} \\
(0.3557)\end{array}$ & $\begin{array}{c}9.80^{\circ} \\
(0.007)\end{array}$ \\
\hline $\mathrm{DF} / \mathrm{DM}$ & $\begin{array}{l}-0.0006 \\
(0.0014)\end{array}$ & $\begin{array}{l}-0.0526 \\
(0.1618)\end{array}$ & $\begin{array}{l}1.65 \\
(0.438)\end{array}$ \\
\hline IL/DK & $\begin{array}{l}-0.0010 \\
(0.0213)\end{array}$ & $\begin{array}{l}-0.0991 \\
(0.1907)\end{array}$ & $\begin{array}{c}2.09 \\
(0.352)\end{array}$ \\
\hline$B F / D H$ & $\begin{array}{l}-0.0225 * \\
(0.0082)\end{array}$ & $\begin{array}{c}0.6007 \\
(0.3695)\end{array}$ & $\begin{array}{l}17.28^{\circ} \\
(0.006)\end{array}$ \\
\hline
\end{tabular}

The Standard errors of the coefficients are given in parentheses; * $(* *)$ denotes rejection at the $5 \%(1 \%)$ level for the hypotheses that $\alpha_{1}=0$ and $\beta_{1}=0$. The Chi-square Statistic pertains to the joint hypothesis that $\alpha_{1}=0$ and $\beta_{1}=0$ ( $p$-Values are given in parentheses). 
been explored in the literature.

First, models that are based strictly on the time series properties of spot and forward exchange rates and assets prices were examined - see the latent variable model of Hansen and Hodrick (1983) with its extensions by Hodrick and Srivastava (1984), Campbell and Clarida (1987), and Giovannini and Jorion (1987). Hansen and Hodrick (1983) relied on the first-order conditions of optimality for a rational representative investor to construct a singlebeta latent variable model to measure risk. They find that there is little evidence against the restrictions imposed by the model and conclude that the latent variable model captures most of the significant variation in the deviation of expected spot rates from forward rates. Hodrick and Srivastava (1984) re-examined the Hansen and Hodrick model and statistically rejected the restriction imposed by the model. They conclude that either parameter instability is responsible for rejection of the latent variable model or some other model of risk and return is necessary to describe equilibrium in the forward market. The presence of conditional heteroskedasticity in forward rate forecast errors prompted Domowitz and Hakkio (1985) to model a timevarying risk premium using the autoregressive conditional heteroskedasticity (ARCH) framework. The theory is taken from Lucas (1982), and the econometric analysis build on the work of Engle (1982). They conclude that their results are generally consistent with the rejection of the unbiasedness hypothesis, but "there is little support for the conditional variance of the exchange rate forecast error being an important sole determinant of the risk premium." Korajczyk (1985) noted that the variability of risk premia in theory can be related to variations in expected real interest rates.

A second approach is to employ some measurement of market fundamentals in an attempt to test specific theories of the risk premium. Frankel (1982) and Frankel and Engel (1984) examined an asset market equilibrium model based on assets demands derived from a two-period mean-variance maximization problem.

The third approach for assessing the risk premium interpretation (the existence of time-varying risk premia) attempts to measure expected depreciation directly, thereby avoiding reliance on inferences from realized depreciations - see Frankel and Froot (1987b), and Froot and Frankel (1989), for instance. This would not tell us about the economic determinants of risk premia, but it could tell us about the importance of risk and market inefficiency in explaining the forward discount bias. 
In order to test whether the existence of time-varying risk premia is the economically important reason for rejection of forward market efficiency, the following equation may be fitted: ${ }^{16}$

$$
E_{t} S_{t+k}-S_{t}=\alpha_{2}+\beta_{2}\left(F_{t+k}-S_{t}\right)+\varepsilon_{t}
$$

where $e_{t}$ is a random error term. The null hypothesis of perfect substitutability implies that $\alpha_{2}=0$ and $\beta_{2}=1$. The degree to which changes in the forward discount reflect changes in the risk premium can be inferred from a regression of expected depreciation on the forward discount [equation (12)]. Under the hypothesis that the correlation of the risk premium with the forward discount is zero (no time-varying risk premia), $\beta_{2}$ wil equal one. By inspection, the $\beta_{2}$-coefficient is precisely equal to $\beta_{2}$ in equation (10), reflecting a deviation from forward discount unbiasedness due to the existence of time-varying risk premia. The results of fitting equation (12) for each currency and for each forecast horizon ( $k=3,6$, and 12 months) are reported in Tables $4 \mathrm{a}, 4 \mathrm{~b}$, and $4 \mathrm{c}$. Overall, the evidence presented suggests a fairly consistent rejection of the hypothesis of perfect substitutability (33 out of 54 possible cases). Rejection of the hypothesis $\beta_{2}=1$ (no time-varying risk premia) was obtained in twenty-three of the fifty-four bilateral exchange rates, so there is considerable evidence of significant variation in risk premia. This further supports the critique made in the introductory section of this chapter suggesting that the pooling of the Japanese Yen, British Pound, Swiss Franc, and German Mark [as carried out by Froot and Frankel (1989)] can potentially obfuscate interesting empirical regularities. Similar results were obtained by MacDonald and Torrance (1989) for survey based tests of uncovered interest parity. In contrast, Frankel and Froot (1987b) and Froot and Frankel (1989) obtain estimates of $\beta_{2}$ that were insignificantly different from one, suggesting that changes in the forward discount primarly reflect changes in expected depreciation rather than changes in the risk premium. It is interesting to note, though, that the results for the EMS exchange rates

16 When the expected depreciation is on the left-hand side of the regressions, forecast horizons longer than the observational frequency do not themselves imply that the error term is serially correlated, since expectations are formed using only contemporaneous and past information. Therefore, equation 12 was estimated using the standard OLS procedure. 
relative to the Deutschmark provide a fairly consistent rejection of the hypothesis $\beta_{2}=1$, indicating that variation in the forward discount primarily reflects changes in the risk premium. On the other hand, the point estimates for non-EMS currencies relative to the Deutschmark suggest that there is no significant variation in risk premia, as evidenced by estimates of $\beta_{2}$ that are insignificantly different from one.

Taken together, the results of both tests - the rationality test and the test of perfect substitutability - suggest that for exchange rates relative to the US Dollar rejection of forward market efficiency is attributable to both irrationality of exchange rate expectations and significant variation in risk premia. However, the results for EMS exchange rates relative to the Deutschmark suggest that rejection of the unbiasedness hypothesis in most instances implies that significant variation in risk premia is the more important explanation, whereas the results for non-EMS currencies relative to the Deutschmark suggest that the forward discount bias is almost entirely due to irrationality and that almost none is due to significant variation in risk premia.

\subsection{Statistical Properties of the Risk Premium}

Theoretical models and empirical analysis of exchange rate risk premia has largely been conditioned on the assumption that economic agents are rational - see for instance the latent variable model of Hansen and Hodrick (1983) with its extensions by Hodrick and Srivastava (1984) and the empirical analysis of Hsieh (1984) and Wolff (1987a). In this section we examine whether the statistical properties of the risk premia that have previously been documented are robust to our constructed premia series which do not rely on the assumption of rationality. We consider the relative size of the risk premia, its correlation with expected exchange rate depreciation, and its time series properties.

As was stated in section 1, Fama (1984) and Hodrick and Srivastava (1986) demonstrate that rejection of forward market efficiency in most instances implies that risk premia are more variable than expected rates of depreciation and that the two covary negatively. In his review of this issue, Bilson (1985) argues the existence of a new "empirical paradigma": the variation in the forward discount consists entirely of variation in exchange 
Table 4.4A Tests of Perfect Substitutability: $E_{t} S_{t+3}-S_{t}=\alpha_{2}+\beta_{2}\left(F_{t} F_{t+3}-S_{t}\right)+e_{t}$ January 1, 1986 through December 1, 1990: 57 Observations

\begin{tabular}{|c|c|c|c|}
\hline & $\hat{\alpha}_{2}$ & $\hat{\beta}_{2}$ & $x^{2}$ \\
\hline JY/US & $\begin{array}{c}0.0075 \\
(0.0041)\end{array}$ & $\begin{array}{r}2.50300^{\circ} \\
(0.5207)\end{array}$ & $\begin{array}{c}9.37^{\circ} \\
(0.009)\end{array}$ \\
\hline SF/US & $\begin{array}{l}-0.0000 \\
(0.0036)\end{array}$ & $\begin{array}{c}1.1743 \\
(0.4891)\end{array}$ & $\begin{array}{c}0.240 \\
(0.887)\end{array}$ \\
\hline BP/US & $\begin{array}{l}-0.0156 . \\
(0.0031)\end{array}$ & $\begin{array}{c}1.9960^{\circ} \\
(0.2026)\end{array}$ & $\begin{array}{l}27.92 \% \\
(0.000)\end{array}$ \\
\hline CO/US & $\begin{array}{c}0.0073 \\
(0.0026)\end{array}$ & $\begin{array}{l}-0.2497^{\circ} \\
(0.5029)\end{array}$ & $\begin{array}{c}8.08^{\circ} \\
(0.018)\end{array}$ \\
\hline FF/US & $\begin{array}{l}-0.019{ }^{\circ} \\
(0.0025)\end{array}$ & $\begin{array}{c}3.1450^{\circ} \\
(0.5636)\end{array}$ & $\begin{array}{l}24.36 \\
(0.000)\end{array}$ \\
\hline DF/US & $\begin{array}{l}-0.0029 \\
(0.0036)\end{array}$ & $\begin{array}{c}2.2215^{\circ} \\
(0.5957)\end{array}$ & $\begin{array}{c}4.68 \\
(0.097)\end{array}$ \\
\hline IL/US & $\begin{array}{l}-0.0410^{\circ} \\
(0.0092)\end{array}$ & $\begin{array}{c}4.1563^{*} \\
(0.9247)\end{array}$ & $\begin{array}{l}26.92 \% \\
(0.000)\end{array}$ \\
\hline BF/US & $\begin{array}{l}-0.0069 " \\
(0.0027)\end{array}$ & $\begin{array}{c}2.0519 \\
(1.1135)\end{array}$ & $\begin{array}{c}8.01^{\circ} \\
(0.018)\end{array}$ \\
\hline DH/US & $\begin{array}{l}-0.0008 \\
(0.0048)\end{array}$ & $\begin{array}{c}1.2573 \\
(0.5973)\end{array}$ & $\begin{array}{c}1.17 \\
(0.558)\end{array}$ \\
\hline IP/US & $\begin{array}{l}-0.0100 \\
(0.0038)\end{array}$ & $\begin{array}{r}1.0441 \\
(0.2139)\end{array}$ & $\begin{array}{l}7.72^{\circ} \\
(0.021)\end{array}$ \\
\hline JY/DM & $\begin{array}{l}-0.0017 \\
(0.0018)\end{array}$ & $\begin{array}{c}0.9355 \\
(0.5432)\end{array}$ & $\begin{array}{c}1.02 \\
(0.600)\end{array}$ \\
\hline SF/OM & $\begin{array}{l}-0.0018 \\
(0.0014)\end{array}$ & $\begin{array}{c}0.9353 \\
(0.6445)\end{array}$ & $\begin{array}{l}1.49 \\
(0.474)\end{array}$ \\
\hline$B P / D M$ & $\begin{array}{c}0.0024 \\
(0.0048)\end{array}$ & $\begin{array}{c}0.5976 \\
(0.3746)\end{array}$ & $\begin{array}{c}5.19 \\
(0.075)\end{array}$ \\
\hline CD/DM & $\begin{array}{c}0.0088 \\
(0.0104)\end{array}$ & $\begin{array}{c}0.2006 \\
(1.0242)\end{array}$ & $\begin{array}{c}0.71 \\
(0.699)\end{array}$ \\
\hline FF/OM & $\begin{array}{l}-0.0006 \\
(0.0016)\end{array}$ & $\begin{array}{c}0.75 \pi \\
(0.1688)\end{array}$ & $\begin{array}{l}21.44 \% \\
(0.000)\end{array}$ \\
\hline DF/DM & $\begin{array}{l}-0.0001 \\
(0.0025)\end{array}$ & $\begin{array}{c}1.6358 \\
(1.3487)\end{array}$ & $\begin{array}{c}1.19 \\
(0.552)\end{array}$ \\
\hline IL/DM & $\begin{array}{l}-0.0280^{\circ} \\
(0.0121)\end{array}$ & $\begin{array}{c}2.3393^{\circ} \\
(0.6998)\end{array}$ & $\begin{array}{c}9.83 \% \\
(0.007)\end{array}$ \\
\hline $\mathrm{BF} / \mathrm{DM}$ & $\begin{array}{c}0.0013 \\
(0.0022)\end{array}$ & $\begin{array}{c}0.2704 " \\
(0.2447)\end{array}$ & $\begin{array}{l}15.48^{*} \\
(0.000)\end{array}$ \\
\hline
\end{tabular}

The Standard errors of the coefficients are given in parentheses; * $\left({ }^{* *}\right)$ denotes rejection at the $5 \%$ (1\%) level for the bypotheses that $\alpha_{2}=0$ and $\beta_{2}=1$. The Chi-square Statistic pertains to the joint hypothesis that $\alpha_{2}=0$ and $\beta_{2}=1$ ( $\mathrm{p}$-Values are given in parentheses). 
Table 4.4B Tests of Perfect Substitutability: $E_{t} S_{t+6}-S_{t}=\alpha_{2}+\beta_{2}\left(F_{t+6}-S_{t}\right)+e_{t}$ January 1, 1986 through December 1, 1990: 54 Observations

\begin{tabular}{|c|c|c|c|}
\hline & $\hat{\alpha}_{2}$ & $\hat{\beta}_{2}$ & $x^{2}$ \\
\hline JY/US & $\begin{array}{c}0.0058 \\
(0.0120)\end{array}$ & $\begin{array}{c}1.3383 \\
(0.6423)\end{array}$ & $\begin{array}{c}0.28 \\
(0.868)\end{array}$ \\
\hline SF/US & $\begin{array}{c}0.0028 \\
(0.0050)\end{array}$ & $\begin{array}{c}0.8337 \\
(0.2741)\end{array}$ & $\begin{array}{c}1.99 \\
(0.369)\end{array}$ \\
\hline BP/US & $\begin{array}{l}-0.0147^{\circ} \\
(0.0062)\end{array}$ & $\begin{array}{c}1.4758 \\
(0.3132)\end{array}$ & $\begin{array}{c}7.86^{\circ} \\
(0.020)\end{array}$ \\
\hline CD/US & $\begin{array}{c}0.0062 * \\
(0.0023)\end{array}$ & $\begin{array}{c}0.3953^{\circ} \\
(0.2102)\end{array}$ & $\begin{array}{c}8.66^{\circ} \\
(0.013)\end{array}$ \\
\hline FF/US & $\begin{array}{l}-0.0111^{*} \\
(0.0032)\end{array}$ & $\begin{array}{r}2.2231 \% \\
(0.3598)\end{array}$ & $\begin{array}{l}14.17^{\circ} \\
(0.000)\end{array}$ \\
\hline DF/US & $\begin{array}{c}0.0068 \\
(0.0053)\end{array}$ & $\begin{array}{c}1.6240 \\
(0.5164)\end{array}$ & $\begin{array}{c}1.74 \\
(0.419)\end{array}$ \\
\hline IL/US & $\begin{array}{l}-0.0436 . \\
(0.0098)\end{array}$ & $\begin{array}{c}2.6067^{\circ} \\
(0.5164)\end{array}$ & $\begin{array}{l}37.73 * \\
(0.000)\end{array}$ \\
\hline BF/US & $\begin{array}{l}-0.0039 \\
(0.0037)\end{array}$ & $\begin{array}{c}2.0172 \\
(0.5858)\end{array}$ & $\begin{array}{c}3.98 \\
(0.137)\end{array}$ \\
\hline OM/US & $\begin{array}{c}0.0099 \\
(0.0060)\end{array}$ & $\begin{array}{c}1.4747 \\
(0.3965)\end{array}$ & $\begin{array}{c}2.89 \\
(0.236)\end{array}$ \\
\hline IPIUS & $\begin{array}{l}-0.0085^{\circ} \\
(0.0045)\end{array}$ & $\begin{array}{c}0.9089 \\
(0.2130)\end{array}$ & $\begin{array}{l}3.63 \\
(0.163)\end{array}$ \\
\hline JY/OM & $\begin{array}{l}-0.0049 \\
(0.0036)\end{array}$ & $\begin{array}{c}1.1953 \\
(0.4751)\end{array}$ & $\begin{array}{c}1.86 \\
(0.394)\end{array}$ \\
\hline SF $/ D H$ & $\begin{array}{l}-0.0031 \\
(0.0017)\end{array}$ & $\begin{array}{c}0.2609 \% \\
(0.1023)\end{array}$ & $\begin{array}{l}63.94 . \\
(0.000)\end{array}$ \\
\hline $\mathrm{BP} / \mathrm{DH}$ & $\begin{array}{l}-0.0019 \\
(0.0105)\end{array}$ & $\begin{array}{c}0.5653 \\
(0.3748)\end{array}$ & $\begin{array}{l}32.59^{\circ} \\
(0.000)\end{array}$ \\
\hline $\mathrm{CO} / \mathrm{DH}$ & $\begin{array}{l}-0.0189 \\
(0.0202)\end{array}$ & $\begin{array}{c}1.4748 \\
(0.9332)\end{array}$ & $\begin{array}{c}4.74 \\
(0.093)\end{array}$ \\
\hline FF/OK & $\begin{array}{l}-0.0014 \\
(0.0021)\end{array}$ & $\begin{array}{r}0.7727^{\circ} \\
(0.1215)\end{array}$ & $\begin{array}{l}26.58^{\circ} \\
(0.000)\end{array}$ \\
\hline OF $/ D H$ & $\begin{array}{c}0.0000 \\
(0.0009)\end{array}$ & $\begin{array}{c}0.3040^{\circ} \\
(0.2990)\end{array}$ & $\begin{array}{c}9.79^{*} \\
(0.008)\end{array}$ \\
\hline IL/DH & $\begin{array}{l}-0.0077 \\
(0.0054)\end{array}$ & $\begin{array}{c}0.8789 \\
(0.1744)\end{array}$ & $\begin{array}{l}73.00^{\circ} \\
(0.000)\end{array}$ \\
\hline $\mathrm{BF} / \mathrm{DH}$ & $\begin{array}{l}-0.0062 \\
(0.0038)\end{array}$ & $\begin{array}{c}1.0429 \\
(0.3401)\end{array}$ & $\begin{array}{l}24.41^{\circ} \\
(0.000)\end{array}$ \\
\hline
\end{tabular}

The Standard errors of the coefficients are given in parentheses; * $\left(^{* *}\right)$ denotes rejection at the $5 \%$ (1\%) level for the hypotheses that $\alpha_{2}=0$ and $\beta_{2}=1$. The Chi-square Statistic pertains to the joint hypothesis that $\alpha_{2}=0$ and $\beta_{2}=1$ ( $p$-Values are given in parentheses). 
Table 4.4C Tests of Perfect Substitutability: $E_{t} S_{t+12}-S_{t}=\alpha_{2}+\beta_{2}\left(F_{t}+12-S_{t}\right)+$ $\mathrm{e}_{\mathrm{t}}$

January 1, 1986 through December 1, 1990: 48 Observations

\begin{tabular}{|c|c|c|c|}
\hline & $\hat{\alpha}_{2}$ & $\hat{\beta}_{2}$ & $x^{2}$ \\
\hline JY/US & $\begin{array}{c}0.0339^{\circ} \\
(0.0118)\end{array}$ & $\begin{array}{c}1.3090 \\
(0.3368)\end{array}$ & $\begin{array}{l}29.33 \% \\
(0.000)\end{array}$ \\
\hline SF/US & $\begin{array}{c}0.0293^{*} \\
(0.0126)\end{array}$ & $\begin{array}{c}1.0144 \\
(0.3418)\end{array}$ & $\begin{array}{l}32.94 \% \\
(0.000)\end{array}$ \\
\hline $\mathrm{BP} / \mathrm{US}$ & $\begin{array}{c}0.0080 \\
(0.0087)\end{array}$ & $\begin{array}{c}0.5474 \\
(0.3183)\end{array}$ & $\begin{array}{c}3.11 \\
(0.211)\end{array}$ \\
\hline co/us & $\begin{array}{c}0.0061 \\
(0.0053)\end{array}$ & $\begin{array}{c}0.4761 \\
(0.3014)\end{array}$ & $\begin{array}{l}5.97 \\
(0.051)\end{array}$ \\
\hline FF/US & $\begin{array}{l}-0.0030 \\
(0.0041)\end{array}$ & $\begin{array}{c}1.8023 * \\
(0.2723)\end{array}$ & $\begin{array}{l}10.65^{\circ} \\
(0.005)\end{array}$ \\
\hline OF/US & $\begin{array}{c}0.0057 \\
(0.0106)\end{array}$ & $\begin{array}{c}0.4079 \\
(0.4804)\end{array}$ & $\begin{array}{l}17.70^{\circ} \\
(0.000)\end{array}$ \\
\hline IL/US & $\begin{array}{l}-0.0497^{\circ} \\
(0.0126)\end{array}$ & $\begin{array}{c}1.9165^{\circ} \\
(0.3462)\end{array}$ & $\begin{array}{l}32.81^{\prime \prime} \\
(0.000)\end{array}$ \\
\hline BF/US & $\begin{array}{c}0.0079 \\
(0.0043)\end{array}$ & $\begin{array}{r}2.0154^{\circ} \\
(0.3500)\end{array}$ & $\begin{array}{c}9.83^{*} \\
(0.007)\end{array}$ \\
\hline DH/US & $\begin{array}{c}0.0128 \\
(0.0110)\end{array}$ & $\begin{array}{c}0.6179 \\
(0.3526)\end{array}$ & $\begin{array}{l}27.01^{-*} \\
(0.000)\end{array}$ \\
\hline IP/US & $\begin{array}{c}0.0056 \\
(0.0069)\end{array}$ & $\begin{array}{r}0.3510^{\circ} \\
(0.2826)\end{array}$ & $\begin{array}{l}5.28 \\
(0.071)\end{array}$ \\
\hline JY/DM & $\begin{array}{l}-0.0021 \\
(0.0027)\end{array}$ & $\begin{array}{c}0.3987^{\circ} \\
(0.2065)\end{array}$ & $\begin{array}{c}8.70^{\circ} \\
(0.013)\end{array}$ \\
\hline SF/DM & $\begin{array}{l}-0.0005 \\
(0.0022)\end{array}$ & $\begin{array}{c}0.7408 \\
(0.3519)\end{array}$ & $\begin{array}{l}0.66 \\
(0.718)\end{array}$ \\
\hline BP/DM & $\begin{array}{c}0.0017 \\
(0.0178)\end{array}$ & $\begin{array}{c}0.4566 \\
(0.3252)\end{array}$ & $\begin{array}{l}91.49^{\circ} \\
(0.000)\end{array}$ \\
\hline$C D / D M$ & $\begin{array}{l}-0.0461 \\
(0.0298)\end{array}$ & $\begin{array}{c}1.3049 \\
(0.6673)\end{array}$ & $\begin{array}{l}41.45^{\circ} \\
(0.000)\end{array}$ \\
\hline FF/DM & $\begin{array}{c}0.0021 \\
(0.0041)\end{array}$ & $\begin{array}{c}0.4423^{*} \\
(0.1195)\end{array}$ & $\begin{array}{c}132.17 \\
(0.000)\end{array}$ \\
\hline OF/DM & $\begin{array}{c}0.0003 \\
(0.0020)\end{array}$ & $\begin{array}{c}0.0948^{*} \\
(0.2593)\end{array}$ & $\begin{array}{l}36.05^{* 1} \\
(0.000)\end{array}$ \\
\hline IL/DM & $\begin{array}{c}0.0090 \\
(0.0142)\end{array}$ & $\begin{array}{c}0.3158^{\circ} \\
(0.2222)\end{array}$ & $\begin{array}{c}229.06 \% \\
(0.000)\end{array}$ \\
\hline BF/DM & $\begin{array}{c}0.0034 \\
(0.0065)\end{array}$ & $\begin{array}{c}0.2657^{\prime \prime} \\
(0.2877)\end{array}$ & $\begin{array}{l}54.37^{\circ} \\
(0.000)\end{array}$ \\
\hline
\end{tabular}

The Standard errors of the coefficients are given in parentheses; ${ }^{* * *}$ denotes rejection at the $5 \%$ (1\%) level for the hypotheses that $\alpha_{2}=0$ and $\beta_{2}=1$. The Chi-square Statistic pertains to the joint hypothesis that $\alpha_{2}=0$ and $\beta_{2}=1$ ( $p$-Values are given in parentheses). 
risk premia, and not at all of variation in expected rates of depreciation. Thus, although empirical evidence suggests that the random walk hypothesis is a relatively accurate characterization of the time series of exchange rates see Meese and Rogoff (1983a and 1983b) and Wolff (1987b) ${ }^{17}$ - it would seem that the random walk may also be a proper characterization of investor's expectations formation, namely that $E_{t} S_{t+k}-S_{t}=0$. The Fama-Hodrick-Srivastava hypothesis - the unconditional variance of the risk premium exceeds the unconditional variance of expected exchange rate depreciation can be tested formally.

From equation (12) it follows that:

$$
\beta_{2}=\frac{\operatorname{cov}\left(F_{t+k}-S_{t}, E_{t} S_{t+k}-S_{t}\right)}{\operatorname{var}\left(F_{t+k}-S_{t}\right)}
$$

Hence, the decomposition of the forward discount in (1) implies that:

$$
\beta_{2}=\frac{\operatorname{var}\left(E_{t} S_{t+k}-S_{t}\right)+\operatorname{cov}\left(E_{t} S_{t+k}-S_{t}, P_{t}^{k}\right)}{\operatorname{var}\left(E_{t} S_{t+k}-S_{t}\right)+\operatorname{var}\left(P_{t}^{k}\right)+2 \operatorname{cov}\left(E_{t} S_{t+k}-S_{t}, P_{t}^{k}\right)}
$$

By inspection, if $\beta_{2} \leq 1 / 2$ it follows that $\operatorname{var}\left(E_{t} S_{t+k}-S_{t}\right) \leq \operatorname{var}\left(P_{t}^{k}\right)$. Table 4.5 reports $t$-tests for the hypothesis that $\beta_{2} \leq 1 / 2$. The alternative hypothesis is that $\beta_{2}>1 / 2$.

The evidence presented suggests a weak rejection of the hypothesis $\beta_{2} \leq$ $1 / 2$ for all forecast horizons and currencies relative to the US Dollar. Rejection of the hypothesis that the variance of the expected depreciation is less than or equal to that of the risk premia was obtained in sixteen of the thirty exchange rates relative to the US Dollar. This corroborates, in contrast to the discussions of Fama (1984) and Hodrick and Srivastava (1986), the findings of Froot and Frankel (1989) on exchange rate expectations for some

17 Meese and Rogoff (1983a and 1983b) and Wolff (1987b) show that standard models of exchange rate determination fail to outperform the predictive power of the random walk hypothesis even when allowing for time-varying model parameters. 
of the major currencies relative to the US Dollar. However, for the exchange rates relative to the Deutschmark failure to reject the null hypothesis $\beta_{2} \leq$ $1 / 2$ occurs with great frequency ( 83 per cent) thus corroborating the FamaHodrick-Srivastava hypothesis that the risk premium is more variable than expected exchange rate depreciation.

Fama (1984) documents the empirical regularity that the exchange rate risk premium is negatively correlated with the expected exchange rate depreciation. ${ }^{18}$ Hodrick and Srivastava (1986) provide an intuitive explanation for these results and investigate whether negative covariation is a plausible outcome of the Lucas (1982) model. They argue that examination of the determination of the risk premium and the expected rate of depreciation in the Lucas (1982) model leads to the conclusion that the negative covariation, per se, does not appear to be a puzzle.

Table 4.6 reports correlation coefficients, from our survey data, between the risk premium and the expected exchange rate depreciation. The results confirm the findings of Fama (1984). In addition, the point estimates suggest that the correlation is weaker for EMS currencies relative to the Deutschmark compared with exchange rates relative to the US Dollar and non-EMS currencies relative to the Deutschmark, respectively.

Nijman, Palm, and Wolff (1991), who extend the analysis in Wolff (1987a), demonstrate that the utility optimizing models of Lucas (1982) and Domowitz and Hakkio (1985) imply that exchange rate risk premia should follow particular classes of time series models. In particular, they demonstrate that, with a few reasonable assumptions, exchange risk premia should follow autoregressive processes of order one. We thus fitted this time series model to our premia series and the results are presented in Table 4.7. The asterisks indicating the degree of statistical significance for the estimated autoregressive coefficients should be analyzed with some caution due to measurement errors in the expected exchange rate series; this errors-invariables problem can be cast in a state-space model framework and, using the results of Cavaglia (1990), it can be shown that any serial correlation that is present in the "true" premium series will also be exhibited by our

18 Fama (1984) suggests that the apparent puzzle of a negative covariation might be explained by the possibilities of an inefficient foreign exchange market, govemment interventions, skewed distributions and stochastic deviations from PPP. 
Table 4.5 Variance of $E_{t} S_{t+k}-S_{t}$ versus variance of $P_{t}^{k}$

January 1, 1986 through December 1, 1990: 57, 54, and 48 Observations

\begin{tabular}{|c|c|c|c|}
\hline & 3 Months & 6 Months & 12 Months \\
\hline & $\mathbf{t}: \hat{\beta}_{2} \leq 1 / 2$ & $t: \hat{\beta}_{2} \leq 1 / 2$ & $\mathrm{t}: \hat{\beta}_{2} \leq 1 / 2$ \\
\hline JY/US & $3.85^{\circ}$ & 1.31 & $2.40^{\circ}$ \\
\hline SF/US & 1.37 & 1.21 & 1.50 \\
\hline BP/US & $7.38^{\circ}$ & $3.12^{\circ}$ & 0.15 \\
\hline CD/US & -1.49 & -0.50 & -0.08 \\
\hline FF/US & $4.69^{\circ *}$ & $4.79^{\circ}$ & $4.79^{\circ}$ \\
\hline DF/US & $2.89^{\circ}$ & $2.18^{\circ}$ & -0.19 \\
\hline IL/US & $3.95^{\circ}$ & $4.08^{\circ}$ & $4.09^{\circ}$ \\
\hline BF/US & 1.39 & $2.59^{\circ}$ & $4.33^{*}$ \\
\hline DH/US & 1.26 & $2.46^{\circ}$ & 0.33 \\
\hline IP/US & $2.54^{\circ}$ & 1.92 & -0.53 \\
\hline JY/DH & 0.80 & 1.45 & -0.49 \\
\hline SF/DH & 0.68 & $-2.34^{\circ}$ & 0.68 \\
\hline$B P / O M$ & 0.26 & 0.17 & -0.13 \\
\hline $\mathrm{CD} / \mathrm{OH}$ & -0.29 & 1.04 & 1.21 \\
\hline FF/DH & 1.53 & $2.24^{\circ}$ & -0.48 \\
\hline$D F / D M$ & 0.84 & -0.66 & -1.56 \\
\hline $1 \mathrm{~L} / \mathrm{DH}$ & $2.63^{\circ}$ & $2.17^{\circ}$ & -0.83 \\
\hline$B F / D M$ & -0.94 & 1.60 & -0.81 \\
\hline
\end{tabular}

T-statistics for estimates of the $\beta_{2}$-coefficient are obtained from regressions of the following form: $\mathrm{E}_{1} \mathrm{~S}_{\mathrm{t}+\mathrm{k}}$ $S_{t}=\alpha_{2}+\beta_{2}\left(F_{t} F_{t}-S_{t}\right)+e_{i} ;^{*}(* *)$ denotes rejection at the $5 \%(1 \%)$ level for the hypothesis that $\beta_{2} \leq$ $1 / 2$. 
Table 4.6 Correlation coefficients of $E_{t} S_{t+k}-S_{t}$ with $P_{t}^{k}$

January 1, 1986 through December 1, 1990: 57, 54, and 48 Observations

\begin{tabular}{|c|c|c|c|}
\hline & 3 Months & 6 Months & 12 Months \\
\hline JY/US & -0.9856 & -0.9810 & $=0.9429$ \\
\hline SF/US & -0.9777 & -0.8958 & -0.9422 \\
\hline BP/US & -0.9953 & -0.9235 & -0.8512 \\
\hline Co/us & -0.9513 & -0.8944 & -0.8462 \\
\hline FF/US & -0.9849 & -0.9628 & -0.9333 \\
\hline DF/US & -0.9869 & -0.9664 & -0.8885 \\
\hline IL/US & -0.9913 & -0.9732 & -0.9408 \\
\hline$B F / U S$ & -0.9836 & -0.9686 & -0.9562 \\
\hline DH/US & -0.9808 & -0.9633 & -0.9444 \\
\hline IP/US & -0.8730 & -0.8754 & -0.8394 \\
\hline $\mathrm{JY} / O \mathrm{OH}$ & -0.9584 & -0.9774 & -0.8305 \\
\hline SF/DM & -0.9853 & -0.7327 & -0.9289 \\
\hline BP/DH & -0.9609 & -0.9548 & -0.9409 \\
\hline $\mathrm{CO} / \mathrm{OH}$ & -0.9926 & -0.9893 & -0.9783 \\
\hline FF/DM & -0.6603 & -0.5741 & -0.3934 \\
\hline$D F / D H$ & -0.9820 & -0.8989 & -0.8592 \\
\hline IL/DM & -0.9710 & -0.6821 & -0.6599 \\
\hline$B F / D M$ & -0.9241 & -0.8836 & -0.7993 \\
\hline
\end{tabular}


Table 4.7 Autoregressive processes of the Risk Premium: $P_{t}^{k}=\alpha+\phi_{1} P_{t-1}{ }^{k}+e_{t}$ January 1, 1986 through December 1, 1990: 57, 54, and 48 Observations

\begin{tabular}{|c|c|c|c|}
\hline & 3 Months & 6 Months & 12 Months \\
\hline & $\hat{\phi}_{1}$ & $\hat{\phi}_{1}$ & $\hat{\boldsymbol{\phi}}_{1}$ \\
\hline JY/US & $0.2598^{\circ}$ & 0.1500 & $0.5494^{\circ}$ \\
\hline SF/US & $0.3211^{*}$ & $0.4364^{\circ}$ & $0.6123^{*}$ \\
\hline BP/US & $0.2441^{\circ}$ & $0.3193^{\circ}$ & $0.4699^{\circ}$ \\
\hline CD/US & $0.3604^{*}$ & $0.3599^{\circ}$ & $0.2698^{\circ}$ \\
\hline FF/US & $0.3610^{*}$ & $0.3425^{\circ}$ & $0.4745^{\circ}$ \\
\hline DF/US & $0.3330^{*}$ & 0.2195 & $0.2894^{\circ}$ \\
\hline IL/US & $0.4048^{\prime \prime}$ & $0.3773^{*}$ & $0.4050^{\circ}$ \\
\hline $8 F / U S$ & $0.4227^{\circ}$ & $0.4086^{\circ}$ & $0.5190^{\circ}$ \\
\hline DH/US & $0.2881^{\circ}$ & $0.4068^{*}$ & $0.6294^{*}$ \\
\hline IP/US & $0.2483^{\circ}$ & $0.2805^{\circ}$ & $0.5167^{\circ}$ \\
\hline JY/DM & $0.2652^{\circ}$ & 0.2168 & $0.3961^{*}$ \\
\hline SF/DM & -0.1064 & 0.7801 & 0.2335 \\
\hline$B P / D M$ & 0.0710 & $0.2163^{\circ}$ & $0.4049^{\circ}$ \\
\hline CD/DM & $0.3062^{* *}$ & $0.6213^{\circ}$ & $0.4515^{\circ}$ \\
\hline$F F / D M$ & 0.1576 & 0.1654 & 0.1740 \\
\hline DF/OM & 0.1130 & -0.0433 & 0.0248 \\
\hline $1 L / D M$ & 0.1330 & 0.1943 & $0.3325^{\circ}$ \\
\hline$B F / D M$ & -0.0610 & 0.2055 & $0.25 \pi$ \\
\hline
\end{tabular}

${ }^{*}(* *)$ denotes rejection at the $5 \%(1 \%)$ level for the hypothesis that $\phi_{1}=0$. 
constructed premium series. ${ }^{19}$ Overall the results suggest that there is some serial correlation in the extracted premia series. It is interesting to note that this generally holds for bilateral rates relative to the US Dollar and the Deutschmark except for EMS exchange rates relative to the Deutschmark. Perhaps this suggests that the underlying fundamentals are different for EMS currencies as compared with non-EMS currencies. This issue requires further investigation.

\subsection{Conclusions}

This chapter has examined exchange rate risk premia using survey data for a set of bilateral rates relative to the US Dollar and relative to the Deutschmark over the 1985-1990 period. In contrast to the results of Froot and Frankel (1989) for survey based tests using some of the major currencies relative to the US Dollar, we find that the bias in the forward discount for these currencies is attributable to both the failure of rational expectations and the existence of a time-varying risk premium. Only the results for non-EMS currencies relative to the Deutschmark corroborate the findings of Froot and Frankel (1989). Contrary to what is commonly assumed in most models in which sterilized foreign exchange intervention is effective, variation in the forward discount does not reflect a statistically significant degree of variation in the risk premium, which suggests that the bias is entirely due to irrationality of market participants. We also find that for the EMS currencies the bias is primarely attributable to significant variation in the premium component. As in Froot and Frankel (1989), our findings on US Dollar exchange rate expectations indicate that in a number of cases, in contrast to the discussions of Fama (1984) and Hodrick and Srivastava (1986), the variability of expected rates of depreciation is larger than the variability of risk premia. For exchange rate relative to the Deutschmark, we find that the variability of the premia exceeds the variability of expected depreciation as in Hodrick and Srivastava (1986). The statistical properties of our exchange risk premia series are broadly consistent with previous work - the premia are negatively correlated with expected depreciation as in Fama (1984) and the premia for

19 Point estimates for the autoregressive parameters will be unbiased. The true standard errors of these point estimates however, can only be obtained with some knowledge of the signal-to-noise ratio. 
bilateral rates relative to the US Dollar and relative to the Deutschmark, except for the EMS exchange rates, exhibit serial correlation patterns as implied by the utility optimizing models of Lucas (1982) and Domowitz and Hakkio (1985).

Given the evidence presented in this chapter we may conclude that risk premia are important for the determination of spot and forward exchange rates in the foreign exchange market. In particular, the results suggest that time-varying risk premia play a fundamental role in the determination of exchange rates participating in the European Monetary System. In contrast with findings based on mean-variation optimization, 20 this suggests that future work should be devoted towards understanding the importance and economic sources of risk in the foreign exchange market, especially within the European Monetary System.

We are inclined, however, to be cautious in our interpretations of the empirical results. There are in fact two main explanations, that do not rely on irrational information processing and the existence of a time-varying risk premium, for our finding that the forward discount is a biased predictor of the future change in the exchange rate. First it is possible that economic agents were still learning the data generating process for the exchange series during our sample and this could have resulted in rejection of the unbiasedness hypothesis. Second, the "peso-problem", first suggested by Krasker (1980), could explain the biasedness of the forecasts, to the extent that there was a small probability of a large exchange rate movement which did not occur in our sample (thus biasing our test statistics towards rejection). This latter explanation seems particularly important for findings of biasedness in the EMS forecasts. This so-called "peso-problem" arises when there is some low-probability event whose potential occurrence is influencing the actions of the market participants - such as official realignments of central rates within the EMS - and when the sample size is not large enough to invoke the central limit theorem with confidence. In this case, it seems likely that the large and time-varying risk premia exhibited by EMS currencies reflect "peso-problems" resulting from expectations of periodic realignments. We feel that further investigation of this issue is warranted.

In the next chapter we explicitly try to model empirically time-varying

20 Using mean-variance optimization Frankel (1982, 1986) shows that the risk premium is small in magnitude and hence quantitatively negligible. 
130

EMS risk premia in the pricing of forward foreign exchange that do not require us to assume rationality of exchange rate expectations nor conditional homoskedasticity of exchange rate returns. ${ }^{21}$

21 Giovannini and Jorion (1987) demonstrate that the assumption of conditional homoskedasticity is invalid and consequently the risk premium can be much larger and, therefore, more important. 


\section{Chapter five}

\section{Empirical Modeling of EMS Exchange Risk Premia}

\subsection{Introduction}

In the previous chapter we concluded that the existence of time-varying EMS risk premia is the economically important reason for the finding that the forward discount is a biased predictor of the future change in the exchange rate. ${ }^{1}$ Motivated by a growing body of empirical evidence against the hypothesis of forward market efficiency, generally attributed to the presence of a time-varying risk premium, ${ }^{2}$ there has been considerable interest in empirically tractable theories of a risk premium. Conditional on the hypothesis that the foreign exchange market is efficient or rational, the existence of time-varying premia has been documented in the literature by Fama (1984), Frankel (1982, 1986), Hansen and Hodrick (1980), Hodrick and Srivastava (1984), Hsieh (1984), Korajczyk (1985), and Wolff (1987a). Alternative methodologies to measure time-varying premia have been explored in the literature.

First, models that are based strictly on the time series properties of spot and forward exchange rates and asset prices were examined - see the latent variable model of Hansen and Hodrick (1983) with its extensions by Hodrick and Srivastava (1984), Campbell and Clarida (1987), and Giovannini and Jorion (1987). The presence of conditional heteroskedasticity in forecast errors prompted Domowitz and Hakkio (1985) to model a time-varying risk

1 An alternative explanation would be the "peso-problem", as discussed in chapter four, for findings of biasedness in the EMS forecasts.

2 See the excellent surveys on the efficiency of the foreign exchange market by Hodrick (1987) and Levich (1985). 
premium using the autoregressive conditional heteroskedasticity (ARCH) framework. Korajczyk (1985) noted that the variability of risk premia in theory can be related to variations in expected real interest rates.

A second approach is to employ some measurement of market fundamentals in an attempt to test specific theories of the risk premium. Frankel (1982) and Frankel and Engel (1984) examined an asset market equilibrium model based on assets demands derived from a two-period mean-variance maximization problem.

The third approach for assessing the risk premium interpretation (the existence of time-varying risk premia) attempts to measure expected depreciation directly, thereby avoiding reliance on inferences from realized depreciations - see Frankel and Froot (1987b), Froot and Frankel (1989), and Cavaglia, Verschoor and Wolff (1992a), for instance. This would not tell us about the economic determinants of risk premia, but it could tell us about the relative importance of risk and market inefficiency in explaining the forward discount bias.

Although some researchers reported significant results for subperiods, in general however, most of the premium models failed to identify empirically significant risk premia terms. One explanation for the poor results with previous models of the risk premium is that these models rely on a number of highly unrealistic assumptions. In most studies, such as Dornbusch (1982), Hansen and Hodrick (1983), and Frankel (1986), it was explicitly assumed that the conditional variances and covariances of returns were constant over time. Recent research by Cumby and Obstfeld (1984) and Giovannini and Jorion (1987), however, suggest that the assumption of constant conditional second moments of exchange rate returns is invalid. Giovannini and Jorion (1987) note on the consequences of assuming the constant conditional seconds moments for risk premia: "Our evidence suggests that tests of assets pricing models which assume constant conditional second moments of returns are likely to be seriously misspecified". In addition, the methodologies used in previous empirical research on premia usually involve measurement of time-varying risk premia conditional on the hypothesis that exchange rate forecasts are rational. Since the results of previous research overwhelmingly favor the conclusion that economic agents exhibit irrational behavior ${ }^{3}$, we propose an alternative approach to measure

${ }^{3}$ See Frankel and Froot (1987a, 1987b) and Cavaglia, Verschoor and Wolff (1992a, $1992 \mathrm{~b}$, and 1992c) for instance. 
premia in the pricing of forward foreign exchange.

In this chapter we explicitly try to model empirically time-varying EMS risk premia in the pricing of forward foreign exchange that do not require us to assume rationality of exchange rate expectations nor conditional homoskedasticity of exchange rate returns. This chapter extends the analysis of Domowitz and Hakkio (1985) to a survey data set of exchange rate expectations covering a wide range of EMS currencies over a different sample period, thereby combining the first and third approach. The principal benefit of using such data is that one obtains a direct measure of agents' beliefs, thus allowing for separate testing of an underlying model of exchange rate determination and a hypothesis about expectations, whereas previous work has been explored conditional on the hypothesis that the foreign exchange market is efficient or rational. Our survey data set begins in January 1986 and ends in September 1991 covering a period of US Dollar depreciation and Deutschmark appreciation relative to the currencies we review. In chapter four, we examined a survey data set of exchange rate expectations, that includes several EMS currencies. Our findings indicate that for EMS exchange rates relative to the Deutschmark, variation in the forward discount primarily reflects changes in risk premia rather than changes in expected depreciation and, thus, that the forward discount bias is primarily attributable to significant variation in the risk premium component. As in Domowitz and Hakkio (1985) and Diebold and Pauly (1988), we employ exchange rate data on a monthly basis. Results covering nearly all EMS currencies provide an interesting complement to previous work that has largely focused on the five most actively traded currencies vis-à-vis the US Dollar. Diebold (1988) and Baillie and Bollerslev (1989) demonstrate that ARCH effects in foreign exchange rates tend to disappear under temporal aggregation, and although significant daily or weekly $\mathrm{ARCH}$ effects may generate a time-varying risk premium, this risk premium may appear to be constant with monthly data. ${ }^{4}$ However, conditional heteroskedasticity appears to be a prominent feature of exchange rate behavior in the post-EMS period - see Diebold and Pauly

4 Indeed, Kendall and McDonald (1989) on using weekly data for the Australian/US Dollar rate obtain a significant estimate for the ARCH-M parameter, as do McCurdy and Morgan (1989) using daily Canadian futures data. However, Pagan and Ullah (1988) find strong support for the presence of a time-varying risk premium in the Canadian/US Dollar market with monthly data over the earlier time period 1970-1978. 
(1988b), and Nieuwland, Verschoor and Wolff $(1991)^{5}$, for instance.

This chapter is presented in six sections. In section 2 , the construction of the exchange rate survey is outlined and summary statistics describing the data are provided. In section 3 , the presence of time-varying risk premia is examined as well as the presence of heteroskedastic OLS residuals. The methodology and models employed to capture the time-varying risk premia are explained in section 4 . Section 5 presents the main empirical results of this study and section 6 contains our concluding remarks.

\subsection{The Survey Data}

This chapter considers survey data on exchange rate expectations for a set of EMS exchange rates relative to the Deutschmark, covering the period from January 1986 through September $1991 .^{6}$ The Belgian Franc, Dutch Guilder, Deutschmark, French Franc, Italian Lire, and Spanish Peseta are the ones considered by the monthly survey.

In this chapter we use exchange rate survey data to divide the forward discount into its two components ${ }^{7}$ - expected depreciation and the risk premium - in order to shed new light on the relative importance of EMS risk premia in the pricing of forward foreign exchange by explicitly modeling time-varying EMS risk premia. The use of survey data allows the direct measurement of a risk premium from the decomposition of the forward discount into its two components - expected depreciation and the risk premium:

5 The observed leptokurtosis may be due to the existence of discontinuities, or jumps, in the data. These jumps can occur for at least two reasons. First, there are the official realignments of central rates within the EMS, and secondly one can think of intramarginal interventions to maintain bilateral parities.

${ }^{6}$ See chapter three for a more detailed description of the construction of the exchange rate survey.

7 As shown by Fama (1984) and Farber (1979) and others, the forward rate can be decomposed into an expected future spot rate and a risk premium. 


$$
\left(F_{t+k}-S_{t}\right)=\left(E_{t} S_{t+k}-S_{t}\right)+P_{t}^{k}
$$

Here $S_{t}$ is defined as the natural logarithm of the spot exchange rate at time $t, E_{t} S_{t+k}$ is defined as the logarithm of the expected spot exchange rate at time $t+k$ formed at time $t$ and ${ }_{t} F_{t+k}$ is defined as the natural logarithm of the forward rate at time $t$ for delivery at time $t+k$ and $P_{t} k$ is the associated risk premium. The left-hand side of (1) is the forward discount, and the right-hand side is the expected rate of depreciation of the home currency relative to the foreign currency (Deutschmark - the exchange rates are expressed as units of home currency per unit of foreign currency) plus the risk premium. Because the surveys are direct estimates they do not require us to assume any particular model of expected depreciation or of the risk premium. Equation (1) is no more than a particular definition of the premium component of the forward exchange rate. The premium term, $\mathrm{P}_{\mathrm{t}}^{\mathrm{k}}$, as it is defined in equation (1), does not yet have any economic content. To give equation (1) economic content, a model of international asset pricing that describes the determination of $\mathrm{P}_{\mathrm{t}}^{\mathrm{k}}$ is required.

Tables 5.1a and $5.1 \mathrm{~b}$ provide summary statistics for the expected exchange rate depreciation and forward discount across forecast horizon and across currencies. The summary statistics for the risk premium across horizon and across currencies are reported in table 5.1c.

For the period analyzed (January 1st, 1986 through September 1st, 1991) the standard deviations of both the expected depreciation and forward discount across the 3, 6, and 12 month horizons are generally larger for the Italian Lira relative to the Deutschmark than the corresponding estimates of the other EMS exchange rates involving the Deutschmark. ${ }^{8}$ Comparing Tables $5.1 \mathrm{a}$ and $5.1 \mathrm{~b}$, one notes that in general the expected rates of depreciation and the forward discount are of the same sign. Thus the currencies that were expected to depreciate were at a forward discount. This confirms the results of Frankel and Froot (1987a, 1987b). Table 5.1c suggest the presence of time-varying risk premia, thus regarding domestic and foreign assets as

8 The provisions of the EMS provide for participating countries to maintain their exchange rates within bilateral limits of $\pm 2.25 \%[ \pm 6 \%$ for Italy and Spain (since June 1989) until recently]. Italy suspended membership as of September 1992 until further notice. 
imperfect substitutes. The numbers differ from summary statistics reported by Frankel and Froot (1987a, 1987b), which demonstrate surprisingly large exchange risk premia in a number of cases. In order to assess the distributional properties of the expected depreciation, forward discount, and risk premia series, the Bera Jarque (1982) Normality test and the Kiefer Salmon (1983) Lagrange multiplier normality test are reported in Tables 5.1a, 5.1b, and $5.1 \mathrm{c}$, where the former is a joint test using both skewness and kurtosis and the latter is an LM test for normal skewness (KS-1) and normal kurtosis (KS-2) ${ }^{9}$ Overall, the evidence presented suggests a fairly consistent rejection of the normality hypotheses. Failure to reject the null occurs in only seven out of fourty-five cases. Thus, in spite of the notion that leptokurtic unconditional densities of ARCH processes approach normality by temporal aggregation - see Diebold (1988) and Baillie and Bollerslev (1989) - it appears that the monthly series used here may be characterized as highly leptokurtic. This is in line with Koedijk, Schafgans and de Vries (1990) who find that for EMS exchange rates ARCH effects become less important in time aggregation whereas fat tails remain important.

\subsection{Time-Varying Exchange Risk Premia}

Survey expectations data can be exploited to decompose the forward discount bias into portions attributable to irrational behaviour of economic agents or to the existence of time-varying risk premia - see Frankel and Froot (1987b), Froot and Frankel (1989), and Cavaglia, Verschoor, and Wolff (1992b), for instance. In order to test whether the existence of time-varying risk premia is the economically important reason for rejection of forward market efficiency, the following equation may be fitted:

$$
E_{t} S_{t+k}-S_{t}=\alpha+\beta\left(F_{t+k}-S_{t}\right)+\varepsilon_{t}
$$

where $\epsilon_{\mathrm{t}}$ is a random error term. The null hypothesis of perfect substitutability implies that $\alpha=0$ and $\beta=1$. The degree to which changes in the forward

9 The Bera Jarque test is asymptotically Chi-square(2) distributed, and the Kiefer Salmon normality tests are asymptotically Chi-square(1) distributed. 
Table 5.1A Summary Statistics of Expected Depreciation: $E_{t} S_{t+k}-S_{t}$ (not annualized)

January 1, 1986 through September 1, 1991: 69 Observations

\begin{tabular}{|c|c|c|c|c|c|}
\hline & $\mathrm{BF} / \mathrm{DM}$ & $\mathrm{DG} / \mathrm{DH}$ & FF/DH & IL/DH & SP/DM \\
\hline \multicolumn{6}{|c|}{3 Months } \\
\hline kean & 0.0018 & 0.0028 & 0.0048 & 0.0067 & 0.0121 \\
\hline St.dev & 0.0107 & 0.0098 & 0.0063 & 0.0257 & 0.0147 \\
\hline$T$-test & 1.41 & 2.34 & 6.41 & 2.16 & 6.84 \\
\hline Skewness & 2.15 & 0.11 & 0.26 & -2.52 & 0.65 \\
\hline Kurtosis & 11.14 & 10.87 & 3.48 & $18: 36$ & 4.84 \\
\hline BJ-test & $243.42 \cdots$ & $178.16 \cdots$ & 1.45 & $\pi 0.80^{\cdots}$ & $14.60^{\cdots}$ \\
\hline Ks- 1 & $52.94 \cdots$ & 0.14 & 0.78 & $72.86 \cdots$ & $4.83^{*}$ \\
\hline $\mathrm{ks}-2$ & $190.49^{\cdots}$ & $178.02 \cdots$ & 0.67 & $677.93^{\cdots}$ & $9.77^{\cdots}$ \\
\hline
\end{tabular}

6 Months

$\begin{array}{lccccc}\text { Mean } & 0.0046 & -0.0010 & 0.0077 & 0.0122 & 0.0198 \\ \text { St.der } & 0.0114 & 0.0078 & 0.0125 & 0.0242 & 0.0202 \\ \text { T-test } & 3.35 & -1.08 & 5.11 & 4.19 & 8.14 \\ \text { Skewness } & 1.13 & -1.86 & 0.20 & -2.90 & 0.83 \\ \text { Kurtosis } & 5.60 & 11.15 & 2.76 & 19.47 & 4.57 \\ \text { BJ-test } & 34.09 \cdots & 230.50^{\cdots} & 0.65 & 876.49^{\cdots} & 15.07^{\cdots} \\ \text { KS-1 } & 14.63^{\cdots} & 39.58^{\cdots} & 0.48 & 96.52^{\cdots} & 7.97^{\cdots} \\ \text { KS-2 } & 19.46^{\cdots} & 190.92^{\cdots} & 0.17 & 77.97^{\cdots} & 7.10^{\cdots}\end{array}$

12 Months

\begin{tabular}{lccccc} 
Mean & 0.0060 & -0.0024 & 0.0122 & 0.0168 & 0.0252 \\
St.dev & 0.0147 & 0.0102 & 0.0144 & 0.0306 & 0.0196 \\
T-test & 3.43 & -1.93 & 7.03 & 4.54 & 10.67 \\
Skewness & 0.79 & -0.31 & 0.16 & -1.50 & 0.60 \\
Kurtosis & 4.20 & 5.07 & 2.65 & 10.17 & 3.32 \\
BJ-test & $11.39 \cdots$ & $13.44^{\cdots}$ & 0.65 & $173.64 \cdots$ & $4.37^{*}$ \\
Ks-1 & $7.26^{\cdots}$ & 1.11 & 0.30 & $28.89 \cdots$ & $4.08^{*}$ \\
KS-2 & $4.13^{\cdots}$ & $12.33^{\cdots}$ & 0.35 & $147.74 \cdots$ & 0.29 \\
\hline
\end{tabular}

Legend: $\mathrm{BF}=$ Belgian Franc; DG = Dutch Guilder; DM = Deutschmark; FF = French Franc; IL = Italian Lire; SP = Spanish Peseta. The BJ-test denotes the Bera Jarque test for normality; KS-1 and KS-2 pertain to the Kiefer Salmon Normality test for respectively skewness and kurtosis; * ${ }^{(* *)}[* * *]$ denotes rejection at the $10 \%(5 \%)[1 \%]$ level of the normality hypotheses. 
Table 5.1B Summary Statistics of Forward Discount: ${ }_{t} F_{t+k}-S_{t}$ (not annualized) January 1, 1986 through September 1, 1991: 69 Observations

\begin{tabular}{|c|c|c|c|c|c|}
\hline & $B F / D H$ & DG/DH & FF/DH & IL/DH & SP/DH \\
\hline \multicolumn{6}{|c|}{3 Months } \\
\hline Mean & 0.0062 & 0.0017 & 0.0080 & 0.0159 & 0.0170 \\
\hline St.dev & 0.0084 & 0.0053 & 0.0050 & 0.0110 & 0.0088 \\
\hline T-test & 6.09 & 2.62 & 13.48 & 12.01 & 15.94 \\
\hline Skewness & 0.72 & -4.69 & 0.79 & 4.67 & -0.25 \\
\hline Kurtosis & 12.57 & 39.45 & 3.95 & 32.08 & 2.73 \\
\hline $8 \mathrm{~J}$-test & $269.19^{\mathrm{*}}$ & $4072^{\cdots}$ & $9.89^{\cdots}$ & $2681^{\cdots}$ & 0.92 \\
\hline KS-1 & $6.01^{*}$ & $253.68^{\cdots}$ & $7.31^{\cdots}$ & $250.37^{\cdots}$ & 0.71 \\
\hline KS-2 & $263.17^{\cdots}$ & $3818^{\ldots \cdots}$ & 2.58 & $2430^{\cdots}$ & 0.22 \\
\hline Mean & 0.0112 & 0.0027 & 0.0151 & 0.0312 & 0.0314 \\
\hline St.dev & 0.0114 & 0.0059 & 0.0092 & 0.0270 & 0.0167 \\
\hline$T$-test & 8.11 & 3.78 & 3.61 & 9.60 & 15.63 \\
\hline Skewness & 2.19 & -3.65 & 0.66 & 6.11 & -0.65 \\
\hline Kurtos is & 18.97 & 28.01 & 3.27 & 46.06 & 2.94 \\
\hline BJ-test & $788.23^{\cdots}$ & $1951^{\cdots}$ & $5.37^{\circ}$ & $5760^{\ldots}$ & $4.84^{\circ *}$ \\
\hline Ks-1 & $54.94^{\cdots}$ & $153.03 \cdots$ & $5.15^{\circ}$ & $429.34^{\cdots}$ & $4.83^{* *}$ \\
\hline$x s-2$ & $733.29^{* *}$ & $1798^{\cdots}$ & 0.22 & $5331 \cdots$ & 0.01 \\
\hline \multicolumn{6}{|c|}{12 Months } \\
\hline Mean & 0.0209 & 0.0064 & 0.0285 & 0.0584 & 0.0587 \\
\hline st.dev & 0.0170 & 0.0137 & 0.0168 & 0.0431 & 0.0297 \\
\hline$T$ - test & 10.21 & 3.88 & 14.11 & 11.25 & 16.45 \\
\hline Skewness & 1.12 & 4.57 & 0.41 & 5.70 & -0.76 \\
\hline Kurtosis & 11.04 & 35.94 & 2.56 & 62.36 & 3.10 \\
\hline$B J$-test & $200.43^{\cdots}$ & $3360^{\cdots} \cdots$ & 2.46 & $4828^{\cdots}$ & $6.61^{\circ}$ \\
\hline ks-1 & $14.53^{\cdots}$ & $240.72^{\cdots}$ & 1.89 & $374.14^{\cdots}$ & $6.58^{\circ}$ \\
\hline Ks-2 & $185.90^{\cdots}$ & $3119^{\cdots}$ & 0.57 & $4.454^{\cdots}$ & 0.03 \\
\hline
\end{tabular}

For notes see Table 5.1A. 
Table 5.1C Summary Statistics of Risk Premium: $P_{t}^{k}$ (not annualized)

January 1, 1986 through September 1, 1991: 69 Observations

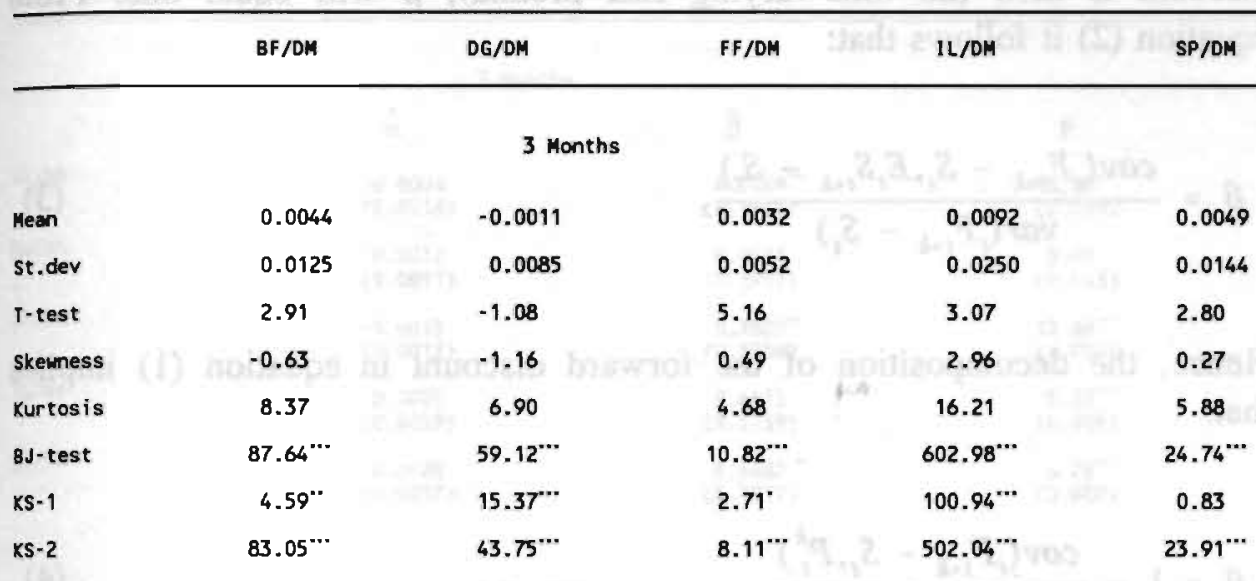

\section{Months}

$\begin{array}{lccccc}\text { Hean } & 0.0065 & 0.0037 & 0.0074 & 0.0190 & 0.0116 \\ \text { St.dev } & 0.0133 & 0.0067 & 0.0086 & 0.0329 & 0.0221 \\ \text { T-test } & 4.09 & 4.57 & 7.08 & 4.79 & 4.38 \\ \text { Skewness } & 1.84 & 1.01 & 0.15 & 5.18 & -0.58 \\ \text { Kurtosis } & 12.94 & 5.11 & 3.02 & 33.01 & 6.39 \\ \text { BJ-test } & 323.18 \cdots & 24.43 \cdots & 0.27 & 2898^{\cdots} & 36.88^{\cdots} \\ \text { KS-1 } & 38.99^{\cdots} \cdots & 11.65 \cdots & 0.27 & 308.86^{\cdots} & 3.92 * \\ \text { ks-2 } & 284.19^{\cdots} & 12.78 \cdots & 0.00 & 2590 \cdots & 32.96 \cdots\end{array}$

12 Months

\begin{tabular}{lccccc} 
Mean & 0.0149 & 0.0088 & 0.0163 & 0.0417 & 0.0336 \\
St.dev & 0.0191 & 0.0162 & 0.0121 & 0.0490 & 0.0296 \\
T-test & 6.46 & 4.48 & 11.19 & 7.06 & 9.42 \\
Skemess & 1.82 & 4.17 & 1.03 & 5.19 & -0.16 \\
Kurtosis & 11.22 & 28.84 & 4.81 & 37.55 & 2.64 \\
BJ-test & $232.30^{\cdots}$ & $2119^{\cdots}$ & $21.73 \cdots$ & $37.41 \cdots$ & 0.67 \\
KS-1 & $38.06^{\cdots}$ & $199.83^{\cdots}$ & 12.27 & $309.54^{\cdots}$ & 0.30 \\
KS-2 & $194.23^{\cdots}$ & $1919^{\cdots}$ & $9.47^{\cdots}$ & $3432^{\cdots}$ & 0.37 \\
\hline
\end{tabular}

For notes see Table 5.1A. 
discount reflect changes in the risk premium can be inferred from a regression of expected depreciation on the forward discount [equation (2)]. Under the hypothesis that the correlation of the risk premium with the forward discount is zero (no time-varying risk premia), $\beta$ will equal one. From equation (2) it follows that:

$$
\beta=\frac{\operatorname{cov}\left(F_{t+k}-S_{t}, E_{t} S_{t+k}-S_{t}\right)}{\operatorname{var}\left(F_{t+k}-S_{t}\right)},
$$

Hence, the decomposition of the forward discount in equation (1) implies that:

$$
\beta=1-\frac{\operatorname{cov}\left(F_{t+k}-S_{t}, P_{t}^{k}\right)}{\operatorname{var}\left(F_{t+k}-S_{t}\right)}
$$

The results of fitting equation (2) for each currency and for each forecast horizon ( $k=3,6$, and 12 months) are reported in Table 5.2.

It is interesting to note that - with the exception of the Dutch Guilder at the 3 month horizon - the results provide a consistent rejection of the hypothesis of perfect substitutability ( $\alpha=0$ and $\beta=1$ jointly) for all forecast horizons and EMS exchange rates. Rejection of the hypothesis $\beta=1$ (no time-varying risk premia) was obtained in twelve out of fifteen cases, so there is considerable evidence of significant variation in risk premia. Similar results were obtained by MacDonald and Torrance (1989) for survey based tests of uncovered interest parity. In contrast, Frankel and Froot (1987b) and Froot and Frankel (1989) obtain estimates of $\beta$ that were insignificantly different from one for survey based tests using some of the major currencies relative to the US Dollar covering the 1981-1985 period.

Thus, as in most models in which sterilized foreign exchange intervention is effective, variation in the forward discount for EMS currencies reflects a statistically significant degree of variation in the risk premium component, which suggests that time-varying risk premia plays a fundamental role in the determination of EMS exchange rates. 
Table 5.2 Tests of Perfect Substitutability: $E_{t} S_{t+k}-S_{t}=\alpha+\beta\left({ }_{t} F_{t+k}-S_{t}\right)+e_{t}$

January 1, 1986 through September 1, 1991: 69 Observations

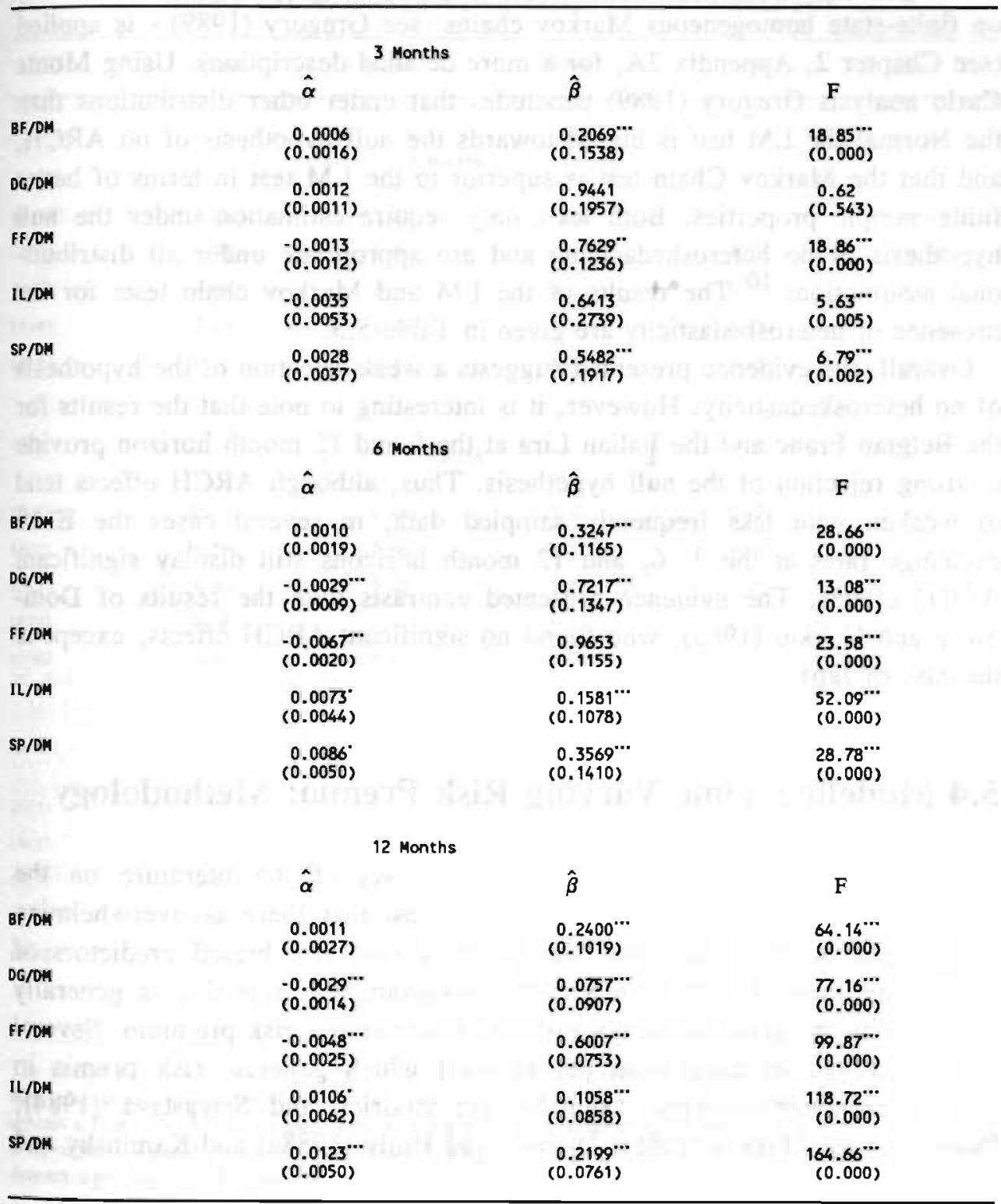

The standard errors of the coefficients are given in parentheses; ${ }^{* * *}\left[{ }^{* * *}\right]$ denotes rejection at the $10 \%$ (5\%) [1\%] level for the hypotheses that $\alpha=0$ or $\beta=1$. The F-statistic pertains to the joint hypothesis that $\alpha=0$ and $\beta=1$ ( $p$-Values are given in parentheses). 
In order to test for the presence of heteroskedastic OLS residuals $\left[\epsilon_{\mathrm{t}}\right.$ from equation (2)], two different approaches are employed. First the Lagrange multiplier tests for autoregressive conditional heteroskedasticity - see Breusch and Pagan (1979) - are performed, and secondly a non-parametric test based on finite-state homogeneous Markov chains -see Gregory (1989) - is applied (see Chapter 2, Appendix 2A, for a more detailed description). Using Monte Carlo analysis Gregory (1989) concludes that under other distributions than the Normal the LM test is biased towards the null hypothesis of no ARCH, and that the Markov Chain test is superior to the LM test in terms of better finite sample properties. Both tests only require estimation under the null hypothesis of no heteroskedasticity and are appropriate under all distributional assumptions. ${ }^{10}$ The results of the LM and Markov chain tests for the presence of heteroskedasticity are given in Table 5.3.

Overall, the evidence presented suggests a weak rejection of the hypothesis of no heteroskedasticity. However, it is interesting to note that the results for the Belgian Franc and the Italian Lira at the 6 and 12 month horizon provide a strong rejection of the null hypothesis. Thus, although ARCH effects tend to weaken with less frequently sampled data, in several cases the EMS exchange rates at the 3,6 , and 12 month horizons still display significant ARCH effects. The evidence presented contrasts with the results of Domowitz and Hakkio (1985), who found no significant ARCH effects, except in the case of Japan.

\subsection{Modeling Time-Varying Risk Premia: Methodology}

Hodrick's (1987) and Levich's (1985) reviews of the literature on the efficiency of foreign exchange market suggest that there is overwhelming evidence in favor of the view that forward rates are biased predictors of future spot rates. For the EMS currencies examined, rejection is generally attributed to the presence of a significant time-varying risk premium. Several theoretical models have been put forward which generate risk premia in foreign exchange markets, examples are Hodrick and Srivastava (1984), Domowitz and Hakkio (1985), Diebold and Pauly (1988a) and Kaminsky and

10 Weiss (1986) has shown that the proposed LM-test is appropriate for non-normal distributions, provided some moment conditions are satisfied. The Markov chain test is completely distribution free. 
Table 5.3 Heteroskedasticity tests of OLS residuals: $E_{t} S_{t+k}-S_{t}=\alpha+\beta\left(F_{t+k}-\right.$ $\left.s_{1}\right)+e_{t}$

January 1, 1986 through September 1, 1991: 69 Observations

\begin{tabular}{lllll}
\hline BF/DM & DG/DM & FF/DM & IL/DM & SP/OH \\
\hline
\end{tabular}

3 Months

$\begin{array}{lccccc}\text { LM(1) } & 0.25 & 1.27 & 3.29^{\circ} & 1.13 & 14.01^{\cdots} \\ \text { LH(2) } & 0.48 & 1.44 & 6.81 & 4.76 & 3.52 \\ \text { LM(5) } & 2.83 & 3.42 & 10.13 & 9.11 & 29.81^{\cdots} \\ \text { LRIM1 } & 0.02 & 5.46^{*} & 0.60 & 0.13 & 0.38 \\ \text { LRIM2 } & 0.16 & 6.61^{\circ} & 1.15 & 3.10 & 0.39\end{array}$

\section{Months}

$\begin{array}{lccccc}\text { LM(1) } & 20.7^{\cdots} & 0.04 & 1.65 & 0.27 & 0.60 \\ \text { LM(2) } & 30.56^{\cdots} & 0.06 & 2.66 & 9.22^{\cdots} & 1.40 \\ \text { LM(5) } & 4.90 & 5.28 & 5.21 & 26.05^{*} & 4.19 \\ \text { LRIM1 } & 3.38^{\circ} & 0.02 & 5.46^{*} & 3.38^{\circ} & 1.22 \\ \text { LRIM2 } & 4.27 & 0.40 & 7.47^{\circ} & 4.35 & 2.36\end{array}$

12 Months

$\begin{array}{llllll}\text { LM(1) } & 14.37^{\cdots} & 0.13 & 1.28 & 0.03 & 0.11 \\ \text { LM(2) } & 10.86^{\cdots} & 0.22 & 1.29 & 10.31 \cdots & 2.22 \\ \text { LM(5) } & 3.36 & 1.91 & 2.83 & 13.08^{\cdots} & 6.63 \\ \text { LRIM1 } & 3.38^{\circ} & 0.37 & 0.38 & 8.05^{\cdots} & 0.02 \\ \text { LRIML } & 4.06 & 2.23 & 0.55 & 9.58 \cdots & 2.96\end{array}$

The $L M(p)$ test is estimated by a regression of squared OLS residuals [equation (2)] on a constant and $p$ lags, and is asymptotically Chi-square(p) distributed. LRIM1 is a Likelihood Ratio test of independence against a first order Markov Chain, and is distributed as Chi-square(1); LRIM2 is a Likelihood Ratio test of independence against a second order Markov Chain, and is distributed as Chi-square(3). * (**) [***] denotes significance at the $10 \%(5 \%)[1 \%]$ level. 
Peruga (1990). Most of these theories share Lucas' (1982) model of the international economy as a starting point. Although this dynamic general equilibrium model provides useful insights into the possible structure of risk premia in the forward foreign exchange markets, direct tests of this model are quite complex without further restrictions. This is due to the sterilized nature and general stochastic structure of the model. The second common denominator in these models is that in general the risk premium depends on the conditional probability distribution of the future spot rate, which may lead to a time-varying risk premium, if this distribution is time-varying. Empirically many specifications for such a risk premium have been employed which depend on the conditional variance of the spot rate. Nevertheless, most of the models have failed to identify statistical significant exchange risk premia and in their review Bollerslev, Chou, and Kroner (1992) note that: "A satisfactory model for the time varying risk premium in the forward foreign exchange market has yet to be formulated".

In this chapter we adopt a different approach which is inspired by the availability of survey data. Neither do we have to assume rational expectations nor do we have to rely on estimation methods using unobserved variables, see Hodrick and Srivastava $(1984,1986)$. Conditional on the hypothesis that the foreign market is efficient or rational, the modelling of time varying risk premia has been explored by Domowitz and Hakkio (1985), Diebold and Pauly (1988a), and Kendall and McDonald (1989), for instance. Based on the utility optimizing models of Lucas (1982), Domowitz and Hakkio (1985) present an intertemporal asset pricing model in which the risk premium is a function of the conditional variances of the domestic and foreign money supplies. ${ }^{11}$ The methodologies used in these papers usually involve measurement of time-varying risk premia conditional on the hypothesis that exchange rate forecasts are rational. Conclusions about the behavior of premia in the pricing of forward foreign exchange are drawn on the basis of rationality on the part of economic agents. Since the results of previous research overwhelmingly favor the conclusion that economic agents exhibit

11 In particular, the intertemporal capital asset pricing model of Lucas (1982) implies that the risk premium is determined by the conditional covariance between the return on a long position in the forward market and the marginal rate of substitution between current and future consumption. 
irrational behavior ${ }^{12}$, we propose an alternative approach to measure premia. The approach implements the use of survey data on exchange rate expectations. The survey data allows the direct measurement of risk premia from the decomposition of the forward discount in (1), thereby avoiding reliance on inferences from a hypothesis about expectations. In addition, several currencies display significant ARCH effects. However, as we do not specify a general equilibrium model we do not know the true structure of the covariance matrix and to what variables it is related. A (G)ARCH model is an acceptable alternative because it can be interpreted as a reduced form of a more complicated dynamic structure for the time-varying conditional second order moments. The ARCH-M model developed by Engle, Lilien and Robbins (1987) which we propose, can be used in addressing questions regarding the risk-return tradeoff in a time series context. This particular model captures several empirical regularities noted in the estimating of exchange rate models, including conditional heteroskadasticity in the forecast errors Cumby and Obstfeld (1982) and Hodrick and Srivastava (1984) - and fattailed behavior - Friedman and Vandersteel (1982). The ARCH-in-mean model extends the ARCH model to allow the conditional variance to affect the conditional mean directly and is given by:

$$
E_{t} S_{t+k}-S_{t}=R P_{t}^{k}+\beta_{1}\left(F_{t+k}-S_{t}\right)+\varepsilon_{t}
$$

$$
R P_{t}^{k}=\beta_{0}+\theta h_{r}
$$

$$
\varepsilon_{t} \mid I_{t} \sim N\left(0, h_{t}^{2}\right)
$$

12 See Frankel and Froot (1987a, 1987b) and Cavaglia, Verschoor and Wolff (1992a, $1992 b$, and 1992c) for instance. 


$$
h_{t}^{2}=\alpha_{0}+\alpha_{1} \varepsilon_{t-1}^{2}
$$

where $I_{t}$ represents the information set at time $t$. The risk premium, $R P_{t}^{k}$, depends directly on the conditional variance of $\epsilon_{t}$ that is denoted $h_{t}{ }^{2}$. The conditional variance of the expected rate of depreciation given time $t$ information is postulated to depend on the realizations of the squared error terms in the previous months. A generalization proposed by Bollerslev (1986) is the GARCH model. For the first order GARCH-in-mean model the conditional variance becomes:

$$
h_{t}^{2}=\alpha_{0}+\alpha_{1} \varepsilon_{t-1}^{2}+\gamma_{1} h_{t-1}^{2}
$$

The degree of persistence in variance is determined by the magnitude of the parameters of the conditional variance equations (8) and (9) and non-negativity constraints are imposed on these parameters. We restrict our attention to a GARCH $(1,1)$ specification since it has been shown to be a parsimonious representation of conditional variance that adequately fits many economic time series - see Bollerslev (1986) and Nieuwland (1992). The estimation of the econometric model described above using maximum likelihood methods is not as straightforward as may seem at first sight.

First of all we assume conditional normality without knowing what the true conditional distribution really is. This leaves the model subject to distributional misspecification. Weiss (1986) has shown that the quasi maximum likelihood parameter estimates are still consistent and asymptotically normal but with a modified asymptotic covariance matrix, which is robust to departures from normality. This all under the condition that the model is correctly specified, see also Bollerslev and Wooldridge (1989). Furthermore the information matrix is not block diagonal in the present framework, as a function of the conditional variance enters the mean equation. This means that we cannot use the scoring algorithm to obtain the maximum likelihood estimates [see Engle (1982)]. Instead we have to rely on numerical maximization of the likelihood function. Finally any misspecification in the conditional variance equation leads to biased estimates in the conditional mean equation, because the parameter estimates in the conditional 
mean equation are not asymptotically independent from the parameter estimates in the conditional variance equation. Diagnostic tests for the conditional variance equation are imperative upon interpretations of the parameter estimates.

We choose the Berndt, Hall, Hall and Hausman (1974) algorithm (BHHH) with numerical derivatives to obtain maximum likelihood estimates. The robust covariance matrix is calculated by pre and post multiplying the inverse of the $\mathrm{BHHH}$ covariance matrix by the inverse of the estimated information matrix. The estimation results and diagnostics of both $\mathrm{ARCH}$ and GARCH-in-mean models are presented in the next section.

\subsection{Empirical Results}

Maximum likelihood estimates of the parameters and their heteroskedasticity consistent asymptotic standard errors were obtained by numerical methods using the BHHH algorithm. ${ }^{13}$ In Tables 5.4 and 5.5 , the estimation results are reported for the two stochastic processes described in the previous section.

Table 5.4 reports the ARCH-in-mean estimation results for each currency and for each forecast horizon ( $k=3,6$, and 12 months). Rejection of the hypothesis $\beta_{1}=1$ (no time-varying risk premia) was obtained in ten out of fifteen cases, thus corroborating the results of Table 5.2, which demonstrate significant time-varying risk premia. In a number of cases, the results provide evidence of both $\theta$ and $\alpha_{1}$ being insignificantly different from zero. Rejection of the hypothesis $\theta=0$ was obtained in seven out of fifteen cases, whereas rejection of $\alpha_{1}=0$ was obtained in five cases, suggesting that timevarying risk premia might be explained by the conditional standard deviation of the expected rate of depreciation. The Italian Lira/Deutschmark exchange rate appears to be integrated-in-variance [see Engle and Bollerslev (1986)], a condition analogous to a unit root in conditional mean. At the 3,6 , and 12 month forecast horizon, the estimated $\alpha_{1}$ coefficient is greater than one which implies that the unconditional distribution of the expected depreciation

${ }^{13}$ All calculations were performed with the software package GAUSS. 
is extremely fat tailed with an infinite variance (see Table 5.1a). ${ }^{14}$

The GARCH-in-mean estimation results for each currency and for each forecast horizon are reported in Table 5.5. It is interesting to note that the generalized specification of the conditional variance significantly improves the fit of the model. The results provide a fairly consistent rejection of the hypothesis $\beta_{1}=1$ (no time-varying risk premia), suggesting significant variation in the risk premium. The estimated $\alpha_{1}$ and $\gamma_{1}$ coefficients are statistically significant in eight out of fifteen cases, thus supporting the GARCH specification. Moreover, all but seven of the estimated models result in statistically significant $\theta$ coefficients, suggesting that premia for EMS exchange rates relative to the Deutschmark depend on the conditional standard deviation of the expected rate of depreciation in a number of cases. We observe that in seven out of eight cases where $\theta$ is significant, $\beta_{0}$ and $\theta$ have opposite signs which indicates that the time-varying risk premium can switch signs. This is one of the prerequisites for an adequate description of the risk premium, as conjectured by Stockman (1978) and Kaminsky and Peruga (1990). In the case of the Italian Lira /Deutschmark exchange rate, the coefficient estimates of $\alpha_{1}+\gamma_{1}$ are greater than one, indicating high persistence in the volatility shocks, or IGARCH behavior [see Engle and Bollerslev (1986)]. As conjectured by Diebold (1986), and Lamoureux and Lastrapes (1990), this may be the result of shifts in monetary regimes which affect the level of the unconditional variances.

In Graphs $1 \mathrm{a}-2 \mathrm{~b}$ two examples of the actual $\left[\mathrm{P}_{\mathrm{t}}^{\mathrm{k}}\right.$ from the decomposition of the forward discount in equation (1)] and estimated premia of both $\mathrm{ARCH}$ and GARCH-in-mean models are presented (the DF/DM and BF/DM exchange rate). Graphs $3 a$ and $3 b$ display corresponding figures of the $\mathrm{ARCH}$ and GARCH premium estimates. The figures indicate substantial variation in the actual exchange risk premia. The GARCH-in-mean premium estimates indicate substantial movement of the conditional variance of the expected rate of depreciation. ${ }^{15}$ For the five exchange rates that we study, the premium patterns presented are shown to be broadly representative.

14 The conditional distribution, which for most purposes is the relevant distribution, is of course still normal with a finite variance.

15 If one would assume that our specification fully represents the true time-varying risk premium, then the difference between the estimated premium (which is now assumed to be the true premium) and the observed premium can be interpreted as the measurement error on the exchange rate expectations. 
Table 5.4 ARCH-in-Mean Models

January 1, 1986 through September 1, 1991: 69 Observations

\begin{tabular}{|c|c|c|c|c|c|c|}
\hline \multicolumn{7}{|c|}{3 Months } \\
\hline & $\hat{\beta}_{0}$ & $\hat{\beta}_{1}$ & $\hat{\theta}$ & $\hat{\alpha}_{0}\left(.10^{2}\right)$ & $\hat{\alpha}_{1}$ & L.L. \\
\hline BF/OM & $\begin{array}{l}-0.0128 \\
(0.0151)\end{array}$ & $\begin{array}{c}0.2632 \\
(0.1003)\end{array}$ & $\begin{array}{c}1.3091 \\
(1.4563)\end{array}$ & $\begin{array}{c}0.006 r^{-} \\
(0.0019)\end{array}$ & $\begin{array}{c}0.5003 * \\
(0.2517)\end{array}$ & 218.54 \\
\hline$D G / D H$ & $\begin{array}{l}-0.0018 \\
(0.0365)\end{array}$ & $\begin{array}{c}0.8339 \\
(0.5004)\end{array}$ & $\begin{array}{c}0.3735 \\
(4.3029)\end{array}$ & $\begin{array}{c}0.0069^{\cdots} \\
(0.0024)\end{array}$ & $\begin{array}{c}0.0006 \\
(1.1530)\end{array}$ & 230.76 \\
\hline$F F / D H$ & $\begin{array}{c}0.0125 \cdots \\
(0.0045)\end{array}$ & $\begin{array}{c}0.7731 \\
(0.1581)\end{array}$ & $\begin{array}{l}-2.8027^{\circ} \\
(1.0187)\end{array}$ & $\begin{array}{c}0.0023^{\cdots} \\
(0.0005)\end{array}$ & $\begin{array}{c}0.0515 \\
(0.0376)\end{array}$ & 268.48 \\
\hline IL/DH & $\begin{array}{l}-0.0176 \\
(0.0159)\end{array}$ & $\begin{array}{c}0.8382 \\
(0.8929)\end{array}$ & $\begin{array}{c}0.5236^{\circ} \\
(0.3124)\end{array}$ & $\begin{array}{c}0.0343 \\
(0.0244)\end{array}$ & $\begin{array}{c}1.2005 \\
(1.1738)\end{array}$ & 159.19 \\
\hline$S P / D M$ & $\begin{array}{l}-0.0146 \\
(0.0136)\end{array}$ & $\begin{array}{c}0.4874 \cdots \\
(0.1730)\end{array}$ & $\begin{array}{c}1.3919^{\circ} \\
(0.8132)\end{array}$ & $\begin{array}{c}0.0149^{\cdots} \\
(0.0052)\end{array}$ & $\begin{array}{c}0.1423 \\
(0.1242)\end{array}$ & 201.47 \\
\hline \multicolumn{7}{|c|}{6 Months } \\
\hline & $\hat{\beta}_{0}$ & $\hat{\beta}_{1}$ & $\hat{\theta}$ & $\hat{\alpha}_{0}\left(.10^{2}\right)$ & $\hat{\alpha}_{1}$ & L.L. \\
\hline$B F / D M$ & $\begin{array}{l}-0.0022 \\
(0.0025)\end{array}$ & $\begin{array}{c}0.5399^{\circ} \\
(0.2780)\end{array}$ & $\begin{array}{c}0.1091 \\
(0.2699)\end{array}$ & $\begin{array}{c}0.0061^{-} \\
(0.0025)\end{array}$ & $\begin{array}{c}0.6493 \\
(0.6348)\end{array}$ & 217.83 \\
\hline OG/OH & $\begin{array}{c}0.0101 \\
(0.0149)\end{array}$ & $\begin{array}{c}0.7170 \\
(0.2251)\end{array}$ & $\begin{array}{l}-2.0323 \\
(2.4406)\end{array}$ & $\begin{array}{c}0.0036^{\circ} \\
(0.0011)\end{array}$ & $\begin{array}{c}0.1341 \\
(0.3673)\end{array}$ & 251.15 \\
\hline FF/DH & $\begin{array}{c}0.0053 \\
(0.0503)\end{array}$ & $\begin{array}{c}0.9482 \\
(0.2061)\end{array}$ & $\begin{array}{l}-1.3584 \\
(6.0928)\end{array}$ & $\begin{array}{c}0.0065^{\cdots} \\
(0.0021)\end{array}$ & $\begin{array}{c}0.0950 \\
(0.2568)\end{array}$ & 231.13 \\
\hline IL/DM & $\begin{array}{c}0.0001 \\
(0.0088)\end{array}$ & $\begin{array}{l}0.3432 \ldots \\
(0.1822)\end{array}$ & $\begin{array}{c}0.4893^{\circ} \\
(0.2444)\end{array}$ & $\begin{array}{c}0.0088 \cdots \\
(0.0018)\end{array}$ & $\begin{array}{l}1.1044^{\cdots} \\
(0.2727)\end{array}$ & 182.84 \\
\hline SP/DH & $\begin{array}{c}0.0085 \\
(0.0074)\end{array}$ & $\begin{array}{c}0.2105 \% \\
(0.1333)\end{array}$ & $\begin{array}{c}0.2588 \\
(0.3319)\end{array}$ & $\begin{array}{c}0.0155^{\circ} \\
(0.0081)\end{array}$ & $\begin{array}{c}0.8533 \\
(0.6892)\end{array}$ & 179.06 \\
\hline \multicolumn{7}{|c|}{12 Months } \\
\hline & $\hat{\beta}_{0}$ & $\hat{\beta}_{1}$ & $\hat{\theta}$ & $\hat{\alpha}_{0}\left(.10^{2}\right)$ & $\hat{\alpha}_{1}$ & L.L. \\
\hline BF/DH & $\begin{array}{l}-0.0076 \\
(0.0058)\end{array}$ & $\begin{array}{c}0.0921^{\cdots} \\
(0.1101)\end{array}$ & $\begin{array}{c}0.8288^{\cdots} \\
(0.2939)\end{array}$ & $\begin{array}{c}0.0080^{\circ} \\
(0.0039)\end{array}$ & $\begin{array}{r}0.7280^{\circ} \\
(0.3534)\end{array}$ & 203.24 \\
\hline$D G / D M$ & $\begin{array}{c}0.0067^{\cdots} \\
(0.0013)\end{array}$ & $\begin{array}{l}-0.0349^{\cdots} \\
(0.0915)\end{array}$ & $\begin{array}{c}0.0220 \\
(0.1232)\end{array}$ & $\begin{array}{c}0.0040^{\cdots} \\
(0.0014)\end{array}$ & $\begin{array}{c}1.0041^{*} \\
(0.4549)\end{array}$ & 222.25 \\
\hline FF/DM & $\begin{array}{l}-0.0266 \cdots \\
(0.0070)\end{array}$ & $\begin{array}{c}0.5944^{\cdots} \\
(0.0754)\end{array}$ & $\begin{array}{c}2.1682 \cdots \\
(0.8023)\end{array}$ & $\begin{array}{c}0.0092 \cdots \\
(0.0017)\end{array}$ & $\begin{array}{c}0.0646 \\
(0.0603)\end{array}$ & 220.24 \\
\hline IL/OM & $\begin{array}{c}0.0079 \\
(0.0096)\end{array}$ & $\begin{array}{c}0.1382 \cdots \\
(0.0992)\end{array}$ & $\begin{array}{c}0.2918^{\prime} \\
(0.0929)\end{array}$ & $\begin{array}{c}0.0098 \% \\
(0.0034)\end{array}$ & $\begin{array}{c}1.3169 \% \\
(0.3596)\end{array}$ & 165.88 \\
\hline SP/DM & $\begin{array}{l}-0.0171 \\
(0.0211)\end{array}$ & $\begin{array}{c}0.2995^{\cdots} \\
(0.0618)\end{array}$ & $\begin{array}{c}1.5984 \\
(1.1739)\end{array}$ & $\begin{array}{c}0.0335 \cdots \\
(0.0071)\end{array}$ & $\begin{array}{c}0.0043 \\
(0.0469)\end{array}$ & 177.98 \\
\hline
\end{tabular}

The heteroskedasticity consistent standard errors of the coefficients are given in parentheses; * (**) [***] denotes significance at the $10 \%(5 \%)[1 \%]$ level for the hypotheses $\beta_{0}=0, \beta_{1}=1, \theta=0, \alpha_{0}=0$ or $\alpha_{1}=0$ respectively. L.L. denotes the log-likelihood values. 
Table 5.5 GARCH-in-Mean Models

January 1, 1986 through September 1, 1991: 69 Observations

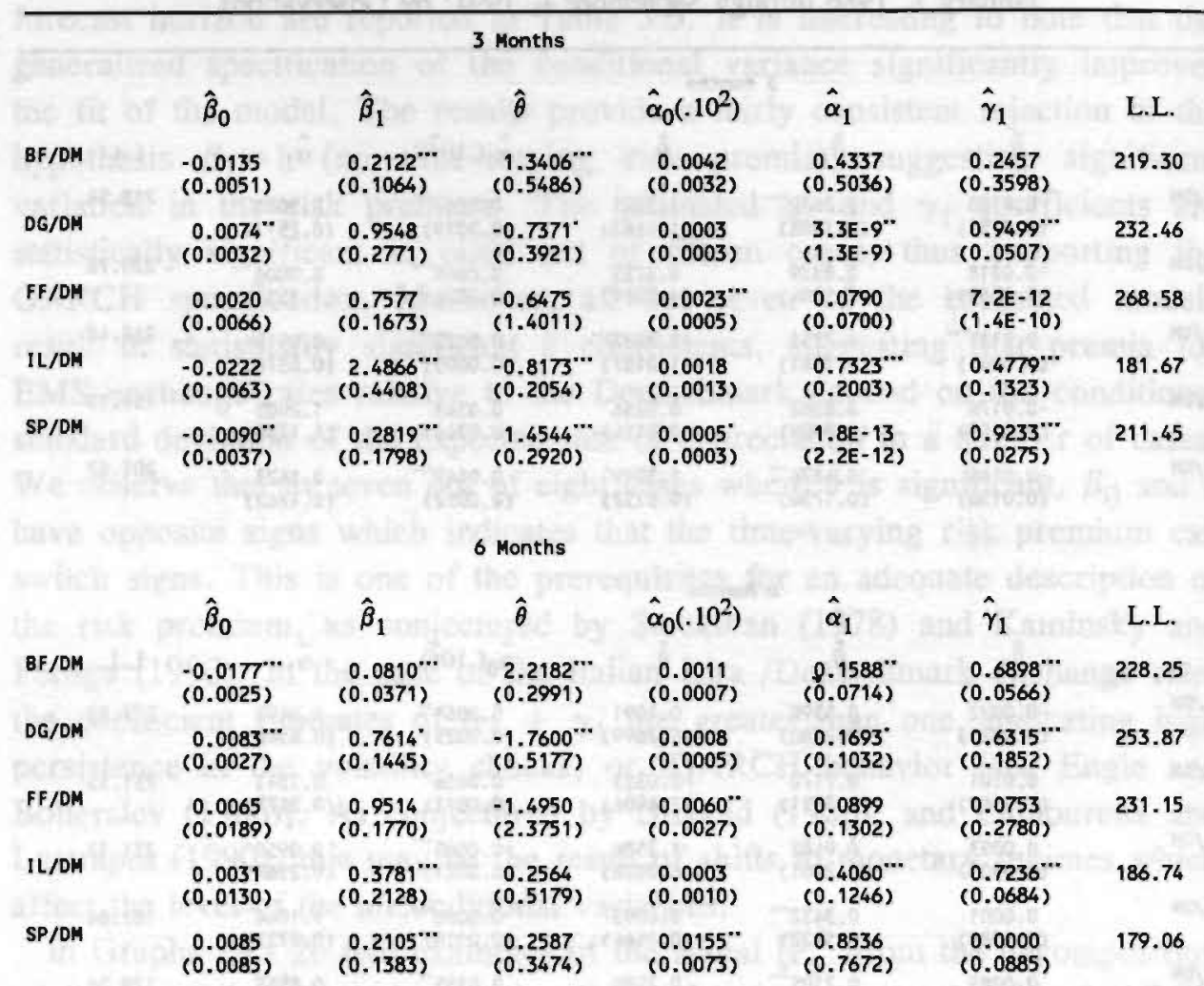

12 Months

\begin{tabular}{|c|c|c|c|c|c|c|c|}
\hline $\mathrm{BF} / \mathrm{DM}$ & $\begin{array}{l}-0.0076 \\
(0.0058)\end{array}$ & $\begin{array}{c}0.0920 \cdots \\
(0.1101)\end{array}$ & $\begin{array}{c}0.8288^{\cdots} \\
(0.2940)\end{array}$ & $\begin{array}{c}0.0080^{\circ} \\
(0.0039)\end{array}$ & $\begin{array}{c}0.7281^{\circ} \\
(0.3534)\end{array}$ & $\begin{array}{c}0.0000 \\
(0.0000)\end{array}$ & 203.24 \\
\hline $\mathrm{DG} / \mathrm{DH}$ & $\begin{array}{c}0.0068 \\
(0.0071)\end{array}$ & $\begin{array}{c}0.0395 \cdots \\
(0.2347)\end{array}$ & $\begin{array}{l}-0.7682 \\
(0.9379)\end{array}$ & $\begin{array}{c}0.0019 \\
(0.0013)\end{array}$ & $\begin{array}{c}0.4264 \\
(0.6647)\end{array}$ & $\begin{array}{c}0.4798 \\
(0.4368)\end{array}$ & 224.15 \\
\hline FF/DH & $\begin{array}{l}-0.0204 " * \\
(0.0114)\end{array}$ & $\begin{array}{c}0.5969 \cdots \\
(0.1324)\end{array}$ & $\begin{array}{c}1.6435 \\
(1.2154)\end{array}$ & $\begin{array}{c}0.0041 \\
(0.0097)\end{array}$ & $\begin{array}{c}0.0136 \\
(0.3429)\end{array}$ & $\begin{array}{c}0.5150 \\
(1.3983)\end{array}$ & 221.84 \\
\hline $1 \mathrm{~L} / \mathrm{DM}$ & $\begin{array}{c}0.0073 \\
(0.0076)\end{array}$ & $\begin{array}{c}0.1542 \cdots \\
(0.0873)\end{array}$ & $\begin{array}{c}0.2353 \\
(0.1705)\end{array}$ & $\begin{array}{c}0.0038 \\
(0.0026)\end{array}$ & $\begin{array}{c}0.7959 \cdots \\
(0.2534)\end{array}$ & $\begin{array}{c}0.3568 \cdots \\
(0.1520)\end{array}$ & 167.69 \\
\hline SP/DM & $\begin{array}{c}0.0215^{\cdots} \\
(0.0044)\end{array}$ & $\begin{array}{l}0.2653 \cdots \\
(0.0655)\end{array}$ & $\begin{array}{l}-0.6997^{\circ} \\
(0.2117)\end{array}$ & $\begin{array}{c}2.2 E-10 \\
(2.2 E-10)\end{array}$ & $\begin{array}{c}6.6 E-9 \\
(5.3 E-9)\end{array}$ & $\begin{array}{c}0.9863 \cdots \\
(0.0051)\end{array}$ & 180.19 \\
\hline
\end{tabular}

The heteroskedasticity consistent standard errors of the coefficients are given in parentheses; ${ }^{*}(* *)[* * *]$ denotes significance at the $10 \%(5 \%)$ [1\%] level for the hypotheses $\beta_{0}=0, \beta_{1}=1, \theta=0, \alpha_{0}=0, \alpha_{1}=0$ or $\gamma_{1}=0$ respectively. L.L. denotes the log-likelihood values. 
Graph 1a: Actual and Estimated ARCH Premia DG/DH 6 Months Forecasts

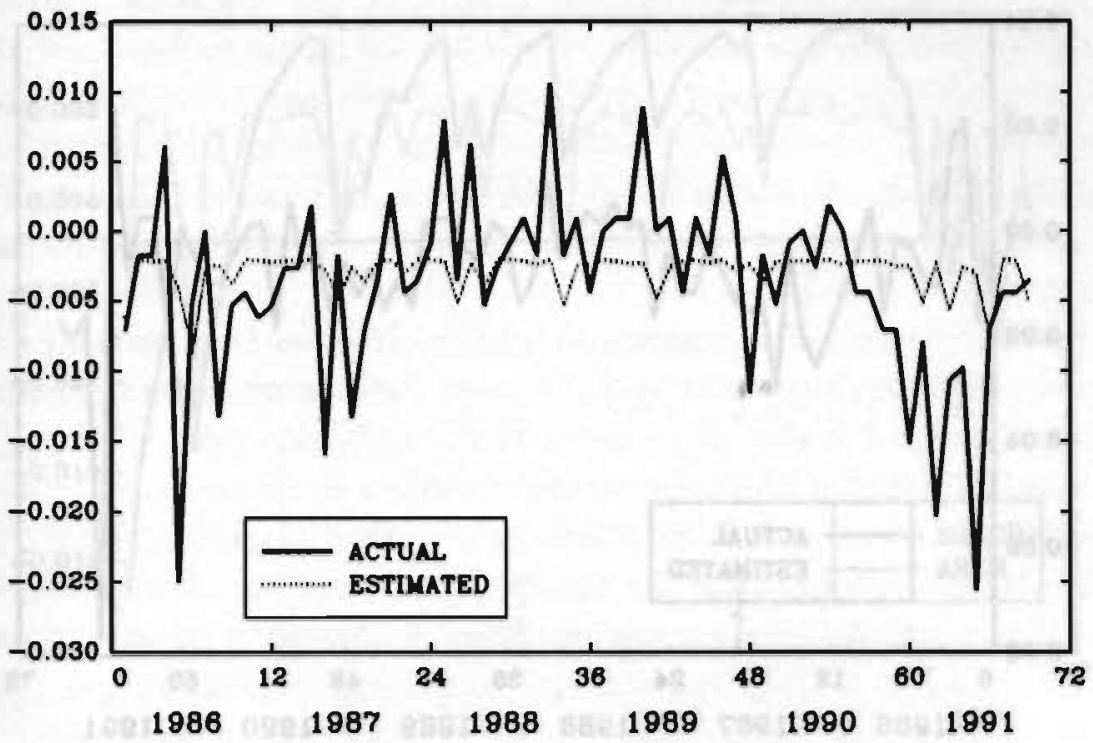

Graph 1b: Actual and Estimated GARCH Premia DG/DM 6 Months Forecasts

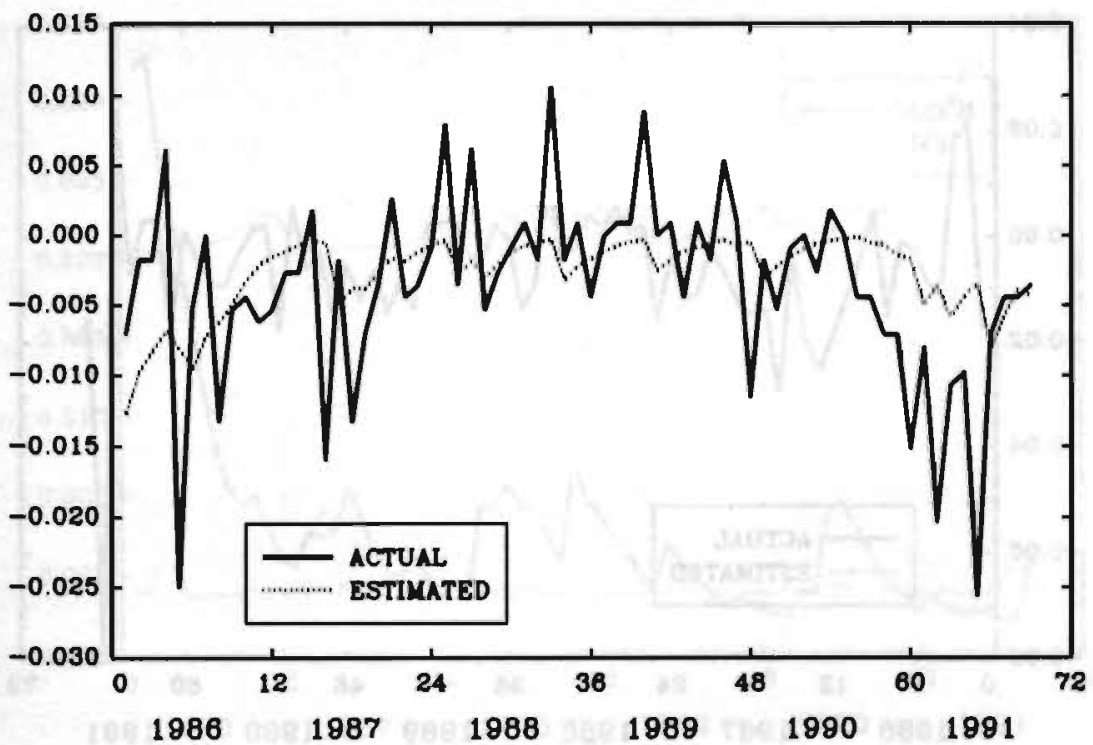


Graph 2a: Actual and Estimated ARCH Premia BF/DM 6 Months Forecasts

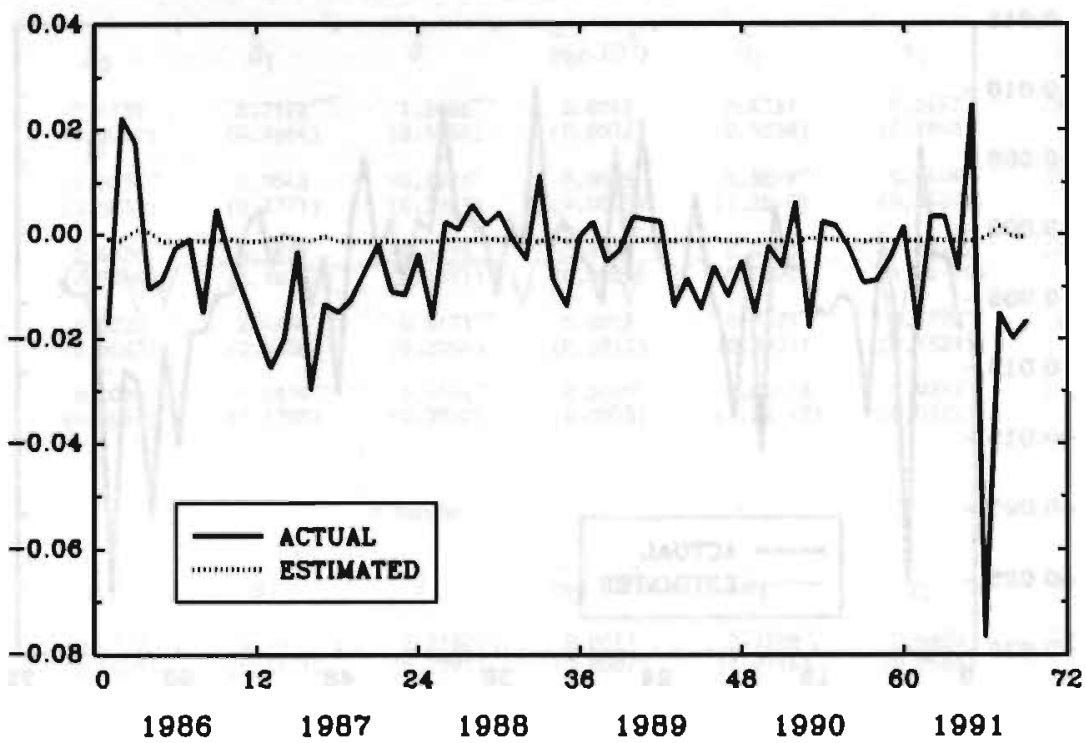

Graph 2b: Actual and Estimated GARCH Premia BF/DM 6 Months Forecasts

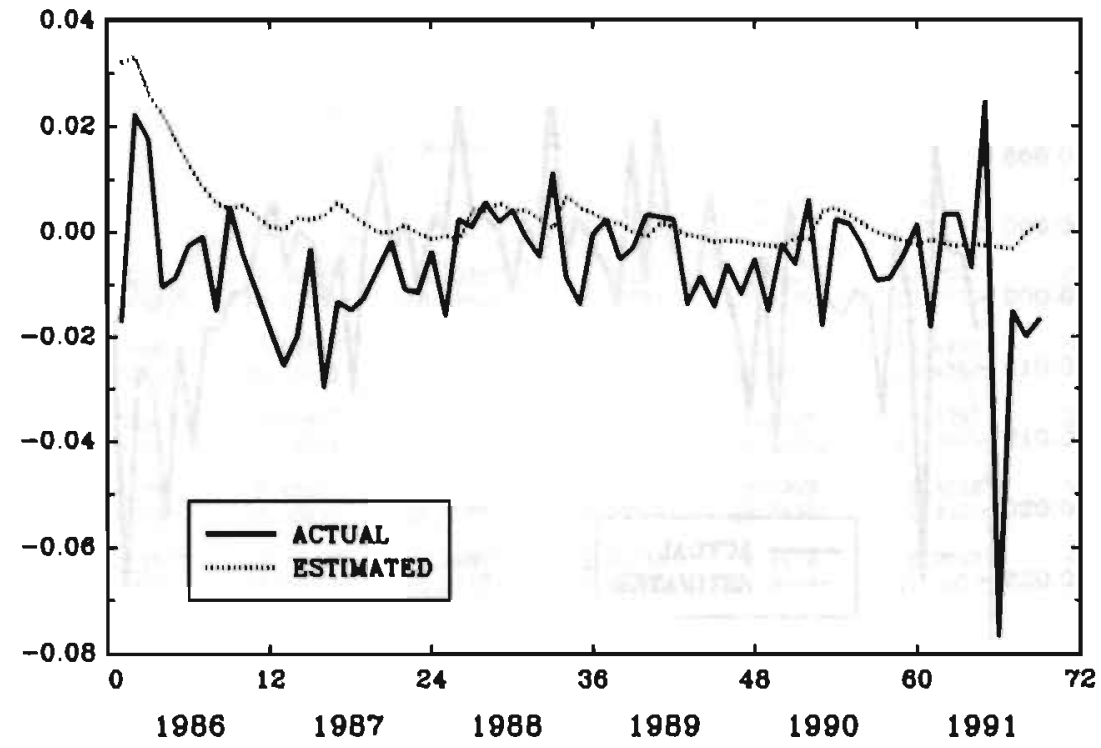


Graph 3a: Estimated ARCH and GARCH Premia DG/DM 6 Months Forecasts

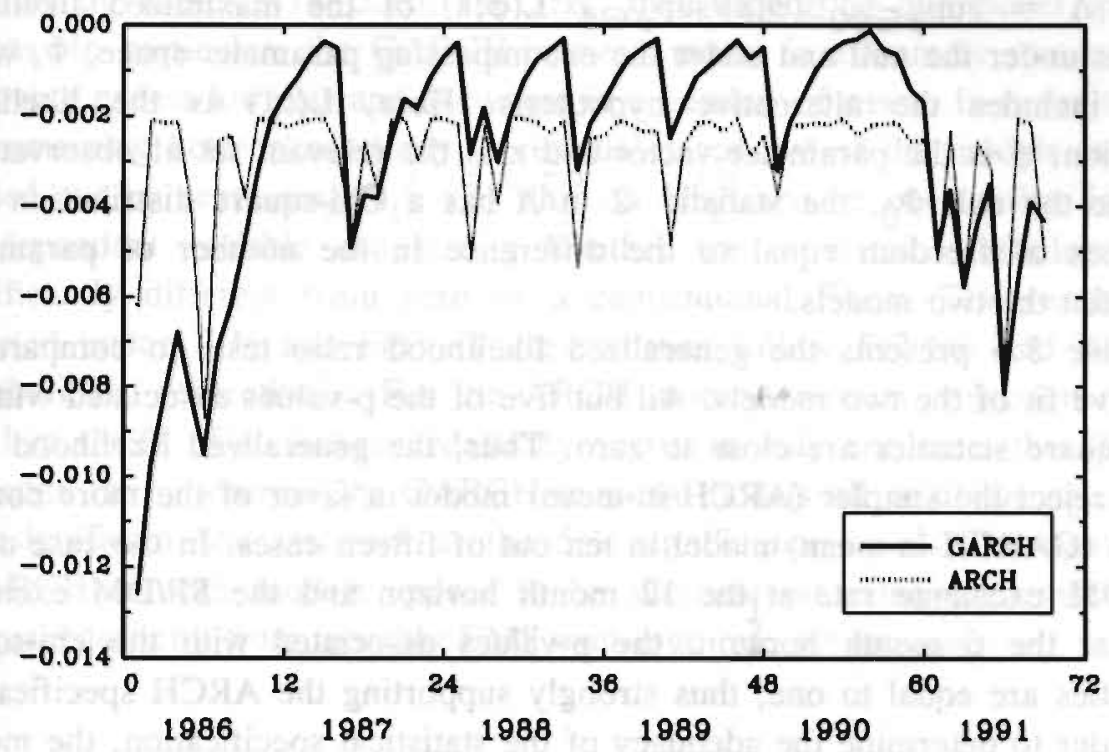

Graph 3b: Estimated ARCH and GARCH Premia BF/DM 6 Months Forecasts

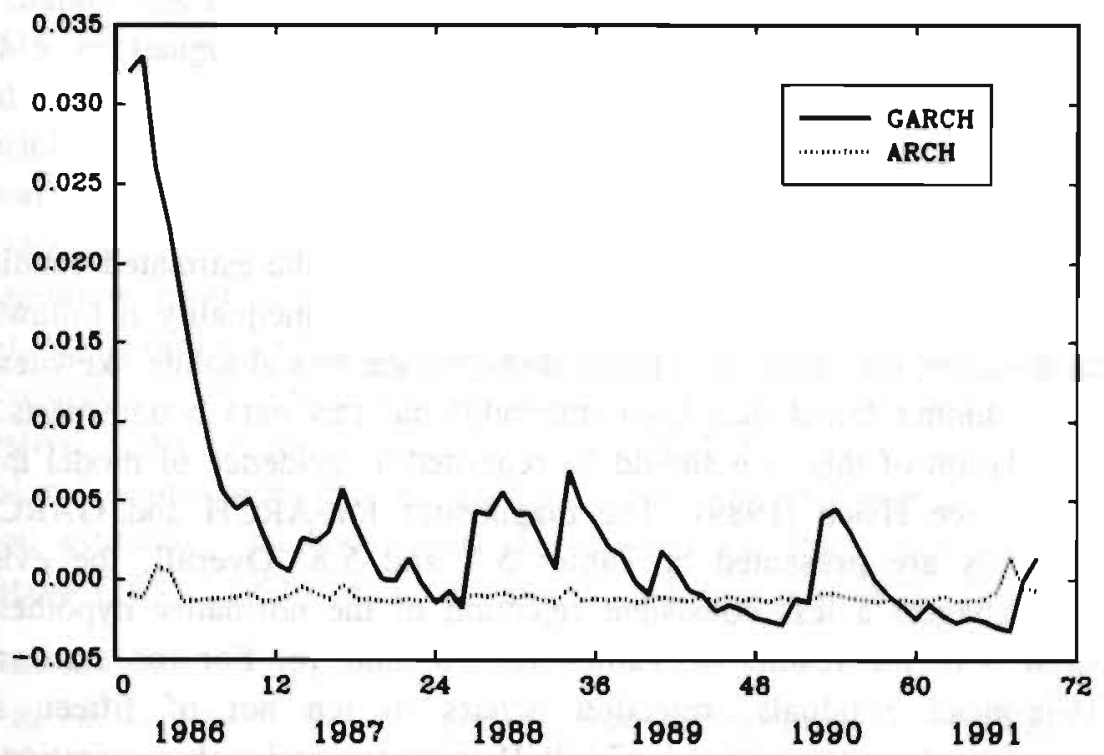


Given the above results, it is interesting to compare the relative fit of both models. We employ generalized likelihood ratio tests to compare nested models. Such nested models can be tested using the generalized likelihood ratio $\Lambda=\sup _{\phi \in \Phi 0} \mathrm{~L}(\phi ; \mathrm{x}) / \sup _{\phi \in \Phi} \mathrm{L}(\phi ; \mathrm{x})$ of the maximized likelihood values under the null and under the encompassing parameter space, $\Phi$, which also includes the alternative hypothesis. Here, $\mathrm{L}(. ;$.$) is the likelihood$ function, $\phi$ is the parameter vector and $\mathrm{x}$ is the relevant set of observations. Under the null $\Phi_{0}$, the statistic $-2 \ln \Lambda$ has a Chi-square distribution with degrees of freedom equal to the difference in the number of parameters between the two models.

Table 5.6 presents the generalized likelihood ratio tests to compare the relative fit of the two models. All but five of the p-values associated with the chi-square statistics are close to zero. Thus, the generalized likelihood ratio tests reject the simpler (ARCH-in-mean) model in favor of the more complicated (GARCH-in-mean) model in ten out of fifteen cases. In the case of the $\mathrm{BF} / \mathrm{DM}$ exchange rate at the 12 month horizon and the SP/DM exchange rate at the 6 month horizon, the p-values associated with the chi-square statistics are equal to one, thus strongly supporting the $\mathrm{ARCH}$ specification. In order to determine the adequacy of the statistical specification, the models are subjected to diagnostic checks on the standardized residuals:

$$
z_{t}=\frac{\hat{\varepsilon}_{l}}{\hat{h}_{t}},
$$

where $\hat{\epsilon}_{\mathrm{t}}$ is the residual from equation (5) and $\hat{h}_{\mathrm{t}}^{2}$ is the estimated conditional variance from equations ( 8 ) and (9). From Jensen's inequality it follows that the standardized residuals, $z_{t}$, should demonstrate less absolute skewness and should be thinner tailed than their unconditional raw data counterparts. Any strong violation of this rule should be regarded as evidence of model misspecification - see Hsieh (1989). The diagnostics for ARCH and GARCH-inmean models are presented in Tables 5.7 and 5.8. Overall, the evidence presented suggest a less consistent rejection of the normality hypotheses as compared with the results of Tables $1 \mathrm{a}, 1 \mathrm{~b}$, and 1c. For the standardized ARCH-in-mean residuals, rejection occurs in ten out of fifteen cases, whereas for the standardized GARCH-in-mean residuals, rejection was 
obtained in only seven cases. In addition, we find that in most cases the estimated statistics - the BJ-test, $\mathrm{KS}-1$, and $\mathrm{KS}-2$ - are smaller than those reported by Tables $5.1 \mathrm{a}, 5.1 \mathrm{~b}$, and $5.1 \mathrm{c}$, thus supporting our model specifications. In particular, the GARCH-in-mean model is extremely succesful at removing excess kurtosis and skewness in a number of cases. In order to test for remaining heteroskedasticity, a residual-based test of the models may be carried out by regressing $\left(\hat{\epsilon}_{\mathrm{t}}^{2}-\hat{\mathrm{h}}_{\mathrm{t}}{ }^{2}\right) / \hat{\mathrm{h}}_{\mathrm{t}}{ }^{2}$ on $1 / \hat{\mathrm{h}}_{\mathrm{t}}{ }^{2}$ and on one to five lags of the dependent variable and testing whether the estimated coefficients are significantly different from zero by a conventional F-test. The results are reported under $F(1)$ and $F(5)$. These statistics follow $F(2,66)$ and $F(6,58)$ distributions, respectively. For the ARCH-in-mean models, rejection of the null hypothesis of no heteroskedasticity occurs in only one case (the SP/DM exchange rate), whereas the GARCH-in-mean models all result in statistically insignificant test statistics at the $5 \%$ significance level. The estimated (G)ARCH-in-mean models appear to be succesful at removing conditional heteroskedasticity from monthly EMS exchange rate movements.

\subsection{Conclusions}

This chapter has examined exchange risk premia using survey data for a set of EMS exchange rates relative to the Deutschmark over the 1985-1991 period. The methodologies used in previous empirical research on premia in the pricing of forward foreign exchange usually involve measurement of time-varying risk premia conditional on market efficiency or rational expectations.

In addition, most studies, such as Dornbusch (1982), Hansen and Hodrick (1983), and Frankel (1986), explicitly assumed that the conditional variances and covariances of returns were constant over time. We implemented an alternative approach to measure premia. Neither do we have to assume conditional homoskedasticity of exchange rate returns ${ }^{16}$ nor do we have to rely on estimation methods using unobserved variables, see Hodrick and Srivastava (1984, 1986), and Giovannini and Jorion (1987). The approach

16 Recent work by Cumby and Obstfeld (1984) and by Giovannini and Jorion (1987) rejects the constancy of conditional covariances of exchange rate returns and argues that this particular restriction should be relaxed. 
Table 5.6 Generalized Likelihood Ratio Tests:

ARCH-in-mean model against GARCH-in-mean model

January 1, 1986 through September 1, 1991: 69 Observations

\begin{tabular}{|c|c|c|c|}
\hline & 3 Months & 6 Months & 12 Months \\
\hline & $x^{2}(1)$ & $x^{2}(1)$ & $\chi^{2}(1)$ \\
\hline$B F / D H$ & $\begin{array}{c}1.52 \\
(0.218)\end{array}$ & $\begin{array}{l}20.84 \cdots \\
(0.000)\end{array}$ & $\begin{array}{l}0.00 \\
(1.000)\end{array}$ \\
\hline$D G / D M$ & $\begin{array}{l}3.40^{\circ} \\
(0.065)\end{array}$ & $\begin{array}{c}5.44^{\circ} \\
(0.020)\end{array}$ & $\begin{array}{c}3.80^{\circ} \\
(0.051)\end{array}$ \\
\hline $\mathrm{FF} / \mathrm{DM}$ & $\begin{array}{c}0.20 \\
(0.655)\end{array}$ & $\begin{array}{c}0.04 \\
(0.841)\end{array}$ & $\begin{array}{l}3.20^{\circ} \\
(0.074)\end{array}$ \\
\hline IL/DM & $\begin{array}{l}44.96 \cdots \\
(0.000)\end{array}$ & $\begin{array}{c}7.80 \cdots \\
(0.005)\end{array}$ & $\begin{array}{c}3.62^{\circ} \\
(0.057)\end{array}$ \\
\hline SP/OM & $\begin{array}{l}19.96 \cdots \\
(0.000)\end{array}$ & $\begin{array}{c}0.00 \\
(1.000)\end{array}$ & $\begin{array}{c}4.42 * \\
(0.035)\end{array}$ \\
\hline
\end{tabular}

P-Values are given in parentheses; ${ }^{*}\left({ }^{* *}\right)\left[{ }^{* * *}\right]$ denotes rejection at the $10 \%(5 \%)[1 \%]$ level. 
Table 5.7 Diagnostics for ARCH-in-Mean Models

January 1, 1986 through September 1, 1991: 69 Observations

\begin{tabular}{|c|c|c|c|c|c|}
\hline & $\mathrm{BF} / \mathrm{DH}$ & $D G / D H$ & $\mathrm{FF} / \mathrm{OM}$ & IL/DM & SP/DM \\
\hline \multicolumn{6}{|c|}{3 Months } \\
\hline Skemness & 1.15 & 1.31 & -0.21 & -3.24 & 0.29 \\
\hline Kurtos is & 4.90 & 7.10 & 4.05 & 16.58 & 6.50 \\
\hline$B J$-test & $25.45 \cdots$ & $67.86 \cdots$ & 3.66 & $650.69^{\cdots}$ & $36.17^{-.}$ \\
\hline $\mathrm{ks}-1$ & $15.20^{\cdots}$ & $19.52^{\cdots}$ & 0.49 & $120.69 \cdots$ & 0.99 \\
\hline$K s-2$ & $10.35 \cdots$ & $48.34 \cdots$ & $3.17^{\circ}$ & $530.29^{\cdots}$ & $35.1 T^{\cdots}$ \\
\hline$F(1)$ & 0.02 & 0.13 & 0.00 & 0.00 & 0.00 \\
\hline$f(5)$ & 0.33 & 0.13 & 1.32 & 0.27 & $6.24^{\cdots}$ \\
\hline
\end{tabular}

6 Months

$\begin{array}{llllll}\text { Skewness } & 0.23 & -0.66 & -0.06 & -0.17 & 0.60 \\ \text { Kurtosis } & 4.50 & 3.86 & 3.08 & 3.27 & 3.89 \\ \text { BJ-test } & 7.06 * & 7.16 * & 0.06 & 0.53 & 6.47^{*} \\ \text { KS-1 } & 0.61 & 5.01 * & 0.06 & 0.32 & 4.19^{*} \\ \text { KS-2 } & 6.46^{*} & 2.16 & 0.02 & 0.20 & 2.29 \\ F(1) & 0.00 & 0.06 & 0.00 & 0.03 & 0.01 \\ F(5) & 0.15 & 1.12 & 0.47 & 0.39 & 0.22\end{array}$

\section{Months}

\begin{tabular}{|c|c|c|c|c|c|}
\hline Skewness & 0.41 & 0.32 & -0.59 & 0.00 & 0.47 \\
\hline Kurtosis & 3.73 & 4.12 & 3.80 & 3.39 & 3.47 \\
\hline BJ-test & 3.49 & $4.83^{\circ}$ & $5.89^{\circ}$ & 0.45 & 3.19 \\
\hline KS-1 & 1.92 & 1.18 & 4.07 & 0.00 & 2.54 \\
\hline$x s-2$ & 1.53 & $3.64^{\circ}$ & 1.82 & 0.47 & 0.64 \\
\hline$F(1)$ & 0.00 & 0.00 & 1.52 & 0.00 & 0.07 \\
\hline$F(5)$ & 0.03 & 0.13 & 0.82 & 0.20 & 0.90 \\
\hline
\end{tabular}

The BJ-test denotes the Bera Jarque test for normality; KS-1 and KS-2 pertain to the Kiefer Salmon Normality test for respectively skewness and kurtosis: * $\left(^{* *}\right)[* *$ ] denotes rejection at the $10 \%(5 \%)$ [1\%] level of the normality hypotheses. 
Table 5.8 Diagnostics for GARCH-in-Mean Models

January 1, 1986 through September 1, 1991: 69 Observations

\begin{tabular}{|c|c|c|c|c|c|}
\hline & BF /DH & $D G / D H$ & FF/DH & IL/DM & SP/DM \\
\hline \multicolumn{6}{|c|}{3 Months } \\
\hline Skemness & 1.27 & 1.23 & -0.16 & -0.23 & -0.21 \\
\hline Kurtosis & 5.49 & 7.17 & 4.00 & 7.11 & 3.02 \\
\hline BJ-test & $36.24^{\circ}$ & $67.55 \%$ & 3.18 & $49.26 \%$ & 0.50 \\
\hline Ks-1 & $18.40^{\cdots}$ & $17.45^{\cdots}$ & 0.30 & 0.62 & 0.50 \\
\hline$k s-2$ & $17.83^{\cdots}$ & $50.09 \%$ & $2.88^{\circ}$ & $48.62^{\cdots}$ & 0.00 \\
\hline$f(1)$ & 0.06 & 0.17 & 0.64 & 0.05 & 0.57 \\
\hline$F(5)$ & 0.35 & 0.15 & 1.02 & 0.11 & 0.88 \\
\hline
\end{tabular}

6 Honths

$\begin{array}{llllll}\text { Skewness } & 0.20 & -0.47 & -0.07 & -0.24 & 0.60 \\ \text { Kurtosis } & 2.84 & 3.97 & 3.09 & 3.47 & 3.89 \\ \text { BJ-test } & 0.54 & 5.20^{\circ} & 0.08 & 1.30 & 6.47^{\circ} \\ \text { KS-1 } & 0.47 & 2.52 & 0.06 & 0.66 & 4.19^{*} \\ \text { KS-2 } & 0.07 & 2.68 & 0.03 & 0.64 & 2.28 \\ \text { F(1) } & 1.13 & 0.49 & 0.49 & 0.44 & 0.01 \\ F(5) & 0.57 & 0.74 & 0.57 & 0.21 & 0.22\end{array}$

12 Months

$\begin{array}{lccccc}\text { Skemess } & 0.41 & 0.42 & -0.43 & -0.05 & 0.26 \\ \text { Kurtosis } & 3.73 & 4.95 & 3.01 & 2.80 & 3.06 \\ \text { BJ-test } & 3.46 & 12.97 \cdots & 2.13 & 0.15 & 0.79 \\ \text { KS-1 } & 1.92 & 1.98 & 2.12 & 0.03 & 0.77 \\ \text { KS-2 } & 1.54 & 10.99 \cdots & 0.01 & 0.11 & 0.01 \\ F(1) & 0.00 & 0.04 & 0.64 & 0.16 & 0.34 \\ F(5) & 0.03 & 0.37 & 0.83 & 0.34 & 2.09^{\circ}\end{array}$

The BJ-test denotes the Bera Jarque test for normality; KS-1 and KS-2 pertain to the Kiefer Salmon Normality test for respectively skewness and kurtosis; * $\left(^{* *}\right)[* *$ ] denotes rejection at the $10 \%(5 \%)$ [1\%] level of the normality hypotheses. 
involves application of survey data to allow the direct measurement of risk premia from the forward discount decomposition into its two components expected depreciation and the risk premium. We extended the analysis of Domowitz and Hakkio (1985) to model time-varying risk premia in the pricing of forward foreign exchange that do not require us to assume rationality on the part of economic agents. We find considerable support for the presence of time-varying EMS risk premia in the pricing of forward foreign exchange. The estimated premium models - ARCH-in-mean and GARCH-in-mean - indicate that time-varying premia may be explained by the conditional standard deviation of the expected rate of depreciation. In particular, the GARCH-in-mean model appears to be moderately successful in accounting for both time-varying risk premia and conditional heteroskedasticity.

The results basically contrast the results of Domowitz and Hakkio (1985), who found only minimal support for the ARCH-in-mean model for some of the major currencies (British Pound, French Franc, Deutschmark, Japanese Yen, and Swiss Franc) relative to the United States Dollar covering the 1973-1982 period. Domowitz and Hakkio (1985) conclude that their results are generally consistent with the rejection of the unbiasedness hypothesis, but "there is little support for the conditional variance of the exchange rate forecast error being an important sole determinant of the risk premium". Note that, conditional on the hypothesis that exchange rate forecasts are rational, they modeled the conditional variance of the exchange rate forecast error with an ARCH specification, instead of using a more parsimonious representation of the conditional variance - the $\operatorname{GARCH}(1,1)$ specification. We therefore conclude that EMS exchange rate risk premia are not time invariant; rather they vary systematically with agent's perception of underlying uncertainty. Whether the significant time-varying risk premia reflect peso-problems resulting from expectations of periodic realignments of central parities, learning on the part of economic agents about policy changes, market inefficiencies or a combination of these factors remain an open question.

The evidence presented in this paper is sufficiently strong to suggest further research as to whether foreign exchange risk can be usefully approximated by a measure of exchange rate variability. In addition, cross sectional dispersion in survey data might be considered as a measure of uncertainty. The dispersion in exchange rate forecasts provides an indicator of the 
heterogeneity in exchange rate expectations, and may be an approximation of the fundamental underlying uncertainty. This issue requires futher investigation in future work. 


\section{Chapter six}

\section{Interest Rate Expectations and Exchange Rates Dynamics}

\subsection{Introduction}

The history of floating exchange rates in the 1970s was characterized by periods of extreme turbulence and volatility. While purchasing power parity (PPP) is at best a long-run phenomenon, the "asset market theory" of exchange rate determination - as developed by Branson, Halttunen and Masson (1977), Dornbusch (1976a, 1976b), Frenkel (1976), Mussa (1976), and Frenkel and Mussa (1980) - appears necessary to understand short-run fluctuations in exchange rates. According to this theory exchange rates are merely the relative prices of assets determined in organized markets where asset prices can be adjusted on an instanteneous basis to whatever "the market" regards as the currently appropriate price. Thus, exchange rates fluctuate in response to the market's perception of future fundamental determinants that affect the supply and demand for foreign exchange. This approach typically places considerable emphasis on the importance of expectations and is generally taken to imply that empirical research on the determinants of exchange rates should relate innovations in exchange rates to innovations in relevant future fundamentals, which are unobservable and difficult to model empirically.

The essential elements of this general "asset market approach" of exchange rate determination may be represented in a simple theoretical framework that relates the current exchange rate to present and future conditions that are expected to affect the foreign exchange market. Consider the following simple model of exchange rate determination: 


$$
S_{t}=Z_{t}+\beta E_{t}\left(S_{t+1}-S_{t}\right)
$$

where $\beta(\beta>0)$ is a coefficient. Equation (1) is due to Frenkel and Mussa (1980) and states that the logarithm of the equilibrium spot exchange rate, $S_{\mathrm{t}}$, is determined not only by a set of current market fundamentals, but also by the expected rate of change of the exchange rate, $E_{t}\left(S_{t+1}-S_{t}\right)$, which motivates domestic and foreign residents to move into or out foreign exchange depending whether the relative price of foreign exchange is expected to rise or fall. Equation (1) represents a general relationship which can be derived from a variety of models of exchange rate determination that generally differ in their interpretation of the elements of the fundamental factors. Rearranging terms and solving for the reduced form of the exchange rate by forward iteration, it follows that: ${ }^{1}$

$$
E_{t} S_{t+k}=\frac{1}{1+\beta} \sum_{j=0}^{\infty}\left[\frac{\beta}{1+\beta}\right] j E_{t} Z_{t+k+j}
$$

The exchange rate that is currently expected to prevail at time $t+k$ depends on a weighted average of expected future $Z_{t}$ 's. In other words, the value of the exchange rate at any point is determined by market perceptions of the entire future path of the relevant fundamentals. Thus the current exchange rate $(k=0)$ and the current expected future spot exchange rate are linked because both depend on expectations concerning future fundamentals.

Alternative competing theoretical models based on the "asset market" approach providing different sets of fundamentals have been described in the literature - for instance the monetary model - Dornbusch (1976a, 1976b) and Frenkel (1976), the portfolio balance model - Branson (1977) et al., and "news" models of exchange rate determination - Frenkel (1981), Edwards (1983), and Isard (1983).

Following the "news" approach of exchange rate determination, according to which innovations in exchange rates respond only to innovations in

${ }^{1}$ When an appropriate boundary condition is imposed, we can ignore $[\beta /(1+\beta)]^{j}$ $\mathrm{E}_{\mathrm{t}} \mathrm{S}_{\mathrm{t}+\mathrm{k}+\mathrm{j}}$ in equation (2). 
relevant future fundamentals, all anticipated movements are already embodied in the current spot rate. Therefore, it is unanticipated rather than anticipated changes in fundamentals that should be closely associated with innovations in exchange rates. Since innovations are inherently unobservable, any empirical study on the "news" approach involves a joint examination of the model and the method that is used to construct innovations. That is, when testing the "news" approach empirically, a specific model of the process of exchange rate determination and an appropriate method of generating expected values of its driving values must be chosen. In constructing innovations, the literature considered three methods to generate expected values of the determinating variables: univariate time series models, vector autoregressions (VAR), and survey data - see Baillie and MacMahon (1989), and MacDonald and Taylor (1992). It should be noted that innovations in exchange rates are nearly always measured as the deviations of forward rates from subsequently realized rates, thus using the forward rate as a proxy for the expected future spot exchange rate and obviously replacing one unobservable variable with an observable, the forward rate, and another unobservable, the risk premium.

The empirical construction of innovations in variables such as interest rates, relative money supplies and real income was undertaken by Frenkel (1981), Edwards (1983), Isard (1983), MacDonald (1983), Copeland (1984), Rose (1984), Baillie (1987), and Wolff (1988). In general the empirical evidence on the importance of different types of "news" is fairly mixed, with inconsistency of results between different authors' findings. Frenkel (1981) used time-series methods to generate "news" on nominal interest differentials. His findings indicate weak explanatory power for surprises in interest differentials, although there is some ambiguity attached to the sign of the estimated "news" coefficient [see Wolff (1986)]. Edwards (1982) and MacDonald (1983) provided mixed support with many coefficients being insignificant for the flexible-price "news" approach, using a seemingly unrelated regression (SUR) estimating technique. Emerging from the documented literature so far, it should be noted that the variable which most consistently yields significant results is certainly "news" concerning unanticipated changes in interest differentials.

In this chapter we implement empirically the "news" version of the Dornbusch-Frankel overshooting model, as derived in Isard (1983), using survey data of matched exchange rate and interest rate expectations. This in 
order to obtain empirical evidence on the relative importance of "news" and "risk" in explaining unanticipated movements in exchange rates. In the present context, the survey-based approach allows us to measure market forecasts of the exchange rate directly and generate expected values of the determining variables. Thus, because market participants' perceptions of future exchange rates as well as their perceptions of interest rates are measured simultaneously, we can avoid problems of artificially generating expectations or "news" from econometric modeling nor do we have to assume time-invariant exchange rate risk premia. ${ }^{2}$

The presentation of this chapter is as follows. In section 2, we start with a description of our survey data set and summary statistics describing the data are provided. In section 3, the methodology and "news" framework are described. The empirical results are presented and discussed in section 4 . Section 5 offers some concluding comments.

\subsection{The Survey Data}

This chapter considers matched interest rate and exchange rate expectations covering eight currencies relative to the Deutschmark over the 1988-1992 period. In addition to the exchange rate survey ${ }^{3}$, since 1988 , survey respondants were also asked to provide their three, six and twelve month ahead expectations regarding domestic interest rates with a three month maturity. Thus, for instance, on December 27th, 1990, respondants were asked to provide their expectations of three-month domestic interest rates starting April 1st, 1991, July 1st, 1991, January 2nd, 1992 and maturing July 1st, 1991, October 1st, 1991, and April 1st, 1992, respectively. Foreign currency deposits denominated in British Pound, Canadian Dollar, French Franc, German Mark, Italian Lira, Japanese Yen, Spanish Peseta, Swiss Franc, and US Dollar are the ones considered by the monthly survey. Since our study is

2 The economic importance of time-varying exchange risk premia in explaining the forward discount bias is confirmed in recent survey-based studies of exchange rates - see Cavaglia, Verschoor and Wolff (1992a, 1992c) and Frankel and Chinn (1991).

${ }^{3}$ See chapter three for a more detailed description of the construction of the exchange rate survey. 
concerned with matched interest rate and exchange rate expectations, survey data availability led us to focus our analysis on the three, six and twelve month ahead exchange rate and domestic interest rate expectations, using the most actively traded exchange rates relative to the Deutschmark. Tables $6.1 \mathrm{a}$ and $6.1 \mathrm{~b}$ provide summary statistics for the survey and forward exchange rate annualized forecast errors across forecast horizon and across currencies. $^{4}$ The summary statistics for the unanticipated three-month domestic interest differential and interest differential across horizon and across currencies are reported in Tables $6.1 \mathrm{c}$ and $6.1 \mathrm{~d}$. Table $6.1 \mathrm{e}$ provide summary statistics for the annualized exchange rate risk premium across horizon and across currencies. In the tables, as in the remainder of the chapter, $S_{t}$ is defined as the natural logarithm of the spot exchange rate at time $t$ (the spot rate is stated in terms of domestic currency units per unit of the foreign currency - the Deutschmark), $E_{t} S_{t+k}$ is defined as the natural logarithm of the expected spot exchange rate at time $t+k$ formed at time $t, F_{t+k}$ is defined as the natural logarithm of the forward exchange rate at time $t$ for delivery at time $t+k, d_{t+k}$ is defined as the three-month domestic interest differential, $i_{t+k}-i_{t+k}^{*}$, for deposits starting at time $t+k$ and maturing at time $t+k+3$, and $E_{t} d_{t+k}$ as the expected three-month domestic interest differential at time $t+k$ formed at time $t$. The use of survey data allows the direct measurement of a risk premium from the decomposition of the forward exchange rate into its two components - the expected future spot rate and a risk premium:

$$
{ }_{t} F_{t+k}=E_{t} S_{t+k}+R P_{t}
$$

For the period analyzed (February 1st, 1988 through May 1st, 1992), both the absolute values and the standard deviations of the mean forecast errors reported in Table $6.1 \mathrm{a}$ - fall markedly as the length of the forecast horizon rises from 3 months to 12 months. This finding could indicate that fundamentals are of more use in predicting the exchange rate in the longer term.

4 Denoting $\mathrm{k}$ to be the forecast horizon in months, annualized retums are obtained by multiplying the log differences by $1200 / \mathrm{k}$. 
Table 6.1 Summary Statistics: February 1, 1988 through May 1, 1992.

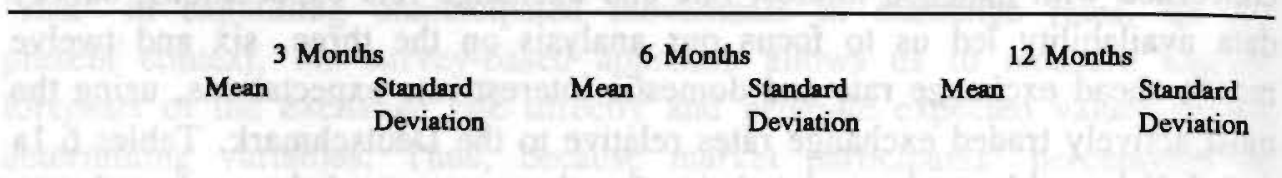

Table 6.1A Survey Forecast Error: $S_{t+k}-E_{1} S_{t+k}$ (percent per annum)

$\begin{array}{lrrrrrr}\text { BP/DM } & -2.00 & 13.65 & -1.47 & 9.23 & -1.44 & 5.99 \\ \text { CD/DM } & -5.49 & 34.55 & -3.64 & 22.97 & -1.90 & 12.00 \\ \text { FF/DM } & -1.29 & 3.79 & -1.13 & 3.11 & -0.94 & 1.49 \\ \text { IL/DM } & -1.58 & 7.07 & -1.53 & 4.50 & -0.65 & 2.97 \\ \text { JY/DM } & 2.69 & 23.95 & 2.55 & 17.28 & 1.83 & 12.92 \\ \text { SF/DM } & 3.17 & 9.69 & 2.43 & 5.87 & 1.87 & 4.01 \\ \text { SP/DM } & -5.28 & 9.91 & -5.75 & 6.09 & -4.86 & 4.04 \\ \text { US/DM } & 0.22 & 31.44 & 2.28 & 19.10 & 3.61 & 10.62\end{array}$

Table 6.1B Forward Rate Forecast Error: $S_{t+k}-{ }_{t} F_{t+k}$ (percent per annum)

$\begin{array}{lrrrrrr}\text { BP/DM } & -3.98 & 13.65 & -4.08 & 9.16 & -4.81 & 6.67 \\ \text { CD/DM } & -4.64 & 28.12 & -4.11 & 20.54 & -5.33 & 11.32 \\ \text { FF/DM } & -2.12 & 3.46 & -2.26 & 2.07 & -2.35 & 1.37 \\ \text { IL/DM } & -5.04 & 6.98 & -5.29 & 6.72 & -4.25 & 2.65 \\ \text { JY/DM } & 2.36 & 22.54 & 1.55 & 17.95 & 0.50 & 14.11 \\ \text { SF/DM } & 2.52 & 9.71 & 2.17 & 6.94 & 1.84 & 4.08 \\ \text { SP/DM } & -6.94 & 9.68 & -7.68 & 7.02 & -8.38 & 5.07 \\ \text { US/DM } & 2.41 & 28.59 & 1.98 & 19.55 & 0.77 & 11.02\end{array}$

Table 6.1C Unanticipated Interest Differential: $d_{t+k}-E_{1} d_{t+k}$ (percent per annum)

$\begin{array}{lrlllll}\text { BP/DM } & -0.33 & 1.27 & -0.47 & 1.77 & -0.85 & 2.05 \\ \text { CD/DM } & -0.15 & 1.16 & -0.60 & 1.69 & -1.36 & 2.33 \\ \text { FF/DM } & -0.33 & 0.62 & -0.71 & 0.72 & -1.48 & 0.85 \\ \text { IL/DM } & -0.26 & 0.70 & -0.64 & 0.84 & -1.39 & 1.07 \\ \text { JY/DM } & -0.16 & 0.86 & -0.45 & 1.19 & -0.67 & 1.57 \\ \text { SF/DM } & 0.28 & 0.74 & 0.25 & 0.78 & 0.33 & 0.99 \\ \text { SP/DM } & -1.54 & 1.14 & -1.87 & 1.24 & -2.05 & 1.04 \\ \text { US/DM } & -0.27 & 0.99 & -0.73 & 1.51 & -1.72 & 1.91\end{array}$


Table 6.10 Interest Diffferential: $\mathrm{d}_{\mathbf{t}}$ (percent per annum)

$\begin{array}{lrrrrrr}\text { BP/DM } & 3.85 & 2.21 & 4.15 & 1.93 & 4.73 & 1.20 \\ \text { CD/DM } & 3.04 & 2.78 & 3.45 & 2.34 & 4.19 & 1.41 \\ \text { FF/DM } & 1.37 & 1.52 & 1.51 & 1.48 & 1.82 & 1.38 \\ \text { IL/DM } & 4.67 & 1.92 & 4.88 & 1.82 & 5.24 & 1.72 \\ \text { JY/DM } & -3.40 & 0.89 & -3.32 & 0.86 & -3.32 & 0.88 \\ \text { SF/DM } & -0.60 & 0.79 & -0.53 & 0.76 & -0.49 & 0.80 \\ \text { SP/DM } & 7.00 & 1.40 & 7.13 & 1.37 & 7.32 & 1.39 \\ \text { US/DM } & -0.70 & 2.61 & -1.01 & 2.38 & -1.55 & 2.04\end{array}$

Table 6.1E Exchange Rate Risk Premium: ${ }_{t} F_{t+k}-E_{t} S_{t+k}$ (percent per annum)

\begin{tabular}{lrrllll|} 
BP/DM & 1.98 & 6.44 & 2.60 & 3.51 & 3.37 & 2.37 \\
CD/DM & -0.85 & 16.70 & 0.47 & 8.40 & 3.42 & 5.08 \\
FF/DM & 0.85 & 2.10 & 1.15 & 1.80 & 1.42 & 1.09 \\
IL/DM & 3.46 & 6.54 & 3.76 & 6.88 & 3.60 & 1.73 \\
JY/DM & 0.34 & 5.84 & 0.99 & 3.74 & 1.34 & 2.67 \\
SF/DM & 0.55 & 3.91 & 0.26 & 2.53 & 0.03 & 1.13 \\
SP/DM & 1.67 & 4.09 & 1.94 & 3.21 & 3.52 & 3.01 \\
US/DM & -2.19 & 8.31 & 0.30 & 4.64 & 2.84 & 3.45
\end{tabular}

Legend: $\quad \mathrm{BP}=$ British Pound; $\mathrm{CD}=$ Canadian Dollar; $\mathrm{DM}=$ German Mark; FF $=$ French Franc; IL $=$ Italian Lire; JY = Japanese Yen; SF = Swiss Franc; SP = Spanish Peseta; US = US Dollar. 
Noteworthy exceptions to this empirical regularity are the US Dollar/Deutschmark exchange rate for all forecast horizons and the Spanish Peseta at the 6 month horizon. It is also interesting to note that both the absolute values and the standard deviations of the mean forecast errors are significantly smaller for the original EMS currencies - the FF/DM and IL/DM exchange rates - than for the SP/DM and BP/DM exchange rate or non-EMS currencies relative to the Deutschmark. ${ }^{5}$

These empirical findings contrast with Table $6.1 \mathrm{~b}$ which uses the forward exchange rate as a proxy for the expected future spot exchange rate in calculating the forecast errors and suggests the presence of exchange risk premia, as evidenced by Table 6.1e.

Table 6.1c provides surprises in interest rate differentials. Overall, we note that innovations in interest differentials are small relative to innovations in exchange rates. This is in line with the results of Frenkel (1981) and Edwards (1982). It is also interesting to note that both the absolute values and the standard deviations of surprises in interest rates differentials rise markedly with the forecast horizon.

\subsection{Interest Rates and Exchange Rates: Methodology}

In this section we use a "news" version of the Dornbusch-Frankel overshooting model, as derived in Isard (1983). In this framework, changes in the current real exchange rate are connected to either corresponding changes in the long-run equilibrium value of the real exchange rate or to changing perceptions of the speed at which the current real exchange rate approaches it long-run equilibrium. Let the long-run equilibrium be $\mathrm{SR}_{\infty}$. We assume that agents hold homogeneous views on this long-run real exchange rate ("the anchor") and on the speed at which the current real exchange rate will move towards its long-run value ("the rope") - illuminating methaphors taken from Isard (1983) and Edwards (1983). We postulate that the difference between the logarithm of the real exchange rate and the logarithm of its expected long-run value is a linear function of the differential between the two current ex-ante real interest rates on the one hand and the current assess-

5 The Spanish Peseta and British Pound joined the ERM of the European Monetary System in July 1989 and October 1990, respectively. The United Kingdom suspended membership as of September 1992 until further notice. 
ment of the risk premium on the other. The equation reads as follow:

$$
S_{t}-P+P^{*}-A\left(r^{*}-r\right)+B\left(R P_{t}\right)=E_{t}\left(S R_{\infty}\right),
$$

where $\mathbf{P}\left(\mathbf{P}^{*}\right)$ is defined as the domestic (foreign) price level, $r\left(r^{*}\right)$ is defined as the domestic (foreign) real interest rate, $\mathbf{R P}_{\mathbf{t}}$ is defined as the risk premium, and $\mathrm{A}$ and $\mathrm{B}$ are coefficients. A simple example can illustrate the implied dynamics of the "news" version of equation (4). For ease of exposition, we assume for the moment that $\mathrm{RP}_{\mathrm{t}}=0$ and that $\mathrm{E}_{\mathrm{t}}\left(\mathrm{SR}_{\infty}\right)$ is a constant. Suppose the money supply in Germany drops unexpectedly. Actual prices are sticky, causing a decline in relative money in real terms. This causes the real interest rate in Germany and thus, other things equal, the real interest differential to rise temporarily above its long-run equilibrium level. The rise in the German interest rate induces an appreciation of the Deutschmark relative to, for instance, the British Pound due to interest arbitrage. The real exchange rate has to rise by enough to achieve an expected depreciation of the Deutschmark relative to the British Pound that offsets the change in the interest differential. Subsequently, prices fall to their equilibrium level and the interest differential and the real exchange rate converge towards their long-run equilibrium levels.

The length of the time for the real exchange rate to converge towards its long-run value depends in the given example on the length of the horizon during which the interest differentials are expected to persist. If, due to the drop in German money, the real interest rate in Germany increases with $n$ percent and if it is expected to take $\mathrm{z}$ years for the interest differential to converge towards its long-run value, the current real exchange rate has to appreciate with approximately $n^{*} z$ percent in order to be able to depreciate towards its long-run equilibrium. Implicit in the discussion until now has been the concept of long-run equilibrium. In the empirical analysis it is of importance to know how distant the long run is, given that the variability of the exchange rate depends directly on the length of time over which the real interest rates are expected to converge towards equilibrium. A source from which we can make inferences about the long run is Frankel and Meese (1987). If real exchange rates converge toward their long-run equilibrium value, we expect real exchange rates to exhibit some mean reversion and 
thus the time series representation of real exchange rates to be significantly different from a random walk. Frankel and Meese (1987) report some evidence of mean reversion in real exchange rates using 116 years of data on the US Dollar/British Pound exchange rate. Frankel and Meese report an adjustment speed of 20 percent a year, suggesting that it would take approximately five years for the real exchange rate to converge towards its long-run equilibrium level.

The formulation in equation (4) is appropriate if agents expect both the real interest differential and the risk premium to converge towards zero over time. We do not not impose, however, the restriction that the real interest rate differential and the risk premium disappear with the same speed.

Relationship (4) must also hold in terms of expectations held by economic agents during k-periods preceding period t. Rewriting equation (4) in terms of these expectations and subtracting, we obtain:

$$
S_{t}-E_{t-k} S_{t}=(P)^{\mu e}-\left(P^{*}\right)^{u e}-A\left(r^{*}-r\right)^{\mu e}-B(R P)^{\mu e}+\left(S R_{\infty}\right)^{\mu e} \text {, }
$$

where $(P)^{\text {ue }}$ and $\left(\mathrm{P}^{*}\right)^{\text {ue }}$ represents the unexpected change in the domestic and foreign (German) price levels, respectively. Similarily, $\left(r^{*}-r\right)^{\text {ue }}$ stands for the unexpected change in the real interest rate differential. The remaining two terms in equation (5) refer to revisions in expectations of the risk premium and the long-run real exchange rate, respectively.

Next, we combine equation (5) with the general identity that spot exchange rates differ from lagged forward exchange rates due to a combination of "news" and "risk":

$$
S_{t+k}-{ }_{t} F_{t+k}=\left(S_{t+k}-E_{t} S_{t+k}\right)+\left(E_{t} S_{t+k}-F_{t+k}\right)
$$

If we shift equation (6) k-periods backwards in time and add it to equation (5), we obtain the following expression:

$$
S_{t}-{ }_{t-k} F_{t}=(P)^{\mu e}-\left(P^{*}\right)^{\mu e}-A\left(r^{*}-r\right)^{\mu e}-B(R P)^{\mu e}+R P_{t-k}+\left(S R_{\infty}\right)^{\mu e} \text {, }
$$


where $R P_{t-k}$ is the lagged level of the risk premium.

Equation (7) has the observable difference between the logarithm of the current spot exchange rate and the logarithm of the forward exchange rate at time $t-k$ for delivery at time $t$ on the left-hand side and a combination of "news" and "risk" on the right-hand side. Note that changes in the risk premium are one element of the "news" in the current period. Since B is a positive constant, the unexpected change in the assessment of the risk premium and t-k period's risk premium have different signs in the expression for the dependent variable. In our view, this is one fundamental reason why it is so difficult to test empirically hypotheses about risk premia in the foreign exchange market. Formally, the situation where both the level and the "news" of an unobservable variable are important, but affect the dependent variable in different directions, is similar to the determination of share prices if we assume that the shareholder gets his return in the form of capital gains. If the required real rate of return is high, share prices may be expected to increase rapidly. If, however, the required real rate of return increases unexpectedly without a corresponding change in the expected stream of future earnings, current share prices have to fall. Empirical evidence that this line of reasoning is indeed important for the stock market is provided in French, Schwert and Stambaugh (1987). They examine the relationship between stock returns and volatility. In addition to finding evidence that the expected market risk premium for US stocks was positively related to volatility, they report: "There is also evidence that unexpected stock returns are negatively related to the unexpected change in the volatility of stock returns. This negative relation provides indirect evidence of a positive relation between expected risk premia and volatility. "

Next we link the dynamics of the price level of both countries to movements in their respective inflation rates. We adopt the following ARIMA specification:

$$
\Delta E_{t} p^{*}=\phi^{*}\left(p^{*}-E_{t-1} p^{*}\right)=\gamma^{*}\left(P^{*}-E_{t-1} P^{*}\right),
$$




$$
\Delta E_{t} p=\phi\left(p-E_{t-1} p\right)=\gamma\left(P-E_{t-1} P\right)
$$

where $\mathrm{p}$ and $\mathrm{p}^{*}$ represents the domestic and foreign inflation rates, respectively. Similarily, $\mathbf{P}$ and $\mathrm{P}^{*}$ denote the price level of both countries. We define:

$$
\omega^{*}=\frac{1}{\gamma^{*}}, \omega=\frac{1}{\gamma} .
$$

Then, as is the case with univariate Box-Jenkins models, changes in the expected rate of inflation are seen to be directly proportional to unexpected movements in the price level. In formula:

$$
\begin{aligned}
& \Delta E_{t} P^{*}=\gamma^{*}\left(P^{*}\right)^{\mu e}, \quad \text { or }, \quad\left(P^{*}\right)^{u e}=\omega^{*} \Delta E_{t} p^{*} \\
& \Delta E_{t} p=\gamma(P)^{u e}, \quad \text { or }, \quad(P)^{u e}=\omega \Delta E_{t} p
\end{aligned}
$$

With respect to the determinants of the long-run equilibrium real exchange rate and the dynamics thereof, very little is known. Huizinga (1987) applies co-integration tests to real exchange rates and several macroeconomic fundamentals and finds very little evidence for co-integration between the real exchange rate and these variables. Since the long-run equilibrium value of the real exchange rate is an unobservable variable, any assumption regarding its stochastic behavior has to be tested jointly with the other assumptions embedded in the exchange rate model. We hypothesize that the real exchange rate in future equilibrium is a function of long-run differences in inflation rates between the two countries. If rates of inflation converge in the long run, then the long-run value of the real exchange rate should 
correspond to PPP. ${ }^{6}$ However, if the long-run characteristics of the countries differ in important respects, there may be persistent capital flows. In such a case, the real exchange rate settles at a level which would induce a long-run capital flow and a corresponding non-zero value for the current account. There is, however, no direct empirical evidence on these assumptions regarding the potential determinants of the long-run real exchange rate. We therefore opt for the following flexible specification:

$$
\Delta S R_{\infty}=C\left(\Delta E_{t} p^{*}-\Delta E_{t} p\right)+u_{t}
$$

where $\mathrm{C}$ is a coefficient. As is apparent from equation (13) all movements in the equilibrium value of the real exchange rate are unexpected. Substitution of equation (11), (12), (8), and (9) and some rearrangement gives:

$$
\begin{aligned}
S_{t}-_{t-k} F_{t}= & A\left(i^{*}-i\right)^{u e}+\left(-A+C-\omega^{*}\right) \Delta E_{t} p^{*}+(A-C+\omega) \Delta E_{t} p \\
& +R P_{t-k}-B(R P)^{u e}+u_{t}
\end{aligned}
$$

where $\left(i^{*}-i\right)^{\text {ue }}$ denotes the unexpected movement in the nominal interest rate differential. The only variables of equation (14) that have not been dealt with so far are the risk terms. We will deal with the risk terms in two distinct ways. First, we will rely on exchange rate expectations from the Business International survey data to compute the ex-ante risk premium in the foreign exchange market. Second, we will use actual interest differential as a proxy for the risk premium.

In the empirical literature concerning risk premia on foreign exchange short term interest differentials across countries have played a dominant role in recent years as at least proximate determinants of these risk premia. Hansen and Hodrick (1983) show that excess returns on five major currencies relative to the US Dollar systematically depend on lagged excess returns

${ }^{6}$ Adler and Dumas (1983) provide an extensive discussion of assuming long-run PPP. 
and the forward premium. Their sample covers the period 1976-1980 and includes the German mark, the Japanese Yen, the British Pound, the Swiss and French Franc. Hodrick and Srivastava (1984) extend the analysis to the period 1976-1982 and provide a theoretical foundation for the inclusion of the forward premium using the dynamic asset pricing model of Lucas (1982). Giovannini and Jorion (1987) further extend the analysis by using data for Italy and the Netherlands in addition to the other currencies mentioned above. The sample period covers 1973-1984. Allowing the two components of the forward premium, that is the US interest rate and the interest rate of the country under investigation, to have independents effects, their results indicate a negative and often significant coefficient on the US interest rate and a positive and somewhat less frequently significant coefficient on the foreign interest rate. This suggests that a high US interest rate coincides with the perception of a risky domestic currency and a high premium on the US dollar, which is consistent with Hansen and Hodrick (1983) and Hodrick and Srivastava (1984).

In estimating our model, we have tried to incorporate innovations in inflation rates generated from the so-called Multi-State Kalman Filter (MSKF). ${ }^{7}$ Our preliminary empirical results indicate that the constructed innovation series of inflation rates consistently yield insignificant coefficients. We have therefore decided to restrict our attention to variables that are observable directly from datasources or from our survey database. The survey-based approach allows us to measure market forecasts of both the exchange rate and interest rate directly and, thus, we can easily generate expected values of the determining variables. Given by the availability of survey data of matched exchange rate and interest rate expectations, we implement empirically a simplified version of equation (14). We direct our attention at the following three alternative representations that capture the relative importance of "news" and "risk" in explaining unanticipated movements in foreign exchange rates:

$$
S_{t+k}-{ }_{t} F_{t+k}=\alpha+\beta_{1}\left(d_{t+k}-E_{t} d_{t+k}\right)+\beta_{2}\left(F_{t+k}-E_{t} S_{t+k}\right)+\varepsilon_{t+k}
$$

7 For a description of the Multi-State Kalman Filter, we refer to Kool (1989). 


$$
\begin{aligned}
& S_{t+k}-{ }_{t} F_{t+k}=\alpha+\beta_{1}\left(d_{t+k}-E_{t} d_{t+k}\right)+\beta_{2}\left(d_{t}\right)+\varepsilon_{t+k} \\
& S_{t+k}-E_{t} S_{t+k}=\alpha+\beta_{1}\left(d_{t+k}-E_{t} d_{t+k}\right)+\beta_{2}\left(d_{t}\right)+\varepsilon_{t+k}
\end{aligned}
$$

The use of survey data allows the direct measurement of the ex-ante risk premium and generate expected values of the interest rate differentials. This means that both exchange risk premia, $\left(\mathrm{r}_{\mathrm{t}}+\mathrm{k}-\mathrm{E}_{\mathrm{t}} \mathrm{S}_{\mathrm{t}+\mathrm{k}}\right)$, and innovations in nominal interest rate differentials, $\left(d_{t+k}-E_{t} d_{t+k}\right)$, are observable.

\subsection{Empirical Results}

The empirical results are provided in Tables 6.2, 6.3, and 6.4. In Table 6.2 we relate the difference between the realized spot rate and the three, six, and twelve month lagged forward rate to "news" about the interest differential and the level of ex-ante exchange risk premium which is computed from the difference between the forward rate and the expected future spot exchange rate. In Table 6.3 we replaced the ex-ante measure of the risk premium by the lagged interest differential as proxy for the risk premium. In Table 6.4, finally, we relate the difference between the realized spot rate and the expected future spot exchange rate to "news" about the interest rate differential and the level of the lagged interest rate differential. The equations were fitted for each currency and for each forecast horizon $(k=3, k=6$, and $\mathrm{k}=12$ ). Realized spot exchange rates were obtained from Datastream. ${ }^{8}$

Hansen and Hodrick (1980) demonstrate that when the forecast horizon is longer than the observational frequency, the forecast error $e_{t+k}$ will be serially correlated. While OLS point estimates of $\beta_{1}$ and $\beta_{2}$ remain consistent in spite of the serially correlated residuals, the OLS standard errors for

${ }^{8}$ The spot exchange rates at time $t+k, S_{t+k}$, used to compute the change in the spot rate are obtained from Datastream on days corresponding to the survey forecast dates. If the forecast date falls on a holiday or weekend, the previous business day is chosen. The spot rate series chosen are London Bourse closing prices. 
the regression coefficients are biased. This can be corrected via the NeweyWest (1987) estimation procedure. More importantly, if the disturbance at time $t+k$ is correlated with some of the explanatory variables at time $t+k$, OLS will not, in general, be consistent. In this section, the difficulty with applying the standard OLS procedure arises because of the endogeneous variables appearing on the right-hand side of the equations and they will not in general be independent of the disturbance term, since they are partly determined by the dependent variable in that equation. ${ }^{9}$ It therefore seems quite unsatisfactory to impose the exogeneity assumption. A general approach to estimation problems of this kind is provided by the method of instrumental variables. In this section, we implemented the instrumental variables estimation technique outlined in Hansen (1982), assuming a moving average process of order $\mathbf{k}$ for the monthly $\mathbf{k}$-month ahead forecast errors. ${ }^{10}$ Instruments used were a constant term and lagged explanatory variables.

Some interesting results emerge from the Tables. In Table 6.2 we find that "news" about the interest rate differential enters significantly in the equations for the British Pound, Japanese Yen, Spanish Peseta, French Franc and US Dollar. Moreover, in most cases the significant coefficients are negative reflecting that an unexpected rise in the interest rate differential tends to strengthen the domestic exchange rate, i.e. reducing $S_{t+k}$, thereby exhibiting the Dornbusch-Frankel overshooting effect. The results indicate that a 1 per cent unanticipated increase in the interest differential for the British Pound will lead to approximately 3 per cent (unanticipated) appreciation of the British Pound. Noteworthy is the significant positive coefficient for the FF/DM exchange rate. As suggested by Frankel (1982) this is consistent with a monetary model of exchange rate determination in which a rise in domestic interest rates may be primarily due to inflationary expectations. For each of the four currencies exhibiting the Dornbusch-Frankel overshooting effect, we also find significant effects of the ex-ante measure of the risk premium. It is interesting to note that the significance of the risk premium increases as the length of the forecast horizon rises from 3 months to 12 months.

${ }^{9}$ This is usually referred to as "simulteneous equation bias".

${ }^{10}$ Note that the $\mathrm{k}$-month ahead forecast is in reality a k-month plus a few days ahead forecast. 
As noted in the previous section it is reported in the literature that the lagged interest differential tends to predict - see, for instance Beekaert and Hodrick (1992) - movements in the excess returns in the foreign exchange market, which are by definition equal to the difference between the spot rate and the lagged forward exchange rate. As a consequence it is argued that the interest rate differential can serve as a proxy for the risk premium in the foreign exchange market. The significant effect of lagged interest differentials in equations for the excess return in the foreign exchange market is confirmed in Table 6.3. For the six and twelve month forecast horizons, the lagged interest differential has a statistically significant effect for 6 out of 8 currencies. Noteworthy is that the US Dollar is the only currency where we fail to find significant evidence of the lagged interest rate differential. The effect of the "news" about the interest differentials is very similar to the results reported in Table 6.2: the effect seems to dominate for the British Pound, Japanse Yen, Spanish Peseta and US Dollar. In order to sort out whether the significant effects of the interest differential in Table 6.3 really reflect time-varying risk premia, we run the same regressions but this time with the difference between the realized spot rate and the expected future spot exchange rate as the dependent variable. If the interest differential truly reflects risk premia we would expect it to be insignificant in equations for the difference between the actual exchange rate and the expected future spot exchange rate in Table 6.4. As is apparent, from Table 6.4, the lagged interest differential is highly significant in most of the equations for "news" on the exchange rate, which tends to suggest that the interest differential does not reflect risk premia. Whether the effect of the interest differential reflects peso problems, learning about policy changes or market inefficiencies remains an open question.

In general the empirical evidence indicates that "news" concerning changes in interest rate differentials contribute significantly to explaining a nonnegligible proportion of the substantial degree of exchange rate fluctuation left undiscounted by the lagged forward exchange rate. Furthermore, the inclusion of the expected future spot rate as an alternative to the lagged forward rate, frequently improves the significant contribution of "news" on interest differentials to explaining unexpected exchange rate movements. 
Table 6.2: $S_{t+k}-F_{t+k}=\alpha+\beta_{1}\left(d_{t+k}-E_{t} d_{t+k}\right)+\beta_{2}\left(F_{t+k}-E_{t} S_{t+k}\right)+e_{t+k}$

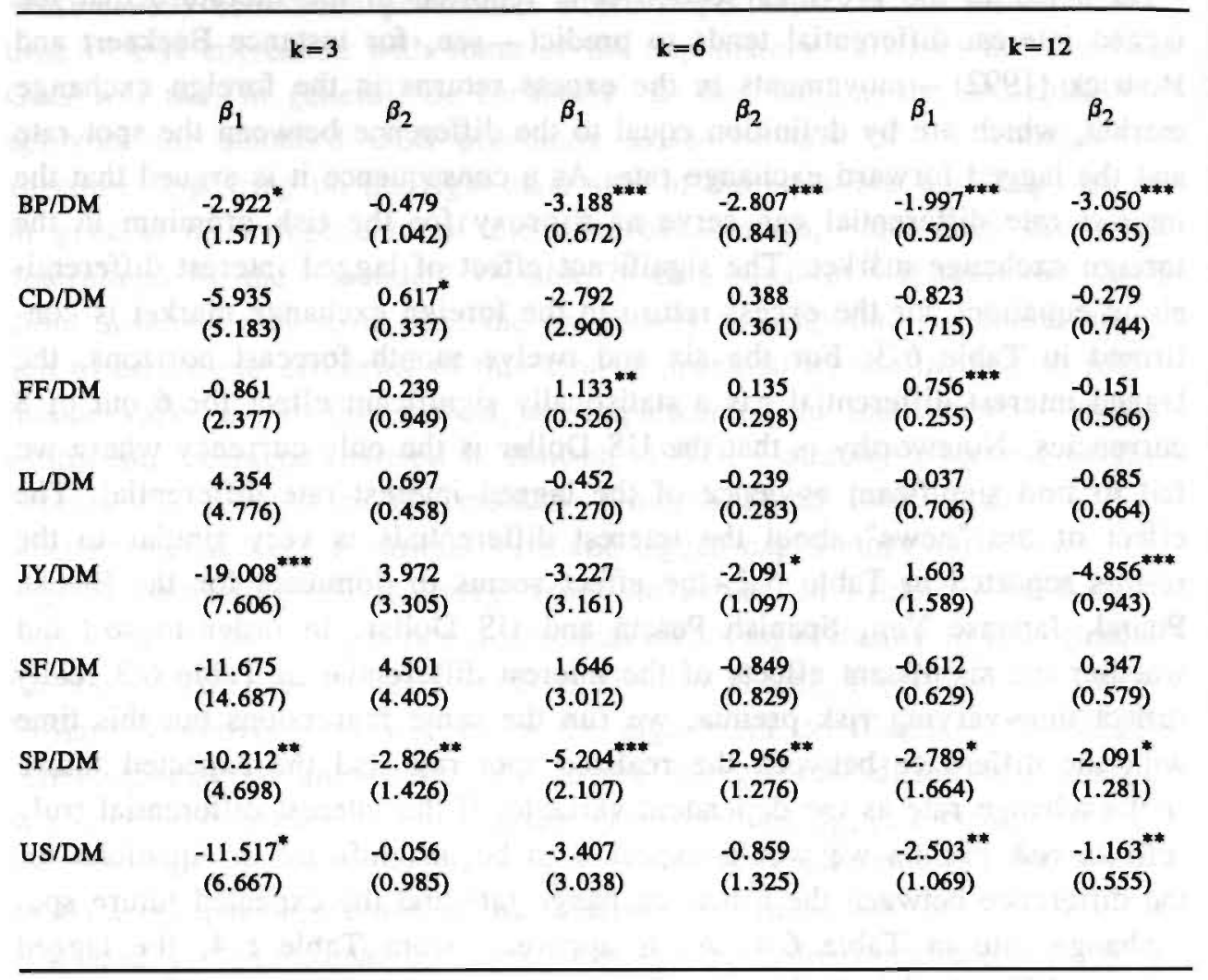

The heteroskedasticity consistent standard errors are given in parentheses. ${ }^{*}\left({ }^{* *}\right)[* * *]$ denotes significance at the $10 \%(5 \%)[1 \%]$ level for the hypotheses $\beta_{1}=0$ and $\beta_{2}=0$, respectively. 
Table 6.3: $S_{t+k}-{ }_{1} F_{t+k}=\alpha+\beta_{1}\left(d_{t+k}-E_{t} d_{t+k}\right)+\beta_{2}\left(d_{t}\right)+e_{t+k}$

\begin{tabular}{|c|c|c|c|c|c|c|}
\hline & \multicolumn{2}{|c|}{$k=3$} & \multicolumn{2}{|c|}{$k=6$} & \multicolumn{2}{|c|}{$k=12$} \\
\hline & $\beta_{1}$ & $\beta_{2}$ & $\beta_{1}$ & $\beta_{2}$ & $\beta_{1}$ & $\beta_{2}$ \\
\hline BP/DM & $\begin{array}{l}-3.867^{* * *} \\
(1.604)\end{array}$ & $\begin{array}{l}-0.421 \\
(0.856)\end{array}$ & $\begin{array}{l}-1.175^{* * *} \\
(0.414)\end{array}$ & $\begin{array}{l}-0.391 \\
(0.773)\end{array}$ & $\begin{array}{c}0.182 \\
(0.494)\end{array}$ & $\begin{array}{c}2.035^{*} \\
(1.211)\end{array}$ \\
\hline $\mathrm{CD} / \mathrm{DM}$ & $\begin{array}{l}-5.460 \\
(5.332)\end{array}$ & $\begin{array}{l}-1.507 \\
(1.330)\end{array}$ & $\begin{array}{c}1.039 \\
(2.724)\end{array}$ & $\begin{array}{l}-3.004^{*} \\
(1.729)\end{array}$ & $\begin{array}{l}-0.798 \\
(1.720)\end{array}$ & $\begin{array}{c}2.343 \\
(2.260)\end{array}$ \\
\hline FF/DM & $\begin{array}{l}-1.231 \\
(1.092)\end{array}$ & $\begin{array}{l}-0.781^{*} \\
(0.408)\end{array}$ & $\begin{array}{c}0.336 \\
(0.422)\end{array}$ & $\begin{array}{l}-0.526^{* * * *} \\
(0.169)\end{array}$ & $\begin{array}{l}-0.044 \\
(0.143)\end{array}$ & $\begin{array}{l}-0.886^{* * * *} \\
(0.155)\end{array}$ \\
\hline IL/DM & $\begin{array}{c}2.698 \\
(2.329)\end{array}$ & $\begin{array}{l}-0.907^{*} \\
(0.550)\end{array}$ & $\begin{array}{l}-0.103 \\
(1.386)\end{array}$ & $\begin{array}{l}-0.780^{*} \\
(0.428)\end{array}$ & $\begin{array}{l}-1.238^{* * *} \\
(0.153)\end{array}$ & $\begin{array}{l}-1.148^{* * *} \\
(0.131)\end{array}$ \\
\hline JY/DM & $\begin{array}{c}-15.462^{* * *} \\
(4.170)\end{array}$ & $\begin{array}{l}-19.370^{* * *} \\
(5.522)\end{array}$ & $\begin{array}{l}-8.005^{* * *} \\
(2.599)\end{array}$ & $\begin{array}{c}-15.770^{* * *} \\
(3.798)\end{array}$ & $\begin{array}{l}-28.637^{* * *} \\
(4.642)\end{array}$ & $\begin{array}{l}-55.418^{* * *} \\
(10.059)\end{array}$ \\
\hline SF/DM & $\begin{array}{c}-12.263^{* *} \\
(5.746)\end{array}$ & $\begin{array}{c}-13.988^{* * * *} \\
(3.672)\end{array}$ & $\begin{array}{l}-2.327 \\
(3.359)\end{array}$ & $\begin{array}{l}-3.241^{* *} \\
(1.492)\end{array}$ & $\begin{array}{l}-1.917^{* * *} \\
(0.795)\end{array}$ & $\begin{array}{l}-4.508^{* * *} \\
(1.370)\end{array}$ \\
\hline SP/DM & $\begin{array}{l}-6.146^{* * *} \\
(2.187)\end{array}$ & $\begin{array}{l}-0.522 \\
(1.430)\end{array}$ & $\begin{array}{l}-3.537^{* * *} \\
(0.771)\end{array}$ & $\begin{array}{l}-1.684^{* * *} \\
(0.702)\end{array}$ & $\begin{array}{l}-2.807^{* * *} \\
(0.322)\end{array}$ & $\begin{array}{l}-2.733^{* * *} \\
(0.222)\end{array}$ \\
\hline US/DM & $\begin{array}{l}-7.595 \\
(6.260)\end{array}$ & $\begin{array}{l}-1.563 \\
(1.937)\end{array}$ & $\begin{array}{l}-4.970^{* * *} \\
(1.932)\end{array}$ & $\begin{array}{l}-1.994 \\
(1.532)\end{array}$ & $\begin{array}{l}-2.857^{* * * *} \\
(0.926)\end{array}$ & $\begin{array}{c}0.607 \\
(0.885)\end{array}$ \\
\hline
\end{tabular}

The heteroskedasticity consistent standard errors are given in parentheses. ${ }^{*}\left({ }^{* *}\right)\left[{ }^{* *}\right]$ denotes significance at the $10 \%(5 \%)[1 \%]$ level for the hypotheses $\beta_{1}=0$ and $\beta_{2}=0$, respectively. 
Table 6.4: $S_{t+k}-E_{t} S_{t+k}=\alpha+\beta_{1}\left(d_{t+k}-E_{t} d_{t+k}\right)+\beta_{2}\left(d_{t}\right)+e_{t+k}$

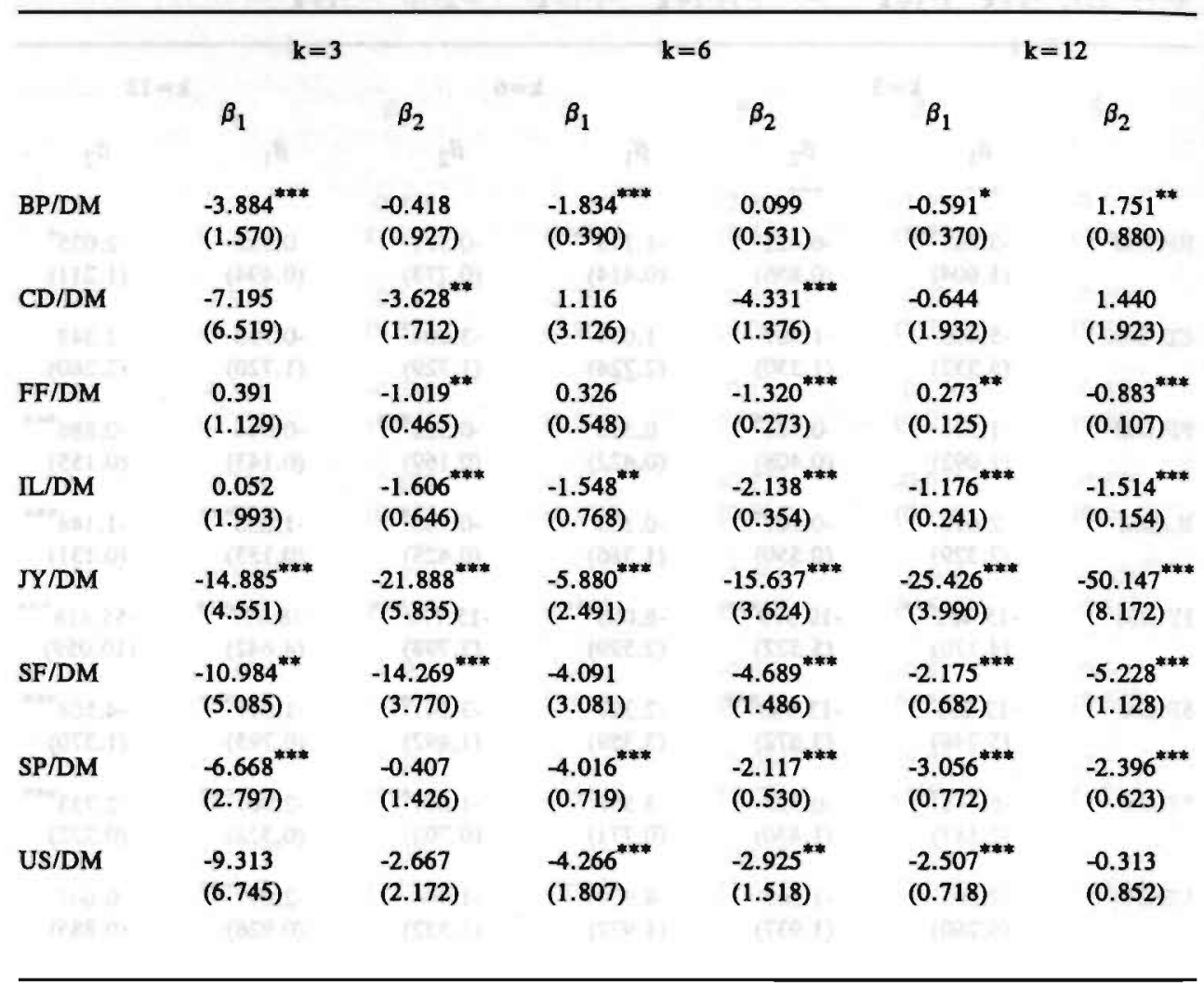

The heteroskedasticity consistent standard errors are given in parentheses. ${ }^{*}\left(^{* *}\right)\left[{ }^{* * *}\right]$ denotes significance at the $10 \%(5 \%)[1 \%]$ level for the hypotheses $\beta_{1}=0$ and $\beta_{2}=0$, respectively. 


\section{Conclusions}

In this chapter we empirically implemented the "news" version of the Dornbusch-Frankel overshooting model, as derived in Isard (1983) using survey data of matched exchange rate and interest rate expectations for eight currencies relative to the Deutschmark. Since the survey data contain both three, six and twelve month ahead exchange rate and interest rate forecasts, we investigate the Isard (1983) model for these three horizons.

Our results indicate that "news" about the interest rate differential enters significantly in the equations for the British Pound, Japanese Yen, Spanish Peseta, French Franc and US Dollar. For most of these currencies we find that "news" on the interest rate differential enters the equations with a negative coefficient suggesting that an unexpected rise in the interest differential tends to strenghten the domestic currency, which is often referred to in the literature as the Dornbusch-Frankel overshooting effect. For each of the four currencies, we also find significant effects of our ex-ante measure of the risk premium. Especially at the 12 month horizon, we find significant effects of the risk premium for the British Pound, Japanese Yen, Spanish Peseta and US Dollar. In addition we test for the effect of the lagged interest differential in the equation for the difference between the realized spot rate and the lagged forward exchange rate, since the view is widely held in the literature that the lagged interest differential might be capturing time-varying risk premia in the foreign exchange market. We find the effect of the lagged interest differential to be highly significant both in the equations for the difference between the realized spot rate and the lagged forward rate and for the difference between the realized spot rate and the expected future spot exchange rate. This evidence suggests that the lagged interest differential in equations for the difference between the realized spot rate and the lagged forward rate does not capture time-varying risk premia but more likely reflects a peso problem, learning about a policy regime, a market inefficiency or a combination of these factors. 
74.

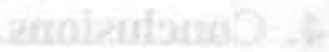

in

xat

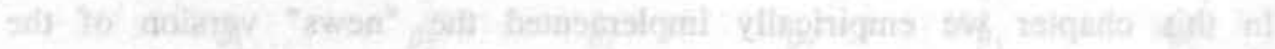

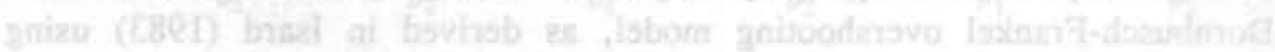

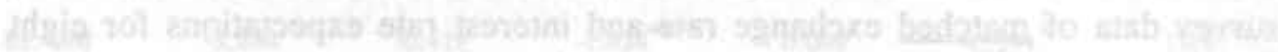

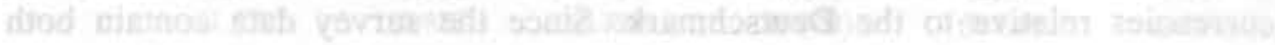

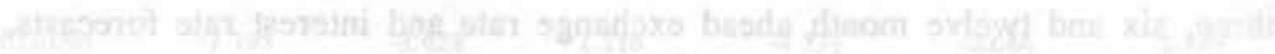

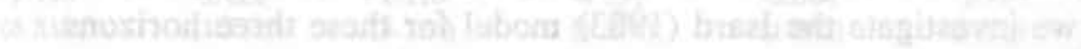

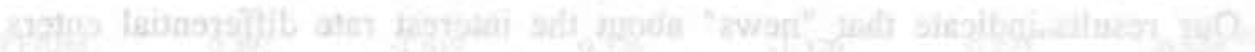

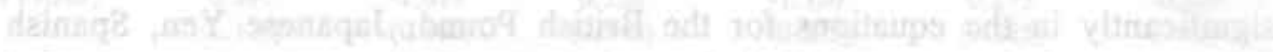

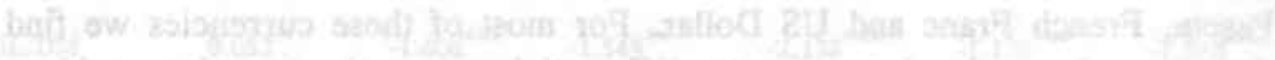

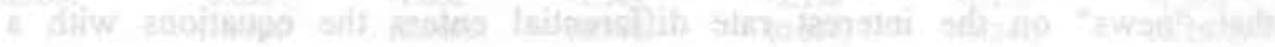

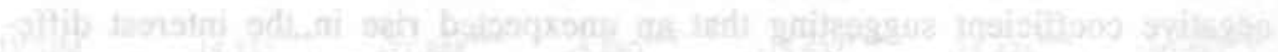

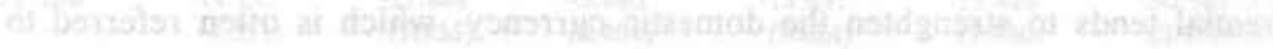

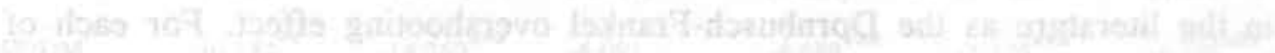

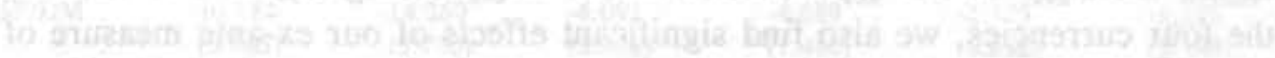

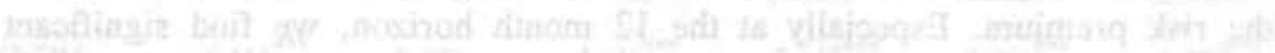

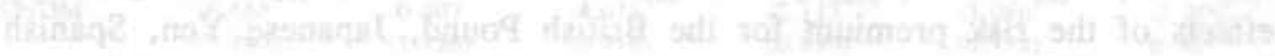

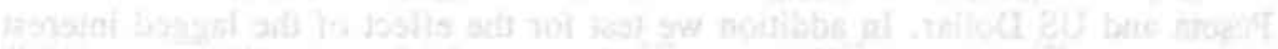

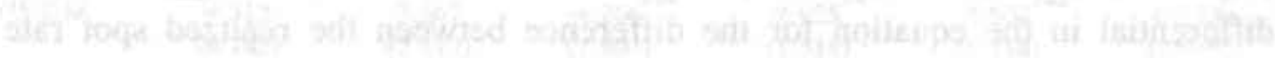

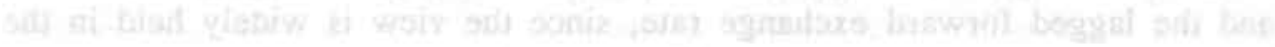

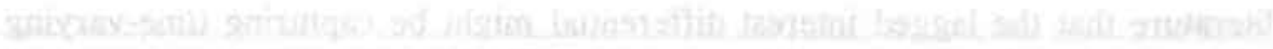

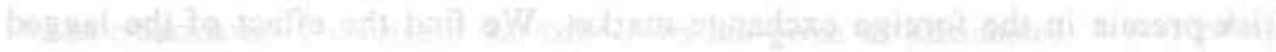

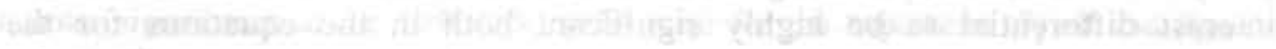

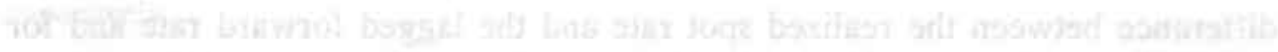

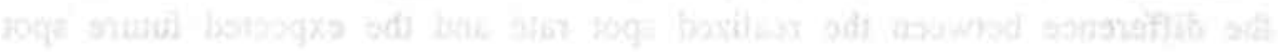

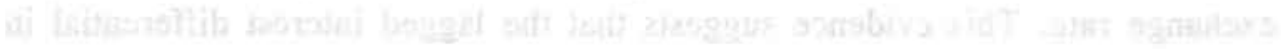

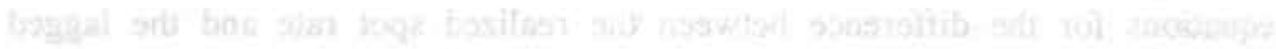

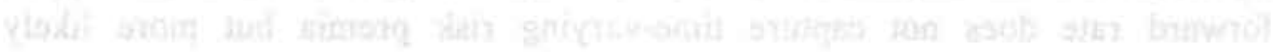

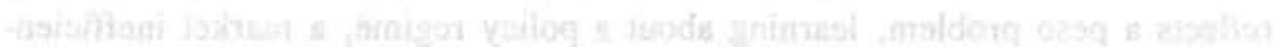

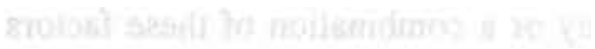




\section{Chapter seven}

\section{Concluding Comments and Suggestions for Future Research}

This study provided a set of empirical results that adress questions regarding the efficiency of forward markets for foreign exchange as well as adressing some explanations of market inefficiency and assessments of the influence of new information on the exchange rate. In this concluding chapter we will outline the central message of each of the preceding chapters and formulate some general conclusions on the basis of the results presented in previous chapters. In addition, we will offer some suggestions for potentially fruitful directions for further research.

Since the breakdown of the Bretton Woods fixed-parity system in the early 1970 s, the nature of exchange rate volatility has changed considerably. The major distinguishing feature of the changeover from the Bretton Woods fixed-parity system to a floating exchange rate system in 1973 has been the dramatic and unexpected increase in the volatility of exchange rates. Nominal exchange rates have strayed over a wide range since 1973. The variability of nominal exchange rates has also substantially exceeded the variability implied by inflation differentials across countries, thereby also yielding substantial changes in real terms. This has been particulary marked over the short to medium term when Purchasing Power Parity (PPP) clearly failed to hold. Compared to the goals of the Bretton Woods Agreement, which tried to provide an international monetary arrangement tailored to supporting the international flow of goods and services and the international division of labour, it remains doubtful whether the regime of flexible exchange rates has been more succesful than the previous fixed-rate system in achieving this goal. A related question is whether the foreign exchange markets efficiently use all the relevant information when determining the current exchange rate. As a consequence of the very high level of exchange 
rate volatility, one argues that monetary authorities should intervene in the foreign exchange market in order to stabilize the exchange rate. The socalled G-7 meetings were established, among other things, in order to set exchange rate targets for the corresponding bilateral rates. The only somewhat durable scheme has turned out to be the Exchange Rate Mechanism (ERM) of the European Monetary System (EMS), which started in March 1979. The intra-European exchange rates would be allowed to fluctuate only within official bilateral limits, to be defended by exchange market intervention. An incipient move beyond the bilateral limit, therefore, should urge the monetary authorities of the two countries in question to intervene in the market.

One major research goal in the study of flexible exchange rates is the desire to find an acceptable model that explains the movement of the nominal spot exchange rate in terms of other macroeconomic variables. Most of the theoretical models considered are based on the asset market approach with the exchange rate determined by the relative supplies and demands of national monies. A major requirement for the validity of these models is that capital is perfectly mobile internationally and that Interest Rate Parity (IRP) holds. Since the early 1980 s empirical exchange rate research has witnessed a recurring conflict between economic theory and empirical observation. The broad conclusion that emerges from the literature is that the asset-approach models have performed well for some time periods, such as the interwar period, and, to some extent, for the first part of the recent floating experience (1973-78); but they have provided largely inadequate explanations for the behavior of the major exchange rates during the latter part of the float. The failure of simple asset-approach equations may be due to severe misspecification in several ways. The misspecification may be of an econometric nature as well as from an economics point of view. The concepts of Purchasing Power Parity (PPP) and Uncovered Interest Rate Parity (UIRP) provide some of the basic building blocks for many of the current models of exchange rate determination. Thus the poor performance of exchange rate models could be very well be the consequence of deviations from PPP and deviations from UIRP - the existence of (time-varying) risk premia.

As was mentioned before, the results of Meese and Rogoff (1983a, 1983b) indicate that existing models of exchange rate determination could not outperform the simple random walk forecasting rule, even though the models' forecast were based on ex-post realized values of future explanatory 
variables. One aspect of the economy that is ignored in constructing their linear models is the nature of risk. Meese and Rogoff (1983a, 1983b) suggest that time-varying risk premia could be an important determination of their findings although they express skepticism about the likelihood of this being the complete explanation. In their review of this issue Frankel and Meese (1987) note: "Yet neither models based on economic fundamentals, nor simple time-series models, nor the forecasts of market participants as reflected in the forward discount or in survey data, seem able to predict better than the lagged spot rate. Also, the proportion of exchange rate movements that can be explained even after the fact, using contemporaneous macroeconomic variables, is disturbingly low."

Fama (1984) developed a methodology to identify and measure premia in the pricing of forward foreign exchange, which assesses empirically the relative variability of the risk premium and forward rate forecast errors over the period 1973-1982. Fama's (1984) results provide useful insight in the relative importance of the risk premium in the foreign exchange market. It is significant because it implies that a time-varying risk premium plays a fundamental role in the determination of spot and forward exchange rates. In contrast, many theoretical rational expectations models of exchange rate determination have focused almost exclusively on the expected rate of depreciation. This suggests that future work should be devoted towards understanding the importance and economic sources of risk in foreign exchange markets as well as examining the rationality of agents' expectations. Both concepts - rational expectations and the existence of (time-varying) risk premia - are inextricably linked with the hypothesis of foreign exchange market efficiency.

In this study we provided empirical evidence on the relative importance of "irrationality", "risk" and "news" in explaining unanticipated movements in foreign exchange rates. In particular, we have tried to shed new light on the relative importance of both irrationality of market participants and the existence of time-varying risk premia in explaining the forward discount bias. This concluding chapter will briefly survey the main empirical results and formulate some general conclusions on the basis of the results presented.

The empirical analysis started in chapter two which considers the statistical time series properties of exchange rate returns within the European Monetary System and attempts to give empirical content to the theory concerning efficient markets and exchange rate volatility - the clustering phenomenon. 
Fama (1970) argues that efficiency requires that actual prices, or rates of return follow a "fair game" process relative to expected equilibrium prices. As pointed out by Levich (1985), however, efficiency only implies randomness of returns if the equilibrium expected return is constant. If the fundamental determinants of the exchange rate (such as relative money and output according to the monetary approach) are serially correlated, then so will the equilibrium exchange rate be. Thus, contrary to popular belief, efficiency does not necessarily imply that the exchange rate should follow a random walk. Our results demonstrated clearly that a significant degree of mean reversion is present in the patterns followed by EMS exchange rates, although one has to approach the data quite carefully to be able to detect this mean reversion. When central parity adjustments are taken into account, the hypothesis that EMS exchange rates follow random walks can be rejected, as opposed to the existing evidence for the case of freely floating exchange rates. The results indicated that jumps, time-varying parameters and conditional leptokurtosis are pertinent features in the empirical distribution of EMS exchange rate returns. There is considerable interference, however, between jumps in the distributions, on the one hand, and allowing for fat tails, on the other hand. Allowance for fat tails tends to increase the average jump size, but to reduce the frequency of jumps to more realistic proportions. Most successful in capturing the relevant features of EMS exchange rate returns is a combined jump-GARCH model with conditionally t-distributed innovations.

The statistical evidence presented in chapter two is sufficiently strong to suggest further research in various directions. Models similar to ours could be estimated in a framework in which the jump intensity depends on an exchange rate's position within the formal exchange rate band. Alternatively, the impact of jumps and stochastic volatility in EMS exchange rates on the pricing of forward foreign exchange could be studied formally. In particular, a derivation of the risk premium under the jump-diffusion-GARCH dynamics for EMS exchange rates presented in chapter two is itself an interesting topic which deserves further research.

The rationality of agents' expectations have been tested in chapter three by analyzing survey data for exchange rate forecasts over relatively long horizons (three, six, and twelve months) covering ten currencies relative to the US Dollar and eight currencies to the Deutschmark. The analysis is extended in chapter four which examines the efficiency in the foreign exchange market and where we used forward rates to impute exchange rate 
risk premia to assess whether the rejection of the forward rate as an unbiased predictor of the spot exchange rate is predominantly attributable to irrationality on the part of economic agents or significant variation in risk premia. The direct observations on exchange rate expectations do not support the rational expectations hypothesis $(\mathrm{REH})$, thus corroborating the earlier finding in the literature that exchange rate forecasts are not rational and that agents do not use all available information efficiently.

Chapter four has examined exchange rate risk premia using survey data of exchange rate expectation to divide the forward discount into its two components - expected depreciation and the risk premium. In contrast to the results of Froot and Frankel (1989) for survey based tests using some of the major currencies relative to the US Dollar, we find that the bias in the forward discount for these currencies is attributable to both the failure of rational expectations and the existence of a time-varying risk premium. We also find that for the EMS currencies the bias is primarely attributable to significant variation in the premium component.

The broad conclusion emerging from chapters three and four is that the joint hypothesis of forward market efficiency - risk neutrality and rational expectations - fails both because economic agents appear to be risk averse and because their expectations do not conform to the rational expectations hypothesis $(\mathrm{REH})$. The simpler version of the efficient market hypothesis (that is, assuming risk neutrality) thus seems to have been rejected for both US Dollar and Deutschmark foreign exchange markets.

The preceding conclusions should be interpreted with some caution. The forward discount decomposition cannot itself shed light on whether the irrational exchange rate expectations are generated by learning on the part of economic agents about policy changes, peso-problems, or by market inefficiency, although neither learning nor peso-problems seem to offer complete explanations of the facts - see Rogoff (1979), Obstfeld (1987), Stulz (1986), and Lewis (1989), for instance. However, these caveats must always be kept in mind when interpreting the empirical results of any study of forward market efficiency.

In addition, Lucas (1982) demonstrated that forward rates need not be unbiased predictors of future spot rates in an efficient market. The Lucas model allows a conditional covariance, which is related to the riskiness of an asset, to separate the forward price from the expected value of the spot exchange rate. Since this conditional covariance can vary through time, the 
nature of the bias in forward rates can be time-varying - as is the case for EMS currencies relative to the Deutschmark. The large and time-varying risk premia exhibited by EMS exchange rates are consequently not necessarily identified with market inefficiency. We concluded that risk premia are important for the determination of spot and forward exchange rates in the foreign exchange market. In particular, the results suggest that time-varying risk premia play a fundamental role in the determination of exchange rates participating in the European Monetary System. In contrast with findings based on mean-variation optimization, this suggests that future work should be devoted towards understanding the importance and economic sources of risk in the foreign exchange market, especially within the European Monetary System. Whether the large and time-varying exchange risk premia exhibited by EMS exchange rates reflect so-called peso-problems resulting from expectations of realignments remains an interesting question. We feel that further investigation of this issue is warranted.

Motivated by the preceding results we explicitly modeled time-varying EMS risk premia in the pricing of forward foreign exchange that do not require us to assume rationality of exchange rate expectations nor conditional homoskedasticity of exchange rate returns. We find considerable support for the presence of time-varying EMS risk premia in the pricing of forward foreign exchange. The estimated premium models - ARCH-in-mean and GARCH-in-mean - indicate that time-varying premia can be explained by the conditional standard deviation of the expected rate of depreciation. In particular, the GARCH-in-mean model appears to be moderately successful in accounting for both time-varying risk premia and conditional heteroskedasticity.

We therefore concluded that EMS exchange rate risk premia are not time invariant; rather they vary systematically with agent's perception of underlying uncertainty. Whether the significant time-varying risk premia reflect peso-problems resulting from expectations of periodic realignments of central parities, learning on the part of economic agents about policy changes, market inefficiencies or a combination of these factors remain an open question.

The evidence presented is sufficiently strong to suggest further research as to whether foreign exchange risk facets can be usefully approximated by a measure of exchange rate variability. In addition, cross sectional dispersion in survey data might be considered as a measure of uncertainty. The dispersion in exchange rate forecasts provides an indicator of the heteroge- 
neity in exchange rate expectations, and may be an approximation of the fundamental underlying uncertainty. Ito (1990) provided evidence of heterogeneous expectations among market participants. This issue requires further investigation in future work.

Finally, we concentrated on the relative importance of "news" and "risk" in explaining unanticipated movements in foreign exchange rates. Chapter six empirically implemented the "news" version of the Dornbusch-Frankel overshooting model, as derived in Isard (1983) by using survey data of matched exchange and interest rate expectations. "News" on interest rate differentials enters significantly and with a negative coefficient in equations for the difference between the spot rate and the lagged forward exchange rate for the British Pound, Japanese Yen, Spanish Peseta and the US Dollar. An unexpected rise in the interest rate differential tends to strengthen the domestic exchange rate, which is often referred to in the literature as the Dornbusch-Frankel overshooting effect. We also find for each of these currencies significant effects of our ex-ante measure of the risk premium. In addition we investigated the effect of lagged interest rate differentials and find that lagged interest differentials do not reflect time-varying risk premia, as is widely suggested in the literature. Instead they probably capture a pesoproblem, learning about a policy change, a market-inefficiency or a combination of these factors.

We will conclude this study by discussing and interpreting several striking facts that emerge consistently from the survey data on exchange and interest rate expectations:

1) The longer the forecast horizon, the more exchange rate expectations reverse recent price trends. While at short horizons, investors expect current trends to continue, at long horizons - 3, 6, and 12 months - they expect the reverse. For example, a recent depreciation of the US Dollar of 10 percent generates the expectation that the Dollar will depreciate another 1.4 percent over the following seven days - see Frankel and Froot (1987a, 1987b). By contrast, the same 10 percent depreciation leads investors to think that the spot rate will appreciate by 3.0 percent over the next three months. This pattern across forecast horizons lends credence to the long-held concern that the foreign exchange market in the short-run reflects an element of "noise trading", trading that is based on factors other than "fundamentals", making the exchange rate too volatile around its long-run equilibrium. 
2) Investors' exchange rate forecasts often provide a biased approximation of actual spot exchange rate realizations. While expected depreciation may be large in magnitude, the actual spot exchange rate process may be close to a random walk, giving rise to bias in predicting future spot exchange rate changes. Indeed, the foreign exchange rate forecasts do not improve the contemporeneous spot exchange rate in predicting actual spot exchange rates. Survey respondents systematically overpredicted actual exchange rate depreciation. In fact, US Dollar exchange rate forecasts predicted the wrong direction of exchange rate depreciation, whereas EMS forecasts are generally of the same sign as those for the actual exchange rate depreciation. Similarly, investors could do better, i.e., reduce their forecast errors, by consistently betting against the forward discount.

3) Forward foreign exchange rates are biased predictors of actual and expected future spot exchange rates. US Dollar forward exchange rates broadly underpredicted actual as well as expected future spot exchange rates, whereas EMS forward rates broadly overpredicted actual as well as expected future spot exchange rates.

4) The nature of the forward discount bias appears to have varied over different currencies or exchange rate regimes. While the bias in the forward discount for currencies relative to the US Dollar is atributable to both failure of rational expectations and the existence of a time-varying risk premium, for EMS currencies the bias is primarely attributable to significant variation in the premium component. While many authors have been prepared to acknowledge the presence of risk, the possibility of the failure of rational expectations is less common. However, apparent irrationality was indicated by the persistent bias found in respondents' expectations, particularly for exchange rates vis-à-vis the US Dollar.

5) "News" on interest rate differentials makes a significant contribution to explaining unanticipated exchange rate fluctuations. Given the occurence of "news" and its likely effect on traders in financial markets it is interesting to assess the relative importance of "news" vis-à-vis anticipated changes in fundamentals. Equations for the difference between the realized spot rate and the three, six, and twelve month lagged forward rate on "news" about the interest differential tend to fit reasonably well, frequently explaining a nonnegligible proportion of the substantial degree of exchange rate fluctuation 
left undiscounted by the lagged forward rate.

How should we interpret this empirical evidence regarding forward market efficiency? Several alternative interpretations of the earlier-mentioned striking facts are discussed. Consideration is given to several viewpoints:

a) Conclude that investors' exchange rate expectations do not conform to the rational expectations hypothesis. The direct observations on exchange rate expectations do not support the rational expectations hypothesis. Thus, although the rational expectations hypothesis has considerable appeal as a theoretical model, it does not appear to provide an adequate explanation of exchange rate expectation in the sample period; our findings apply to the post 1986 period, thus questioning the assertion of Frankel and Froot (1987a) that "the nature of the rejection of rational expectations strongly depends on the sample period". It is therefore important to consider alternatives to rational expectations or other models of expectations formation. Clearly, there is considerable scope for further reasearch in this area. The finding of systematic exchange rate forecast errors can plausibly stem from a variety of sources, including - but certainly not limited to investors irrationality. We therefore explore the following alternative explanations.

b) Consider the possibility of influential, but uncommon events. "Pesoproblems" may lead to repeated exchange rate forecast errors in small samples and consequently invalidate standard statistical inference. While this argument applies with equal force to virtually all empirical analyses, it may be that the type of government policies and other exogeneous processes that determine exchange rates make this problem particularly strikingly manifest in this study. Such a possibility probably deserves more study than it has received so far. Especially within the European Monetary System, where socalled peso-problems may result from expectations of periodic realignments of central parities.

c) Investigate whether investors learn as they go. Explicit examples of the failure of the rational expectations assumption because of learning by economic agents have also started to be produced. If investors are in the process of learning about floating exchange rates or other regime changes, 
then exchange rate changes will be affected by the learning. Periods of history in the foreign exchange market may well be consistent with some type of learning mechanism in the formation of expectations that gradually converges to rationality in some sense.

d) Consider heterogeneous exchange rate expectations across investors. The present study adopted the standard theoretical and empirical framework that assumes homogeneous expectations across investors. Heterogeneity amongst market participants, if it exists, was aggregated out. However, if market participants differ in the forecasting characteristics, then focusing on the geometric mean forecast of survey responses would insufficiently describe the market in terms of forecasts. Heterogeneous expectations and their role in determining foreign exchange market dynamics may well be important areas for future research.

e) Compensation for bearing foreign exchange risk. Lucas (1982) demonstrated that forward rates need not be unbiased predictors of future spot rates in an efficient market. The Lucas model allows a conditional covariance, which is related to the riskiness of an asset, to separate the forward price from the expected value of the spot exchange rate. Since this conditional covariance can vary through time, the nature of the bias in forward rates can be time-varying. It follows that any profit earned from trading on the forecasts may simple reflect fair compensation for bearing exchange risk, characterized by time-varying risk premia, rather than an excess return for exploiting unusual forecasting expertise.

f) Foreign exchange market-inefficiency. Taken as a whole, the evidence suggests that the simpler version of the forward market efficiency hypothesis fails both because economic agents require to be compensated for bearing exchange risk and because their expectations do not conform to the rational expectations hypothesis. Some of our results appear to be sensitive to the exchange rate regime. However, the previously mentioned caveats - pesoproblems, learning by agents, and heterogeneous expectations - must always be kept in mind in interpreting the empirical results of forward market efficiency tests. Our results tend to indicate that more effort should be expended on "peso" and "learning" effects as explanations for the suboptimality of the forward premium as a predictor of the exchange rate change. Furthermore, Ito (1990) demonstrated, using a highly disaggregated survey 
database, that exchange rate expectations appear to be highly heterogeneous. This suggests that explanations which allow for the possibility of heterogeneity of exchange rate expectations should be seriously investigated as well. 


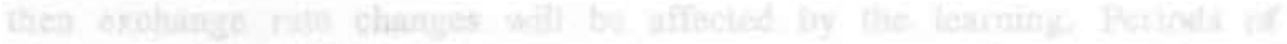

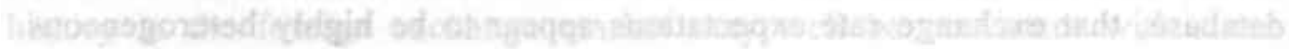

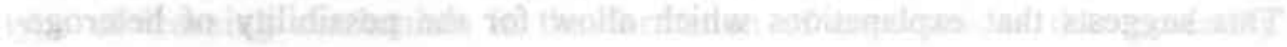

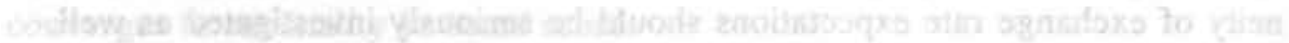

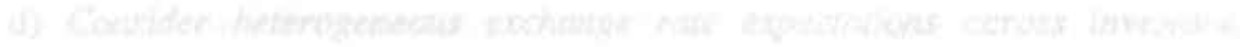

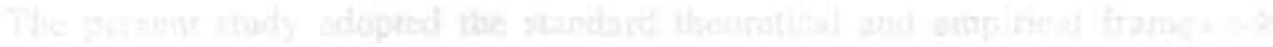

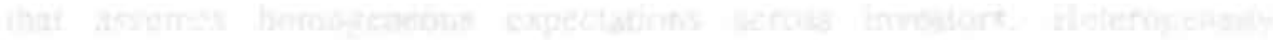

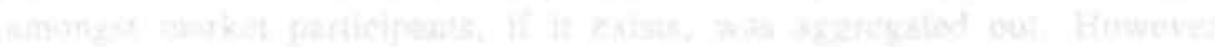

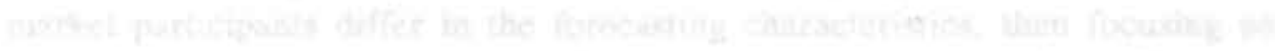

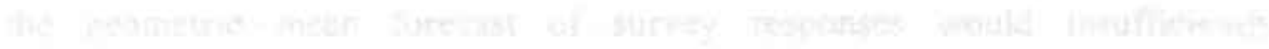

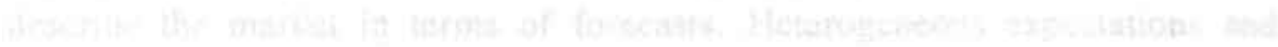

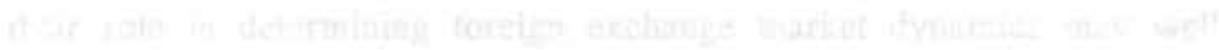




\section{References}

Adler, M. and B. Dumas, 1983, "International Portfolio Choice and Corporation Finance: A Synthesis", Journal of Finance, 38: 925-84.

Allen, H. and M.P. Taylor, 1990, "Charts, Noise, and Fundamentals in the London Foreign Exchange Market", The Economic Journal, 100: 49-59.

Akgiray, V. and G.G. Booth, 1988, "Mixed Diffusion-Jump-Process Modeling of Exchange Rate Movements", Review of Economics and Statistics, 70: 63137.

Akgiray, V., 1989, "Conditional Heteroskedasticity in Time Series of Stock Returns: Evidece and Forecasts", Journal of Business, 1: 55-80.

Artis, M.J. and M.P. Taylor, 1988, "Exchange Rates, Interest Rates, Capital Controls and the European Monetary System: Assessing the Track Record", in: F. Giavazzi et al., eds., The European Monetary System, Cambridge: Cambridge University Press.

Baillie, R.T., 1987, "Inference in Dynamic Models Containing "Surprise" Variables", Journal of Econometrics, 35: 101-17.

Baillie, R.T., 1989, "Econometric Tests of Rationality and Market Efficiency", Econometric Review, 8: 151-86.

Baillie, R.T., R.E. Lippens and P.C. McMahon, 1983, "Testing Rational Expectations and Efficiency in the Foreign Exchange Market", Econometrica, 51: $553-63$.

Baillie, R. and P.C. MacMahon, 1987, The Foreign Exchange Market: Theory and Econometric Evidence, Cambridge University Press, Cambridge.

Baillie, R.T. and T. Bollerslev, 1989, "The Message in Daily Exchange Rates: A Conditional Variance Tale", Journal of Business and Economic Statistics, 3: 297-305.

Baillie, R.T. and T. Bollerslev, 1990, "A Multivariate Generalized ARCH Approach to Modeling Risk Premia in Forward Foreign Exchange Rate Markets", Journal of International Money and Finance, 9: 309-324.

Baillie, R.T. and R.P. DeGennaro, 1990, "Stock Returns and Volatility", Journal of Financial and Quantitative Analysis, 2: 203-214.

Ball, C. and W. Torous, 1985, "On Jumps in Common Stock Prices and Their Impact on Call Option Pricing", Journal of Finance, 40: 155-73.

Bekaert, G. and R.J. Hodrick, 1992, "Characterizing Predictable Components in Excess Returns on Equity and Foreign Exchange Markets", Journal of Finance, 47: 467-510. 
Bera, A.K. and C.M. Jarque, 1982, "Model Specification Tests: A Simultaneous Approach", Journal of Econometrics, 20: 59-82.

Berndt, E.K., B.H. Hall, R.E. Hall and J.A. Hausman, 1974, "Estimation and Inference in Nonlinear Structural Models", Annals of Economic and Social Measurement, 4: 653-665.

Bertola, G. and R. Caballero, 1989, "Target Zones and Realignments", Working Paper, Princeton University and Columbia University.

Bertola, G. and L. Svensson, 1990, "Stochastic Devaluation Risk and the Empirical Fit of Target Zone Models", Working Paper, Institute for International Economic Studies.

Bilson, J.F.O., 1981, "The Speculative Efficiency Hypothesis", Journal of Business, 54: 435-51.

Bilson, J.F.O., 1985, "Macroeconomic Stability and Flexible Exchange Rates", American Economic Review, 75: 62-67.

Black, F. and M. Scholes, 1973, "The Pricing of Options and Corporate Liabilities", Journal of Political Economy, 81: 637-59.

Bollerslev, T., 1986, "Generalized Autoregressive Conditional Heteroskedasticity", Journal of Econometrics, 31: 307-327.

Bollerslev, T., 1987, "A Conditional Heteroskedastic Time Series Model for Speculative Prices and Rates of Returns", Review of Economics and Statistics, 69: 542-547.

Bollerslev, T., R.F. Engle and J.M. Wooldridge, 1988, "A Capital Asset Pricing Model with Time-Varying Covariances" ${ }^{n}$, Journal of Political Economy, 1: 116-131.

Bollerslev, T. and J. Wooldridge, 1989, "Quasi Maximum Likelihood Estimation of Dynamic Models with Time Varying Covariances", unpublished manuscript, Department of Economics, MIT.

Bollerslev, T., R. Chou, N. Jayaraman and K. F. Kroner, 1990, "ARCH Modeling in Finance: A Selective Review of the Theory and Empirical Evidence, with Suggestions for Future Research", Working Paper, Northwestern University.

Bollerslev, T., Ray Y. Chou, and Kenneth F. Kroner, 1992, "ARCH Modeling in Finance: A Review of the Theory and Empirical Evidence", Journal of Econometrics, 52: 5-59.

Boothe, P. and D. Glassman, 1987, "The Statistical Distributions of Exchange Rates: Empirical Evidence and Economic Implications", Journal of International Economics, 22: 297-319.

Box, G.E.P. and G.M. Jenkins, 1970, Time Series Analysis: Forecasting and Control, San Francisco: Holden Day.

Branson, W.H., 1977, "Asset Markets and Relative Prices in Exchange Rate Determination", Sozialwissenschaftliche Annalen, 69-89. 
Branson, W., H. Halttunen and P. Masson, 1977, "Exchange Rates in the Short Run: The Dollar/Deutschmark Raten", European Economic Review, 10: 303324.

Breusch, T.S. and A.R. Pagan, 1979, "A Simple Test for Heteroskedasticity and Random Coefficient Variation", Econometrica, 47: 1287-94.

Box, G.E.P. and G.C. Tiao, 1973, "Bayesian Inference in Statistical Analysis", Addison-Wesley, Reading.

Chou, R.Y., 1988, "Volatility Persistence and Stock Valuations: Some Empirical Evidence using GARCH", Joumal of Applied Econometrics, 3: 279-294.

Campbell, J. and R. Clarida, 1987, "The Term Structure of Euromarket Interest Rates: An Empirical Investigation", Journal of Monetary Economics, 19: 2544.

Cavaglia, S., 1990, "Permanent and Transitory Components of the Time Series of Real Exchange Rates and Real Interest Rates", Ph.D. Thesis, University of Chicago.

Cavaglia, S., W.F.C. Verschoor and C.C.P. Wolff, 1992a, "On the Biasedness of Forward Foreign Exchange Rates: Irrationality or Risk Premia?", Working Paper, University of Limburg and OECD.

Cavaglia, S., W.F.C. Verschoor and C.C.P. Wolff, 1992b, "Further Evidence on Exchange Rate Expectations", Journal of International Money and Finance, forthcoming.

Cavaglia, S., W.F.C. Verschoor and C.C.P. Wolff, 1992c, " Asian Exchange Rate Expectations", Journal of the Japanese and International Economies, forthcoming.

Cavaglia, S., K.G. Koedijk, W.F.C. Verschoor and C.C.P. Wolff, 1992d, "Interest Expectations and Exchange Rate Dynamics", Working Paper, University of Limburg, Maastricht.

Collins, S.M., 1986, "The Expected Timing of Devaluation: A Model of Realignment in the European Monetary System", Mimeo, Harvard University, Cambridge, MA.

Copeland, L.S., 1984, "The Pound Sterling/Dollar Exchange Rate and the "News", Economics Letters, 15: 109-13.

Cornell, N.B., 1977, "Spot Rates, Forward Rates and Exchange Market Efficiency", Journal of Financial Economics, 5: 55-65.

Cornell, N.B. and J.K. Dietrich, 1978, "The Efficiency of the Market for Foreign Exchange under Floating Exchange Rates", Review of Economics and Statistics, 60: 11-120.

Cumby, R. and M. Obstfeld, 1984, "International Interest Rate and Price Level Linkages under Flexible Exchange rates: A Review of Recent Evidence", in: 
Exchange Rate Theory and Practice, Chicago: Chicago University Press. Cutler, D.M., J.M. Poterba and L.H. Summers, 1990, "Speculative Dynamics", National Bureau of Economic Research, Working Paper \# 3242.

Diebold, F.X., 1988, " Empirical Modeling of Exchange Rate Dynamics", Springer Verlag, New York.

Diebold, F.X. and P. Pauly, 1988a, "Endogenous Risk in a Portfolio Balance Rational Expectations Model of the Deutschmark-Dollar Rate", European Economic Review, 32: 27-53.

Diebold, F.X. and P. Pauly, 1988b, "Has the EMS Reduced Member Country Exchange Rate Volatility?", Empirical Economics, 13: 81-102.

Dickey, D. A. and W. Fuller, 1979, "Distributions of the Estimators for Autoregressive Time Series With a Unit Root", Journal of the American Statistical Association, 74: 427-32.

Dickey, D. A. and W. Fuller, 1981, "Likelihood Ratio Statistics for Autoregressive Time Series With a Unit Root", Econometrica, 49: 1057-72.

Dominguez, K.M., 1986, "Are Foreign Forecast Rational? New Evidence from Surrvey Data", Economics Letters, 21: 277-281.

Dominguez, K.M. and J. Frankel, 1989, "Some New Tests of Foreign Exchange Intervention: The Portfolio and Expectations Effects", Kennedy School of Government, Harvard University.

Domowitz, I. and C. Hakkio, 1985, "Conditional Variance and the Risk Premium in the Foreign Exchange Market", Journal of International Economics, 19: 47-66.

Dooley, M.P. and J.R. Shafer, 1976, "Analysis of Short-Run Exchange Rate Behavior: March 1973 to September 1975", International Discussion Paper \#76, Federal Reserve System, Washington D.C.

Dooley, M.P. and J.R. Shafer, 1983, "Analysis of Short-Run Exchange Rate Behavior: March 1975 to November 1981", in: D. Bigman and T. Taya, eds., Exchange Rate and Trade Instability, Cambridge Massachusetts: Ballinger.

Dornbusch, R., 1976a, "Expectations and Exchange Rate Dynamics", Journal of Political Economy, 84: 1161-76.

Dornbusch, R., 1976b, "The Theory of Flexible Exchange Rate Regimes and Macroecomic Policy", Scandinavian Journal of Economics, 78: 255-76.

Drost, F.C., and T.E. Nijman, 1990, Temporal Aggregation of GARCH Processess", Working Paper, Tilburg University.

Dumas, B. and L. Svensson, "How Long Do Unilateral Target Zones Last?", Working Paper, Presented at the EEA Meeting 1991, Cambridge.

Edison, H.J., 1985, "The Rise and Fall of Sterling: Testing Alternative Models of Exchange Rate Determination", Applied Economics, 17: 1003-21. 
Edwards, S., 1982, "Exchange Rates and "News": a Multi-Currency Approach", Journal of International Money and Finance, 1: 211-224.

Edwards, S., 1983, "Floating Exchange Rates, Expectations and New Information", Journal of Monetary Economics, 11: 321-336.

Engle, R.F., 1982, "Autoregressive Conditional Heteroskedasticity with Estimates of the Variance of U.K. Inflation", Econometrica, 50: 987-1008.

Engle, R.F., D.F. Hendry and D. Trumble, 1985, "Small Sample Properties of ARCH Estimators and Tests", Canadian Joumal of Economics, 18: 66-93.

Engle, R.F. and T. Bollerslev, 1986, "Modeling the Persistence of Conditional Variances", Econometric Reviews, 5: 1-50.

Engle, R.F., D.M. Lilien and R.P. Robbins, 1987, "Estimating Time-varying Risk Premia in the Term Structure: The ARCH-M Model ${ }^{n}$, Econometrica, 55: 391-407.

Fama, E.F., 1965, "The Behavior of Stock Market Prices", Journal of Business, 38: 34-105.

Fama, E.F., 1970, "Efficient Capital Markets: A Review of Theory and Empirical Work", Journal of Finance, 25: 383-417.

Fama, E.F., 1984, "Forward and Spot Exchange Rates", Journal of Monetary Economics, 14: 319-338.

Fama, E.F., 1991, "Efficient Capital Markets: II", Journal of Finance, 5: 15751617.

Flavin, M.A., 1981, "The Adjustment of Consumption to Changing Expectations about Future Income", Journal of Political Economy, 5: 974-1009.

Flood, R. and P. Garber, 1989, "The Linkage between Speculative Attack and Target Zone Models of Exchange Rates", NBER Working Paper \# 2918.

Frankel, J.A., 1980, "Tests of Rational Expectations in the Forward Exchange Market", Southern Economic Journal, 46: 1083-1101.

Frankel, J.A., 1982, "In Search of the Exchange Risk Premium: A Six Currency Test Assuming Mean-Variance Optimization", Journal of International Money and Finance, 1: 255-74.

Frankel, J.A., 1983, "Monetary Portfolio Balance Models of Exchange Rate Determination", in: J.S. Bhandari and B.H. Putnam, eds., Economic Interdependence and Flexible Exchange Rates, Cambridge Massachusetts: MIT Press.

Frankel, J.A., 1985, "The Dazzling Dollar", Brookings Papers on Economic Activity, 1: 319-38.

Frankel, J.A. and C. Engel, 1984, "Do Assets Demands Optimize over the Mean and Variance of Real Returns? A Six-Currency Test", Journal of International Economics, 17: 309-23. 
Frankel, J.A., 1986, "The Implications of Mean-Variance Optimization for Four Questions in International Macroeconomics", Journal of International Money and Finance, 5: S53-S76.

Frankel, J.A. and K.A. Froot, 1987a, "Using Survey Data to Test Propositions Regarding Exchange Rate Expectations", American Economic Review, 5: 133-153.

Frankel, J.A. and K.A. Froot, 1987b, "Short-Term and Long-Term Expectations of the Yen/Dollar Exchange Rate: Evidence from Survey Data", Journal of the Japanese and International Economies, 1: 249-274.

Frankel, J.A. and R. Meese, 1987, "Are Exchange Rates Excessively Variable?", Macroeconomics Annual.

Frankel, J.A., 1988, "Recent Estimates of Time-Variation in the Conditional Variance and in the Exchange Risk Premium", Journal of International Money and Finance, 7: 115-25.

Frankel, J.A. and M. Chinn, 1991, "Exchange Rate Expectations and the Risk Premium: Tests for a Cross-Section of 17 Currencies", NBER Working paper \# 3806.

Frankel, J.A. and S. Phillips, 1991, "The European Monetary System: Credible at last?", NBER Working Paper \# 3819.

French, K.R., G.W. Schwert and R.F. Stambaugh, 1987, "Expected Stock Returns and Volatility", Journal of Financial Economics, 19: 3-29.

Frenkel, J.A., 1976, "A Monetary Approach to the Exchange Rate: Doctrinal Aspects and Empirical Evidence", Scandinavian Journal of Economics, 78: 200-24.

Frenkel, J.A., 1978, "Purchasing Power Parity: Doctrinal Perspectives and Evidence from the 1920s", Journal of International Economics, 8: 169-91.

Frenkel, J.A., 1980, "Exchange Rates, Prices and Money: Lessons From the 1920s", American Economic Review, 70: 235-42.

Frenkel, J.A., 1981, "Flexible Exchange Rates, Prices and the Role of "News": Lessons from the 1970s", Journal of Political Economy, 89: 655-705.

Frenkel, J.A., and M. Mussa, 1980, "The Efficiency of the Foreign Exchange Maarket and Measures of Turbulence, American Economic Review, 70: 37481.

Friedman, M., 1953, "Essays in Positive Economics, University of Chicago Press, Chicago.

Friedman, D. and S. Vandersteel, 1982, "Short-Run Fluctuations in Foreign Exchange Rates", Journal of International Economics, 13: 171-186.

Froot, K.A. and J.A. Frankel, 1989, "Forward Discount Bias: Is it an Exchange Risk Premium?", Quarterly Journal of Economics, 1: 139-61. 
Froot, K.A. and J.A. Frankel, 1990, "Exchange rate Forecasting Techniques, Survey Data, and Implications for the Foreign Exchange Market", IMF Working Paper, \# 90/43, International Monetary Fund.

Froot, K.A. and T. Ito, 1989, "On the Consistency of Short-Run and Long-Run Exchange rate Expectations", Journal of International Money and Finance, 8: $487-510$.

Froot, K.A. and R. Thaler, 1990, "Anomalies: Foreign Exchange", Journal of Economic Perspectives, 4: 179-192.

Fuller, W.A, 1976, Introduction to Statistical Time Series, London, John Wiley.

Garman, M.B. and S. Kohlhagen, 1983, "Foreign Currency Option Values", Journal of International Money and Finance, 2: 231-37.

Giavazzi, F.S. Misossi and M. Miller, 1988, The European Monetary System, Cambridge, Cambridge University Press.

Giavazzi, F.S. and A. Giovannini, 1989, Limiting Exchange Rate Flexibility: The European Monetary System, Cambridge: MIT Press.

Giavazzi, F.S. and L. Spaventa, 1990, "The "New" EMS", Centre for Economic Policy Research, Working Paper \#369.

Giovannini, A. and P. Jorion, 1987, "Interest Rates and Risk Premia in the Stock Market and in the Foreign Exchange Market", Joumal of Intermational Money and Finance, 6: 107-24.

Giovannini, A., 1990, "European Monetary Reform: Progress and Prospects", Brookings Papers on Economic Activity, 2: 217-91.

Granger, C.W.J. and P. Newbold, 1986, Forecasting Economic Time Series, London: Academic Press, Inc.

Gregory, A.W., 1989, "A Non-Parametric Test for Autoregressive Conditional Heteroskedasticity: A Markov-Chain Approach", Journal of Business and Economic Statistics, 7: 107-115.

Gruijters, A.P.D., 1991, "De Efficiëntie van Valutamarkten: een Overzicht", Maandschrift Economie, 55: 244-267.

Hansen, L.P. and R.J. Hodrick, 1980, "Forward Exchange Rates as Optimal Predictors of Future Spot Rates: An Econometric Analysis", Journal of Political Economy, 88: 829-53.

Hansen, L.P., 1982, "Large Sample Properties of Generalized Method of Moments Estimators", Econometrica, 50: 1029-1054.

Hansen, L.P. and R.J. Hodrick, 1983, "Risk Averse Speculation in the Forward Exchange Market: An Econometric Analysis in Linear Models", in J.A. Frenkel, ed., Exchange Rates and International Macroeconomics, Chicago University Press, Chicago.

Harvey, A.C., 1981, Time Series Models, London: Philip Allen. 
Harvey, A.C., 1981, The Econometric Analysis of Time Series, London: Philip Allen.

Hodrick, R.J., 1981, "International Asset Pricing with Time-varying Risk Premia", Journal of International Economics, 1: 573-77.

Hodrick, R.J., 1987, The Empirical Evidence on the Efficiency of Forward and Futures Foreign Exchange Markets, Chur, Harwood Academic Publishers.

Hodrick, R.J. and S. Srivastava, 1984, "An Investigation of Risk and Return in Forward Foreign Exchange Market", Journal of International Money and Finance, 3: 5-29.

Hodrick, R.J. and S. Srivastava, 1986, "The Covariation of Risk Premiums and Expected Future Spot Exchange Rates", Journal of International Money and Finance, 5: 5-21.

Hsieh, D.A., 1984, "Tests of Rational Expectations and No Risk Premium in Forward Exchange Markets", Journal of International Economics, 17:: 173-84.

Hsieh, D.A., 1988, "The Statistical Properties of Daily Foreign Exchange Rates: 1974-1983", Journal of International Economics, 24: 129-45.

Hsieh, D.A., 1989, " Modeling Heteroskedasticity in Daily Foreign Exchange Rates", Journal of Business and Economic Statistics, 7: 307-317.

Huizinga, J., 1987, "An Empirical Investigation of the Long Run Behavior of Real Exchange Rates", Carnegie Rochester Conference Series on Public Policy, 27: $149-214$.

Isard, P., 1983, "An Accounting Framework and some Issues for Modeling How Exchange Rates respond to the News", in J.A. Frenkel, ed., Exchange Rates and International Macroeconomics, Chicago University Press, Chicago.

Ito, T., 1990, "Foreign Exchange Rate Expectations: Micro Survey Data", American Economic Review, 80: 434-49.

Jorion, P., 1988, "On Jump Processes in the Foreign Exchange and Stock Markets", Review of Financial Studies, 1: 427-45.

Kaminsky, G. and R. Peruga, 1990, "Can a Time-Varying Risk Premium explain Excess Return in the Forward Market for Foreign Exchange?", Journal of International Economics, 28: 47-70.

Katona, G., 1958, "Business Expectations in the Famework of Psychological Economics (Towards a Theory of Expectations), in: M.J. Bouwman, ed., Expectations, Uncertainty, and Business Behavior, Social Science Research Council, New York.

Kendall, J.D. and A.D. McDonald, 1989, "Univariate GARCH-M and the Risk Premium in a Foreign Exchange Market", unpublished manuscript, University of Tasmania.

Kiefer, N.M. and M. Salmon, 1983, "Testing Normality in Econometric Models" , Economics Letters, 11: 123-127. 
Klein, L.R., 1954, "Applications of Survey Methods and Data to the Analysis of Economic Fluctuations, in: L.R. Klein, ed., Contributions of Survey Methods to Economic Fluctuations, Columbia University Press, New York.

Kodde, D.A. and F.C. Palm, 1986, "Wald Criteria for Jointly Testing Equality and Inequality Restrictions", Econometrica, 5: 1243-1248.

Koedijk, K.G., M.M.A. Schafgans, and C.G. de Vries, 1990, "The Tail Index of Exchange Rate Returns", Journal of International Economics, 29: 93-108.

Koedijk, K.G., and C.J.M. Kool, 1992, "Tail Index Estimates of East European Exchange Rates", Journal of Business and Economic Statistics, 10: 33-54.

Kool, C.J.M., 1989, "Recursive Bayesian Forecasting in Economics: The Multi State Kalman Filter Method", Ph.D. Dissertation, Erasmus University, Rotterdam.

Korajczyk, R.A., 1985, "The Pricing of Forward Contracts for Foreign Exchange", Journal of Political Economy, 93: 346-68.

Krasker, W.S., 1980, "The "Peso Problem" in Testing the Efficiency of Forward Exchange Markets", Journal of Monetary Economics, 6: 269-276.

Krugman, P., 1991, "Target Zones and Exchange Rate Dynamics", Quarterly Journal of Economics, 56: 669-82.

Krugman, P. and J. Rotemberg, 1990, "Target Zones and Limited Reserves", NBER Working Paper, \# 3418.

Lamoureux, C. and W.D. Lastrapes, 1990, "Persistence in Variance, Structural Change and the GARCH Model", Journal of Business and Economic Statistics, 1: 225-34.

Lastrapes, W.D., 1989, "Exchange Rate Volatility and U.S. Monetary Policy: An ARCH Application", Journal of Money, Credit, and Banking, 21: 66-77.

Levich, R., 1979, "On the Efficiency of Markets For Foreign Exchange, in: R. Dornbusch and J.A. Frenkel, eds., International Economic Policy: An Assesssment of Theory and Evidence, Kohn Hopkins University Press, Baltimore.

Levich, R., 1985, "Empirical Studies of Exchange Rates: Price Behavior, Rate Determination, and Market Efficiency", in: Handbook of International Economics, R. Jones and P. Keenan, eds., Amsterdam: North Holland.

Lewis, K.K., 1989, "Changing Beliefs and Systematic Rational Forecast Errors with Evidence from Foreign Exchange", American Economic Review, 79: 621-636.

Lintner, J., 1965, "Security Prices, Risk and Maximal Gains From Diversification", Journal of Finance, 20: 587-615.

Ljung, G.M. and G.E.P. Box, 1978, "On a Measure of Lack of Fit in Time Series Models", Biometrika, 65: 297-303. 
Longworth, D., 1981, "Testing the Efficiency of the Canadian-US Exchange Market under the Assumption of no Risk Premium", Journal of Finance, 36: 439.

Lucas, R.E., 1978, "Asset Prices in an Exchange Economy", Econometrica, 46: 1429-1445.

Lucas, R.E., 1982, "Interest Rates and Currency Prices in a Two-Country World", Journal of Monetary Economics, 10: 335-60.

MacDonald, R., 1983, "Tests of Efficiency and the Impact of "News" in Three Foreign Exchange Markets: The Experience of the 1920s", Bulletin of Economic Research, 35; 123-44.

MacDonald, R., 1990, "Are Foreign Exchange Market Forecasters "Rational?": Some Survey-Based Tests", The Manchester School, 58: 229-242.

MacDonald, R. and T. Torrance, 1988, "On Risk, Rationality and Excessive Speculation in the Deutschmark-US Dollar Exchange Market: Some Evidence Using Survey Data", Oxford Bulletin of Economics and Statistics, 50: 107-122.

MacDonald, R. and T. Torrance, 1989, "Some Survey Based Tests of Uncovered Interest Parity" in R. MacDonald and M. Taylor, eds., Exchange Rates and Open Macroeconomics, Cambridge: Basil Blackwell.

MacDonald, R. and T. Torrance, 1990, "Expectations, Formation and Risk in Four Foreign Exchange Markets", Oxford Economic Papers, 42: 544-561.

MacDonald, R. and M.P. Taylor, 1992, "Exchange Rate Economics", International Monetary Fund Staff Papers, 39: 1-57.

Mandelbrot, B., 1963, "The Variation of Certain Speculative Prices", Journal of Business, 36: 394-419.

Masera, R. and R. Triffin, 1984, Europe's Money: Problems in European Monetary Coordination and Integration, Oxford, Clarendon Press.

McCurdy, T.H. and I. Morgan, "Evidence of Risk Premia in Foreign Currency Futures Markets", unpublished manuscript, Department of Economics, Queen's University.

McFarland, J.W., R.R. Pettit and S.K. Sung, 1982, "The Distribution of Foreign Exchange Price Changes: Trading Day Effects and Risk Measurement", The Journal of Finance, 3: 693-715.

Meese, R.A., 1985, "Empirical Assessment of Foreign Currency Risk Premiums", in: C.C Stone, ed., Financial Risk: Theory, Evidence and Implications, St. Louis Federal Reserve Bank.

Meese, R.A. and K. Singleton, 1982, "On Unit Roots and the Empirical Modeling of Exchange Rates", Journal of Finance, 37: 1029-1035.

Meese, R.A. and K. Rogoff, 1983a, "Empirical Exchange Rate Models of the Seventies: Do They Fit Out of Sample?", Journal of International Economics, 
14: 3-24.

Meese, R.A. and K. Rogoff, 1983b, "The Out-of-Sample Failure of Empirical Exchange Rate Models: Sampling Errors or Misspecification?", in: Exchange Rates and International Macroeconomics, J. Frenkel, ed., Chicago: University of Chicago Press for The National Bureau of Economic Research.

Meese, R.A. and A.K. Rose, 1990, "Nonlinear, Nonparametric, Nonessential Exchange Rate Estimation", American Economic Review, 92-196.

Mehra, R. and E.C. Prescott, 1985, "The Equity Premium, A Puzzle", Journal of Monetary Economics, 15: 145-161.

Merton, R.C., 1973, "An Intertemporal Capital Asset Pricing Model", Econometri$c a$, 5: 867-887.

Modigliani, F. and O.W. Sauerlender, 1955, "Economic Expectations and Plans of Firms in Relation to Short-Term Forecasting, in: Short-Term Economic Forecasting, NBER Studies in Income and Wealth \#17, Princeton University Press, Princeton.

Mood, A.M., F.A. Graybill, and D.C. Boes, 1988, "Introduction to the Theory of Statistics", third edition, McGraw-Hill.

Muth, J.F., 1960, "Optimal Properties of Exponentially Weighted Forecasts", Journal of the Amarican Statistical Association, 55: 299-306.

Muth, J.F., 1961, "Rational Expectations and the Theory of Price Movements", Econometrica, 29: 315-35.

Newey, W. and K. West, 1987, "A Simple, Positive Semi-Definite Heteroskedasticity and Autocorrelation Consistent Covariance Matrix", Econometrica, 55: 703-708.

Nieuwland, F.G.M.C., 1991, "Conditional Distributions for Stock Returns", Working Paper, University of Limburg, Maastricht.

Nieuwland, F.G.M.C., W.F.C. Verschoor and C.C.P. Wolff, 1991, "EMS Exchange Rates", Journal of International Financial Markets, Institutions and Money, 2: 21-42.

Nieuwland, F.G.M.C., W.F.C. Verschoor and C.C.P. Wolff, 1991, "A Comparison of Pre- and Post-EMS Exchange Rate Patterns", in S.G. Rhee and R.P. Chang, eds., Pacific-Basin Capital Markets Research Volume II, Amsterdam: North-Holland.

Nieuwland, F.G.M.C. and W.F.C. Verschoor, 1992, "EMS Exchange Rate Expectations and Time-Varying Risk Premia", Working Paper, University of Limburg, Maastricht.

Nijman, T.E., F.C. Palm and C.C.P. Wolff, 1992, "Premia in Forward Exchange as Unobserved Components", Journal of Business and Economic Statistics, forthcoming. 
Nurske, R, 1944, Intemational Currency Experience, League of Nations, Geneva. Obstfeld, M., 1987, "Peso Problems, Bubbles, and Risk in the Empirical Assessment of Exchange-Rate Behavior", National Bureau of Economic Research, Working Paper, \#2203.

Obstfeld, M., 1990, "The Effectiveness of Foreign-Exchange Intervention: Recent Experience 1985-1988", In: W. Branson, J. Frenkel and M. Goldstein, eds., International Policy Coordination and Exchange Rate Determination, University of Chicago Press, Chicago.

Pagan, A.R. and A. Ullah, 1988, "The Econometric Analysis of Models with Risk Terms", The Journal of Applied Econometrics, 3: 87-105.

Pantula, S.G., 1986, "Modelling the Persistence of Conditional Variances: A Comment", Econometric Reviews, 5: 71-74.

Perron, P., 1988, "Trends and Random Walks in Macroeconomic Time Series", Journal of Economic Dynamics and Control, 12: 297-332.

Perron, P., 1989, "The Great Crash, the Oil Price Shock, and the Unit Root Hypothesis", Econometrica, 6: 1361-1401.

Peseran, M.H., 1987, The Limits to Rational Expectations, Oxford: Basil Blackwell.

Phillips, P., 1987, "Time Series Regression with a Unit Root", Econometrica, 55: 277-301.

Phillips, P. and P. Perron, 1988, "Testing for a Unit Root in Time Series Regression", Biometrika, 75: 335-46.

Poole, W., 1967, "Speculative Prices as Random Walks: An Analysis of Ten Time Series of Flexible Exchange Rates", Southern Economic Journal, 33: 46878 .

Rogoff, K., 1979, "Essays on Expectations and Exchange Rate Volatility", Ph.D. Dissertation, Massachusetts Institute of Technology.

Rogoff, K., 1984a, "Can Exchange Rate Predictability be Achieved Without Monetary Convergence? Evidence from the EMS", European Economic Review, 28: 93-115.

Rogoff, K., 1984b, "On the Effects of Sterilized Intervention: An Analysis of Weekly Data", Journal of Monetary Economics, 14: 133-150.

Roll, R. and B. Solnik, 1977, "A Pure Exchange Asset Pricing Model", Journal of International Economics, 7: 161-79.

Rose, A.K. and L. Svensson, 1991, "Expected and Predicted Realignments: The FF/DM Exchange Rate during the EMS", NBER Working Paper \# 3685.

Rose, A.K., 1984, "Testing for "News" in Foreign Exchange Markets", Economics Letters, 14: 369-76.

Sharpe, W.F., 1964, "Capital Asset Prices: A Theory of Market Equilibrium Under Conditions of Risk", Journal of Finance, 19: 425-42. 
Schwarz, G., 1978, "Estimating the Dimension of a Model", Annals of Statistics, 6: $461-464$.

Stockman, A.C., 1978, "Risk, Information and Forward Exchange Rates", in J.A. Frenkel and H.G. Jonhson, eds., The Economics of Exchange Rates, Reading, Massachusetts.

Stulz, R., 1981, "A Model of International Asset Pricing", Journal of Financial Economics, 9: 383-406.

Stulz, R., 1986, "An Equilibrium Model of Exchange Rate Determination and Asset Pricing with Non-Traded Goods and Imperfect Information", mimeo, Ohio State University.

Sweeney, R.J., 1986, "Beating the Foreign Exchange Market", Journal of Finance, 41: 163-82.

Tagaki, S., 1991, "Exchange Rate Expectations: A Survey Of Survey Studies", International Monetary Fund, Staff Papers, 38: 156-183.

Tauchen, G.E. and M. Pitts, 1983, "The Price Variability-Volume Relationship on Speculative Markets", Econometrica, 2: 485-505.

Taylor, S.J., 1990, "Modeling Stochastic Volatility", Unpublished Manuscript, University of Lancaster.

Taylor, S.J., 1986, Modeling Financial Time Series, Chichester: John Wiley and Sons.

Taylor, M., 1989, "Expectations, Risk and Uncertainty in the Foreign Exchange Market: Some Results Based on Survey Data", The Manchester School of Economic and Social Studies, 2: 142-153.

Ungerer, H., J.J. Hauvonen, A. Lopez-Claros and T. Mayer, 1990, "The European Monetary System: Developments and Perspectives", IMF Occasional Paper \#73, Washington.

Vlaar, P. and F.C. Palm, 1992, "The Message in Weekly Exchange Rates in the EMS: Mean Reversion, Conditional Heteroskedasticity and Jumps", Working Paper, University of Limburg.

Vuong, Q.H., 1989, " Likelihood Ratio Tests for Model Selection and Non-Nested Hypotheses ", Econometrica, 2: 307-333.

Weber, A., 1991, "Reputation and the Credibility in the European Monetary System", Economic Policy, 12: 57-102.

Weiss, A.A., 1984, "ARMA Models with ARCH errors", Journal of Time Series Analysis, 5: 129-143.

Weiss, A.A., 1986a, "Asymptotic Theory for ARCH Models: Estimation and Testing", Econometric Theory, 2: 107-131.

Weiss, A.A., 1986b, "ARCH and Bilinear Time Series Models: Comparison and Combination", Joumal of Business and Economic Statistics, 4: 59-70. 
208

Westerfield, J.M., 1977, "An Examination of Foreign Exchange Risk under Fixed and Floating Rate Regimes", Journal of International Economics, 7: 181200.

Wolff, C.C.P., 1986, "Exchange Rate Models and Innovations", Economics Letters, 20: 373-76.

Wolff, C.C.P., 1987a, "Forward Foreign Exchange Rates, Expected Spot Rates and Premia: A Signal - Extraction Approach", The Journal of Finance, 42: 395-406.

Wolff, C.C.P., 1987b, "Time-Varying Parameters and the Out-of-Sample Forecasting Performance of Structural Exchange Rate Models", Journal of Business and Economic Statistics, 5: 87-97.

Wolff, C.C.P., 1988, "Exchange Rates, Innovations and forecasting", Journal of International Money and Finance, 7: 234-45. 


\section{Summary in Dutch}

$\mathrm{Na}$ het loslaten van het Bretton Woods' stelsel van vaste wisselkoersen (1973) is de aandacht voor de werking van valutamarkten sterk toegenomen als gevolg van een bij tijd en wijle zeer grillig verloop van de wisselkoersen. De overgang van het Bretton Woods' vaste wisselkoerssysteem naar een systeem van zwevende wisselkoersen in april 1973 heeft het karakter van de wisselkoersfluctuaties aanzienlijk veranderd. Het voornaamst kenmerkende onderscheid van de introductie van het systeem van zwevende wisselkoersen is de enorm en onvoorziene toegenomen volatiliteit van de wisselkoers. Begin jaren zeventig was men de mening toegedaan dat de overgang naar een systeem van zwevende wisselkoersen een meer evenwichtig kader voor het voeren van binnenlandse monetaire en fiscale politiek zou opleveren. Echter, de turbulente ontwikkelingen gedurende de laatste twee decennia geven alle aanleiding om bovengenoemde opvatting te herzien.

Binnen de theorieën die het wisselkoersgedrag pogen te verklaren neemt de efficiënte markthypothese een centrale plaats in. Mede als gevolg van bovengenoemde ontwikkelingen is, gedurende de afgelopen twee decennia, het empirisch onderzoek naar het wisselkoersverloop sterk gericht op de efficiënte werking van valutamarkten. De efficiënte markthypothese is een theorie over de wijze, waarop informatie tot uitdrukking komt in de prijzen van activa op financiële markten. Een efficiënte markt is een markt waarop de prijzen alle beschikbare informatie weerspiegelen. Als de valutamarkten efficiënt zijn, wordt nieuwe informatie snel in de wisselkoersen verwerkt. Deze verwerking vindt plaats via de verwachtingen van marktparticipanten. Nieuws omtrent onvoorziene gebeurtenissen leidt tot een verandering in de wisselkoersverwachtingen van de economische subjecten. Op basis van veranderende verwachtingen zullen de marktparticipanten andere marktposities innemen. Hoe de economische subjecten in de praktijk wisselkoersverwachtingen vormen is niet direct waarneembaar. In de literatuur worden daarom diverse verwachtingshypothesen gehanteerd.

De efficiënte markthypothese, toegepast op wisselkoersen, heeft een samengesteld karakter als gevolg van de aanname van rationele verwachting- 
en van marktparticipanten en risico-neutraliteit. De rationele verwachtingshypothese gaat uit van nutsmaximaliserende economische subjecten die, teneinde tot winstgevende beslissingen te komen, alle relevante informatie verzamelen en optimaal gebruiken bij het vormen van hun wisselkoersverwachting. Welke informatie relevant is, wordt bepaald door het model dat de economische werkelijkheid beschrijft. De rationele verwachtingshypothese veronderstelt dat de economische subjecten handelen alsof zij dit model kennen. Hun subjectieve wisselkoersverwachting komt dan overeen met de waarde die het model van de werkelijkheid voorspelt. Als marktparticipanten risiconeutraal zijn, verlangen zij geen risicopremie voor het nemen van wisselkoersrisico. Empirische toetsing van valutamarktefficiëntie is bij voorbaat beperkt door het samengestelde karakter van de hypothese. Een probleem bij de interpretatie van marktefficiëntie toetsen is dat onduidelijk is of de verwerping van de nulhypothese van marktefficiëntie te wijten is aan irrationele verwachtingen en/of het bestaan van tijdsvariërende risicopremies.

Dit proefschrift bevat een empirische analyse van volatiliteit, wisselkoersverwachtingen, risicopremies en innovaties binnen de valutamarkt. In deze studie concentreren we ons met name op het relatieve belang van irrationaliteit, risico en nieuws voor het begrijpen en verklaren van wisselkoersen. In het bijzonder analyseren we de relatieve betekenis van irrationele wisselkoersverwachtingen en het bestaan van tijdsvariërende risicopremies ter verklaring van geconstateerde systematische voorspelfouten in de prijsvorming van termijncontracten.

In het navolgende bespreken we de afzonderlijke hoofdstukken en presenteren we de belangrijkste conclusies. Hoofdstuk twee geeft een empirische beschrijving van de bilaterale wisselkoersen tussen EMS-valuta met behulp van wekenlijkse waarnemingen voor de periode vanaf 15 maart 1979 tot 27 februari 1992. Het Europese Monetaire Stelsel (EMS), opgericht in 1979, biedt een interessant voorbeeld van een formeel wisselkoersarrangement en raamwerk voor internationale beleidscoördinatie. De waargenomen tijdreekspatronen van EMS wisselkoersen wijken in het algemeen af van de tijdreekspatronen die men aantreft bij volledig vrije wisselkoersen omdat het EMS overheidsingrijpen in de valutamarkt behelst. In dit verband is de vraag of EMS wisselkoersen beschreven kunnen worden via een "random walk" met een drift term of dat het wisselkoersarrangement, binnen het EMS, ervoor zorgt dat EMS wisselkoersen beschreven kunnen worden met behulp van een naar een gemiddeld terugkerend proces ("mean reversion"), van belang. Onze resultaten laten zien dat de hypothese van een 
"random walk", voor alle geanalyseerde valuta, niet verworpen kan worden. Dit betekent dat het EMS er niet in slaagt de bilaterale wisselkoersen op lange termijn aan bepaalde "target rates" te onderwerpen. Echter indien we corrigeren voor officiële pariteitsaanpassingen ("realignments") verwerpen we de hypothese van een "random walk". Tussen twee opeenvolgende pariteitsaanpassingen worden de EMS wisselkoersen dus weergegeven door een gemiddeld terugkerend proces, afgedwongen door de centrale banken van de participerende landen indien de betreffende EMS koers één van zijn beide interventielimieten raakt. Een volgende stap in de analyse is de verklaring van de waargenomen scheefheid en gepiektheid ("leptokurtosis") in de empirische verdeling van procentuele wisselkoersveranderingen. We toetsen een zestal lognormale modellen voor de EMS wisselkoersen: het diffusie-proces, sprong-diffusie-proces, diffusie-(G)ARCH-proces en sprongdiffusie-(G)ARCH-proces. In het hoofstuk worden voor de verschillende modelschattingen de resultaten weergegeven en ook worden de zes processen formeel met elkaar vergeleken. In navolging van de normale verdeling gebruiken we tevens de Student t-verdeling om de onderliggende statistische verdeling van EMS wisselkoersveranderingen adequaat te kunnen beschrijven. Onze conclusie luidt dat EMS wisselkoersveranderingen het best beschreven kunnen worden via een gecombineerd sprong-diffusie-GARCHproces met conditioneel Student $t$-verdeelde innovaties.

In het derde hoofdstuk, alsook in de overige hoofdstukken, wordt gebruik gemaakt van directe waarnemingen voor de rente- en wisselkoersverwachtingen, zgn. panel-data, die verkregen zijn via maandelijkse enquêtes onder marktparticipanten - valutahandelaren bij financiële instellingen en multinationals verspreid over vier continenten. De panel-data, samengesteld door Business International Corporation, zijn beschikbaar sinds december 1985 en omvatten tien valuta vis-à-vis de US Dollar en acht valuta tegenover de Duitse Mark. Een voordeel van de panel-data is dat direct bekeken kan worden of de marktparticipanten systematische voorspelfouten maken zonder allerlei veronderstellingen ten aanzien van een risicopremie, zoals in de standaard speculatieve efficiëntie hypothese (SEH) toetsen. Ten einde de hypothese van rationele verwachtingen te toetsen en verwachtingsprocessen te analyseren, is het gebruik van panel-data van wisselkoersverwachtingen van marktparticipanten essentieel.

In eerste instantie is het empirisch onderzoek vooral gericht op de toetsing van de hypothese dat participanten op de valutamarkt rationele verwachtingen 
vormen ten aanzien van de wisselkoers - hoofdstuk drie. In hoofdstuk vier, vervolgens, analyseren we het relatieve belang van zowel (ir)rationele wisselkoersverwachtingen alsook het bestaan van tijdsvariërende risicopremies ter verklaring van geconstateerde systematische voorspelfouten in de prijsvorming van termijncontracten. Het gebruik van directe waarnemingen voor de wisselkoersverwachtingen veronderstelt een directe meting voor de risicopremie als zijnde het verschil tussen het termijnagio en de verwachte wisselkoersmutatie. De resultaten geven alle aanleiding om de hypothese van rationele verwachtingen te herzien. De marktparticipanten zijn niet strikt rationeel, d.w.z. ze zouden hun verwachtigen kunnen verbeteren op basis van beschikbare informatie. Zo blijkt, in navolging van Meese en Rogoff (1983a, 1983b), de feitelijke contante koers een betere voorspeller voor de toekomstige koers dan de opgegeven wisselkoersverwachting. De empirische resultaten bevestigen dat de termijnkoers, in het voorspellen van de toekomstige contante koers, systematische voorspelfouten maakt. Echter het karakter van deze geconstateerde systematische voorspelfouten varieert met het onderhavige systeem van wisselkoersen. Voor EMS wisselkoersen zijn de voorspelfouten van de termijnkoers voornamelijk toe te schrijven aan het bestaan van variabele risicopremies en is de variabiliteit van de risicopremie groter dan de variabiliteit van de verwachte wisselkoersmutatie.

De bovengenoemde conclusies moeten met enige terughoudendheid worden geïnterpreteerd. In dit verband is aandacht besteed aan het zgn. pesoprobleem en rationele leerprocessen. Beide verschijnselen kunnen een alternatieve verklaring bieden voor ex-post geconstateerde systematische voorspelfouten gedurende kortere perioden - met name binnen het EMS - en zijn consistent met de efficiënte markthypothese.

Mede als gevolg van bovengenoemde empirische bevindingen, introduceren we in hoofdstuk vijf een aangepaste versie van het Domowitz en Hakkio (1985) model voor een variabele risicopremie. Ten einde te achterhalen of de risicopremie een goede verklaring biedt voor geconstateerde systematische voorspelfouten, proberen we deze expliciet te modelleren. In tegenstelling tot eerder uitgevoerd empirisch onderzoek met betrekking tot risicopremiemodellen, gaat de empirische toetsing van het door ons aangepast econometrisch risicopremiemodel niet gepaard met beperkende veronderstellingen. We zien af van de veronderstelling van zowel conditionele homoskedasticiteit van wisselkoersveranderingen alsook van de hypothese van rationele wisselkoersverwachtingen. In het econometrisch model, toegepast op de panel-data, is de risicopremie afhankelijk van de variantie in de voorspelfouten van 
wisselkoersmutaties in de loop van de tijd. Deze voorspelfouten worden verondersteld een (G)ARCH-proces te volgen. De resultaten geven een empirisch bewijs voor het bestaan van tijdsvariërende risicopremies. We concluderen dat de variantie in de voorspelfouten een determinant is van de risicopremie. De tijdsvariërende risicopremies worden het best beschreven via een GARCH-in-mean model.

In hoofdstuk zes concentreren we ons met name op het belang van risico en nieuws - d.i. onvoorziene gebeurtenissen - ter verklaring van onverwachte wisselkoersveranderingen. We nemen de zgn. "nieuws" versie van het Dornbusch-Frankel wisselkoersmodel, zoals dat afgeleid is door Isard (1983) en Edwards (1983), als uitgangspunt. Het verschil tussen de termijnkoers en de toekomstige contante koers blijkt een functie te zijn van nieuws betreffende renteverschillen en van risicotermen. Bij de empirische invulling maken we gebruik van passende ("matched") rente- en wisselkoersverwachtingen. Nieuws omtrent binnen- en buitenlandse renteverschillen blijkt een significante bijdrage te leveren aan de verklaring van geconstateerde systematische voorspelfouten. Vervolgens constateren we dat, op basis van de geschatte negatieve nieuwscoëfficiënt, een onvoorziene toename omtrent het renteverschil tot een versterking van de binnenlandse wisselkoers kan leiden. Dit effect wordt in de literatuur omschreven als het zgn. Dornbusch-Frankel "overshooting" effect.

Tenslotte geven we in hoofdstuk zeven de belangrijkste empirische resultaten van elk afzonderlijk hoofdstuk weer en formuleren we een aantal algemene conclusies betreffende onze bevindingen. Tevens wordt aandacht besteed aan mogelijk toekomstig onderzoek naar aanleiding van de discussie in dit hoofstuk. 



\section{Curriculum Vitae}

Willem F.C. Verschoor (May 24th 1962, Dordrecht) is presently Assistant Professor of Finance at the Department of Finance of the University of Limburg, Maastricht, the Netherlands. In august 1983, after his military service, he started to study Business Economics at the University of Groningen and specialized in International Finance and Investment Theory. Following his graduation (Master degree in Business Economics) from the University of Groningen, in january 1989 he became a Research Associate ["onderzoeker-in-opleiding"] at the University of Limburg supported by grant 450227-011 from the Economics Research Foundation (Ecozoek), which is part of the Netherlands Organization for Scientific Research (NWO).

During the period january 1989 - december 1992 he completed his work on this Ph.D. dissertation. Parts of his research has been published and is forthcoming in various academic journals, including: Journal of International Money and Finance and Journal of the Japanese and International Economies. Furthermore, he participated and lectured at many leading international conferences, including the Annual Meetings of the American and European Finance Association. 
